UNIVERSIDAD POLITÉCNICA DE MADRID ESCUELA TÉCNICA SUPERIOR DE ARQUITECTURA

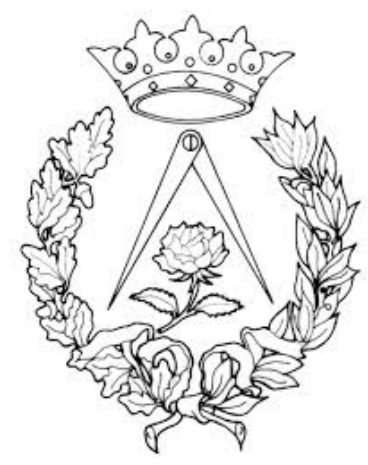

\title{
LA LOCALIZACIÓN EN EL VALOR URBANÍSTICO DEL SUELO RURAL: LA ACCESIBILIDAD A NÚCLEOS DE POBLACIÓN
}

Tesis Doctoral

Rosa María González Ruiz Arquitecto. Técnico Urbanista 



\title{
LA LOCALIZACIÓN EN EL VALOR URBANÍSTICO DEL SUELO RURAL: LA ACCESIBILIDAD A NÚCLEOS DE POBLACIÓN
}

\author{
Tesis Doctoral
}

Rosa María González Ruiz. Arquitecto. Técnico Urbanista.

Directores:

Federico García Erviti. Doctor Arquitecto

Sandra Martínez Cuevas. Doctor Arquitecto 

Tribunal nombrado por el Sr. Rector Magfco. de la Universidad Politécnica de Madrid, el día. de. de $20 . .$.

Presidente:

Vocal:

Vocal:

Vocal:

Secretario:

Suplente:

Suplente:

Realizado el acto de defensa y lectura de la Tesis el día de. de $20 \ldots$. en la E.T.S.I. /Facultad.

Calificación

EL PRESIDENTE

LOS VOCALES

EL SECRETARIO 
La localización en el valor urbanístico del suelo rural: La accesibilidad a núcleos de población. 


\section{INDICE DE CONTENIDOS}

Resumen

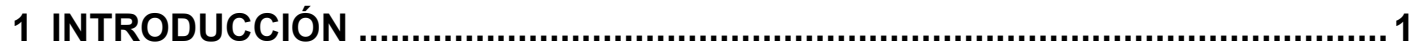

1.1 Introducción y desarrollo del documento ................................................ 1

1.2 Justificación de la investigación ....................................................... 2

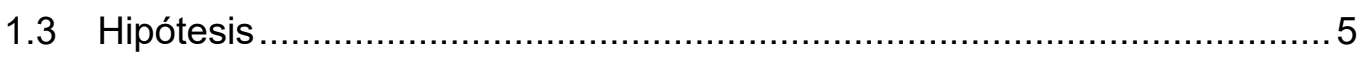

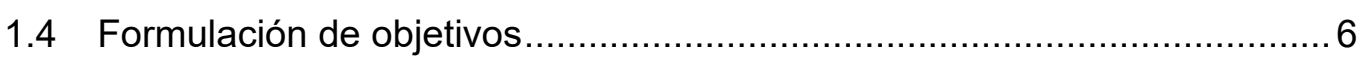

2 ANTECEDENTES: El marco jurídico........................................................ 7

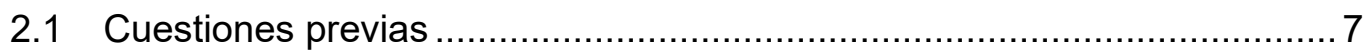

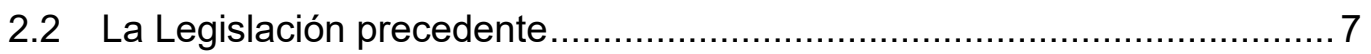

2.2.1 La regulación de las valoraciones urbanísticas desde 1956 a

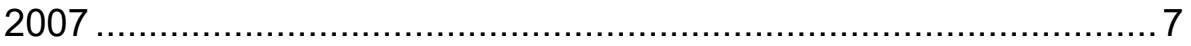

2.2.2 La valoración de las expectativas en la valoración de suelo rural .......15

2.3 La doctrina de los tribunales sobre las expectativas urbanísticas en la valoración del suelo rural ............................................................ 19

2.3.1 Jurisprudencia del Tribunal Supremo .............................................. 19

2.3.2 Doctrina de los Tribunales Superiores de Justicia.............................29

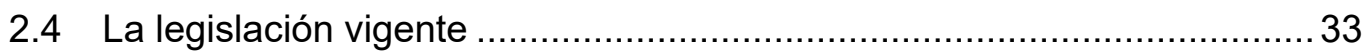

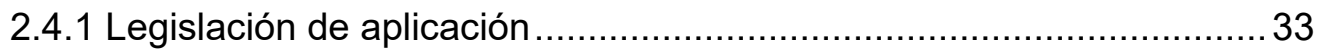

2.4.2 Análisis comparativo entre el TRLS 2008 (sustituido por el TRLSRU 2015) y el RD 1492/2011 por el que se aprueba el Reglamento de valoraciones de la Ley de Suelo.............................37

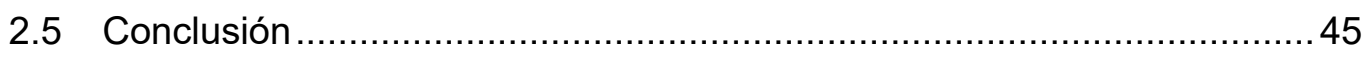

3 EL VALOR TERRITORIAL Y LA LOCALIZACIÓN: Marco teórico...................49

3.1 Geografía y economía urbana ........................................................ 49

3.2 La localización en la valoración agraria............................................... 51

3.3 Los modelos de economía espacial ...................................................52

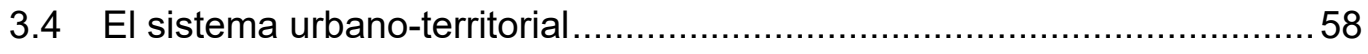

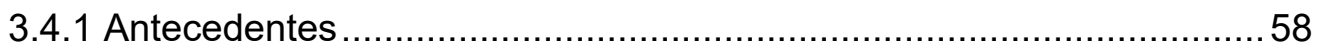

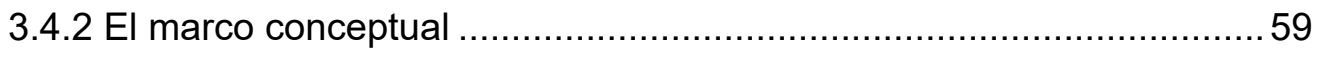

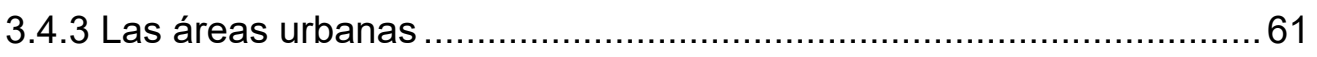

3.4.4 Los canales de relación - Los flujos - El Sistema de 
Comunicación 64

3.4.5 El sistema urbano-territorial: conclusión 64

3.5 la incidencia de la localización en la valoración de suelo: Conclusiones

4 METODOLOGÍA

4.1 Antecedentes del cálculo del Factor de Corrección por Localización

(FL) en el suelo rural según el RVLS 2011

4.1.1 Aplicación al municipio de Leganés (Madrid)...................................67

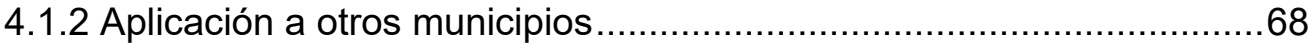

4.1.3 Conclusiones de los antecedentes del cálculo del factor de corrección.

4.2 Línea metodológica para el cálculo del factor por accesibilidad a núcleos de población en españa ........................................................ 74

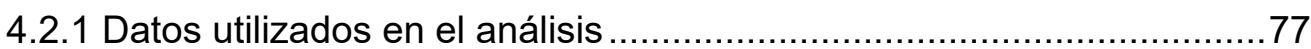

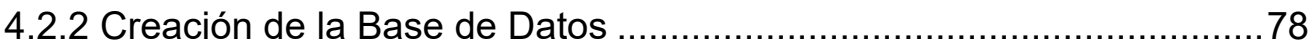

4.2.3 Creación del Sistema de Información Geográfica (SIG) ....................80

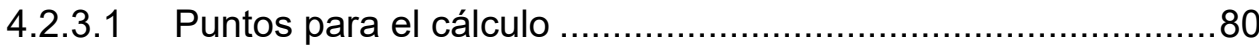

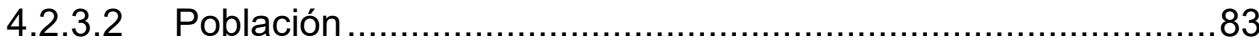

4.2.3.3 Clasificación urbanística del suelo.........................................86

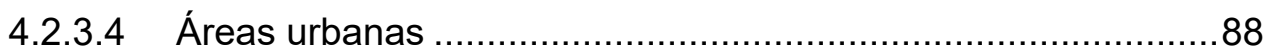

4.2.3.5 Canales de relación - Flujos - El Sistema de Comunicación ..91

4.2.4 Análisis geoestadístico y espacial..................................................92

4.2.4.1 Características y tipologías de semivariogramas teóricos........93

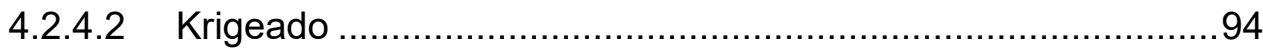

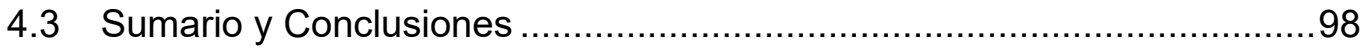

5 APLICACIÓN DE LA METODOLOGÍA EN ESPAÑA ..................................101

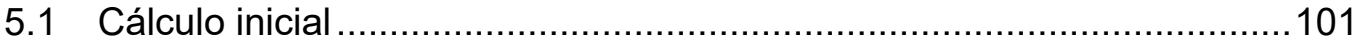

5.2 Valores discretos del factor $\mathrm{u}_{1}(1.836$ puntos) .................................103

5.3 Valores continuos del factor $\mathrm{u}_{1}$. Geoestadística ................................106

5.3.1 Geoestadística. Resultados ........................................................ 106

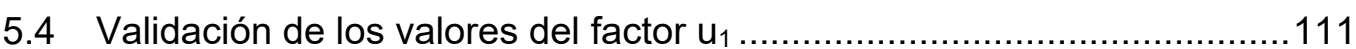

5.5 Aplicación de la metodología: Conclusiones ......................................111

6 ANÁLISIS Y DISCUSIÓN DE RESULTADOS: LA ACCESIBILIDAD A NÚCLEOS DE POBLACIÓN .......................................................................113

6.1 Las relaciones entre los elementos de la formula del artículo 17.2

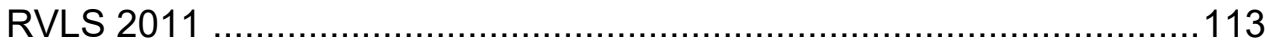

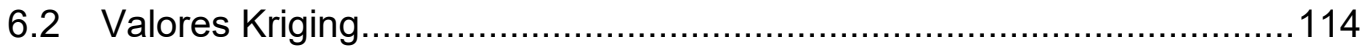

6.3 Acerca del factor $\mathrm{u}_{1} \mathrm{y}$ las expectativas urbanísticas ...........................118 
6.3.1 Factor $\mathrm{u}_{1}$ y expectativas en la Comunidad de Madrid 121

6.3.1.1 Conclusión Comunidad de Madrid 131

6.3.2 Factor $\mathrm{u}_{1}$ y expectativas en la Región de Murcia 132

6.3.2.1 Conclusión Región de Murcia 140

6.3.3 Factor $\mathrm{u}_{1}$ y expectativas en Cataluña 141

6.3.3.1 Conclusión Cataluña 149

6.3.4 Sobre las expectativas urbanísticas 151

6.4 Acerca del Factor $u_{1}$ y El sistema urbano-territorial Español 153

6.4.1 Acerca del Factor $\mathrm{u}_{1}$ y las Áreas Urbanas .153

6.4.1.1 Factor $u_{1} y$ Área Urbana de Madrid .................................. 155

6.4.1.2 Factor $\mathrm{u}_{1} \mathrm{y}$ área urbana de Murcia .................................... 158

6.4.1.3 Factor $\mathrm{u}_{1} \mathrm{y}$ Área Urbana de Barcelona............................... 162

6.4.1.4 Factor $\mathrm{u}_{1} \mathrm{y}$ las áreas urbanas........................................ 170

6.4.2 El Factor $\mathrm{u}_{1} \mathrm{y}$ las redes de comunicación...................................... 171

6.4.3 Conclusión sobre el factor $\mathrm{u}_{1}$ y el sistema urbano-territorial español

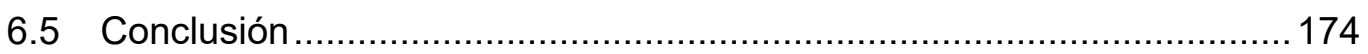

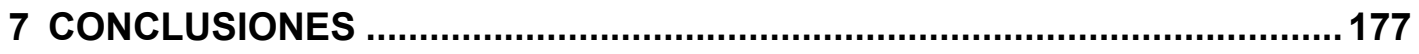

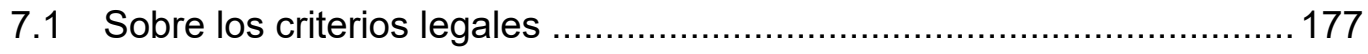

7.2 Sobre la fórmula del RVLS 2011 y los valores de sus componentes ..... 179

7.3 Validación de las Hipótesis de partida................................................. 180

7.3.1 Hipótesis 1. Es viable un cálculo sistemático del factor de corrección por accesibilidad a núcleos de población, que permita la aproximación a un valor objetivo.

7.3.2 Hipótesis 2. La aplicación del factor de corrección por accesibilidad a núcleos de población contradice la prohibición de la consideración de las expectativas urbanística

7.3.3 Hipótesis 3. El plusvalor de posición de la legislación refleja la estructura, el desarrollo y dinamismo del sistema urbanoterritorial español

8 NUEVAS LÍNEAS DE INVESTIGACIÓN 185

9 BIBLIOGRAFÍA y DOCTRINA JURISPRUDENCIAL .................................. 187

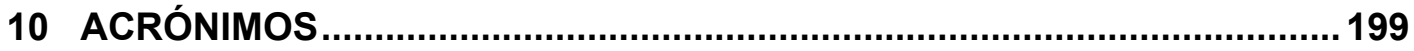

11 ANEJOS DOCUMENTACIÓN DE APOYO PARA EL CÁLCULO.................203

ANEJO 0: Mapa puntos calculados, numerado ..........................................205

ANEJO 1: Valores $\mathrm{u}_{1}, \mathrm{n}^{\circ}$ orden, coordenadas $\mathrm{x}$ e y ..................................209

ANEJO 2: $\mathrm{N}^{\circ}$ orden, valores $\mathrm{u}_{1}$, coordenadas $\mathrm{x}$ e y .................................219

ANEJO 3: Valores $P_{1}$ por municipio, superficie, promedio, mínimo, 
máximo y Desviación estándar de $\mathrm{P}_{1}$

ANEJO 4: Valores $P_{2}$ por municipio, superficie, promedio, mínimo, máximo y desviación estándar de $\mathrm{P}_{2}$

ANEJO 5: Valores $u_{1}$ por municipio, superficie, promedio, mínimo, máximo y Desviación estándar de u

ANEJO 6: Áreas urbanas, superficie, densidad, $\mathrm{n}^{\circ}$ viviendas y $\mathrm{n}^{\circ}$ hogares.

ANEJO 7: Áreas urbanas, número de municipios, superficie, población, SUS Y SUNS. 


\section{RESUMEN}

El presente trabajo de investigación está motivado por la introducción que la Ley 8/2007 de los denominados factores objetivos de localización en el cálculo del valor del suelo en situación básica rural. Estos factores están definidos en el artículo 22.1.a del vigente Texto Refundido de la Ley de Suelo y Rehabilitación Urbana y desarrollados por el Real Decreto 1492/2011, de 24 de octubre, por el que se aprueba el Reglamento de Valoraciones de la Ley de suelo.

La relación de la localización con el valor económico del suelo ha sido ampliamente estudiada por los analistas desde el siglo XIII. La distribución de los precios de suelo está basada en gran medida en las rentas de accesibilidad, la idea de territorio como espacio de intercambio es en lo que se ha apoyado el análisis teórico de la economía territorial. En el desarrollo del trabajo se ha estudiado la distribución espacial del plusvalor generado por dichas rentas en suelo rural y su conexión con la estructura socio-económica del territorio, así como la posible relación entre la aplicación del factor de corrección por accesibilidad a núcleos de población $\left(\mathbf{u}_{1}\right)$ y la consideración de las futuras expectativas urbanísticas de los suelos a valorar.

Para la consecución de los objetivos de este estudio se ha hecho uso de los SIG (Sistemas de Información Geográfica) y de la metodología geoestadística, basada tanto en la construcción de un semisemivariograma, como en la interpolación del kriging ordinario, lo que permite identificar los patrones espaciales del plusvalor de accesibilidad. Los SIG permiten recopilar, organizar, administrar, analizar, compartir y distribuir información geográfica, y su aplicación ha permitido clasificar y visualizar 1.836 puntos distribuidos por todo el territorio español, calculando la población situada a las distancias de $4 \mathrm{Km}$. y $40 \mathrm{Km}$. de cada punto analizado, para calcular posteriormente el valor del factor de corrección $\mathbf{u}_{1}$.

La metodología utilizada ha permitido comprobar que no existe vinculación entre el factor de corrección por accesibilidad y las posibles expectativas urbanísticas, y ha podido concluirse que la aplicación de dicho factor de acuerdo con la legislación que lo regula es coherente con la estructura del denominado sistema urbano-territorial español. 



\section{ABSTRACT}

This research work is motivated by the introduction of Law 8/2007 of the so-called objective location factors in the calculation of the value of land in a rural basic situation. These factors are defined in article 22.1.a of the current Consolidated Text of the Urban Land and Rehabilitation Law and developed by Royal Decree 1492/2011, of October 24, which approves the Valuation Regulation of the Law of ground.

The relationship of location to the economic value of the land has been widely studied by analysts since the thirteenth century. The distribution of land prices is based largely on accessibility income, the idea of territory as a space for exchange is what has supported the theoretical analysis of territorial economy. In the development of the work, the spatial distribution of the surplus value generated by these rents in rural land and its connection with the socio-economic structure of the territory has been studied, as well as the possible relationship between the application of the correction factor for accessibility to population centers $\left(\mathbf{u}_{1}\right)$ and the consideration of future urban planning expectations of the land to be valued.

In order to achieve the objectives of this study, GIS (Geographic Information Systems) and geostatistical methodology have been used, based both on the construction of a semi-semi-program, and on the interpolation of ordinary kriging, which allows identifying the Spatial patterns of accessibility surplus value. GIS allow to collect, organize, manage, analyze, share and distribute geographic information, and its application has allowed to classify and visualize 1.836 points distributed throughout the Spanish territory, calculating the population located at distances of $4 \mathrm{Km}$. and $40 \mathrm{Km}$. each point analyzed, to later calculate the value of the correction factor $\mathbf{u}_{1}$.

The methodology used has allowed us to verify that there is no link between the correction factor for accessibility and the possible urban expectations, and it has been concluded that the application of said factor in accordance with the legislation that regulates it is consistent with the structure of the so-called urban system - Spanish territory. 



\section{LISTADO TABLAS}

\section{CAPÍTULO 3}

Tabla 3.1. Distancias y precios por Ha. (fuente: Santi Juárez (1952) y elaboración propia)

\section{CAPÍTULO 4}

Tabla 4.1 Resultados $\mathrm{u}_{1}$ en Leganés. (fuente: elaboración propia)

Tabla 4.2 Valores de $u_{1}$ en otros municipios (fuente: elaboración propia)

Tabla 4.3 Valores de $\mathrm{u}_{1}$ de los puntos de estudio previo (fuente: elaboración propia)

Tabla 4.4 Flujo de trabajo desarrollado en el estudio (fuente: elaboración propia)

Tabla 4.5 Base de datos con las propiedades de los atributos del estudio (fuente: elaboración propia)

Tabla 4.6 Puntos obtenidos para el cálculo de u (fuente: elaboración propia)

\section{CAPÍTULO 5}

Tabla 5.1 Datos iniciales antecedentes previos (fuente: elaboración propia)

Tabla 5.2 Datos calculados en el SIG (fuente: elaboración propia)

Tabla 5.3 Clasificación de los valores de $\mathrm{u}_{1}$, número de puntos en cada una de las clases (fuente: elaboración propia)

Tabla 5.4 Estadísticos preliminares de la variable "Factor de corrección u " (fuente: elaboración propia)

Tabla 5.5 Definición de los variogramas (fuente: elaboración propia)

Tabla 5.6 Validación cruzada del modelo kriging ordinario según distintos semivariogramas (fuente: elaboración propia)

\section{CAPÍTULO 6}

Tabla 6.1 Intervalos y frecuencias del factor $\mathrm{u}_{1}$ (fuente: elaboración propia)

Tabla 6.2 Superficie en categorías de $\mathrm{u}_{1}$ e incremento de valor de suelo (fuente: elaboración propia)

Tabla 6.3 Categorías $u_{1}$ y clasificación de suelo (fuente: elaboración propia)

Tabla 6.4 Valores totales comparados con la CM (fuente: elaboración propia)

Tabla 6.5 Categorías $u_{1}$ y clasificación de suelo Región de Murcia (fuente: elaboración propia)

Tabla 6.6 Valores totales comparados con la Región de Murcia (fuente: elaboración propia)

Tabla 6.7 Categorías $u_{1}$ y clasificación de suelo (fuente: elaboración propia)

Tabla 6.8 Valores totales comparados en las provincias de Cataluña (fuente: elaboración propia)

Tabla 6.9 Valores totales comparados de las CCAA estudiadas (fuente: elaboración propia) 
Tabla 6.10 Valores área urbana de Madrid (fuente: elaboración propia)

Tabla 6.11 Valores Región de Murcia (fuente: elaboración propia)

Tabla 6.12 Valores de áreas urbanas de Barcelona, Tarragona, Lérida y Gerona (fuente: elaboración propia)

Tabla 6.13 Valores totales comparados en las áreas urbanas estudiadas (fuente: elaboración propia)

Tabla 6.14 Longitud de los corredores (fuente: elaboración propia)

Tabla 6.15 Carreteras en las distintas zonas de valor de $\mathrm{u}_{1}$ (fuente: elaboración propia)

Tabla 6.16 Categorías de las distintas zonas de valor de $u_{1}$ (fuente: elaboración propia) 


\section{LISTADO FIGURAS}

\section{CAPÍTULO 1}

Figura 1.1 Plano Comunidad de Madrid cálculo $u_{1}$ municipio Leganés. (fuente: elaboración propia)

\section{CAPÍTULO 2}

Figura 2.1 INE BASE. Nomenclátor: Población del Padrón Continuo por Unidad Poblacional. (fuente: Instituto Nacional de Estadística)

\section{CAPÍTULO 3}

Figura 3.1 Modelo de la localización de la actividad económica (Von Thünen 17831850) (fuente: elaboración propia)

Figura 3.2 Modelo de la "Teoría geográfica" de Walter Christaller (1893-1969) (fuente: elaboración propia)

Figura 3.3 Modelo Alfred Weber (1929) (fuente: elaboración propia)

\section{CAPÍTULO 4}

Figura 4.1 Mapa de España de densidades de población(fuente:http://alarcos.infcr.uclm.es/per/fruiz/pobesp/map/espania.htm\#densidad y elaboración propia)

Figura 4.2 Ubicación de Layna (fuente: elaboración propia)

Figura 4.3 Ubicación de Alares (fuente: elaboración propia)

Figura 4.4 Ubicación de Tembleque (fuente: elaboración propia)

Figura 4.5 Ubicación de Almagro (fuente: elaboración propia)

Figura 4.6 Ubicación de Córdoba (fuente: elaboración propia)

Figura 4.7 Valores de $\mathrm{u}_{1}$ superiores a 2 en color naranja (fuente: elaboración propia)

Figura 4.8 Valores de $u_{1}$ superiores a 2 en color naranja, según el Anteproyecto del RVLS 2011 (fuente: elaboración propia)

Figura 4.9 Infraestructura de datos espaciales (fuente: http://www.idee.es/)

Figura 4.10.Cuadrícula 50x50 y 392 puntos (fuente: elaboración propia)

Figura 4.11 Distintas cuadrículas en el desarrollo:

1.- Cuadrícula $50 \times 50$ vértices y $60 \times 60$ vértices y centroides.

2.- igual que 1 y $70 \times 70$ vértices y centroides.

3.- igual que 2 y $80 \times 80$ vértices.

4.- igual que 3 y nuevo $50 \times 50$ vértices y centroides

(fuente: elaboración propia)

Figura 4.12. Coropletas población Comunidad de Madrid y alrededores (fuente: elaboración propia)

Figura 4.13. Entidades de población España (fuente: elaboración propia) 
Figura 4.14 Entidades de población Francia y Portugal (fuente: elaboración propia)

Figura 4.15 Datos facilitados SIU sobre clasificación de suelo (fuente: elaboración propia)

Figura 4.16. Áreas urbanas del territorio nacional categorizadas por población (fuente: elaboración propia)

Figura 4.17. Áreas urbanas del territorio nacional categorizadas por: 1.-superficie (Ha) y 2.- densidad (habitantes/Ha) (fuente: elaboración propia)

Figura 4.18 Canales de relación - Flujos - Sistema de Comunicación (fuente: elaboración propia)

\section{CAPÍTULO 5}

Figura 5.1. x.1) Densidad de población y x.2) entidades de población de: a Leganés, b Layna y c Alares. (fuente: elaboración propia)

Figura 5.2 x.1) Densidad de población y x.2) entidades de población de: d Tembleque, e Almagro y Córdoba. (fuente: elaboración propia)

Figura 5.3 a) Valor de $\mathrm{P}_{1}$ (número de habitantes a una distancia de $4 \mathrm{Km}$.), b) valor $\mathrm{P}_{2} / 3$ (número de habitantes situados a más de $4 \mathrm{Km}$. y a menos de $40 \mathrm{Km}$.) (fuente: elaboración propia)

Figura 5.4 Distribución del valor del factor de corrección por accesibilidad a núcleos de población u1. Representación en cada uno de los 1836 puntos (fuente: elaboración propia)

Figura 5.5 Tendencia global "muy débil" lineal de los puntos del Factor de corrección $\mathrm{u}_{1}$ (línea azul: NS, línea verde: WE) (fuente: elaboración propia)

Figura 5.6 Modelo de semivariograma exponencial con distintos azimuts (fuente: elaboración propia)

Figura 5.7 Interpolación de kriging ordinario de la variable "Factor de corrección u" (fuente: elaboración propia)

Figura 5.8 Zonificación obtenida con la interpolación kriging ordinario superpuesto el valor del "Factor de corrección un" (fuente: elaboración propia)

\section{CAPÍTULO 6}

Figura 6.1 Comparación valores $\mathrm{P}_{1}, \mathrm{P}_{2} / 3$ y $\mathrm{u}_{1}$ (fuente: elaboración propia)

Figura 6.2 Histograma con los valores discretos del facto $u_{1}$. (fuente: elaboración propia)

Figura 6.3 Representación de los valores de $u_{1}$ más altos en el mapa (fuente: elaboración propia)

Figura 6.4 $\mathrm{KO}$ con valores de $\mathrm{u}_{1}$ y clasificación y categorías urbanísticas del suelo de la Comunidad de Madrid (fuente: elaboración propia)

Figura 6.5 Clasificación urbanística del suelo de la Comunidad de Madrid (fuente: elaboración propia)

Figura 6.6 Superposición de clasificación urbanística del suelo de la Comunidad de Madrid y valores $\mathrm{u}_{1}$ (fuente: elaboración propia)

Figura 6.7 Densidad de población y número de habitantes de la Comunidad de Madrid (fuente: Atlas Digital de la Áreas Urbanas Ministerio de Fomento) 
Figura 6.8 Diagrama de columnas clasificación de suelo, clasificación de $u_{1}$ y superficie en Comunidad Madrid (fuente: elaboración propia)

Figura 6.9 Diagrama de líneas clasificación suelo, calificación de $u_{1}$ y superficie en CM (fuente: elaboración propia)

Figura 6.10 Diagrama de columnas y líneas clasificación de suelo, clasificación de u y superficie en municipios de Madrid, Leganés, Aranjuez y Robledo de Chavela (fuente: elaboración propia)

Figura 6.11 Diagrama de columnas clasificación de suelo, clasificación de $\mathrm{u}_{1}$ y superficie en municipios de Patones, Cenicientos, Robledillo de la Jara, Prádena, La Hiruela y Robregordo (fuente: elaboración propia)

Figura 6.12 Superposición de clasificación urbanística del suelo de la Comunidad de Madrid, valores $u_{1}$ y cantidad de población, municipios estudiados marcados en densidad de población (fuente: elaboración propia)

Figura 6.13 1) Instrumentos planeamiento general- 2) Fecha de publicación del planeamiento de la Región de Murcia

Figura 6.14 Municipios estudiados de la CM: Madrid, Leganés, Aranjuez, Robledo de Chavela, Patones, Cenicientos, Robledillo de la Jara, La Hiruela y Robregordo (fuente: elaboración propia)

Figura 6.15 Clasificación urbanística del suelo de la Región de Murcia (fuente: elaboración propia)

Figura 6.16 Superposición de clasificación urbanística del suelo de la Región de Murcia y valores $\mathrm{u}_{1}$. ETRS 89 UTM (fuente: elaboración propia)

Figura 6.17 Densidad de población y número de habitantes de la Región de Murcia (fuente: ATLAS ÁREAS URBANAS SIU)

Figura 6.18 Diagrama de columnas y líneas, clasificación de suelo, clasificación de u y superficie en la Región de Murcia (fuente: elaboración propia)

Figura 6.19 Diagrama de columnas y líneas, clasificación de suelo, clasificación de $u_{1}$ y superficie en el Municipio de Murcia (fuente: elaboración propia)

Figura 6.20 Superposición de clasificación urbanística del suelo de la Región de Murcia, valores $u_{1}$ y cantidad de población (fuente: elaboración propia)

Figura 6.21 1) Instrumentos planeamiento general. 2) Fecha de publicación del planeamiento de la Región de Murcia

Figura 6.22 Municipios estudiados de la Región de Murcia (fuente: elaboración propia)

Figura 6.23 Clasificación urbanística del suelo de Cataluña (fuente: elaboración propia)

Figura 6.24 Superposición de clasificación urbanística del suelo de Cataluña y valores $\mathrm{u}_{1}$ (fuente: elaboración propia)

Figura 6.25 Densidad de población y número de habitantes de Cataluña (fuente: elaboración propia)

Figura 6.26 Densidad de población y número de habitantes de Cataluña, por provincias (fuente: elaboración propia)

Figura 6.27 Diagrama de columnas clasificación de suelo, clasificación de $\mathrm{u}_{1}$ y superficie en Cataluña (fuente: elaboración propia)

Figura 6.28 Diagrama de líneas clasificación suelo, calificación de $\mathrm{u}_{1}$ y superficie en Cataluña (fuente: elaboración propia)

Figura 6.29 Diagrama de columnas y líneas, clasificación de suelo, clasificación de $\mathrm{u}_{1}$ y superficie en Cataluña (fuente: elaboración propia) 
Figura 6.30 Superposición de clasificación urbanística del suelo de Cataluña, valores $\mathrm{u}_{1}$ y cantidad de población (fuente: elaboración propia)

Figura 6.31 1) Instrumentos planeamiento general. 2) Fecha de publicación del planeamiento de Cataluña (fuente: elaboración propia)

Figura 6.32 Mapa fecha publicación de planeamiento general municipal. (fuente: SIU Ministerio de Fomento)

Figura 6.33 Áreas urbanas del territorio nacional (fuente: elaboración propia)

Figura 6.34 Área urbana de Madrid (fuente: elaboración propia)

Figura 6.35 Área urbana de Madrid sobre plano de clasificación urbanística del suelo y valores de $\mathrm{u}_{1}$ (fuente: elaboración propia)

Figura 6.36 Diagrama de columnas y líneas, clasificación de suelo, clasificación de $u_{1}$ y superficie en el área urbana de Madrid (fuente: elaboración propia)

Figura 6.37 Área urbana de Murcia (fuente: elaboración propia)

Figura 6.38 Área urbana de Murcia sobre plano de clasificación urbanística del suelo y valores de $\mathrm{u}_{1}$ (fuente: elaboración propia)

Figura 6.39 Diagrama de columnas y líneas, clasificación de suelo, clasificación de $u_{1}$ y superficie en el área urbana de Murcia (fuente: elaboración propia)

Figura 6.40 Área urbana de Barcelona (fuente: elaboración propia)

Figura 6.41 Áreas urbanas de Barcelona, Tarragona, Lérida y Gerona sobre plano de clasificación urbanística del suelo y valores de $\mathrm{u}_{1}$ (fuente: elaboración propia)

Figura 6.42 Diagrama de columnas y líneas, clasificación de suelo, clasificación de $\mathrm{u}_{1}$ y superficie en el área urbana de Barcelona (fuente: elaboración propia)

Figura 6.43 Diagrama de columnas y líneas, clasificación de suelo, clasificación de $u_{1}$ y superficie en el área urbana de Tarragona (fuente: elaboración propia)

Figura 6.44 Diagrama de columnas y líneas, clasificación de suelo, clasificación de $\mathrm{u}_{1}$ y superficie en el área urbana de Lérida (fuente: elaboración propia)

Figura 6.45 Diagrama de columnas y líneas, clasificación de suelo, clasificación de $\mathrm{u}_{1}$ y superficie en el área urbana de Gerona (fuente: elaboración propia)

Figura 6.46 Corredores (fuente: elaboración propia)

Figura $6.47 \mathrm{KO}$ con valores $\mathrm{u}_{1}$, valores de $\mathrm{u}_{1}$ y corredores. (fuente: elaboración propia)

Figura 6.48 Clasificación de suelo y valor de $u_{1}$ (fuente: elaboración propia)

\section{CAPÍTULO 7}

Figura 7.1 Comparación valores $\mathrm{P}_{1}, \mathrm{P}_{2} / 3$ y $\mathrm{u}_{1}$ (fuente: elaboración propia) 


\section{INTRODUCCIÓN}

\subsection{INTRODUCCIÓN Y DESARROLLO DEL DOCUMENTO}

La aprobación de la Ley 8/2007, de 28 de mayo, de Suelo (en adelante Ley 8/2007) supuso un cambio radical en numerosos conceptos jurídico-urbanísticos y, en especial, en la creación de dos situaciones básicas de suelo, rural y urbanizado, que transformaron el sistema de valoración existente hasta ese momento. En el marco de la nueva situación legislativa, la valoración del suelo rural adquiere una especial relevancia, puesto que la situación básica correspondiente incluye suelos de alto valor económico en el mercado, como los clasificados como urbanizables, tanto sectorizados como sin sectorizar e, incluso, en determinadas circunstancias, incorpora también los suelos urbanos sin urbanización consolidada.

Ese cambio se consolidó posteriormente en el Texto Refundido de la Ley de Suelo aprobado por Real Decreto Legislativo 2/2008, de 20 de junio, por el que se aprueba el Texto Refundido de la Ley de Suelo (en adelante TRLS 2008), desarrollado posteriormente por el Real Decreto 1492/2011, de 24 octubre, por el que se aprueba el Reglamento de valoraciones de la Ley de suelo (en adelante RVLS 2011). Finalmente, el TRLS 2008 fue derogado por el vigente Real Decreto Legislativo 2015, de 30 de octubre, por el que se aprueba el Texto Refundido de la Ley de Suelo y Rehabilitación Urbana (en adelante TRLSRU 2015), pero mantiene en su totalidad lo regulado en materia de valoraciones.

Este sistema legislativo derivado de la Ley 8/2007 introduce en el cálculo del valor del suelo en situación básica rural el método de capitalización de rentas, de amplia tradición en el sistema jurídico-urbanístico español. Sin embargo, en la aplicación de este procedimiento de determinación del valor se introducen en la Ley de 2007 nuevos conceptos que han sido objeto de escaso estudio y que suponen una innovación en relación con la legislación precedente. En concreto, se regulan los denominados "factores objetivos de localización" definidos en la actualidad en el artículo 22.1.a del TRLSRU 2015, que constituyen, en parte, el objeto de este trabajo.

La Ley 8/2007 y el TRLS 2008, si bien preveían la aplicación de esos factores, establecían la posibilidad de corrección al alza en una magnitud igual "hasta un máximo del doble". El 11 de septiembre de 2014 se dictó Sentencia por el Tribunal Constitucional en la que se declaraba inconstitucional y nula dicha limitación. De este modo la corrección del valor del suelo rural atendiendo al TRLS 2008 se lleva a cabo 
mediante la aplicación de los factores objetivos de localización sin limitación ninguna.

En el presente trabajo de investigación se ha realizado el estudio exclusivo de uno de los factores, el denominado factor de corrección por accesibilidad a núcleos de población, señalado con la notación $\mathbf{u}_{1}$ en el RVLS 2011. El motivo de dicho estudio es el interés de la cuantificación de la población como parámetro determinante del plusvalor del suelo en situación básica rural. Por otro lado, el citado factor es el que está dotado de mayor peso en el factor global de localización: mientras el $\mathrm{u}_{2}$-que pondera la accesibilidad a actividades económicas- varía entre 1 y 1,6, y el $\mathrm{u}_{3}$-relativo a las localizaciones de especial interés ambiental- varía entre 1,1 y 2, el factor $\mathbf{u}_{1}$ puede variar de 1 a 3,82, como se comprobará en el desarrollo de este trabajo.

Por otra parte, la creación de este sistema de obtención de un plusvalor del suelo rural en relación con su localización parece entrar en contradicción con la prohibición expresa de la incorporación de las expectativas urbanísticas en el cálculo de dicho valor. En efecto, el artículo 36.2 TRLSRU 2015 dispone, en relación con la valoración en suelo rural, que "en ninguno de los casos previstos en el apartado anterior [la valoración de los terrenos, edificaciones, plantaciones, construcciones, indemnizaciones, etc.] podrán considerarse expectativas derivadas de la asignación de edificabilidades y usos por la ordenación territorial o urbanística que no hayan sido aun plenamente realizados". Al análisis de esta relación no deseada por el legislador y su conexión con el incremento del valor de capitalización en suelo rural por aplicación de los factores de localización, se dedica también este trabajo.

Finalmente, uno de los aspectos de mayor interés en el análisis del plusvalor de posición de la accesibilidad a núcleos de población reside en su conexión con lo que en este trabajo se denomina el sistema urbano-territorial, que se define como el conjunto complejo de relaciones, básicamente sociales y económicas, constituido por las distintas ciudades españolas, sus áreas de influencia y los corredores que las conectan.

\subsection{JUSTIFICACIÓN DE LA INVESTIGACIÓN}

En el apartado VI de la Exposición de motivos del TRLS 2008 (derogado por el TRLSRU 2015) se afirmaba que la Ley proponía la búsqueda de sencillez y claridad en los criterios de valoración; sin embargo, como se verá en adelante, tanto el TRLS 2008 (y en la actualidad el TRLSRU 2015) como el RVLS 2011 no consiguen la sencillez y claridad buscadas en los criterios de valoración. Esta reflexión, motivada por la 
necesidad del cálculo de los diferentes factores de corrección recogidos en la legislación, ha sido una de las causas que han llevado a la realización del presente trabajo de investigación. Como se ha indicado en la Introducción y se verá posteriormente en el desarrollo del texto, este estudio se ha referido en concreto a uno de los factores que desarrolla el RVLS 2011, el denominado factor de corrección por accesibilidad a núcleos de población $\mathbf{u}_{1}$. Si bien el RVLS 2011 formula el cálculo de dicho factor con propósitos de objetividad, la realidad práctica demuestra que, al realizar el desarrollo numérico, existen innumerables interrogantes no aclarados en el citado Reglamento, cuya regulación conduce además a un cálculo complejo y laborioso que introduce una carga subjetiva elevada en los resultados obtenidos.

Una de las motivaciones para la realización del presente estudio fue precisamente la de simplificar la obtención de los valores del citado factor $\mathbf{u}_{1}$. Previamente al inicio del estudio se había realizado un primer trabajo de investigación ${ }^{1}$, en el que se había constatado la complejidad en el cálculo del factor $\mathbf{u}_{1}$. La necesidad de recopilación de una gran cantidad de datos administrativos, así como la metodología para la medición de las distancias necesarias para determinar los valores de población a introducir en los sumandos de la fórmula de cálculo, resultaron enormemente complejos. Además, el procedimiento era excesivamente artesanal, lo que no parecía adecuado para la realización profesional de valoraciones en las que, tras el cálculo de la capitalización de rentas en suelos en situación básica rural, era necesario considerar el factor $\left(\mathbf{u}_{1}\right)$.

En aquel primer trabajo de investigación la representación gráfica se realizó mediante cartografía en un formato de documento portable ( $p d f)$, en el que visualmente se reconocían las entidades de población que se encontraban a las distancias legalmente establecidas en el RVLS 2011 y se hacía el recuento de población para el cálculo del factor $\mathbf{u}_{1}$.

\footnotetext{
1 "Los efectos de la localización en la valoración del suelo rural: Análisis de los factores de corrección", Rosa María González Ruiz. XXXIII Curso Superior de Estudios Territoriales y Urbanísticos. Segundo año. 2011
} 


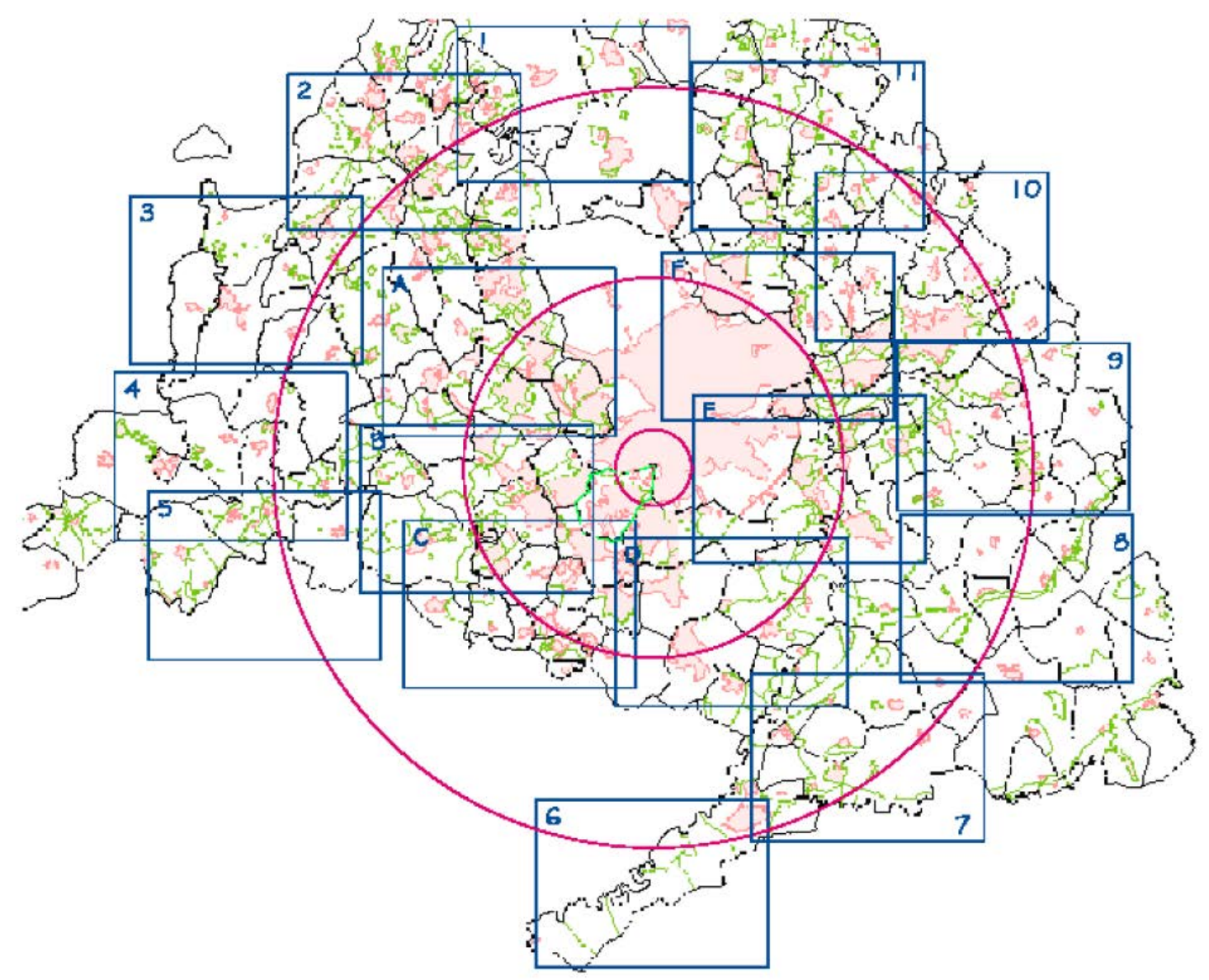

Figura 1.1. Plano Comunidad de Madrid cálculo u municipio Leganés. (fuente: elaboración propia)

Obviamente, este trabajo artesanal podía conllevar errores, tanto por la escala de la representación como por la precisión en el cálculo de las distancias. Estos inconvenientes motivaron la necesidad de buscar un procedimiento que resultara más sencillo y preciso para el cálculo del factor objeto de la presente investigación. Para ello, como se verá en el desarrollo del trabajo, se planteó la utilización de un sistema de información geográfica (SIG) que permitía subsanar algunos de los inconvenientes aludidos, además de la posibilidad de la representación del cálculo del factor $\mathbf{u}_{\mathbf{1}}$ en la totalidad de territorio nacional.

Por otro lado, el hecho de lograr un cálculo más preciso y sistemático mediante la herramienta arriba descrita, permite hacer un análisis del significado del factor $\mathbf{u}_{1}$ en la valoración de suelos en situación básica rural. La posibilidad de análisis de los datos obtenidos podría llevar implícita una representación clara de la distribución espacial de los resultados y de su significado, analizando de este modo el sentido que el legislador quiso enfatizar al introducir dicho factor en el cálculo del valor de suelo en situación básica rural en la nueva legislación de suelo estatal. 
Además, existen en la comunidad científica ${ }^{2}$, como más adelante se verá, distintas opiniones que consideran que los factores objetivos de localización pueden estar relacionados con las denominadas "expectativas urbanísticas" que incrementan el valor intrínseco del suelo rural obtenido en función de su exclusiva capacidad de producción. El conocimiento analítico de esta cuestión ha sido otra de las motivaciones para la realización de este trabajo. El hecho de que el legislador del año 2007 hiciera especial hincapié en la exclusión de dichas "expectativas urbanísticas" en la obtención del valor, tal y como se recoge en la exposición de motivos de la Ley 8/2007, sería aparentemente contradictorio con la introducción de los factores de corrección aplicables en el cálculo del valor de suelos en situación básica rural, si se considera implícita la aplicación de estos últimos a la incorporación al valor de ciertas expectativas urbanísticas.

Durante el desarrollo de la investigación se observó cómo la representación de los resultados del factor $\mathbf{u}_{1}$ en el territorio español trasponía perfectamente la estructura territorial de nuestro país. Este descubrimiento creó una nueva motivación para el desarrollo del trabajo: la relación de los valores del factor de localización por accesibilidad a núcleos de población $\mathbf{u}_{1}$ con la jerarquía del sistema de ciudades. Además, como veremos, ese análisis llevó al conocimiento de una compleja estructura territorial, no solo destacable por la jerarquía del sistema de ciudades, sino por otros conceptos fundamentales, lo que en la presente investigación se ha considerado como un conjunto indisociable denominado, como se ha indicado, sistema urbano-territorial, que está representado con claridad en los resultados obtenidos en el cálculo del factor $\mathbf{u}_{1}$.

\subsection{HIPÓTESIS}

El presente trabajo plantea las siguientes hipótesis de partida, cuya validación, en su caso, se llevará a cabo en las conclusiones del mismo:

1. Es viable un cálculo sistemático del factor de corrección por accesibilidad a núcleos de población, que permita la aproximación a un valor objetivo.

2. La aplicación del factor de corrección por localización en la valoración del suelo rural está conectada con la prohibición de la consideración de las expectativas urbanísticas y puede entrar en conflicto con ella.

\footnotetext{
2 Juan Antonio Chinchilla, Ana María de la Encarnación, Álvaro Jiménez Bueso
} 
3. El plusvalor de posición regulado en la legislación estatal de suelo vigente refleja la estructura, el desarrollo y dinamismo del sistema urbano-territorial español.

\subsection{FORMULACIÓN DE OBJETIVOS}

Los objetivos de la tesis planteada son:

- Desarrollar de forma analítica y práctica el estudio de la accesibilidad a núcleos de población en el valor del suelo rural.

- Analizar las leyes de formación de la variación del valor en el suelo rural.

- Crear unos criterios objetivos de cálculo del valor de posición.

- Analizar y comprobar la relación entre el valor del factor de corrección por accesibilidad a núcleos de población y las expectativas urbanísticas en el valor territorial.

- Constatar las relaciones entre el plusvalor de posición en suelo rural y la estructura del sistema urbano-territorial.

- Desarrollar los criterios de valoración del suelo en situación básica rural, intentando analizar teórica y prácticamente los denominados "factores objetivos de localización" definidos en el artículo 36.1.a, tercer párrafo del TRLSRU 2015 y del artículo 17 del RVLS 2011 y, en concreto, el factor de corrección por accesibilidad a núcleos de población $\mathbf{u}_{1}$.

- Estudiar la variación de los valores alcanzados por el factor de corrección por accesibilidad a núcleos de población en relación con la estructura del ámbito territorial donde se encuentre el suelo a valorar. 


\section{ANTECEDENTES: EL MARCO JURÍDICO}

\subsection{CUESTIONES PREVIAS}

A lo largo de la trayectoria legislativa histórica en materia de valoraciones de suelo en España, ha sido constante el interés del legislador en considerar esta disciplina como ciencia objetiva. Como ha indicado Roca Cladera (2007), durante el siglo XIX y la primera mitad del siglo $X X$, se consolidó la idea de que "la noción de justa indemnización no debe incluir plusvalías no ganadas por el propietario original de los terrenos", y así se aunaron esfuerzos en la determinación del justiprecio expropiatorio. Pero con la aprobación de la Ley de Expropiación Forzosa de 16 de noviembre de 1954 (en adelante LEF), tal y como recoge Roca Cladera "En este sentido el legislador aborda con "el corazón dividido" la cuestión de la indemnización expropiatoria. Por una parte afirma con rotundidad la necesidad de una determinación objetiva del valor, peor por otra reafirma la finalidad última de referir las tasaciones a la realidad del mercado. Dualidad de caminos que la Ley intentará conciliar, pero que inevitablemente estallarán en confrontación abierta."

Sin embargo, como se verá en el presente estudio, la realidad ha sido que, a pesar de la búsqueda de objetividad en el cálculo del valor, se han incluido como componente del valor, "otras" consideraciones que lo han incrementado basándose en "futuras" acciones. Si bien la intención del legislador de 2007 y sus desarrollos posteriores ha sido, tal y como recoge Roca Cladera (2007), "la búsqueda de un valor basado en el ser, que no en el devenir", la realidad ha sido diferente con ayuda de la doctrina jurisprudencial.

El incremento del valor intrínsecamente rústico, transformando el valor inicial en lo que se ha denominado "valor real", se ha justificado, en el caso concreto de las expropiaciones, como "la justa indemnización"3. Esta transformación del valor inicial en el valor real, tradicionalmente se ha denominado de diferentes formas, tal y como veremos en el presente capítulo.

\subsection{LA LEGISLACIÓN PRECEDENTE}

\subsubsection{La regulación de las valoraciones urbanísticas desde 1956 a 2007}

Para analizar la evolución histórica de las valoraciones a las que se refiere la presente

\footnotetext{
${ }^{3}$ Exposición de motivos de la Ley de 19 de diciembre de 1954, de Expropiación Forzosa
} 
investigación, se ha considerado oportuno adoptar como punto de partida la Ley de Expropiación Forzosa de 16 de noviembre de 1954 (en adelante LEF) vigente en la actualidad.

En la LEF se regula la obtención del justiprecio de un solar de acuerdo con el "valor que tenga asignado para los efectos del arbitrio municipal sobre el incremento del valor de los terrenos, aumentando en un diez por ciento, o, en su defecto, el valor en venta fijado a los efectos de la atribución territorial", de acuerdo con lo establecido en el artículo 38.1 de la citada Ley. En definitiva, se adoptaban valores fiscales en relación con los valores de mercado, aunque de acuerdo con el artículo 43 de la citada Ley se permitía "aplicar criterios estimativos" si el valor fijado de acuerdo al artículo 38.1 fuera "notoriamente inferior o superior al valor real de los bienes, haciendo uso de los criterios estimativas que juzgue más adecuados". De este modo, lo que en la práctica se buscaba era un valor "real" de mercado (Roca Cladera 1998).

En este sentido, existe una jurisprudencia muy persistente sobre la identificación del valor real que constituye la base imponible del Impuesto sobre Transmisiones Patrimoniales -artículo 10 del Real Decreto Legislativo 1/1993, de 24 de septiembre, por el que se aprueba el Texto refundido de la Ley del Impuesto sobre Transmisiones Patrimoniales y Actos Jurídicos Documentados- con el valor de mercado del bien transmitido. En una reciente sentencia, el Tribunal Supremo, aun reconociendo la dificultad de establecer un criterio concreto para la definición del término, ha insistido en esa identificación en estos términos:

"El valor real configura un concepto jurídico indeterminado de imprecisos perfiles, como esta Sala ha subrayado en una jurisprudencia constante y uniforme, puesto que no se ampara en definición legal alguna y, permite, sea cual fuere el medio de comprobación o determinación que en cada caso se utilice, un cierto margen legítimo.

El valor real no arroja - no puede hacerlo- un guarismo exacto, único y necesario, sino una franja admisible entre un máximo y un mínimo. Así sucede cuando se acepta el valor declarado por el administrado -que puede variar en unos y otros casos-; también cuando se acude al dictamen de peritos de la Administración (artículo 57.1.e) LGT4); o, en fin, si se emplean otros medios de comprobación legalmente previstos, como los precios medios de mercado o las valoraciones atribuidas a efectos de aseguramiento o hipotecarios." (STS 2186/2018 de

\footnotetext{
${ }^{4}$ Ley 58/2003, de 17 de diciembre, General Tributaria.
} 
23/05/2018)

Dos años después de la entrada en vigor de la LEF se aprobó la primera Ley del Suelo estatal, la Ley de Régimen del Suelo y Ordenación Urbana de 12 de mayo de 1956 (en adelante LS 56), que en el régimen de valoraciones asignaba diferentes valores dependiendo de la clasificación del suelo, regulando, en síntesis, los siguientes criterios:

- Suelo Urbano: se le asigna un valor comercial tasándose según valor de mercado. (Valor comercial o venal)

- Suelo de reserva urbana: se le asigna un valor en el cual se consideran las expectativas urbanísticas y de edificación. (Valor urbanístico y valor expectante)

- Suelo rústico: se le asigna un valor inicial en el que solamente se tenía en cuenta los rendimientos agrícolas, sin incluir aprovechamiento urbanístico. (Valor inicial), estando previsto que, en aquellos suelos en los que pudiera existir posibles usos urbanos en un plazo de quince años, se considerara el valor expectante.

Posteriormente mediante Decreto de 21 de agosto de 1956, se aprobó el Anexo de Coeficientes en cumplimiento de la autorización de la disposición final tercera de la LS 56. En el Anexo "se establecen los criterios de justicia que han de servir de base a toda valoración urbanística de cualquier tipo de terreno, volumen de edificabilidad por metro cuadrado, módulo o coste del metro cúbico de edificación, grado de la urbanización y tipo de ciudad en cuyo perímetro se halla enclavado." Ciertamente el Anexo establecía unos criterios claros y alejados de posibles interpretaciones evitando de este modo subjetividad alguna en su cálculo.

En el citado Anexo a la Ley de 1956 se parte en un principio de unas "normas" para la determinación del valor que, como veremos en el desarrollo de este trabajo están conectadas con los para los resultados obtenidos en el mismo:

- Norma primera, en la que se definen las diferentes circunstancias que había que tener en cuenta para la aplicación de los coeficientes, siendo estas:

a. Tipo de ciudad en la que se encuentra enclavado el terreno a valorar.

b. Clase y calidad del terreno, así como la previsión temporal de utilización.

c. La urbanización efectivamente realizada.

d. Volumen de edificabilidad permitida por el planeamiento 
- Norma segunda, en la que se define la circunstancia a. recogida en la Norma primera, como "agrupación de ciudades" aunque realmente se está refiriendo, tal y como recoge en su explicación a "los diferentes grados de desarrollo urbanístico" agrupándolas de la siguiente forma:

- Primer grupo: Madrid, Barcelona, Valencia y Bilbao.

- Segundo grupo: Resto de ciudades de más de 100.000 habitantes.

- Tercer grupo: "Resto de los núcleos urbanos"

- Norma tercera, en la que se establece la diferencia entre las diferentes categorías y grados, definiendo de este modo la circunstancia b. de la Norma primera.

En esta última norma se distinguen 3 categorías, $A$, B y $\mathrm{C}$ y en cada una de ellas tres grados, $1,2,3$. De tal forma que un terreno en la categoría $C$ grado 3 es aquel con circunstancias urbanísticas más desfavorables, con la menor dotación de agua, con "carencia de acceso rodado pavimentado a una distancia inferior a $300 \mathrm{~m}$ ", terreno donde la cimentación del edificio no se puede llevar a cabo por sistemas normales, sino que requiere sistemas especiales costosos en su ejecución y además tenga una "topografía accidentada que dificulte gravemente la cimentación". En el otro extremo, un terreno en la categoría A grado 1 era aquel que reunía las "mejores circunstancias urbanísticas normales" además de reunir 6 de las siguientes condiciones: "Paisaje de interés destacado entre los terrenos de condiciones semejantes", "vegetación rica por el número y calidad de las plantaciones ...", "situación privilegiada de la que gozan menos de un diez por ciento de los terrenos del perímetro de análogas condiciones", "planeamiento de calidad excepcional reconocida por los Órganos urbanísticos", "transporte público inmediato de intensa frecuencia", "abastecimiento de agua con caudal superior a mil seiscientos litros por vivienda y día" y/o "el conjunto de los servicios sociales disponibles de forma inmediata y completa".

- Norma cuarta, recoge el grado de urbanización definiendo de este modo la circunstancia c. de la Norma primera. Para el cálculo de la parte de coeficiente distingue: entre si las obras de urbanización han sido realizadas a cargo de los propietarios, que en este caso se determinará por su valor actual o si las obras de urbanización no han sido realizadas por sus propietarios, en ese caso se determinará, si se trata de urbanización completa como el $10 \%$ del coste de la edificabilidad permitida, siempre que esta no exceda de $6 \mathrm{~m}^{3} / \mathrm{m}^{2}$, si excediese se le aplicaría una escala regresiva indicada en la propia Norma. 
- Norma quinta, que, tal como se considera en la circunstancia d. recogida en la Norma primera, trata sobre el volumen de edificabilidad, de este modo el volumen de edificabilidad se define por el número máximo de metros cúbicos por metro cuadrado que el planeamiento autorice en cada caso. Esta norma señala que el módulo o coste metro cúbico de edificabilidad será determinado por los Órganos urbanísticos competentes, teniendo en cuenta el coste real que en la localidad tenga el metro cúbico de edificios destinados a vivienda y distinguiendo tres categorías según los distintos sectores, lujo, media y económica.

- Norma sexta en la que se determinan los coeficientes a utilizar en el cálculo del valor urbanístico de los terrenos situados en una ciudad de primer orden (ver norma segunda) en función de la categoría y grado del terreno (ver norma tercera) en relación con el volumen de edificabilidad máxima (norma quinta). Define que, si las obras de urbanización estuvieran terminadas estas se valorarán de forma independiente, de tal forma que el coeficiente que surgiera como aplicación de la norma cuarta pasaría a ser un sumando más del coeficiente que se obtenga de la tabla que adjunta dicho anexo.

- Norma séptima, en la que se determinan los coeficientes a utilizar en el cálculo del valor urbanístico de los terrenos situados en ciudades de segundo y tercer grupo. En esta Norma se especifica que las ciudades de segundo grupo se reducirán los coeficientes definidos en la Norma sexta en un $25 \%$ y las ciudades del tercer grupo en un $50 \%$. Puntualiza, además que en caso de los terrenos con urbanización completa son invariables.

- Norma octava, en la que se denomina "análisis de circunstancias" y trata sobre como pude ser posible la mejora del grado definido en la Norma tercera.

- Finalmente, la Norma novena que define qué se requiere para considerar la urbanización completa y la forma de reducción, si no estuviera completa, según la Norma cuarta.

Como se observa en lo expuesto sobre el Anexo de coeficientes de la LS 56, el valor a calcular tiene cuatro factores importantes a tener en cuenta, que determinarán el valor final, de acuerdo con la aplicación de los coeficientes definidos en él:

- Tipo de ciudad en la que se encuentra enclavado el terreno a valorar.

- Clase y calidad del terreno, así como la previsión temporal de utilización. 
- La urbanización efectivamente realizada.

- Volumen de edificabilidad permitida por el planeamiento

Como ya se ha indicado, a la relación de estos factores con la valoración del suelo rural de acuerdo con la accesibilidad a núcleos de población de conformidad con la legislación vigente se hará mención en el desarrollo del presente trabajo.

En este momento de la publicación y vigencia del Anexo a la LS 56 surge una cierta contraposición con la LEF, ya que los criterios valorativos de la legislación de suelo y expropiatoria diferían en ambos textos legales. En todo caso, la LS 56 preveía un tipo de valoración urbanística y otra no urbanística, mientras que la LEF no hacía dicha distinción, de modo que la legislación de suelo se postulaba como una variante urbanística de la legislación expropiatoria.

En el año 1962 se aprueba la Ley 52/1962, de 21 de julio sobre valoración de terrenos sujetos a expropiación en ejecución de los planes de vivienda y urbanismo (valoraciones urbanísticas). En la exposición de motivos de esta Ley se indica lo siguiente:

"Debido a la ejecución del Plan Nacional de Vivienda ..., los Planes Generales y Parciales de Ordenación Urbana y proyectos de servicios urbanos de inmediata realización, aconsejan y exigen un sistema de valoración de los terrenos necesarios que responda tanto a la máxima objetividad en las determinaciones del justiprecio de cada una de las fincas sujetas a expropiación, como a los principios derivados de la función social de la propiedad y de igualdad de los administrados respecto de sus obligaciones en cuanto a los fines y servicios públicos."

Con esta legislación se pretendía dejar clara la diferencia entre las valoraciones urbanísticas y las que no tenían esta finalidad, intentando de este modo evitar la libertad estimativa del artículo 43 de la LEF.

Posteriormente se aprueba la Ley 19/1975 como reforma de la LS 56. El Real Decreto 1346/1976, de 9 de abril, por el que se aprueba el texto refundido de la Ley sobre Régimen de Suelo y Ordenación Urbana (en adelante TRLS 76) refunde ambas leyes. EI TRLS 76 fue desarrollado reglamentariamente por el Reglamento de Planeamiento (en adelante RP), el Reglamento de Gestión Urbanística (en adelante RGU) y el Reglamento de Disciplina Urbanística (en adelante RDU). En la citada Ley de 1975 se incorporan los conceptos de valor urbanístico y valor inicial para el cálculo del valor de 
suelo con aprovechamiento urbano y aprovechamiento rústico respectivamente. En el cálculo del valor urbanístico se tomará como base el valor fiscal de los suelos y para ello, sería necesario hacer uso de las ponencias de valores catastrales, teniendo en cuenta los supuestos recogidos en el artículo 145 del RGU.

En el año 1990 se aprueba la Ley 8/1990, de 25 de julio, de Reforma del Régimen Urbanístico y Valoraciones de Suelo, y el Real Decreto Legislativo 1/1992, de 26 de junio, por el que se aprueba el Texto Refundido de la Ley sobre el Régimen de Suelo y Ordenación Urbana (en adelante TRLS 92). En estas dos disposiciones, los propietarios del suelo van adquiriendo gradualmente las facultades urbanísticas en función de los diferentes derechos que obtienen condicionados por el cumplimiento de diferentes deberes:

- Derecho a urbanizar cuando se ha aprobado planeamiento específico. En este momento el suelo pasa de rústico a urbanizable.

- Derecho a obtener aprovechamiento urbanístico establecido por el planeamiento: cuando se cumplen los deberes de cesión, equidistribución y urbanización en los plazos fijados, el suelo pasa de urbanizable a urbano.

En el TRLS 92 el sistema de valoraciones de suelo no solamente es aplicable a las valoraciones por razones urbanísticas, sino que, por vez primera en la legislación estatal de suelo, se extiende a cualquier otra finalidad de la expropiación (artículo 46.2) anteponiéndose así a la regulación del justiprecio en la LEF. De este modo, a partir de este momento desaparece la separación entre las distintas valoraciones expropiatorias, urbanísticas y no urbanísticas, de suelo.

La Sentencia del Tribunal Constitucional de 20 de marzo de 1997 (en adelante STC 61/1997), además de declarar inconstitucional gran parte del TRLS 92 se pronuncia dejando clara la competencia estatal en materia de valoraciones cuya finalidad fuera expropiatoria (previamente ya se había atribuido al Estado la competencia en materia de valoraciones en la STC 37/1987):

“(...) las llamadas expropiaciones urbanísticas o por razón de urbanismo pueden ser procedimientos expropiatorios especiales, y así ocurre en la legislación vigente. Pero su regulación compete al Estado, pues sólo éste puede regular las diversas variantes de la institución expropiatoria y los distintos tipos o modalidades de expropiación, según afirma expresamente la Sentencia citada. En segundo lugar, la competencia estatal en materia de expropiaciones urbanísticas incluye los 
criterios y sistema de valoración del justiprecio con el fin de impedir que los bienes objeto de expropiación puedan ser evaluados con criterios diferentes en unas y otras partes del territorio nacional, y todo lo relativo al procedimiento expropiatorio (en sentido complejo o global) considerado, ante todo, desde la perspectiva garantista" (STC 61/1997, de 20 de marzo de 1997).

Este criterio se ha vuelto a ratificar más recientemente en la STC 14/2007 de 18 en estos términos:

"A este respecto, no conviene olvidar que este Tribunal ya descartó en la STC 61/1997, de 20 de marzo, que la valoración correspondiera a la exclusiva competencia de las Comunidades Autónomas debido a las relaciones que dicha valoración tiene con los títulos competenciales estatales derivados de los arts. 149.1.1 y 149.1.18 CE. En la medida en que las valoraciones urbanísticas fijan cuantitativamente el contenido de la propiedad inmueble de cada dueño, y teniendo presente que ya hemos señalado (STC 61/1997, de 20 de marzo, FJ 19) que los criterios de valoración urbanística de los suelos sujetos a planeamiento no pueden quedar desvinculados de los criterios de valoración aplicables a esos mismos suelos cuando quedan afectos a un expediente expropiatorio, la identidad de criterios de valoración constituye un elemento clave para lograr la igualdad de los propietarios de inmuebles urbanos en todo el territorio nacional, puesto que de esta forma se atiende a la garantía del justiprecio y a la previsión de criterios de evaluación uniformes en todo el territorio del Estado." (STC 14/2007, de 18 de enero de 2007).

La Ley 6/1998, de 13 de abril, sobre régimen del suelo y valoraciones, vino a llenar el vacío legal que se produjo tras la STC 61/1997. De acuerdo con su exposición de motivos, el objetivo perseguido en este texto legal era asignar a cada clase de suelo el valor real atribuido por el mercado. Según su Exposición de motivos, "En lo que concierne a los criterios de valoración del suelo, la Ley ha optado por establecer un sistema que trata de reflejar con la mayor exactitud posible el valor real que el mercado asigna a cada tipo de suelo, renunciando así formalmente a toda clase de fórmulas artificiosas que, con mayor o menor fundamento aparente, contradicen esa realidad y constituyen una fuente interminable de conflictos, proyectando una sombra de injusticia que resta credibilidad a la Administración y contribuye a deslegitimar su actuación".

Vuelve a diferenciarse nuevamente en esta Ley la forma de valoración en función de la 
clasificación del suelo, y de este modo:

- En suelo no urbanizable y urbanizable no incluido en ámbitos delimitados, se aplicará el método de comparación, siempre y cuando existan fincas análogas, y si no fuera posible conseguir valores comparables, se valorará el suelo mediante la capitalización de las rentas reales y potenciales.

- En el suelo urbanizable incluido en ámbitos delimitados para los que el planeamiento haya establecido las condiciones para su desarrollo, el valor se obtendrá aplicando al aprovechamiento que le corresponda, el valor básico de repercusión deducido de la ponencia de valores catastrales. Si la ponencia ha perdido su vigencia o no fuera aplicable, el valor de se obtendrá por aplicación del método residual dinámico definido en la normativa hipotecaria (modificación introducida por la Ley 10/2003, de 20 de mayo, de medidas urgentes de liberación en el sector inmobiliario y transportes).

- En el suelo urbano la valoración se realizará aplicando asimismo los valores de repercusión resultantes de la aplicación de las ponencias catastrales, así como el método residual en los supuestos de inexistencia o pérdida de vigencia de aquellas, con la salvedad de que, en este caso, no queda definido el procedimiento de cálculo del valor residual de suelo.

Posteriormente mediante la Ley $\mathbf{5 3 / 2 0 0 2}$, de 30 de diciembre, de medidas fiscales, administrativas y de orden social, se modificó la Ley 6/1998, en concreto el artículo 25, en el que se especifica cómo deberá determinarse la valoración de los suelos destinados a infraestructuras y servicios públicos de interés general.

\subsubsection{La valoración de las expectativas en la valoración de suelo rural}

La idea de la consideración de expectativas urbanísticas como incremento al valor inicial del suelo ha sido recogido, ampliamente por la doctrina en materia de valoraciones urbanísticas. A este respecto, el hecho de la consideración de "futuribles" como parte integrante del valor del suelo, lejos de la consideración del valor objetivo del mismo tan reiteradamente referenciado en los deseos de la legislación, es lo que ha se ha venido a denominar "expectativas urbanísticas".

La búsqueda del valor real por el legislador, lejos de la consideración de meras posibilidades, no ha dado fruto, gracias precisamente a la legislación de aplicación a lo 
largo del tiempo y a los criterios de la doctrina jurisprudencial.

Ese incremento de las valoraciones de suelo se lleva a cabo teniendo en cuenta simplemente los derechos inherentes al estatuto de propiedad del suelo, sin tener en consideración el cumplimiento de los deberes de dicho estatuto, que lleva precisamente a la obtención de dichos derechos.

Podríamos definir las expectativas urbanísticas como la incorporación al valor de un suelo de los derechos inherentes al estatuto jurídico de la propiedad de suelo sin consideración alguna del cumplimiento de los deberes, también inherentes a dicho estatuto, simplemente por el mero hecho de estar amparado por la clasificación urbanística que el planeamiento le ha otorgado.

\section{El artículo 36 LEF dispone:}

"1.- Las tasaciones se efectuarán con arreglo al valor que tengan los bienes o derechos expropiables (...), sin tener en cuenta las plusvalías que sean consecuencia directa del plano o proyecto de obras que den lugar a la expropiación y las previsibles para el futuro."

De acuerdo con el literal de esta disposición, la LEF excluía las futuras expectativas que surgieran como consecuencia de una determinada planificación. Sin embargo, la redacción e interpretación del artículo 43 de la citada Ley, relativo a la posibilidad de recurrir a la valoración estimativa cuando la aplicación de la norma no diera lugar al valor real del bien expropiado, permitía, sin embargo, valorar dichas expectativas, siempre que éstas formaran parte del citado valor real.

Con posterioridad a la entrada en vigor de la LEF, la LS 56, si bien pretendía impedir, tal y como veremos, la consideración de expectativas y el cómputo de un valor superior al urbanístico, introducía el denominado "valor expectante", en el que se consideraban el futuro aprovechamiento del suelo. Con este fin se aprobó el Anexo al que se ha hecho mención en el apartado anterior, relativo al estudio de la regulación de las valoraciones urbanísticas desde 1956 a 2007.

La complejidad introducida por la aplicación del Anexo a la LS 56 en el desarrollo del aumento del valor calculado mediante coeficientes, facilitó que se mantuviera la aplicación del artículo 43 de la LEF como libertad estimativa para el incremento del valor del suelo. De este modo, la exposición de motivos de la LS 56 indica que (el énfasis es propio) “.... sin olvidar que en trance de tasar terrenos no urbanizados ante la 
disyuntiva de valorarlos a precio alto, con beneficio para el primitivo propietario o a precio económico, no mayor que el correspondiente a la utilización actual y sin considerar expectativas futuras, la elección es clara: es preferible que el primero no obtenga beneficio y que el que hubiere de derivarse de la transformación de terreno en solar se atribuya, como estímulo, al urbanizador. Lo mismo cuando se trata de justipreciar solares retenidos indefinidamente sin edificar por sus poseedores: por ello la Ley previene explícitamente que en este supuesto no serán aplicables valores comerciales..." Pero, a pesar de ello, como se ha dicho, el artículo 43 de la LEF permitió de forma indirecta el recurso a la valoración de las expectativas como base en la valoración estimativa.

De este modo se inicia la tendencia favorable a la consideración de lo que se han denominado "expectativas urbanísticas", tanto en la regulación legal como en la jurisprudencia de los tribunales, como se verá en el desarrollo del presente trabajo.

Con la Ley 19/1975 y el TRLS 76, así como los Reglamentos que lo desarrollan (RP, RGU y RDU), se intentó, tal y como se recoge en su exposición de motivos (el énfasis es propio) recurrir a una valoración objetiva y suprimir la posibilidad de incorporar las expectativas en el valor: “...El principio según el cual el planeamiento no concede directamente el derecho a edificar tiene su reflejo, en materia de valoraciones del suelo, en la adopción del criterio según el cual el valor que a éste se reconoce debe estar en función del grado de cumplimiento de las obligaciones y cargas derivadas del Plan que se observe en cada caso...Las innovaciones en esta materia, comporta una estrecha relación con la valoración fiscal y una gran simplificación, se contempla: a) Llevando a sus últimas consecuencias el principio de valoración objetiva que se quebraba en la Ley de Suelo con el reconocimiento de unos valores "comerciales"...b) Eliminando el valor expectante, aplicable hasta ahora a la reserva "urbana", con independencia de la actividad de los interesados...". En el cálculo del valor urbanístico se tomará como base el valor fiscal de los suelos, para lo que sería necesario hacer uso de las ponencias de valores catastrales, teniendo en cuenta los supuestos recogidos en el artículo 145 del RGU. Pero, a pesar de ello, lo cierto era que el cumplimiento de los supuestos del RGU, solía ser complejo, y de este modo comenzaron, nuevamente, a producirse libertades estimativas que además fueron apoyadas por los tribunales. De este modo volvía a tomar protagonismo el artículo 43 de la LEF.

EI TRLS 92 recogía en su exposición de motivos recogía lo siguiente (el énfasis es propio): “...2. Resulta, por ello, obligado diferenciar las diversas facultades que 
gradualmente se van incorporando, en correspondencia con el proceso de ejecución del planeamiento, definiéndolas, fijando los requisitos para su adquisición y las causas de extinción y establecimiento de criterios para la valoración de los terrenos en cada una de ellas. 3. La valoración de estas facultades en función de los aprovechamientos urbanísticos solo es aceptable y coherente para las sugeridas a partir de un determinado momento del proceso de ejecución del planeamiento. Para las anteriores, su valoración debe prescindir de aquellos e incorporar sólo la posibilidad efectiva de modificación física del terreno, pues aún no se han adquirido dichos aprovechamientos..." De esta forma el nuevo texto legal mantenía la idea de impedir la consideración de incrementos que no se hayan producido de forma "efectiva", excluyendo la posibilidad de considerar los aprovechamientos no materializados en el momento de la valoración y, por tanto, las expectativas de su materialización futura, criterio que, como se verá más adelante, no siempre se mantuvo por los tribunales.

En la Ley 6/1998, no existía una prohibición expresa de la consideración de expectativas, ni en su exposición de motivos ni en su articulado. No obstante, mediante la Ley 10/2003, de 20 de mayo, de medidas urgentes de liberación en el sector inmobiliario y transportes, que modifica la citada Ley $6 / 1998$, se pretendió aclarar los métodos valorativos que debían aplicarse al suelo urbano y urbanizable, así como eliminar elementos especulativos o futuras expectativas "inciertas" del suelo urbanizable. Para ello, en su artículo 1 cuatro modifica el artículo 27 de la Ley 6/1998 que regula la valoración del suelo urbanizable incluido en ámbitos delimitados para los que el planeamiento haya establecido las condiciones para su desarrollo, indicando expresamente: “... En cualquier caso, se descartarán los elementos especulativos del cálculo de aquellas expectativas cuya presencia no esté asegurada". Asimismo, en la regulación de la valoración del suelo urbanizable no incluido en ámbitos delimitados para los que el planeamiento no haya establecido condiciones para su desarrollo se indica que el valor se obtendrá “... sin consideración alguna de su posible utilización urbanística"

Sin embargo, como veremos en el siguiente apartado, la modificación introducida no fue lo suficientemente clara en la prohibición expresa de la inclusión de expectativas en la valoración del suelo no urbanizable. 


\subsection{LA DOCTRINA DE LOS TRIBUNALES SOBRE LAS EXPECTATIVAS URBANÍSTICAS EN LA VALORACIÓN DEL SUELO RURAL}

Como se ha visto, tanto en la LS 56, que incorpora el denominado "valor expectante", como en las sucesivas leyes promulgadas hasta la Ley 6/1998, nada impedía incrementar el valor regulado para el suelo no urbanizable en razón de las expectativas urbanísticas que pudieran haberse incorporado al mismo.

Esta falta de prohibición expresa, junto con la aplicación del artículo 43 de la LEF, en el que se permitía que, tanto el propietario como la Administración expropiante pudieran llevar a cabo la valoración "aplicando los criterios estimativos que juzguen más adecuados", dio pie a la posibilidad de la "corrección" al alza de los valores obtenidos para el suelo no urbanizable con base en su potencialidad exclusivamente rural.

En este sentido, desde la LS 56 hasta hoy, los tribunales han introducido una serie de criterios doctrinales para la interpretación de los principios legislativos reguladores de las valoraciones de suelo. Con carácter habitual, los tribunales han "retocado" los valores de los suelos de naturaleza rústica en función de diferentes criterios, como la proximidad a "grandes núcleos de población" o núcleos urbanos, así como la cercanía a grandes vías de comunicación o "centros de actividad empresarial".

Tradicionalmente, los tribunales han considerado en la valoración de los terrenos rústicos o no urbanizables un incremento de su valor inicial motivado por "factores urbanos", también denominados de forma expresa en ocasiones como "expectativas urbanísticas", con la finalidad de alcanzar el "valor real" de los suelos con destino agrario.

Es necesario mencionar que diferentes Tribunales Superiores de Justicia marcan una línea jurisprudencial, con menor influencia, durante la vigencia de la Ley 8/1990 y el TRLS 92, en la que se mantiene la prohibición de tomar en consideración posibles expectativas urbanísticas en la valoración de terrenos clasificados como suelo no urbanizable o urbanizable no sectorizado. Igualmente, esta línea jurisprudencial "se mantiene durante la vigencia de los criterios subjetivos (de mercado) de la Ley 6/1998" tal y como indica Chinchilla Peinado (2004).

\subsubsection{Jurisprudencia del Tribunal Supremo}

El Alto Tribunal ha reiterado, en innumerables ocasiones, la posibilidad de corrección 
de los valores del suelo rústico a efectos expropiatorios, por estar influidos por "factores urbanos". Estas consideraciones apoyadas, además, en el artículo 43 de la LEF, permitían la corrección del valor obtenido utilizando unos criterios estimativos, por considerarse estos adecuados. De este modo, y justificado en el artículo 43 se aumentaban los valores calculados de forma indiscriminada:

“... que siendo cierto que el artículo 43 establece un sistema de valoración, de subsidiaria aplicación respecto los que se indican en los artículos que le preceden, de preferente juego de la actividad justipreciadora del Jurado, no lo es menos, que la facultad que a éste otorga aquel precepto para hacer uso «de los criterios estimativos que juzgue más adecuados», sólo está realmente supeditado a que el propio Jurado «considere que el precio obtenido con sujeción a las reglas de los anteriores (artículos) resulta notoriamente inferior o superior al valor real de los bienes», expresión legal ésta, que no cabe interpretar, con el sentido y riguroso alcance que sostiene la parte recurrente, como determinante de una absoluta subordinación de tal facultad del Jurado, a la concreta expresión del cálculo aritmético del artículo 39, a la matemática comparación del mismo con el valor real ya exhaustivo razonamiento justificador del desprecio de los sistemas valorativos legalmente preferentes; porque, de dicho texto legal, lo que se deduce (teniendo muy en cuenta que se emplea el verbo considerar, y en tiempo subjuntivo), es que esa facultad simplemente se halla condicionada a que, previamente, el Jurado estime y razone suficientemente, que existe una notoria disconformidad del valor real del bien expropiado (...) lo cierto es que, de hecho, la regla del artículo 43 ha ido abriéndose paso en la vía expropiatoria hasta convertirse en norma general de actuación de los Jurados" (STS n 1369/1960 de 12 de noviembre de 1960).

Los factores urbanos a los que se refiere en sus sentencias son la proximidad a núcleos de población y el emplazamiento cercano a importantes vías de comunicación, entre otros.

Como se ha indicado, en las exposiciones de motivos de la legislación de suelo estatal anterior a la Ley 6/1998, se hacía referencia a la prohibición de la consideración de "futuras expectativas", aunque lo cierto es que en los articulados respectivos no existía una prohibición expresa (salvo en la Ley 6/1998). Esta discrepancia se ha interpretado por los Tribunales de diferentes formas, pero considerando en numerosas ocasiones la posibilidad de considerar las "expectativas" como causa de incremento de valor del suelo no urbanizable. 
En este sentido, son varias las sentencias del TS en las que no se duda en "añadir" al valor puramente agrícola de un suelo rural otras consideraciones que incrementen su valor, tales como la proximidad a infraestructuras de comunicación:

“... No puede partirse del valor puramente agrícola de la finca expropiada, por consistir ésta, según el recurrente, en una finca rústica, ..., atenuándose la distinción entre rústica y urbana en los casos de fincas situadas en la zona de ensanche de una gran población en expansión, próxima a varias arterias de comunicación urbana y extraurbana..." (STS n 1369/1960 de 12 de noviembre de 1960).

En otros casos se puede observar cómo el TS recurre a los "factores urbanos" para incrementar el valor de suelo destinado a cultivo agrícola considerando como factores urbanos la proximidad al núcleo urbano y sus posibilidades de edificación:

“... el valor de un terreno destinado al cultivo agrícola, a pesar de no reunir la condición legal de solar ni hallarse comprendido dentro de un plan de urbanización, puede venir determinado no sólo por su inicial naturaleza urbana, sino que este valor debe, en muchos casos, venir incrementado por el que se derive de aquellos factores urbanos cuyo radio de influencia alcance la finca, como son su proximidad al núcleo urbano y sus condiciones o posibilidades de edificación ..." (STS n² 238/1967 de 13 de mayo de 1967).

Es habitual también en esta jurisprudencia la reiterada identificación de los factores urbanos de expansión urbanística, con la proximidad a núcleo urbano o nuevamente, por el emplazamiento junto a importantes vías de comunicación.

“...conforme a la doctrina contenida, entre otras, en las sentencias de 14 abril, 14 marzo, 25 octubre y 14 noviembre 1958, 19 febrero y 19 junio 1957, 9 noviembre 1960 y 16 abril 1975, en la estimación del valor de los bienes inmuebles es inadecuado aplicar de forma rígida los conceptos de rústica y finca urbana, tomándolos como conceptos absolutamente separados e incomunicables, pues en la realidad económica se producen, en contra de ello y con harta frecuencia, supuestos de fincas rústicas influidas por factores urbanos que determinan un considerable aumento del precio que les correspondería atendiendo a su simple valor inicial o rústico; ya esta Sala en sentencia de 19 Junio 1965, confirmada por el Tribunal Supremo en sentencia de 21 junio 1966, tuvo que enfrentarse con la valoración de una finca sita en la Dehesa de las Vacas expropiada para la 
ampliación de la pista de suelo del Aeropuerto de esta Ciudad, muy próxima a la de autos, y entonces el Jurado, es decir el sano 1963, conceptuó los terrenos como "finca rústica situada en lugar en que es previsible una expansión de la zona urbanista, esta es, zona de influencia urbana, por su proximidad al núcleo urbano ..., más su emplazamiento junto a importantes vías de comunicación" y dichas sentencias, "como terrenos sitos en zona de influencia urbana de naturaleza mixta" criterio que fue retirado en sentencia de 23 Octubre 1971..." (STS nº 404/1978 de 26 de junio de 1978).

“...Es inadecuado aplicar de forma rígida los conceptos de rústicas y finca urbana, tomándolos como conceptos absolutamente separados e incomunicables, pues en la realidad económica se produce, en contra de ellos y con relativa frecuencia, supuestos de fincas rústicas influidas por factores urbanos que determinan un considerable aumento del precio que les correspondería atendiendo a su simple valor inicial o rústico ..." (STS n² 2510/1979 de 28 de febrero de 1979).

En este último pronunciamiento se mencionan abiertamente las "expectativas urbanísticas", a las que se atribuyen unos incrementos de valor en porcentajes desde el $25 \%$ al $100 \%$, definiendo el porcentaje del $100 \%$ como "la máxima expectativa". El posible incremento a considerar en el suelo a valorar está motivado por el favorable emplazamiento de las parcelas, debido a su proximidad a núcleo urbano y a las favorables comunicaciones, haciendo referencia a términos tales como: la renta de situación y "la expectativa urbanística propia del suelo rústico". En concreto, el reconocimiento de la renta de situación es determinante en el desarrollo del presente trabajo, debido a su vinculación conceptual con el factor de corrección $\mathbf{u}_{1}$, como veremos en apartado siguientes:

“... las expectativas urbanísticas se han de ponderar en función de la concreta calificación urbanística, de tal modo que no teniendo el predio un aprovechamiento propio de suelo urbano ni siquiera de urbanizarle programado (antigua reserva urbana), las posibilidades de edificación que le dotan de valor económico son las limitadas del suelo rústico o no urbanizable en que se integra y a las que se ha de atemperar la expectativa apreciada para incrementar el indiscutido valor intrínseco o agrícola de tales fincas ..., y si la Sala de instancia ha incrementado tal valor, para expropiaciones similares, en porcentajes graduales que van del $25 \%$ al 100\%, según reconoce en el séptimo considerando, in fine, la sentencia recurrida, no es procedente atribuir en este caso la máxima expectativa del 100\% que equipara el predio a suelo urbano, máxime cuando el aprovechamiento 
constructivo idóneo de edificaciones agropecuarias ya está efectuado y permanece en el resto de la finca; de tal manera que procede, en cambio, entender que dado el favorable emplazamiento de las parcelas (proximidad al núcleo urbano, buenas comunicaciones, etc.) la renta de situación y la expectativa urbanística propia de suelo rústico, a tenor de las limitadas posibilidades edificatorias que a tal suelo confiere el artículo 86 en relación con el artículo 85-2a. de la Ley del Suelo de 9 de abril de 1976..." (STS No 3438/1980, de 30 de abril de 1980).

Siguiendo con el criterio referenciado en la sentencia inmediatamente precedente, en otras posteriores se considera nuevamente un porcentaje de incremento de valor intrínsecamente rústico en consideración de las expectativas, advirtiéndose, además, que no se trata de un valor especulativo, ya que según se afirma se está teniendo en cuenta el valor de mercado libre:

“... Las expectativas establecidas por la sentencia, igualmente han de confirmarse en el 90 y 70 por ciento según la situación de las fincas respecto al casco urbano y la red principal de carreteras, que normalmente son las que determinan la edificación de los terrenos (...) tampoco puede admitirse que estas expectativas sean la base de un valor especulativo puesto que al seguirse los criterios de la Ley del Suelo, que impide tener en cuenta el valor de mercado libre salvo para el valor comercial, no existe especulación de clase alguna en la apreciación de los elementos que reconoce la sentencia apelada ..." (STS n ${ }^{\circ}$ $3626 / 1980$ de 16 de diciembre de 1980).

En otras ocasiones se recoge abiertamente la "reiterada admisión de los valores expectantes, urbanísticos" tales como la proximidad a centros urbanos, acceso a vías públicas de comunicación y expansión de grandes núcleos de población.

“... En cuanto a la indemnización del valor expectante, la doctrina de esta Sala es reiterada en la admisión de los valores expectantes, urbanísticos, siempre que realmente se den los factores para su admisión de proximidad a centros urbanos, acceso de la finca a vías públicas de comunicación y creciente expansión de grandes núcleos de población que afecten por su inmediación a la finca expropiada, y es de destacar que tal supuesto existe al iniciarse la expropiación por la cercanía clara de la finca expropiada a centro urbano de población, así como el acceso de la misma a vías públicas de comunicación, aparte del valor intrínseco del bien, cual es el predio rústico y tipo de cultivo existente en el mismo 
en el momento de la ocupación, no ha sido desvirtuado por la actora ni en la fase administrativa ni en la judicial y es marcada doctrina jurisprudencial que los acuerdos del Jurado Provincial de Expropiación Forzosa gozan de presunción «iuris tantum» de veracidad y acierto y que sólo puede destruirse cuando se acredite que en los acuerdos se ha incurrido en error, injusticia o defectuosa apreciación de la prueba..." (STS n 5083/1986 de 30 de septiembre de 1986).

$Y$ en otros supuestos se reitera lo ya expuesto en las sentencias precedentes sobre los denominados valores expectantes urbanísticos:

“... la doctrina jurisprudencial es reiterada en la admisión de los valores expectantes urbanísticos, ajenos al plan u obra que motiva la acción expropiatoria, siempre que realmente se den los factores para su admisión, de proximidad a centros urbanos, acceso de la finca a vías públicas de comunicación y creciente expansión de los núcleos de población, que afecten por su inmediación a la finca expropiada, como en el presente caso acontece ..." (STS n 897/1991 de 30 de septiembre de 1991).

En todo caso, la jurisprudencia sobre esta cuestión advierte que, para alegar la existencia de los factores urbanos como la proximidad a núcleo urbano, se requiere su acreditación, tal y como se recogía en las sentencias de los años 80 :

“... finca... muy próxima al casco urbano... Y se ha de tener en cuenta para valorar los bienes, como ha puesto de manifiesto la doctrina jurisprudencial que, aun no desconociendo que el valor del terreno destinado a cultivo agrícola,..., puede venir incrementado por el que se derive de aquellos factores urbanos cuyo radio de influencia alcance a la finca, como son su proximidad al núcleo urbano, ..., siempre que, como ocurre en este caso, la realidad de esta influencia urbana venga fehacientemente acreditada a través de una prueba directa no susceptible de ser sustituido por meros criterios subjetivos..." (STS n 5113/1995 de 17 de octubre de 1995).

Al igual que en la sentencia STS n 3438/1980, de 30 de abril de 1980, a la que se ha hecho referencia en párrafos anteriores, en otras ocasiones se hace referencia nuevamente a factores de situación y emplazamiento ("renta de situación", en los términos de la sentencia citada) pero en este caso se vincula dicha circunstancia a las expectativas urbanísticas: 
“... ahora bien, y en ello hemos de coincidir con la Sala de instancia, la proximidad de la finca expropiada con el límite del casco urbano, del que le separan unos cuarenta metros, es un factor de situación y emplazamiento que ha de considerarse en orden a las posibles expectativas urbanísticas que de ello se derivan $y$, por tanto, susceptible de tenerse en cuenta a la hora de fijar el justiprecio, que es precisamente lo que hizo el Jurado al fijar la valoración de la finca en cuestión ..." (STS n 3400/1996 de 4 de junio de 1996).

Para cuantificar el incremento de valor debido a las expectativas, las sentencias determinan porcentajes que varían con la aplicación de las reglas de la sana crítica a los dictámenes periciales que obran en Autos:

“... las fincas expropiadas para el pantano de La Serena en el término municipal de Esparragosa de Lares quedan muy próximas al núcleo urbano, lo que supone un incremento de su valor en venta hasta un cincuenta por ciento por sus posibilidades de más alta productividad y rendimiento, según se deduce del informe pericial emitido en esta segunda instancia..." (STS n 6611/1996 de 23 de noviembre de 1996).

“...es suficiente demostrativa del error valorativo en que inciden los acuerdos recurridos, desde el momento que estamos en presencia de una parcela calificada como rústica, pero que por estar muy próxima al casco urbano y a la zona industrial, ...alcanza, como relata la Sala de primera instancia, un "contenido económico que excede, en mercado, del aprovechamiento rústico acercándolo al urbano" y que en todo caso debe ser superior al señalado por el Jurado..." (STS n ${ }^{\circ}$ $1621 / 1998$ de 10 de marzo de 1998).

En otras sentencias posteriores parece que el criterio sentado hasta entonces, en el que simplemente se recogía la proximidad a núcleos de población, aparece ahora una referencia a un parámetro urbanístico, el "aprovechamiento", propio de los suelos cuya clasificación urbanística es distinta a la de suelo no urbanizable.

“...En contra del parecer de la Sala de instancia, que por ello ha vulnerado la jurisprudencia interpretativa del artículo 43 de la Ley de Expropiación Forzosa en relación con las denominadas expectativas urbanísticas del suelo rústico, esta Sala del Tribunal Supremo, además de en las sentencias citadas en este motivo de casación por la recurrente, ha reconocido, entre otras, en sus Sentencias de fechas 26 de junio de 1993, 9 de julio de 1994, 18 de noviembre, 18 y 20 de 
diciembre de 1995, 19 de abril, 27 de mayo, 28 de mayo, 4 de junio, 2 de julio, 8 de julio y 10 de octubre de 1996, 8 y 18 de febrero 6 y 17 de mayo, 11 de junio, 19 de julio, 11 y 25 de octubre, 19 de noviembre y 9 de diciembre de 1997, 9 de febrero, 2, 3, 10 y 17 de marzo de 1998, 10 de mayo, 1 y 22 de junio de 1999, que la proximidad a un núcleo urbano del suelo expropiado debe ser tenida en cuenta como un elemento determinante de la existencia de tales expectativas aunque no se haya aprobado instrumento alguno de planeamiento para su adecuada urbanización..." (STS nº 6440/1999 de 18 de octubre de 1999).

A partir de este momento se habla abiertamente de expectativas urbanísticas como incrementos del valor de suelo no urbanizable, pero se exige que dichas expectativas sean reales.:

“...Bajo la vigencia del Texto Refundido de la Ley del Suelo y Ordenación Urbana de 1976 esta Sala ha venido considerando que en el suelo no urbanizable es susceptible de ser valorado teniendo en cuenta sus expectativas urbanísticas. Se exige que éstas sean reales y resulten probadas en función de las diversas circunstancias del terreno, como la proximidad a suelo urbano y los servicios e infraestructura existentes..." (STS n 1461/2001 de 27 de febrero de 2001).

En el transcurso del tiempo se siguen considerando abiertamente las expectativas urbanísticas en relación con la proximidad a un núcleo urbano como requisito suficiente para su consideración:

“...y lo que a las expectativas urbanísticas se refiere, debe tenerse en cuenta lo que es una reiterada jurisprudencia de esta Sala (por todas, sentencia de 5 de abril de 2006- Rec. 3909/03) en el sentido de que es necesario que quede acreditada la realidad de las expectativas urbanísticas, pudiendo constituir un índice de tales expectativas, ... o el hallarse a escasos kilómetros de un núcleo urbano, ..." (STS nº 6246/2006 de 26 de octubre de 2006).

Por otra parte, en el siguiente caso se consideran "intensas" expectativas urbanísticas simplemente por el hecho de la situación a escasos kilómetros de un núcleo urbano, justificando que la legislación de suelo desde el 76 al 98, salvo la del 92, no prohibía expresamente dicha consideración, lo que permite incrementar el valor en un 500\%:

“...La finca expropiada disfruta de unas innegables e intensas expectativas urbanísticas, ya que se encuentra próxima a la zona de expansión urbana ... 
Recuérdese que, según nuestra jurisprudencia, pueden constituir índice de tales expectativas una edificación progresiva de la zona o el hallarse el suelo a escasos kilómetros de un núcleo urbano, ... Indiscutible la realidad de las expectativas, se ha de tener presente que, como ya hemos tenido ocasión de afirmar en ocasiones anteriores (véanse las sentencias, que acabamos de citar, de 26 de octubre de 2006, FJ 5, y de 13 de noviembre de 2007, FJ 4º), la Ley 6/1998 ha reestablecido el criterio del Texto Refundido de 9 de abril de 1976, permitiendo apreciarlas en un suelo rústico para evaluarlo a efectos expropiatorios, ya que no efectúa ninguna reserva expresa al respecto, como hacía el Texto Refundido de 26 de junio de 1992.

... el suelo se tasará conforme al criterio de capitalización de sus rentas reales o potenciales, en cuyo caso el resultado se incrementará hasta un 500 por 100 para integrar en el precio las expectativas urbanísticas, ..." (STS n 6058/2008 de 17 de noviembre de 2008).

En la Sala de lo Contencioso-Administrativo, Sección $6^{a}$, el TS hace una definición de lo que considera como expectativa urbanística:

“(..) concurren tales expectativas cuando existen indicios de una edificación progresiva en la zona o el suelo se ubica a escasos kilómetros de un núcleo urbano, con una razonable previsibilidad de que en un tiempo significativo en términos económicos se incorporará al proceso urbanizador". (STS n²723/2009 de 24 de abril de 2009).

A pesar de la fecha de la Sentencia se trata de un procedimiento en el que la legislación de aplicación era la Ley 6/1998. Este desfase en la fecha de la sentencia y la referencia de la valoración es patente en otros casos en los que el juzgador está influido por conceptos que, no estando vigentes en la fecha a la que se refieren las actuaciones, ya han surgido en la fecha de publicación de la sentencia. Este es el caso de la primera aparición de la proximidad a centros de actividad económica como "circunstancia" necesaria para ponderar las expectativas urbanísticas, lo que hace referencia explícita a uno de los factores de localización regulados por primera vez en el RVLS 2011:

“...que constituye doctrina reiterada de esta Sala aquélla que admite en la valoración del suelo rústico la ponderación de las expectativas urbanísticas, entendiendo por tales las posibilidades, futuras o hipotéticas, que el terreno pueda tener por determinadas circunstancias, como la proximidad a núcleos urbanos, a 
vías de comunicación y centros de actividad económica, entre otras. Así, en las sentencias de esta Sala de 13 de noviembre de 2007 (recurso 6851/04 ), 17 de febrero de 2010 (recurso 1308/06), 16 de septiembre de 2011 (recurso 4254/08), 30 de noviembre de 2011 (recurso 6513/2008) y 22 de octubre de 2012 (recurso 6736/2009), hemos reconocido la posibilidad de valorar, al aplicar los criterios del artículo 26 de la Ley 6/1998, las denominadas expectativas urbanísticas de los terrenos que tengan la condición de suelo no urbanizable entendiendo que «... al disponer en su artículo 26 que el valor del suelo no urbanizable se determinará por el método de comparación a partir de valores de fincas análogas y no hacer reserva alguna en relación con la imposibilidad de tener en cuenta las expectativas urbanísticas, puede estimarse que la Ley 6/1998, ha venido a restablecer el criterio inicial, refiriéndolo ahora a todo tipo de expropiaciones, de modo que si la ley se limita a establecer un método y que lo que se quiere hallar es el valor real de mercado, habrá que incluir, como un elemento más de ese valor real, las expectativas urbanísticas que el terreno tenga... ".

"La aplicación de la doctrina de mención, como con acierto se sostiene en la sentencia recurrida en su fundamento de derecho séptimo, no puede cuestionarse por la circunstancia de que el artículo 27.2 de la Ley 6/1998, en su redacción dada por la Ley 10/2003, prevea que "El valor del suelo urbanizable, no incluido por el planeamiento en los ámbitos a los que se refiere el apartado anterior y hasta tanto no se apruebe el planeamiento de desarrollo que establezca la legislación urbanística, se determinará en la forma establecida para el suelo no urbanizable, sin consideración alguna de su posible utilización urbanística»..." (STS no $3721 / 2013$ de 1 de julio de 2013).

$Y$ esta circunstancia se repite en las sentencias posteriores en relación a los factores de localización por proximidad a núcleos de población, vías de comunicación y centros de actividad económica, aspectos regulados en el RVLS 2011 como susceptibles de incrementar el valor de la capitalización del suelo rural.

“...El criterio seguido por esta Sala ha sido el de incrementar el valor unitario fijado en un porcentaje determinado, en función de las circunstancias de los terrenos (proximidad a núcleos de población, a vías de comunicación, a centros de actividad económica, como más relevantes), tal y como dice la Sentencia del Tribunal Supremo de 17 de noviembre de 2008 y las sitúan, en aplicación de dichas circunstancias hasta en un 500\% del valor básico ..." (STS n 3069/2014 de 8 de julio de 2014). 
“..Por todas y entre otras citaremos nuestras sentencias de 24 de marzo de 2014 (Rec. 3012/2011 ) en relación a las fincas 52 y 54 en el término de Loeches sentencia de 2 de diciembre de 2013 (Rec. 1088/2011) en relación a finca 34 y sentencia de 27 de enero de 2014 (Rec. 2808/2011) en relación a finca 23, todas del mismo expediente Carretera M-203, conexión de la M-100 y N-Il en Alcalá de Henares con la M-208 y la R-3 en Mejorada del Campo (esta última finca en el término municipal de Mejorada del Campo).

Es verdad que la finca que nos ocupa está en municipio distinto, Soto Aldovea de San Fernando de Henares, pero la doctrina general sobre expectativas urbanísticas es plenamente aplicable al caso de autos.

«Esta Sala ha venido admitiendo en la valoración del suelo rústico la ponderación de las expectativas urbanísticas, entendiendo por tales las posibilidades, futuras o hipotéticas, que el terreno pueda tener por determinadas circunstancias, como la proximidad a núcleos urbanos, a vías de comunicación y centros de actividad económica, entre otras.»..." (STS n² 2792/2016 de 13 de junio de 2016).

Si bien, la siguiente STS no corresponde con las consideraciones recogidas en las anteriores sentencias, sino que se considera el Factor de Corrección por localización de la legislación vigente, ha parecido de interés recogerla en este apartado para mostrar la similitud en la descripción de dicho factor con lo que tradicionalmente ha considerado el TS como la consideración de las "expectativas urbanísticas":

“...Para ser más exactos, la hoja de aprecio de la propiedad, fiel a los dictados del Texto Refundido de la Ley del Suelo (), corrige al alza el valor básico del suelo, obtenido mediante la capitalización de su renta neta potencial, aplicando un factor de corrección que cifra en 1,25, en función de criterios tales como la accesibilidad a núcleos de población, centros de actividad económica..." (STS n 685/2018 de 1 de marzo de 2018).

\subsubsection{Doctrina de los Tribunales Superiores de Justicia}

Del mismo modo que el Alto Tribunal ha considerado el incremento de la valoración de suelo no urbanizable con las "expectativas", los Tribunales Superiores de Justicia, también lo han hecho así. El patrón de ambos tribunales ha sido similar.

En la Sentencia siguiente se reitera lo ya comentado sobre las sentencias del TS que se han recogido anteriormente con relación a la influencia de los "factores urbanos" como elemento determinante de aumento de valor a los suelos objeto de expropiación: 
“... Como declara la jurisprudencia, es inadecuado aplicar de forma rígida los conceptos de finca rústica y de finca urbana, considerándolos como absolutamente separados e incomunicados, pues en la realidad existen con relativa frecuencia fincas rústicas influidas por factores urbanos que determinan un considerable aumento del precio que les correspondería atendiendo a su simple valor inicial o rústico (SSTS de 28 Feb. 1979 y 4 Mar. 1982) siempre que dichas expectativas no tengan un carácter meramente hipotético y posible, sino real y efectivo (SSTS de 2 Nov. 1981; 14-5 y 30 Sep. 1986), siendo especialmente de considerar a tales efectos la proximidad a centros urbanos, buenas comunicaciones, proximidad a carreteras, existencia de agua potable, energía eléctrica etc. La jurisprudencia en los supuestos de concurrencia de estas circunstancias ha entendido que el precio puede incrementarse entre un 20 y un 50\% según los casos" (STSJ MU n 3323/2000 de 15 de noviembre de 2000).

En otros casos se considera un aumento en el valor de suelo aplicándole un factor de corrección de un valor 1,5 por su ubicación y proximidad a un núcleo urbano importante, si bien, en el momento del pronunciamiento del Tribunal de Justicia de Aragón todavía no se había aprobado la Ley 8/2007 que introduce el Factor global de localización.

“... a este respecto el Jurado señala que dicho terreno está calificado catastralmente como rústico y que a tenor del planeamiento urbanístico vigente debe aplicarse para su valoración el artículo 26 de la Ley 6/1998, de 13 de abril, de Régimen del Suelo y Valoraciones, asignándole un precio unitario de 4,20 euros $/ \mathrm{m}^{2}$, cifra resultante de aplicar a su valor agrícola un índice corrector de 1,5 "por su ubicación y proximidad al núcleo urbano de Zaragoza" (STSJ AR nº 1706/2006 de 30 de noviembre de 2006).

En la fecha en la que dicta la sentencia que se refiere a continuación (2012) ya estaban en vigor el TRLS 2008 y el RVLS 2011, motivo por el cual el Fundamento de derecho tercero se refiere: “... la época a la que hay que referir la valoración”. Sin embargo, como veremos después en ninguno de ambos textos legales se trasluce la posibilidad de incremento de valor o ponderación por las expectativas urbanísticas.

Nuevamente, al igual que en las sentencias del TS que se ha citado, a partir de una determinada fecha se introduce no solamente la ponderación de las expectativas urbanísticas por la proximidad a núcleos de población o a vías de comunicación sino 
también a centros de actividad económica. En definitiva, se trata de una sentencia que, aunque juzga un asunto referido a la Ley 6/1998, se publica después de la vigencia de una legislación que prohíbe expresamente las expectativas urbanísticas en la valoración de suelo rural (Ley 8/2007, TRLS 2008, e incluso el RVLS 2011). Por este motivo, la sentencia hacer suyos ambos conjuntos de normas -anterior y posterior a la Ley 8/2007- y acude a los conceptos regulados en esta última sobre el incremento del valor por "razones objetivas de localización" -la proximidad a núcleos de población, a vías de comunicación o a centros de actividad económica- para justificar la ponderación de las mencionadas expectativas en el valor agrario, excluidas a partir de 2007 pero permitidas en la legislación precedente:

“...(es) evidente una excelente situación de la finca, reconocida por el Jurado, que, en la época a la que hay que referir la valoración sin duda implicaba un muy superior valor del suelo respecto de un valor puramente agrario. Como nos recuerda la STS de 17 de octubre de 2012, la jurisprudencia ha venido admitiendo en la valoración del suelo rústico la ponderación de las expectativas urbanísticas, entendiendo por tales las posibilidades, futuras o hipotéticas, que el terreno pueda tener por determinadas circunstancias, como la proximidad a núcleos urbanos, a vías de comunicación y centros de actividad económica, entre otras. Así, entre otras, en las Sentencias de esta Sala de 13 de noviembre de 2007 (recurso 6851/04), 17 de febrero de 2010 (recurso 1308/06) y 16 de septiembre de 2011 (recurso 4254/08), el Tribunal Supremo ha reconocido la posibilidad de valorar, al aplicar los criterios del artículo 26 de la Ley 6/1998, las denominadas expectativas urbanísticas de los terrenos que tengan la condición de suelo no urbanizable..." (STSJ CLM n 3502/2012 de 17 de diciembre de 2012).

En otra sentencia que hace mención a la del TS de 17 de noviembre de 2008, en la que se incrementaba el valor básico hasta en un 500\%, se considera que independientemente del valor agrícola de un suelo, hay que tener en cuenta el incremento en su valor por su proximidad a vías de comunicación, sin referencia alguna de forma expresa a las expectativas urbanísticas:

“... tal y como dice la Sentencia del Tribunal Supremo de 17 de noviembre de 2008 y las sitúan, en aplicación de dichas circunstancias hasta en un 500\% del valor básico. En este caso, no se puede olvidar que se trata de un municipio muy cercano a Madrid, de unos terrenos próximos a vías de comunicación tales como la que constituye objeto del proyecto expropiatorio y otras vías, como la A-41, la M-506 y la M-50. A ello se une que el municipio de Fuenlabrada queda claramente 
bajo la influencia de la capital de la nación pues conforma su área metropolitana, que el valor de sus terrenos está teniendo un crecimiento elevado, a lo que se debe unir el dato de la notoriedad de la escasez de suelo en la Comunidad de Madrid. Todos estos elementos deben tener el efecto de incrementar ese porcentaje de manera notable. Ahora bien, el valor del suelo en atención a su específico cultivo resulta ajeno al cálculo de las expectativas urbanísticas, que proceden respecto a todo suelo con independencia de su específico fin o destino. En el caso presente nos encontramos con que la carretera atraviesa fincas con destinos diferentes lo que conlleva que la valoración de las mismas sea diferente en función de si se trata de parcelas de labor de regadío que en el mercado tiene un valor superior a otros tipos de suelo como son los de secano, aprovechamiento para pastos, incluso suelos improductivos, los cuales incorporados al proceso urbanizador tienen las mismas expectativas urbanísticas. Esta razón nos lleva a entender que en atención a las expectativas el valor definitivo mucho más próximo al real, atendidas esas circunstancias, siendo ese porcentaje ha de ser el del 400\%..." (STSJ M n 757/2013 de 22 de enero de 2013).

Concluyendo el análisis de la jurisprudencia sobre las expectativas, puede afirmarse que, unos y otros tribunales se han pronunciado en referencia a la valoración del suelo rural disponiendo que el valor calculado mediante la capitalización de las rentas de la explotación debía incrementarse mediante la consideración de lo que denominaba en alguna época, "factores urbanos" y en otras "expectativas urbanísticas".

En la jurisprudencia anterior a la Ley 6/1998, la consideración de los denominados "factores urbanos", se justificaba por la "proximidad a núcleos de población" o el "emplazamiento junto a importantes vías de comunicación" y, en algunos casos, por sus condiciones o posibilidades de edificación, factores que, tal y como interpretaban los tribunales, determinaban un importante "aumento de precio" en relación con el valor inicial o rústico del terreno.

Posteriormente, se sustituye el concepto "factores urbanos" por el de "expectativas urbanísticas", que también está asociado a la proximidad a núcleo urbano. Y también se incorporan circunstancias como que el suelo a valorar esté bien comunicado, por encontrarse próximo a las redes de carreteras o vías públicas de comunicación. En el transcurso del tiempo se introduce una nueva premisa como la "creciente expansión de los núcleos de población" próximos a los suelos a valorar.

En definitiva, a lo largo del tiempo los tribunales atribuyen al concepto de "expectativa urbanística" porcentajes de incremento que oscila entre el $10 \%$ y el $500 \%$. 


\subsection{LA LEGISLACIÓN VIGENTE}

\subsubsection{Legislación de aplicación}

El actual TRLSRU 2015 es el texto legislativo aplicable en 2019 en materia de valoraciones a efectos reparcelatorios, expropiatorios y de responsabilidad patrimonial de las Administraciones Públicas, tal y como se recoge en su artículo 34.

De acuerdo con la Exposición de motivos de la Ley 8/2007, el sistema de valoraciones que esta regula: “...Con independencia de las ventajas que pueda tener la técnica de la clasificación y categorización del suelo por el planeamiento, lo cierto es que es una técnica urbanística, por lo que no le corresponde a este legislador juzgar su oportunidad. Además, no es necesaria para fijar los criterios legales de valoración del suelo. Más aún, desde esta concreta perspectiva, que compete plenamente al legislador estatal, la clasificación ha contribuido históricamente a la inflación de los valores del suelo, incorporando expectativas de revalorización mucho antes de que se realizaran las operaciones necesarias para materializar las determinaciones urbanísticas de los poderes públicos y, por ende, ha fomentado también las prácticas especulativas, contralas que debemos luchar por imperativo constitucional...

...para facilitar su aplicación y garantizar la necesaria seguridad de tráfico, ... deber buscar la sencillez y la claridad, además por supuesto la justicia... Debe valorarse lo que hay, no lo que el plan dice que puede llegar a haber en un futuro incierto". Con base en ello, se prescinde de la clasificación y categorización urbanística del suelo, que tradicionalmente ha servido de base para el inicio de las valoraciones, para valorar los suelos de acuerdo con la realidad física y jurídica de los mismos.

Para ello, desde la Ley 8/2007 hasta el TRLSRU 2015 se prevé la división del suelo en función de su situación básica a los solos efectos de su valoración, cuestión en la que el legislador estatal mantiene la competencia con base en la STC 61/1997, como se ha indicado con anterioridad. Por tanto, a los efectos del TRLSRU 2015, todo el suelo se encuentra o en situación básica de suelo rural o de suelo urbanizado.

En el artículo 21.2 del TRLSRU 2015 se define la situación de suelo rural en estos términos:

"Está en la situación de suelo rural:

a) En todo caso, el suelo preservado por la ordenación territorial y urbanística de su transformación mediante la urbanización, que deberá incluir, como mínimo, los 
terrenos excluidos de dicha transformación por la legislación de protección o policía del dominio público, de la naturaleza o del patrimonio cultural, los que deban quedar sujetos a tal protección conforme a la ordenación territorial y urbanística por los valores en ellos concurrentes, incluso los ecológicos, agrícolas, ganaderos, forestales y paisajísticos, así como aquéllos con riesgos naturales o tecnológicos, incluidos los de inundación o de otros accidentes graves, y cuantos otros prevea la legislación de ordenación territorial o urbanística.

b) El suelo para el que los instrumentos de ordenación territorial y urbanística prevean o permitan su paso a la situación de suelo urbanizado, hasta que termine la correspondiente actuación de urbanización, y cualquier otro que no reúna los requisitos a que se refiere el apartado siguiente."

Por otro lado, en los artículos 21.3 y 21.4 del TRLSRU 2015 se define el suelo urbanizado como sigue:

“3. Se encuentra en la situación de suelo urbanizado el que, estando legalmente integrado en una malla urbana conformada por una red de viales, dotaciones y parcelas propia del núcleo o asentamiento de población del que forme parte, cumpla alguna de las siguientes condiciones:

a) Haber sido urbanizado en ejecución del correspondiente instrumento de ordenación.

b) Tener instaladas y operativas, conforme a lo establecido en la legislación urbanística aplicable, las infraestructuras y los servicios necesarios, mediante su conexión en red, para satisfacer la demanda de los usos y edificaciones existentes o previstos por la ordenación urbanística o poder llegar a contar con ellos sin otras obras que las de conexión con las instalaciones preexistentes. El hecho de que el suelo sea colindante con carreteras de circunvalación o con vías de comunicación interurbanas no comportará, por sí mismo, su consideración como suelo urbanizado.

c) Estar ocupado por la edificación, en el porcentaje de los espacios aptos para ella que determine la legislación de ordenación territorial o urbanística, según la ordenación propuesta por el instrumento de planificación correspondiente.

4. También se encuentra en la situación de suelo urbanizado, el incluido en los núcleos rurales tradicionales legalmente asentados en el medio rural, siempre que la legislación de ordenación territorial y urbanística les atribuya la condición de suelo urbano o asimilada y cuando, de conformidad con ella, cuenten con las dotaciones, infraestructuras y servicios requeridos al efecto." 
De este modo el TRLSRU 2015 define cada una de las situaciones básicas de suelo y plantea un régimen de valoraciones basándose en ambas, definiendo la metodología concreta a utilizar en cada una de ellas.

Es necesario hacer una reflexión sobre la identificación de cada una de las situaciones básicas de suelo recogidas en el TRLSRU 2015 y la clasificación y categorización urbanística que tradicionalmente se ha venido utilizando también en el ámbito de las valoraciones. De este modo la definición de suelos en situación básica rural del artículo 27 del TRLSRU 2015 puede entenderse referida $a^{5}$ :

- Suelo no urbanizable (SNU)

- Suelo urbanizable no sectorizado (SUNS)

- Suelo urbanizable sectorizado (SUS)

- Situaciones concretas de Suelo urbano no consolidado (SUNC).

Mientras que cuando nos referimos a suelo urbanizado nos estamos refiriendo a:

- Suelo urbano consolidado (SUC)

- En situaciones concretas de Suelo urbano no consolidado (SUNC).

En lo relativo al Suelo urbano no consolidado, es necesario distinguir cuándo un Suelo urbano así categorizado se encuentra en situación básica de suelo urbanizado y cuando se encuentra en situación básica de suelo rural. Considerando lo recogido en el artículo 21 del TRLSRU 2015, y simplificando su contenido, un Suelo urbano no consolidado se encuentra en situación básica de suelo urbanizado solo si ha sido urbanizado en ejecución del correspondiente instrumento de ordenación. Esto quiere decir que, para poder ser urbanizado, previamente se ha tenido que tramitar la gestión urbanística de dicho suelo, cumpliendo las estipulaciones del instrumento de planeamiento aprobado; y una vez cumplido dicho requisito se procedería a urbanizar los suelos con la calificación urbanística de Suelo urbano no consolidado. Luego un Suelo urbano no consolidado se podrá considerar en situación básica de suelo urbanizado siempre y cuando se haya aprobado el planeamiento que el Plan General de Ordenación Urbana (o planeamiento general asimilable) haya considerado para dicho ámbito y se hayan cumplido los deberes estipulados legalmente (en general los recogidos en el artículo 18.1 del TRLSRU 2015 y en particular los recogidos en

\footnotetext{
${ }^{5}$ Se ha homogenizado la nomenclatura de las clases y categorías urbanísticas, sin tener en cuenta las diferentes denominaciones que recogen las distintas CCAA.
} 
legislación urbanística de aplicación).

Si bien la legislación vigente en el momento de redactar este trabajo es el TRLSRU 2015, es necesario hacer una referencia a la legislación aprobada en fecha anterior a la entrada en vigor del mismo y a la Sentencia 141/2014, de 11 de septiembre de 2014 del Tribunal Constitucional ${ }^{6}$ (en adelante STC 141/2014). Ello debido al interés, tanto en el desarrollo reglamentario en materia de valoraciones, como en la modificación de las definiciones recogidas en la legislación de las situaciones básica s de suelo, así como por la declaración de inconstitucionalidad de algún criterio recogido en la legislación aprobada.

Con fecha 9 de noviembre de 2011 se publicó en el B.O.E. el Real Decreto 1492/2011, de 24 de octubre de 2011, por el que se aprueba el Reglamento de valoraciones de la Ley de Suelo, denominado en el presente trabajo como RVLS 2011. Tal y como se ha recogido en capítulos anteriores el desarrollo reglamentario en materia de valoración del TRLS 2008 se hace a través del RVLS 2011 pero además este último introduce pequeñas modificaciones en las definiciones de las situaciones básicas del suelo.

Posteriormente, tal y como se ha recogido igualmente en capítulos anteriores del presente trabajo, con fecha 27 de junio de 2013 se publica en el B.O.E la Ley 8/2013 de 26 de junio, de rehabilitación, regeneración y renovación urbanas, que introduce de nuevo modificaciones a las definiciones de las situaciones básicas de suelo recogidas en el RVLS 2011

En lo que se refiere al objetivo central de este trabajo, la STC 141/2014 es la primera que se pronuncia sobre el factor de corrección por localización. En dicha Sentencia, el TC considera que la corrección efectuada mediante la aplicación del citado dicho Factor sobre el resultado de la capitalización de las rentas del suelo en situación básica rural, no es inconstitucional, si bien se ha la única salvedad del inciso "hasta el máximo del doble" que se recoge en el párrafo tercero del apartado 1.a) del artículo 23 del TRLS 2008. De este modo en el artículo 36 1.a) del vigente TRLSRU 2015 ya no aparece el límite máximo del factor de corrección por localización.

\footnotetext{
${ }^{6}$ Desde la aprobación de la legislación estatal, han sido numerosas las cuestiones de inconstitucionalidad planteadas por diferentes Comunidades Autónomas ante el Tribunal Constitucional (TC) en relación con la legislación de suelo. El contenido de estas ha sido muy variado y el pronunciamiento del TC también; sin embargo, en el presente punto de la investigación, simplemente se hará mención al pronunciamiento del TC en referencia al Factor de corrección por localización
} 
La razón de la constitucionalidad de la aplicación del repetido Factor es, tal y como recoge el TC en la Sentencia citada, que "... la localización influye en el valor del suelo, siendo la renta de posición un factor relevante en la formación tradicional del precio de la tierra", expresión que el TC obtiene de la exposición de motivos del TRLS 2008.

Posteriormente, Con fecha 31 de octubre de 2015 se publica en el B.O.E. el Real Decreto Legislativo 2015, de 30 de octubre, por el que se aprueba el texto refundido de la Ley de Suelo y Rehabilitación Urbana, donde se refunden la Ley 8/2013 y el TRLS 2008. Tal y como se indicado, las modificaciones introducidas en este último texto legal no afectan al tema del estudio del presente trabajo.

\subsubsection{Análisis comparativo entre el TRLS 2008 (sustituido por el TRLSRU 2015) y el RD 1492/2011 por el que se aprueba el Reglamento de valoraciones de la Ley de Suelo}

En este punto se pretende hacer un análisis teórico entre el articulado del TRLS 2008, traspuesto al articulado del TRLSRU 2015 tras su derogación, y el del RVLS 2011, con objeto de estudiar el desarrollo reglamentario del método de cálculo de las valoraciones para el suelo rural y los conceptos que intervienen en ellas. También se analizan los conceptos y metodología para el cálculo reglamentado en el RVLS 2011.

Puesto que el TRLSRU 2015, que deroga el TRLS 2008, recoge de forma prácticamente análoga el articulado del TRLS 2008 en lo que se refiere a las valoraciones, en los párrafos posteriores se referenciará solamente el TRLSRU 2015, salvo en la Exposición de Motivos, para la que se hará referencia a la del TRLS 2008.

EI TRLS 2008 menciona en su exposición de motivos que desde la LS 56 se ha tenido en olvido el artículo 36 de la LEF, que advierte que en las tasaciones expropiatorias no han de tenerse en cuenta los plusvalores que sean consecuencia directa de los planos que motiven la expropiación ni de las previsibles para el futuro, y propone que para dar solución a todo lo que ello conlleva "buscar la sencillez y la claridad" y, por supuesto, la justicia. Además, se afirma que los criterios de valoración establecidos persiguen determinar "con la necesaria objetividad y seguridad jurídica el valor de sustitución en el mercado por otro similar en su misma situación". Por último, cuando se refiere a la valoración en el suelo rural, se reitera la necesidad de "asegurar su objetividad y la eliminación de elementos especulativos".

En el Preámbulo del RVLS 2011 se propone el desarrollo de la Ley, así como dar 
respuesta al deseo del legislador de 2008 , de mejorar el funcionamiento del mercado del suelo y hacerlo más transparente y eficiente, combatiendo, además, en la medida de lo posible, las eventuales prácticas especulativas en su utilización. Se especifica igualmente la necesidad, por mandato constitucional, de eliminar las expectativas urbanísticas. Además, en este texto se menciona la STC 61/1997 del Tribunal Constitucional y, asimismo, cita el artículo 149.1. 18 $\mathrm{CE}$ reconociendo la competencia exclusiva del Estado en materia de valoraciones.

Es necesario tener en cuenta que el RVLS 2011 introduce modificaciones en la definición del suelo en situación básica urbanizado que como veremos serán a su vez modificadas por la Ley $8 / 2013$, tal y como se ha indicado en el apartado anterior.

Finalmente, el TRLSRU 2015 define el ámbito del régimen de valoraciones y define los criterios generales para la valoración de inmuebles, tales como las siguientes:

- El suelo se tasará tal y como se define en el articulado del TRLSRU 2015 según su situación básica. Este criterio será de aplicación también para los suelos destinados a infraestructuras y servicios públicos de interés general y supramunicipal.

- En el suelo rural, las edificaciones, construcciones e instalaciones, los sembrados y las plantaciones se tasarán con independencia del valor de suelo siempre que se ajusten a la legalidad al tiempo de la valoración, sean compatibles con el uso o rendimiento considerado en la valoración del suelo y no hayan sido tenidos en cuenta en dicha valoración por su carácter de mejoras permanentes.

A este respecto, es relevante que el TRLSRU 2015 determina que el suelo se valorará de acuerdo con su situación básica, independientemente de su destino, para evitar de este modo la diferenciación que ha existido en la doctrina jurisprudencial ${ }^{7}$ entre los suelos destinados a sistemas generales o dotaciones abocados a servir al suelo urbano; se trata de una referencia a los suelos que, de acuerdo con la terminología utilizada por el Tribunal Supremo, "crean ciudad", y como tales, están destinados a la ejecución de "infraestructuras de interés general contempladas en proyectos de ámbito estatal"

De las dos situaciones básicas que la legislación distingue, la que es de interés para el

\footnotetext{
7 STS 21 de octubre 1997, STS 30 de enero 2001, STS 4 de julio de 2002, STS 3 de diciembre 2002, STS
} 14 de febrero 2003, STS 22 de diciembre de 2006, STS 8 de mayo de 2006, entre otras muchas. 
presente trabajo es la del suelo en situación básica rural. De tal forma que el artículo 36 del TRLSRU 2015 establece que la valoración de estos suelos se realizará mediante la aplicación del método de capitalización de la renta anual o potencial de la explotación según el estado en el momento que debe hacerse la valoración, adoptándose el mayor de los obtenidos. El método de capitalización de rentas ha sido tradicionalmente utilizado en la valoración agraria desde la Ley de suelo de 1956.

Para el cálculo de la renta potencial se considerará el rendimiento del uso, disfrute o explotación de que sean susceptibles los suelos atendiendo a la legislación aplicable y con los medios técnicos normales para su producción. Se incluirán como ingresos las subvenciones que con carácter estable se concedan en referencia al cultivo o explotación considerada y se deducirán los costes necesarios para la explotación.

Este valor podrá ser corregido al alza en función de factores objetivos de localización, como la accesibilidad a núcleos de población o a centros de actividad económica, así como la ubicación en entornos de singular valora ambiental o paisajístico, cuya aplicación y ponderación habrá de ser justificada. Como se ha comentado anteriormente, el objeto específico del presente trabajo es el estudio del cálculo, análisis y resultados del factor denominado de corrección por localización.

A este respecto sería necesario aclarar que, si bien en la exposición de motivos del TRLS 2008 se plantea el objetivo de la búsqueda de la objetividad en las valoraciones, la determinación de este coeficiente, también denominado factor objetivo de localización, carece de la objetividad que se pretende, al menos hasta la aprobación definitiva del RVLS 2011, ya que no está regulado en la propia Ley su procedimiento de cálculo.

El RVLS 2011, por su parte, como desarrollo reglamentario de la Ley comienza el articulado, dividido en diferentes capítulos de acuerdo con su contenido; definiciones, determinación de los métodos de cálculo, establecimiento de los criterios de capitalización de la renta de la explotación, etc. Lo que realmente es de interés para el presente trabajo es la definición y desarrollo de cálculo del denominado Factor de Corrección por Localización FL, y en concreto la definición y desarrollo del factor de corrección por accesibilidad a núcleos de población $\mathbf{u}_{1}$

El artículo 17 RVLS 2011 desarrolla el cálculo de dicho factor en los siguientes términos:

- El inmueble debe encontrarse en una localización espacial concreta para 
corregir su valor de capitalización.

- Dicho factor se obtendrá del producto de tres factores de corrección:

- Por accesibilidad a núcleos de población, el denominado factor $\mathbf{u}_{1}$

- Por accesibilidad a centros de actividad económica, el denominado factor $\mathrm{u}_{2}$

- Por ubicación en entornos de singular valor ambiental o paisajístico, el denominado $\mathrm{u}_{3}$

De este modo la valoración final del suelo resultaría al aplicar la siguiente fórmula:

$$
\mathrm{V}_{\mathrm{f}}=\mathrm{V} \times \mathrm{FI}=\mathrm{V} \times \mathrm{u}_{1} \times \mathrm{u}_{2} \times \mathrm{u}_{3}
$$

Según el artículo 17.3 del RVLS 2011, el cálculo del factor de corrección u u se obtiene por aplicación de la siguiente fórmula:

$$
u_{1}=1+\left[P_{1}+\frac{P_{2}}{3}\right] \times \frac{1}{1.000 .000}
$$

Siendo:

$\boldsymbol{P}_{\mathbf{1}} \rightarrow$ "Número de habitantes de los núcleos de población situados a menos de 4 $\mathrm{Km}$. de distancia media a vuelo de pájaro, entendida como la distancia en línea recta medida sobre la proyección en un plano horizontal."

$\boldsymbol{P}_{\mathbf{2}} \rightarrow$ "Número de habitantes de los núcleos de población situados a más de 4 $\mathrm{Km}$. y a menos de $40 \mathrm{Km}$. de distancia media a vuelo de pájaro, o 50 minutos de trayecto utilizando los medios habituales de transporte $y$ en condiciones normales."

Antes de continuar con el resto de los factores correctores, se considera necesario analizar diferentes aspectos a tener en cuenta en el futuro cálculo del presente factor $\mathbf{u}_{1}$.

Para su determinación es necesario un estudio previo del concepto "núcleo de población”, puesto que la legislación estatal (el TRLSRU 2015 y el RVLS 2011) no lo define. Para conocer el sentido que el legislador ha querido dar a dicho concepto debe acudirse al Reglamento de Planeamiento para el Desarrollo y Aplicación de la Ley sobre Régimen del Suelo y Ordenación Urbana (en adelante RP), vigente en la actualidad como legislación supletoria. En concreto el artículo 34 del RP, regula las determinaciones que los Planes Generales de Ordenación Urbana deben contener en referencia al suelo urbanizable no programado (en la actualidad se consideraría suelo en situación básica rural, de acuerdo con el TRLSRU 2015), en los siguientes 40 
términos:

"Definición, a efectos de lo dispuesto en el Artículo 85 de la Ley de Suelo, del concepto de núcleo de población, con base en las características propias del municipio, estableciendo las condiciones objetivas que den lugar a su formación"

El Instituto Nacional de Estadística (en adelante INE) codifica los núcleos de población desde el año 1.981, con ocasión del Censo Poblacional de dicho año. En él se define:

"Se considera Núcleo de población a un conjunto de al menos diez edificaciones, que están formando calles, plazas y otras vías urbanas. Por excepción, el número de edificaciones podrá ser inferior a 10, siempre que la población que habita las mismas supere los 50 habitantes. Se incluyen en el núcleo aquellas edificaciones que, estando aisladas, distan menos de 200 metros de los límites exteriores del mencionado conjunto, si bien en la determinación de dicha distancia han de excluirse los terrenos ocupados por instalaciones industriales o comerciales, parques, jardines, zonas deportivas, cementerios, aparcamientos y otros, así como los canales o ríos que puedan ser cruzados por puentes.

Las edificaciones o viviendas de una entidad singular de población que no pueden ser incluidas en el concepto de núcleo se consideran en diseminado.

Una entidad singular de población puede tener uno o varios núcleos, o incluso ninguno, si toda ella se encuentra en diseminado.

Ninguna vivienda puede pertenecer simultáneamente a dos o más núcleos, o a un núcleo y un diseminado."

Teniendo en cuenta las definiciones arriba transcritas parece lógico considerar que el legislador estatal identifica los núcleos de población como lugares habitados, debiendo incluirse en el cómputo de habitantes a los pertenecientes a los denominados "diseminados" por el INE.

Por tanto, para garantizar la objetividad necesaria en el desarrollo del presente trabajo de investigación, para el cálculo del factor $\mathbf{u}_{1}$ se tomará la ubicación y número de habitantes de todas las entidades de población (no solo de los núcleos de población) que el INE incluye entre sus datos oficiales. 


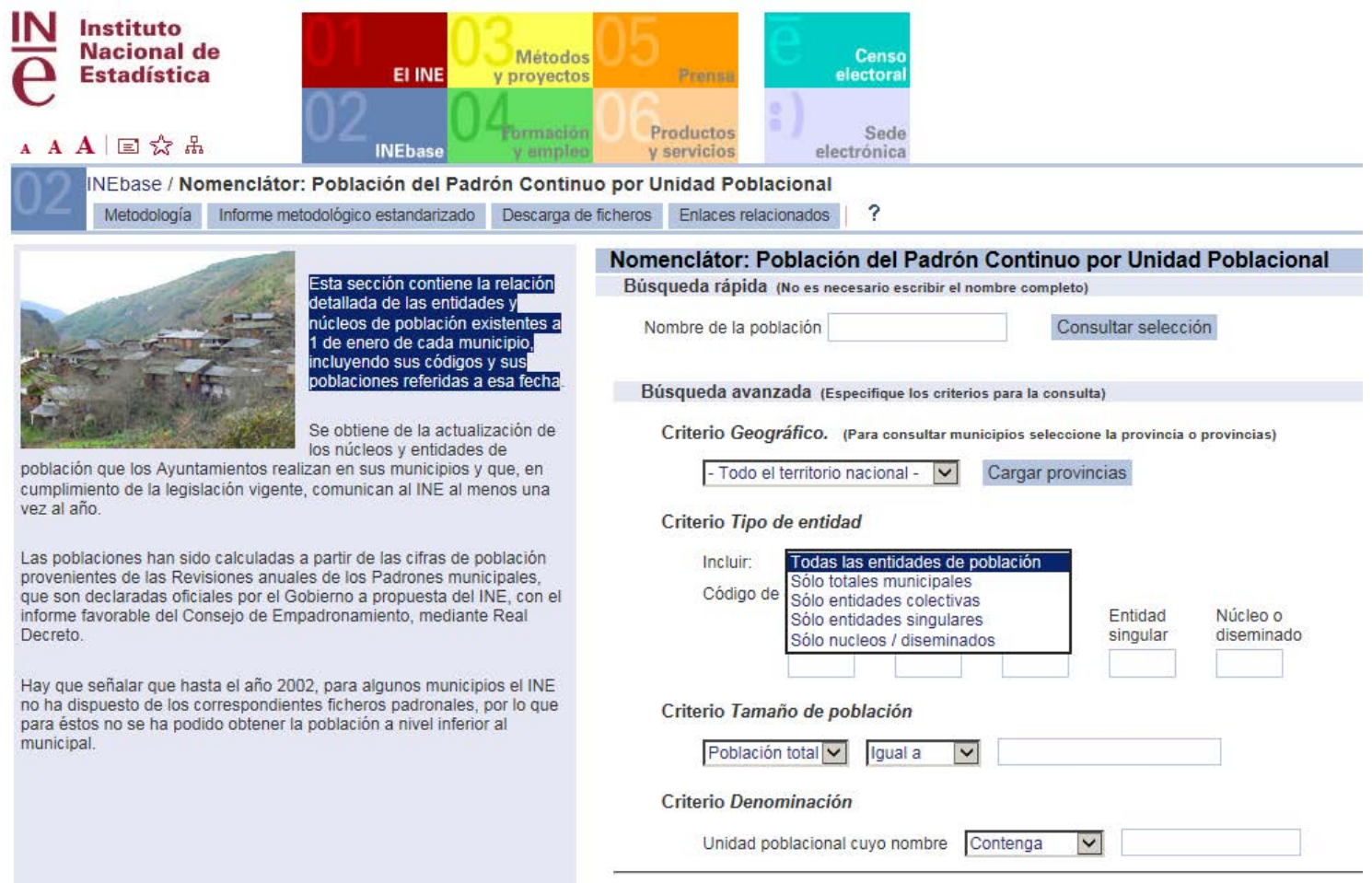

Figura 2.1. INE BASE. Nomenclátor: Población del Padrón Continuo por Unidad Poblacional. (fuente: Instituto Nacional de Estadística)

En el cálculo de cada una de las variables de la fórmula del artículo 17.3 del RVLS 2011, para determinar el numerador $\mathbf{P}_{1}$ es preciso determinar, en primer lugar, “(...) si la distancia de $4 \mathrm{Km}$. se traza mediante círculos cuyo centro se sitúe en el interior del terreno a valorar, con el fin de localizar los núcleos de población incluidos dentro de cada uno de ellos y cuantificar el número de habitantes que corresponde a cada núcleo de población" (González Ruiz 2011). Pero, en segundo término, surgen nuevas dudas interpretativas, como por ejemplo "(...) la ubicación del centro del círculo dentro de la finca". Así, si este punto fuera el acceso a la finca, puede plantearse "(...) qué sucedería si la finca no tuviera acceso conocido, si tuviera varios accesos, e incluso si no existiera tal acceso". Además, debe tenerse en cuenta que "(...) En el caso de que el centro del círculo que constituyera el origen de la medición fuera el punto central de la parcela, si se trata de un terreno de morfología regular el cálculo no ofrecería mayor dificultad; pero si el perímetro fuera irregular habría que plantearse la elección del punto geométrico que representara el centro de gravedad de la parcela" (González Ruiz 2011).

Por otra parte, podría existir una alternativa a este criterio de cálculo del factor $\mathbf{P}_{\mathbf{1}}$, como “(...) el trazado de líneas paralelas a una distancia de $4 \mathrm{Km}$. de las que constituyen el perímetro de la parcela a valorar." (González Ruiz 2011). 
Estas consideraciones serán las que se tendrán en cuenta para el cálculo del factor $\mathbf{u}_{1}$ en el desarrollo de este trabajo.

Para el cálculo del factor $\mathbf{u}_{\mathbf{2}}$ habrá que estar a lo dispuesto en el artículo 17.4 del RVLS 2011 en estos términos:

"Cuando el suelo rural a valorar esté próximo a centros de comunicaciones y de transporte, por la localización cercana a puertos de mar, aeropuertos, estaciones de ferrocarril, y áreas de intermodalidad, así como próximos a grandes complejos urbanizados de uso terciario, productivo o comercial relacionados con la actividad que desarrolla la explotación considerada en la valoración el factor $u_{2}$, se calcula de acuerdo con la siguiente expresión:

$$
u_{2}=1,6-0,01 \times d
$$

d es la distancia kilométrica desde el inmueble objeto de la valoración utilizando las vías de transporte existentes y considerando el trayecto más favorable. Esta distancia, en ningún caso, será superior a $60 \mathrm{Km}$."

Es necesario, también en este caso, aclarar diferentes conceptos:

- Puertos de mar. El RVLS 2011 no define a qué tipo de puerto se está refiriendo, como los Puertos de Interés General de Estado, puertos de alguna Comunidad Autónoma o, simplemente, un puerto deportivo. No obstante, debe sobreentenderse que la referencia está hecha a los puertos con actividades comerciales propias de las explotaciones de los suelos en situación básica rural cuya rentabilidad se valora.

- Aeropuertos. Del mismo modo que ocurre con los puertos de mar, no se define a qué tipo de aeropuerto se refiere; aunque en este caso se supone que la referencia está hecha a los Estatales, ya que los de competencia de las Comunidades Autónomas solamente son aeropuertos deportivos, sin actividad comercial, circunstancia que, como en el caso de los puertos, parece que debería determinar la consideración de estas infraestructuras.

- Estaciones de ferrocarril. Al igual que en los casos anteriores, no se refiere a qué tipo de estación se refiere e incluso se podría llegar a plantear la duda si los apeaderos podrían considerarse como tales.

- Áreas de intermodalidad, tampoco se define ni a qué tipo de área se refiere, de viajeros, de transporte o de mercancías. 
- Grandes complejos urbanizados, sin que tampoco se delimite el ámbito al que se refiere este concepto indeterminado, ni cuáles son las dimensiones a tener en cuenta para considerarlos.

- Distancia kilométrica. En cuanto a este concepto, el RVLS 2011 tampoco se define el punto concreto de origen de la finca valorada, y de destino de la infraestructura correspondiente, a la que debe medirse dicha distancia.

En definitiva, se pone de manifiesto que el desarrollo reglamentario de la Ley carece de la concreción necesaria en la regulación de los conceptos incluidos en la determinación del coeficiente $\mathbf{u}_{2}$, remitiendo a la discrecionalidad del autor de la valoración la interpretación de los parámetros necesarios para aplicación de la fórmula del artículo 17 del RVLS 2011. Se pone así en duda la consecución de la objetividad pretendida por el legislador en el desarrollo reglamentario del TRLS 2008, al menos en lo que se refiere a este aspecto concreto.

Para el cálculo del factor $\mathbf{u}_{3}$ habrá que estar a lo dispuesto en el artículo 17.5 del RVLS 2011:

"Cuando el suelo rural a valorar esté ubicado en entornos de singular valor ambiental o paisajístico, resultará de aplicación el factor corrector $u_{3}$ que se calcula de acuerdo a la siguiente expresión:

$$
u_{3}=1,1+0,1 \times(p+t)
$$

A los efectos de la aplicación del factor corrector $u_{3}$, se considerarán como entornos de singular valor ambiental o paisajístico aquellos terrenos que, por sus valores ambientales, culturales, históricos, arqueológicos, científicos y paisajísticos, sean objeto de protección por la legislación aplicable y, en todo caso, los espacios incluidos en la Red Natura 2000...

El coeficiente de ponderación, $\boldsymbol{p}$, deberá determinarse sobre la base de criterios objetivos de acuerdo con los valores reconocidos a los terrenos objeto de la valoración en los instrumentos de ordenación urbanística y territorial o, en su caso, en las redes de espacios protegidos. Estará comprendido entre unos valores de 0 y 2, y atenderá a los valores y cualidades del entorno, siendo mayor cuanto mayor sea su calidad ambiental y paisajística o sus valores culturales, históricos, arqueológicos y científicos.

$\boldsymbol{t}$ coeficiente de ponderación según el régimen de usos y actividades. 
El coeficiente de ponderación, $\boldsymbol{t}$, se aplicará únicamente cuando se acredite que, según los instrumentos de ordenación territorial y urbanística, en los terrenos se permite un régimen de usos y actividades diferentes a los agropecuarios o forestales que incrementan el valor. Estará comprendido entre unos valores de 0 y 7, y atenderá a la influencia del concreto régimen de usos y actividades en el incremento del valor del suelo sin consideración alguna de las expectativas urbanísticas, siendo mayor cuanto mayor sea tal influencia..."

En este caso se introducen también, como en el caso del factor $\mathbf{u}_{1}$ y el factor $\mathbf{u}_{2}$, conceptos indeterminados, tanto jurídica como técnicamente, a los que se les puede dar diferentes interpretaciones, pudiéndose obtener valores muy dispares en función de dichas interpretaciones. Por otra parte, en este caso se incrementa aún más la subjetividad en la determinación de los coeficientes en cuestión que forman el factor de corrección $\mathbf{u}_{3}$

Por último, del análisis de los casos prácticos que se desarrollará más adelante, puede concluirse que el resultado del cálculo propuesto por el legislador para este coeficiente FI es de una complejidad desproporcionada y de escasa validez para la aplicación propuesta.

A partir de este punto de la investigación se procederá solamente al estudio del factor de corrección por accesibilidad a núcleos de población, el factor $\mathbf{u}_{1}$. Los motivos que propician esta decisión son los siguientes:

- El interés de la cuantificación de la población como parámetro determinante del plusvalor.

- El mayor peso en el factor global de localización lo tiene el factor $\mathbf{u}_{1}$. Mientras que el factor por accesibilidad a núcleos de actividad económica $\mathrm{u}_{2}$ tiene un valor entre 1 y 1,6 y el factor por ubicación en entornos de singular valor ambiental o paisajístico $u_{3}$ entre 1,1 y 2 , el factor $\mathbf{u}_{1}$ puede variar entre 1 y 3,82 .

- El factor $\mathbf{u}_{2}$ es redundante con el factor $\mathbf{u}_{1}$, claramente los núcleos con mayor número de población gozan de centro de comunicaciones y de transporte.

\subsection{CONCLUSIÓN}

En la valoración del suelo rural ha sido constante el debate legislativo, doctrinal y jurisprudencial sobre el incremento del valor rústico de los terrenos con la incorporación de determinadas consideraciones, que como se ha expuesto en este capítulo se han considerado "expectativas urbanísticas". 
Es inevitable, atendiendo a la doctrina de los tribunales, ya sea la jurisprudencia del TS o los pronunciamientos de los TSJ, encontrar una cierta similitud, entre el denominado factor de corrección por accesibilidad a núcleos de población $\mathbf{u}_{1}$ y lo que tradicionalmente los tribunales han denominado en primera instancia "factores urbanos" y posteriormente "expectativas urbanísticas".

Tanto en las teorías clásicas como en los desarrollos más recientes sobre el análisis económico espacial, el valor de las rentas de cualquier explotación en el territorio rural está incrementado por la reducción de los costes de transporte y de las distancias a centros de producción de mano de obra o puntos de transformación y distribución de materias primas.

La similitud dialéctica que la jurisprudencia ha establecido entre los factores urbanos y las expectativas urbanísticas, junto a la idea desarrollada, tanto por la teoría de la valoración agraria como en los modelos de la economía espacial, de que la localización es un factor de incremento del valor territorial, plantean la posibilidad de interpretar que el factor $\mathbf{u}_{1}$ incorpora la consideración de dichas expectativas. Sin embargo, este planteamiento está formalmente descartado en art. 36.2 TRLSRU 2015, en el que, después de enumerar los supuestos y elementos valorados en suelo rural, se advierte: "En ninguno de los casos previstos en el apartado anterior podrán considerarse expectativas derivadas de la asignación de edificabilidades y usos por la ordenación territorial o urbanística que no hayan sido aun plenamente realizados". A pesar de ello, distintos autores han considerado que el factor de corrección por localización aplicado en la valoración del suelo rural refleja el plusvalor de las expectativas urbanísticas futuras.

Así, Jiménez Bueso (2013) afirma que la inclusión del factor de corrección en la Ley 8/2007 “... pretende apelar al hecho de que la localización de un terreno influye en su rentabilidad agraria", a lo que opone, "El argumento carece, sin embargo, de la más elemental consistencia, ya que en los criterios de accesibilidad a núcleos de población o a centros de actividad económica a los que alude, junto al de la ubicación en entornos de singular valor ambiental o paisajístico, los arts. 23 del TRLS/2008 (LA LEY 8457/2008) y 17 del RVLS 2011 subyace, sin duda, el concepto de expectativas urbanísticas acuñado por la jurisprudencia como una valoración adicional que tiene su origen en la posible incorporación de los terrenos al desarrollo urbano aledaño."

Por otro lado, Ana María De La Encarnación Valcarcel (2015) siguiendo el mismo 
razonamiento del autor anterior, recoge: "Así, tras comparar las valoraciones atribuidas por el Jurado con las que ofrece la Encuesta de Precios de las Tierras de Cultivo del Ministerio de Agricultura, para aprovechamientos agrarios similares y con las que resultaría de capitalizar las rentas agrarias producidas, se observa claramente que la distancia de las tierras al centro de Madrid es una variable mucho más explicativa de su valor monetario que su calidad agronómica. Precisamente, ese factor distancia ha eclipsado la incidencia del factor calidad en las valoraciones del Jurado La fuerte correlación observada entre las valoraciones del Jurado y la distancia al casco urbano permite concluir en este informe que estas valoraciones están fuertemente influidas por las expectativas urbanísticas, dado que independientemente del tipo de cultivo, el precio del suelo parece calcularse más teniendo en cuenta la proximidad a los núcleos urbanos que cualquier otra consideración, independientemente de que sus accesos por carretera sean de $1^{a}$ o $2^{a}$ o de que sean vertederos en mitad del camino"

Como se verá en el desarrollo del presente trabajo, es necesario tener en cuenta la diferencia entre las plusvalías económicas y las plusvalías urbanísticas (De La Encarnación 2015) que afectan a un inmueble: "De este modo, si el inmueble de que se trate se encuentra en la situación básica de rural a la fecha de la valoración, toda adición de valor derivada de circunstancias urbanísticas meramente futuribles, hipotéticas o no actuales está tajantemente descartada. De ahí que la imposibilidad o limitación para edificar en un suelo rústico o no urbanizable no debe incluir una partida referente a expectativas, dado que no existe un derecho a edificar en este tipo de suelo. Al tratarse, por tanto, de aumentos de valor o de beneficios que emanan de la transformación urbanística del suelo, bien podrían denominarse plusvalías urbanísticas, ya que aunque son distintas a las plusvalías económicas, comparten con éstas el nacer de un incremento de valor. De tal forma que podemos identificar plenamente estas expectativas con las plusvalías urbanísticas". Según la distinción realizada por dicha autora parece entenderse que con la aplicación del factor de corrección el legislador pretende tener en cuenta las plusvalías económicas del bien, mientras que dicho factor nada tiene que ver con las plusvalías urbanísticas que se refieren, estas si, a unas expectativas futuras.

Si atendemos a las consideraciones del Tribunal Constitucional, el factor de corrección por localización a núcleos de población $\mathbf{u}_{1}$, se trata de una corrección al alza del valor de capitalización cuya finalidad es garantizar el razonable equilibrio entre el daño expropiado y su reparación, tal y como recoge la Constitución. Para ello, se define reglamentariamente (en el artículo 17 del RVLS 2011) el procedimiento de cálculo de dicho factor, cuya aplicación estaría al margen de las expectativas urbanísticas. 
La localización en el valor urbanístico del suelo rural: La accesibilidad a núcleos de población. 


\section{EL VALOR TERRITORIAL Y LA LOCALIZACIÓN: MARCO TEÓRICO}

En las últimas décadas economistas y geógrafos han compartido y coordinado sus estudios tanto de economía regional como de geografía económica, dando lugar al conocimiento y desarrollo de la economía territorial.

En dicha disciplina, el territorio es el lugar de localización e intercambio de la actividad económica. Dicha localización influye directamente en los precios de suelo, donde las rentas de accesibilidad son elementos importantes en el valor a calcular. La situación física del suelo lleva implícita una renta específica de posición presentando un plusvalor diferencial de localización, frente a otros suelos en ubicaciones diferentes.

De este modo, las rentas de explotación en el territorio rural vendrían favorecidas por los costes de distribución de materias primas y las distancias a los puntos de elaboración, así como las distancias a los centros de producción de mano de obra. Esta es la base tanto de las teorías clásicas como de los desarrollos más recientes del análisis económico espacial (Fujita et al 1999).

\subsection{GEOGRAFÍA Y ECONOMÍA URBANA}

En los estudios históricos sobre economía urbana han sido ampliamente estudiados por los analistas los orígenes de la relación de la localización con el valor económico del suelo. En los siglos XVIII y XIX Cantillón (1.755), A. Smith (1776) y David Ricardo (1817) consideran los "efectos espaciales" en la economía, toda una teoría para la valoración territorial en función de la localización diferencial en los terrenos.

En la primera mitad del siglo XIX, Von Thünen (1783-1850) creará un "modelo de localización" de la actividad económica. Su modelo (Figura 3.1) concéntrico, donde el centro es el "centro de consumo" o mercado, lugar encarnado por la ciudad; en torno a este punto central se localizan, en forma radial, las actividades agrícolas dependiendo del producto. El espacio se suponía uniforme y homogéneo en cuanto a las técnicas de producción, sin embargo, los costes de transporte y los precios de los productos variaban en función de la localización en relación con las zonas anulares en torno al centro. De esta forma cuanto más cercano a la ciudad se encuentra el terreno valorado, menores costes de transporte requiere su explotación, lo que representa un mayor beneficio y viceversa.

La representación gráfica del modelo de Von Thünen, recuerda al cálculo del 
coeficiente de corrección por accesibilidad a núcleos de población $\mathbf{u}_{1}$ como veremos en el desarrollo metodológico de este trabajo.

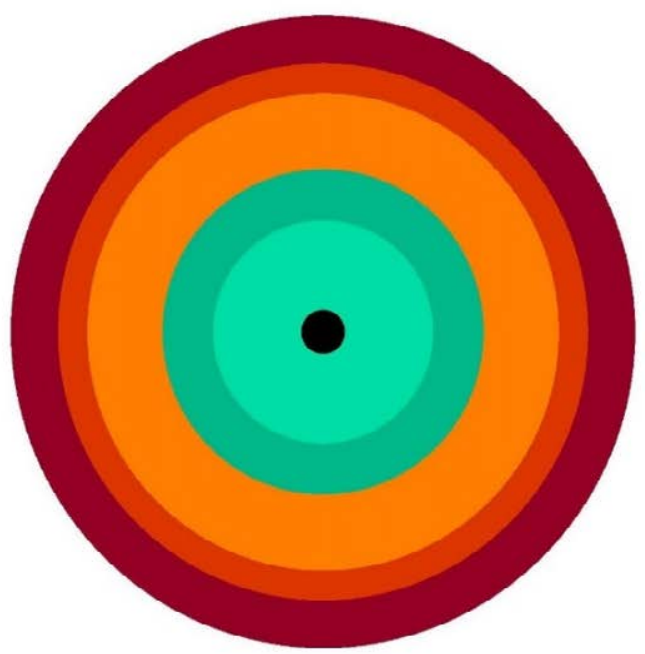

mercado hortalizas productos forestales graminias (intensivas)

graminias (extensivas)

pastos

Figura 3.1 Modelo de la localización de la actividad económica (Von Thünen 1783-1850) (fuente: elaboración propia)

El geógrafo alemán Walter Christaller (1893 - 1969) elaboró en 1933 una teoría general para explicar el número y distribución de los asentamientos humanos en el territorio. Su "teoría del lugar central", elaborada a partir de la hipótesis de un espacio isótropo, homogéneo en todas las direcciones tanto en términos de densidad demográfica como de características físicas y de infraestructuras, estructura unas concentraciones productivas equidistantes y unas áreas de mercado hexagonales. Con esta teoría, (Figura 3.2), Christaller pretendía demostrar que una empresa de servicio ubicada en un lugar central, esto es, con mayor accesibilidad para la población, obtendría mayores beneficios económicos que las que no se encontraran en dicho lugar.
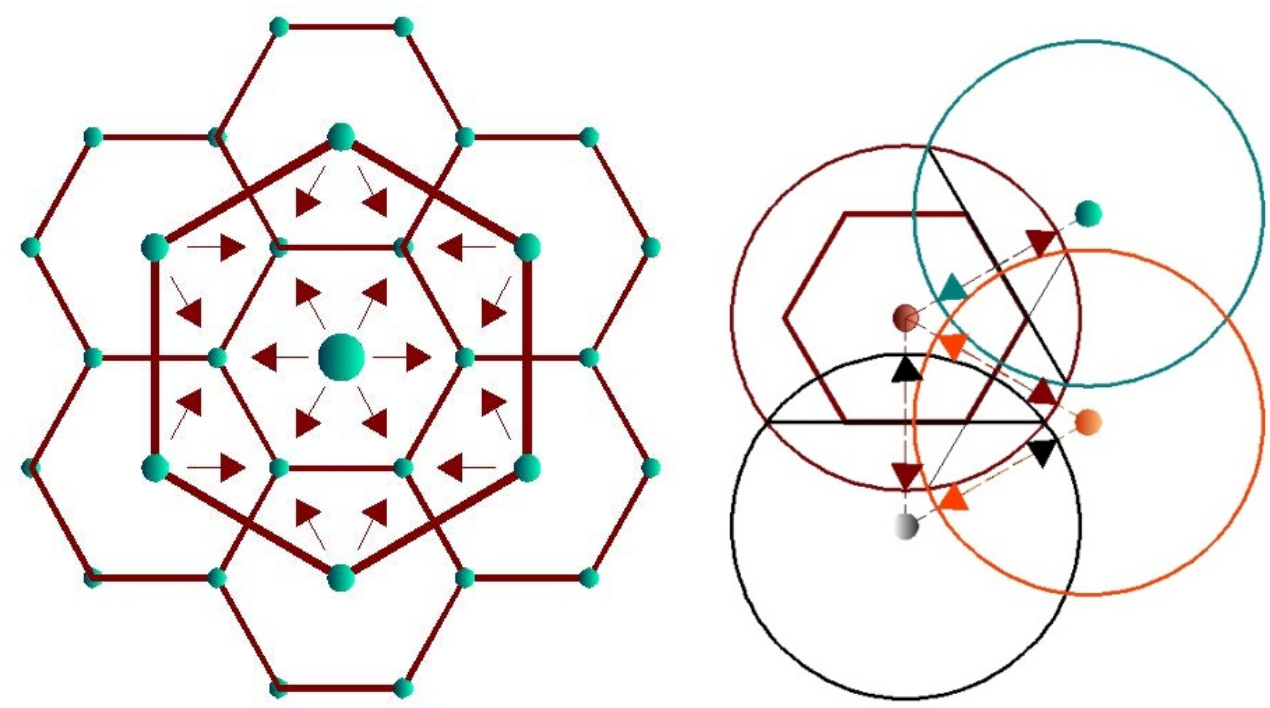

Figura 3.2 Modelo de la "Teoría geográfica" de Walter Christaller (1893-1969) (fuente: elaboración propia) 
Por otra parte, en la misma época, Alfred Weber (1929) considera la utilización de círculos concéntricos que representan el coste del transporte de un área, denominándolos isodápana o isodapan (iso=igual dapane=costo).

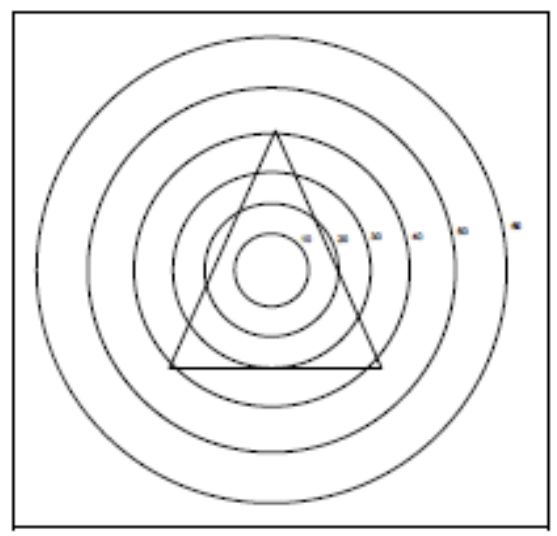

Figura 3.3 Modelo Alfred Weber (1929) (fuente: elaboración propia)

Finalmente, August Lösch (1906-1945) publicó en 1938 su Teoría Económica Espacial, inspirada en las ideas de Christaller, que constituyó un desarrollo de la Teoría del Lugar central y que, a su vez, inspiró la teoría gravitacional basada en la acción de las fuerzas centrífugas y centrípetas propias de la economía espacial, a la que nos referiremos más adelante.

Como ha podido comprobarse, todas estas teorías clásicas sobre el valor económico territorial se basan en las distancias de los centros de producción a los de transformación y distribución. En este concepto básico se inspira también el legislador del suelo de 2007, así como sus transformaciones y desarrollos posteriores, para determinar el plusvalor de posición que incrementa el valor de capitalización de los rendimientos de la explotación.

\subsection{LA LOCALIZACIÓN EN LA VALORACIÓN AGRARIA}

En el campo específico de la valoración agraria, distintos autores han reseñado, en España, la relevancia de la localización en valor del suelo. Ruiz García (1986) recoge el concepto de "anormalidades en las fincas que hacen precisa su corrección de valor", concepto que a su vez recoge de Santi Juárez (1952). De este modo incorpora, entre otros, las depreciaciones debidas a un emplazamiento geoeconómico incorrecto, siendo el claro precedente del RVLS 2011, concretado en el "excesivo alejamiento de los centros urbanos" y la "falta o deficiencia de las vías de comunicación". El "excesivo alejamiento de los centros urbanos" lo basa en Santi Juárez, que proponía una escala de depreciaciones para los distintos alejamientos (Tabla 3.1). 


\begin{tabular}{cc} 
Distancia (a núcleo urbano) & Precio por Ha \\
\hline $15 \mathrm{Km}$. & $\mathrm{P}$ \\
\hline De 15 a $20 \mathrm{Km}$. & $0,85 \mathrm{P}$ \\
\hline De 20 a $30 \mathrm{Km}$. & $0,80 \mathrm{P}$ \\
\hline De 30 a $50 \mathrm{Km}$. & $0,80-0,70 \mathrm{P}$ \\
\hline Mas de $50 \mathrm{Km}$. & Discrecional \\
\hline
\end{tabular}

Tabla 3.1 Distancia - Precio por Ha. (fuente: Santi Juárez (1952) y elaboración propia)

Por su parte Alonso e Iruretagoyena (1995), se refieren a otros autores que han introducido variables de posición en la determinación del valor agrario en los métodos sintéticos, citando a Ballesteros (1991) y Salazar (1950), quienes incorporan elementos tales como las comunicaciones, las diferencias en la situación geográfica y la distancia a los centros de consumo. Los propios Alonso e Iruretagoyena ejemplifican el método sintético mediante la aplicación de un factor de corrección por distancia cuando ello supone "unos costes de transporte por desplazamiento para la realización de las labores superiores al medio". Por su parte, Caballer (2008) afirma que entre las características a considerar en la aplicación del método sintético de comparación espacial se encuentra "la distancia de la finca a un centro urbano".

En todo caso, es preciso mencionar que los denominados "métodos sintéticos" de valoración (o métodos comparativos) han sido desplazados por la normativa valorativa regulada a partir de la Ley $8 / 2007$, que ha optado exclusivamente por el "método analítico", consistente básicamente en "capitalización de una renta tipo de interés dado" (Caballer 2008). Desde el punto de vista práctico, este último método permite superar los inconvenientes de los métodos sintéticos de valoración en un mercado de fincas como el agrario, que, como advierte Caballer, no es homogéneo, no presenta transacciones frecuentes y no es transparente (Caballer 2008). Pero ello no obsta para que, se utilice un método analítico o sintético, resulte de aplicación un factor de corrección de localización que todos los autores incorporan como atributo en el cálculo del valor de la tierra.

\subsection{LOS MODELOS DE ECONOMÍA ESPACIAL}

En los inicios de los estudios económicos sobre el valor de la tierra, el factor territorial no se tenía en cuenta. El estudio del territorio pertenecía a la ciencia de la geografía y la conexión entre geografía y economía tardó en realizarse.

La oposición campo-ciudad y la controversia entre ambos conceptos ha sido analizada por los especialistas en sociología urbana, como Lefebvre: "El tejido urbano, 
compuesto de redes más o menos distantes, ¿acabará por cubrir con sus filamentos todo el territorio de los países industrializados? ¿Se producirá, de este modo, la superación de la antigua oposición campo-ciudad? Cabe imaginarlo, aunque no sin una reseña crítica. Si se denomina así una confusión generalizada en la que el campo se pierde en el seno de la ciudad y la ciudad absorbe el campo extraviándose en él, esta confusión puede refutarse teóricamente. La teoría refuta toda estrategia basada en esta concepción del tejido urbano. Los geógrafos han encontrado un neologismo, que ya ha sido asumido, para designar esta confusión: lo rururbano. En esta hipótesis, la expansión de la ciudad y de la urbanización haría desaparecer lo urbano (la vida urbana), afirmación que no resulta admisible. Dicho de otro modo, la superación de la oposición no puede concebirse como una neutralización recíproca. Ninguna razón teórica permite admitir la desaparición de la centralidad a partir de la fusión de la sociedad urbana y el campo. La oposición "ruralidad-urbanidad" se acentúa en lugar de desaparecer, mientras se atenúa la oposición campo-ciudad. Por tanto, vemos un desplazamiento de la oposición y del conflicto. Por si fuera poco, como es sabido, el conflicto campo-ciudad está lejos de resolverse a escala mundial". (Lefebvre 2017).

Por otra parte, distintos investigadores (Derycke 1971; Harvey 1977 y Lipietz, 1979, entre otros) han considerado que los atributos asociados al valor territorial vienen determinados por su posición o situación con respecto a los denominados centros de actividad, además de la consideración del factor población. Así, Harvey analiza el concepto de "renta diferencial" creado por Ricardo y desarrollado por Marx, señalando que "la renta diferencial no puede entrar dentro del precio de los productos porque surge simplemente de las ganancias extraordinarias que ciertos proveedores adquieren en virtud de su ventajosa situación. Estas ganancias extraordinarias pueden ir a parar al bolsillo de los propietarios de la tierra en forma de renta" (Harvey 1977).

$\mathrm{Y}$, puesto que Marx heredó de Ricardo este concepto, Harvey constata que "Marx combina todos estos elementos y muestra cómo combinaciones diferentes de suelos, en diferentes emplazamientos, con diferentes características, explotados en secuencias diferentes, con diferentes cantidades de capital, pueden crear varios modelos de renta diferencial (El capital, libro III, 605-606, 625-635; Teorías de la plusvalía, vol. 2, 310-312)". También indica que "la situación de las fincas tiene, en lo que se refiere a la renta diferencial en los alquileres de casas, la misma importancia que la fertilidad y la situación en cuanto a la renta agrícola" (Teorías de la plusvalía, vol. 1, p 521)", concluyendo: "La renta diferencial cobra significado en un espacio relativo que está estructurado por diferencias de capacidad productiva en diferentes emplazamientos y que está espacialmente estructurado a través de relaciones de 
costos de transporte" (Harvey 1977).

Como puede observarse, la justificación teórica que Harvey hace del concepto de renta diferencial de posición no está referida al ámbito territorial, al que este autor cita como una simple extensión de los núcleos urbanos, en tanto que "La población rural de los alrededores de las grandes ciudades se ve desplazada sin mucha ceremonia al expandirse estas, como ya había vaticinado Lefebvre en los años sesenta presintiendo que la clara distinción de otro tiempo entre la ciudad y el campo parecía irse difuminando gradualmente dando lugar a espacios porosos con un desarrollo geográfico desigual bajo el dominio del capital y del estado" (Harvey 2013). Pero, aun así, la idea desarrollada por Harvey conecta directamente con el incremento del valor de capitalización de los rendimientos de la explotación en suelo rural -en los "espacios porosos" de las periferias urbanas, pero también en sus extensiones más despobladas- mediante la aplicación de un factor de corrección por localización, que se convierte así en una renta diferencial de situación a modo de plusvalor, tal y como lo planteó la Ley 8/2007 y ha sido desarrollado por la legislación estatal posterior.

Por su parte, Lipietz también hace una crítica marxista de la concepción del espacio desde el punto de vista económico y discute la incidencia del parámetro "distancia" en el valor territorial, en oposición a las teorías de la "economía espacial" de Lösch y Von Thünen a Alonso, afirmando: "He demostrado, a propósito del 'tributo territorial urbano', la debilidad de esas teorías que entienden el suelo como un 'bien' caracterizado por la 'distancia al centro' y la 'superficie'. En realidad, lo que se paga es el 'derecho a disponer' en un espacio jurídico que se superpone (se articula) a una división económica y social del espacio, que es el efecto espacial concreto de la articulación de las múltiples relaciones y prácticas de la esfera económico-social" (Lipietz 1979). Pero Lipietz tan solo se está refiriendo aquí a la oportunidad de la aplicación de las teorías económico-espaciales en el ámbito estrictamente urbano, sin que todavía haya accedido al territorio y a su relación con lo urbano. No obstante, más adelante desarrolla su teoría del valor asociado al denominado "tribut foncier", señalando que "el espacio es un bien que puede tener un precio: precio del terreno, renta territorial, en suma, lo que puede llamarse 'tributo territorial' para indicar el hecho de que ese precio tiene que ver más con una tasa que con el valor de una mercancía" (Lipietz 1979). De modo que, continuando con la analogía con el concepto del factor de localización de la vigente legislación estatal de suelo, el valor de posición del suelo rural operaría, en los términos de Lipietz, como una tasa o tributo (el "derecho a disponer" de un terreno mejor situado), añadida al valor de producción de la explotación, que representaría el valor puramente mercantil de la tierra. 
La aplicación del valor de localización en suelo rural está, por otra parte, vinculado a la teoría de los modelos denominados "gravitacionales" en los que la cantidad de población y la distancia a núcleos donde habitan forma parte del plusvalor aplicable a las rentas de explotación en suelo rural. La formulación del factor de localización en relación con la población del RVLS es, en último término, un desarrollo de la "Ley de la gravitación comercial" de Reilly (1931), inspirada a su vez en la ley de la gravitación universal, según la cual la fuerza de atracción -o interacción espacial- entre dos cuerpos es directamente proporcional al producto de sus masas e inversamente proporcional al cuadrado de la distancia que los separa. Según Reilly, las ventas que dos localidades atraen de una localidad intermedia son directamente proporcionales a las poblaciones de aquellas- esto es, al número de potenciales consumidores existentes en ellas- e inversamente proporcionales al cuadrado de las distancias entre la localidad intermedia y las localidades consideradas (Camagni 2004).

Si se traslada la ley de Reilly al ámbito de la valoración del suelo rural, el plusvalor de posición de la tierra en cualquier punto del territorio estaría relacionado con las distancias de ese punto a las poblaciones próximas (a las situadas a $4 \mathrm{~km}$. y $40 \mathrm{~km}$. en el RVLS) y con el número de habitantes de estas poblaciones, idealmente potenciales consumidores de los productos resultantes de la explotación agraria o de otro tipo. La aplicación de la ley de la gravitación comercial de Reilly a la teoría del valor territorial se inscribe por Derycke (1983) en el análisis de la "red jerarquizada de ciudades" precedente del "sistema urbano-territorial" al que más adelante nos referiremosafirmando que "la intuición sugiere que la influencia de una ciudad sobre el espacio circundante decrece con la distancia y crece con la importancia de la ciudad, es decir, con su extensión y, sobre todo, su población". Ambos parámetros, distancia y población, son, por tanto, los atributos básicos del valor territorial, tal y como se regulan por el art. 17.2 RVLS para determinar el factor de corrección por accesibilidad a núcleos de población. Según Derycke, "la formulación de Reilly exige recurrir a una métrica euclidiana", lo que presenta varios inconvenientes superados cuando "se reemplazan las distancias euclidianas por distancias kilométricas, conseguidas a partir de los mapas de carreteras". Ambos criterios, el euclidiano y el cartográfico, se utilizan por el RVLS de forma indistinta para determinar el citado factor de corrección por accesibilidad a núcleos de población: mientras que en la determinación del parámetro $\mathrm{P}_{1}$ se cuantifica "el número de habitantes de los núcleos de población situado a menos de $4 \mathrm{~km}$ de distancia medida a vuelo de pájaro, entendida como la distancia en línea recta medida sobre la proyección en un plano horizontal", en el cálculo de $\mathrm{P}_{2}$ se incluye "el número de habitantes de los núcleos de población situados a más de 4 km 
y a menos de $40 \mathrm{~km}$ de distancia medida a vuelo de pájaro o 50 minutos de trayecto utilizando los medios habituales de transporte y en condiciones normales". Pero, en todo caso, no cabe duda de que el RVLS se inspira en los modelos gravitacionales para evaluar la corrección por accesibilidad a núcleos de población.

Mas recientemente, Fujita, Krugman y Venables (1999) desarrollan la denominada "nueva geografía económica", también denominada "economía espacial", en la que investigan cómo en los espacios geográficos se forman diferentes aglomeraciones de la actividad económica. Un ejemplo de ello se encuentra en la formación de las ciudades, idea en la que también se apoyan los modelos gravitacionales de localización espacial. Para estos autores, el modelo de Von Thünen puede parecer hoy completamente simple y obvio, pero en realidad constituye un ingenioso y profundo análisis, resultando, en particular, un sorprendente ejemplo del potencial de los modelos económicos para generar ideas inesperadas. $\mathrm{Y}$, en este sentido, aplican también las relaciones entre distancias y volúmenes comerciales -o cantidades poblacionales de potenciales consumidores, para establecer la relación con el modelo propuesto por el RVLS- y acuden también a los modelos gravitacionales, señalando que la distancia aparece siempre como un elevado significado determinante de los flujos comerciales.

En definitiva, estos autores estudian la estructura centro-periferia de la economía espacial donde se puede relacionar y analizar las fuerzas que se generan en el ámbito regional y estatal, dejando ver que dichas fuerzas se encuentran en equilibrio inestable. En cualquier caso, cada uno de los diferentes tipos de aglomeraciones, forma parte de un sistema más complejo, afectado por las relaciones existentes entre todas ellas (Fujita y Krugman 2004): "Una vez que el número de ciudades es/sea suficientemente grande, el tamaño de dichas ciudades y la distancia entre ellas tenderá a estabilizarse a un nivel constante, determinado por la fuerza relativa de las fuerzas centrípetas y centrífugas, proporcionando cierta justificación de la teoría del lugar central de Lösch (1954). Si hay múltiples industrias que se diferencian en términos de economías de escala y/o costes de transporte, la economía tenderá a desarrollar una estructura jerárquica con reminiscencias de Christaller (1933). Esta línea de trabajo proporciona pues un vínculo con algunas de las más antiguas tradiciones de la teoría de la localización y la geografía económica”.

Tal y como recoge Krugman (2004) "La cuestión a destacar en la NGE (Nueva Geografía Económica) es que se trata de proporcionar alguna explicación a la formación de una gran diversidad de formas de aglomeración (o concentración 
económica en espacios geográficos. La aglomeración o agrupación (clustering) de la actividad económica tiene lugar a distintos niveles geográficos y tiene una variedad de formas distintas. Tomando un ejemplo, un tipo determinado de aglomeración surge con la agrupación de pequeñas tiendas y restaurantes en un barrio. Otro tipo de aglomeraciones lo encontramos en el proceso de formación de las ciudades, donde todas adquieren distintos tamaños ... en la emergencia de una variedad de distritos industriales; o en la existencia de fuertes desigualdades regionales dentro de un país. En el otro extremo del espectro se encuentra la estructura centro-periferia de la economía global, correspondiente al dualismo norte-sur. Es asimismo importante señalar que todos estos tipos distintos de aglomeración, a diversos niveles, están a su vez insertos en una economía mayor, formando en su conjunto un complejo sistema". En este sentido, Krugman sostiene que "la estructura geográfica de una economía es determinada por la tensión existente entre estas fuerzas", con referencia a las fuerzas centrípetas que concentran la actividad económica y las fuerzas centrífugas que la separan. Plantea así que, para obtener una visión en conjunto de la economía, es necesario tener en cuenta los costes de transporte -siguiendo la estela de la teoría de Weber citada anteriormente-, considerando las rentas generadas y los recursos utilizados.

Por tanto, la "nueva geografía económica" inscribe de alguna forma su teoría tanto en Von Thünen, Lösch, Christaller y Weber, como en los teóricos de la gravitación, sustituyendo las ciudades por las aglomeraciones o concentraciones urbanas en un contexto territorial -e, incluso, supraterritorial- que tiene por escenario el ámbito de las regiones y los estados, así como en el más amplio de la geopolítica de las distintas naciones.

Concluyendo, "la economía espacial estudia la forma en que los agentes económicos toman las decisiones de localización; esto es, cómo la población, en general, y los empleados, en particular, se localizan espacialmente en concentraciones pequeñas o grandes, cómo las regiones se desarrollan dentro de un país y cómo el transporte juega un papel relevante en la estructura espacial de una economía" (Trivez 2004). Por tanto, el valor económico del territorio regulado en la legislación estatal de suelo se inscribe en el ámbito de la disciplina de la economía espacial, en tanto que establece el sistema de relaciones entre los agentes interesados, esto es, lo propietarios de suelo rural y las administraciones expropiantes, mediante la aplicación del factor de corrección del valor resultante de la capitalización de las rentas de la explotación en función de la localización en el territorio y su vinculación a los polos de atracción. $Y$ todo ello considerando que, de acuerdo con el Preámbulo del RVLS, dicha 
explotación está referida a "una amplia gama de actividades económicas ya presentes, o susceptibles de ser desarrolladas en el suelo rural, diferentes del aprovechamiento convencional, propias de una economía moderna y avanzada".

Para ello, el legislador recurre (artículo 17.3 RVLS) a parámetros vinculados a las distancias existentes desde el punto de referencia a los núcleos de población (factor $\mathbf{u}_{1}$ ), así como a los centros de actividad económica (factor $\mathrm{u}_{2}$ ). $\mathrm{Y}$ estos factores $\mathrm{o}$ variables -que determinan el factor global de corrección $y$, en consecuencia, el plusvalor espacial de posición ${ }^{8}$ - representan las fuerzas de atracción producidas entre los distintos polos, reflejando las características del sistema que regula las relaciones territoriales entre los núcleos urbanos, los centros de producción y sus áreas de influencia mediante las conexiones establecidas a través de las infraestructuras, corredores y otros canales y vías de comunicación, así como de la diversidad de flujos que los recorren.

\subsection{EL SISTEMA URBANO-TERRITORIAL}

\subsubsection{Antecedentes}

Desde la época romana, pasando por la reconquista (siglo $\mathrm{XI}$ ) y la Edad Media, se comenzaron a crear las bases del actual sistema de ciudades español. El modelo de ciudad de la Edad Media, amurallada en la que se localizaba gran parte de la actividad económica, se mantiene con sus rasgos fundamentales hasta finales del siglo XIX, momento en que la revolución industrial genera grandes cambios en este modelo de ciudad.

Las infraestructuras de comunicación, que transportan mercancías tanto para el abastecimiento como para las actividades comerciales y el transporte de las personas, permiten que las ciudades se transformen y experimenten un proceso de crecimiento provocando el desarrollo de las mismas y su conexión con otras de similares características o complementarias a ellas, todo ello impulsado por la industrialización.

En este momento comienza a variar el modelo de ciudad, motivado por el crecimiento demográfico, y comienza la población a hacinarse en los centros históricos. De este modo se produce la expansión de las ciudades en los denominados ensanches, donde se ubicaba la burguesía, mientras que en las periferias aparecían los suburbios donde

\footnotetext{
${ }^{8}$ Se excluye de este análisis el factor de corrección u3 por su escasa conexión con los principios de la economía espacial
} 
las clases bajas se asentaban, de manera desordenada y carente de servicios mínimos.

Posteriormente, la emigración desde el ámbito rural a las ciudades a mitad del siglo XX produce cambios numerosos en este sistema de ciudades. Comienzan a aparecer las áreas metropolitanas que se podrían definir como extensiones formada por ciudades "activas" que crecen hacia municipios cercanos. En 1.960 el 20,5\% de la población del país se encuentra en 10 ciudades españolas ${ }^{9}$.

La desindustrialización y la terciarización, de nuevo, comienza a provocar cambios en el sistema de ciudades. Con la llegada de la democracia, y la estructura socioeconómica formada hasta entonces, se consolida la distribución del sistema de ciudades contemporáneo. Finalmente, la nueva estructura del territorio español conlleva la conexión del sistema de ciudades español con la red europea.

En el Plan Director de Infraestructuras 1993-2007 (Ministerio de Obras públicas) es la primera planificación estratégica y global del sistema básico de infraestructuras de España. En dicho instrumento, aparte del contenido sectorial propio constituido por las infraestructuras, se pretende establecer una estrategia de ordenación del territorio, que contiene incluso unas directrices para el periodo mencionado, en las que el Plan caracteriza "el modelo territorial" español, inserto en el contexto europeo.

\subsubsection{El marco conceptual}

Por un lado, entendemos por sistema de ciudades el conjunto de la ubicación de una población en diferentes poblamientos, asentamientos o núcleos de población, en un territorio determinado, así como los canales de relación existentes (infraestructuras, conexiones socio-económicas...) entre ellos y su entorno.

Esta definición recuerda a la que del Sistema Territorial se hace en la disciplina de la Ordenación del Territorio, de acuerdo con Gómez Orea (2013): “Los componentes del sistema territorial son: el medio físico o sistema natural en el estado actual (incluidos los usos primarios de suelo), la población, sus actividades: de producción, consumo y de relación social, el poblamiento o sistema de asentamientos de población, los canales de relación a través de los que se intercambian personas, mercancías, energía e información, las instituciones y agentes que vertebran la sociedad y el marco

9 INE "Ciudades españolas":

https://www.ign.es/espmap/mapas_ocupacion_eso/OcupaESO_Mapa_08.htm 
legal que define las reglas". De forma complementaria a esta definición, en el Sistema de Ciudades el "protagonista" es la CIUDAD, siendo además el Sistema de Ciudades un subsistema de cualquier Sistema Territorial, como puede deducirse de la definición anterior.

En este contexto se inscribe el marco estratégico y modelo territorial y urbano descrito en la Agenda Urbana Española, definido en estos términos: "(...) la Agenda Urbana Española parte de la necesaria apuesta por una visión integral del componente territorial y por la defensa del concepto de geografía variable respecto de las estrategias, porque es el vector de la propia estrategia el que define el ámbito territorial y no al revés. Ese enfoque de estrategia territorial amplia, que tiene en cuenta las áreas metropolitanas, las nuevas centralidades, las áreas urbanas funcionales donde se generan nuevas relaciones territoriales y economías de aglomeración y de flujos entre diversos municipios, las disparidades interregionales e intrarregionales, las áreas industriales en declive, los territorios concretos afectados por el progresivo descenso demográfico y la despoblación, la ausencia de inversiones que impiden el desarrollo económico y social y otros muchos aspectos, es clave para potenciar la articulación y la integración desde un enfoque holístico del territorio" ${ }^{10}$.

Tal y como recoge Fernández Güell (2006) "el análisis de los sistemas urbanos descansa en tres áreas de conocimiento básicas: 1, la teoría general de sistemas ..., 2, la geografía urbana ...,3, la ecología urbana..." Aunque el análisis de estos sistemas desborda los objetivos del presente trabajo de investigación, si parece interesante considerar, dentro de la estructura del sistema de ciudades, varios conceptos básicos desarrollados por el citado autor y que posteriormente serán de interés en la presente investigación (Fernández Güell 2006):

"Sistema urbano: es un conjunto de asentamientos ubicados en un determinado territorio, creados y organizados por la sociedad que los habita, y que mantienen relaciones entre sí.

Rango: mide la importancia relativa de un lugar dentro de un sistema urbano mediante un conjunto de indicadores.

Flujo: representa los movimientos cuantificados de personas, mercancías, servicios telecomunicaciones o correo entre los diversos elementos del sistema urbano.

Área de influencia: es el ámbito territorial que cubren determinados núcleos para la provisión de bienes y servicios.

\footnotetext{
${ }^{10}$ Agenda Urbana Española 2019. Ministerio de Fomento 2018.
} 
Red urbana: es un conjunto de centros urbanos entre los que se establecen unas relaciones de interacción basadas en la complementariedad y especialización de sus funciones."

Lo recogido en el presente apartado servirá como base para la definición de lo que en el presente trabajo se ha denominado el sistema urbano-territorial.

\subsubsection{Las áreas urbanas}

El Ministerio de Fomento desde el año 2000 ha publicado diferentes Atlas Estadísticos de las Áreas Urbanas donde se han recogido la evolución y la realidad de las principales áreas urbanas españolas, cuya versión digital se puede consultar desde 2007. A través del SIU11 se accede a la delimitación de las denominadas "áreas urbanas", donde se tiene acceso a diferentes variables e indicadores a nivel de municipio, área urbana, provincia y comunidad autónoma.

No es objeto de este trabajo el análisis evolutivo de la formación de las áreas urbanas, pero es útil conocer los datos facilitados por el Ministerio de Fomento para poder analizar la relación de las mismas con el valor de corrección por la localización.

A estos efectos parece necesaria la descripción de las denominadas "áreas urbanas", denominación que el Ministerio de Fomento recoge en su documento "Las áreas urbanas 2017" que se encuentra en el siguiente acceso: https://apps.fomento.gob.es/CVP/handlers/pdfhandler.ashx?idpub=BAW050

Para ello se utiliza como último dato de referencia el Padrón municipal de habitantes de 2016, así como, los datos del Censo de población y viviendas de 2011, los datos de hogares de la Encuesta de Población Activa 2015 y los del Nomenclátor de población 2016. En el documento citado se recoge que estas fuentes proporcionan el mayor nivel de información municipal existente para el conjunto de todo el territorio español.

Como resultado de toda la información utilizada se concluye en la división del territorio nacional en tres tipos de ámbitos, delimitados en función de su relación con el fenómeno urbano.

La división recogida en el documento es la siguiente:

\footnotetext{
11 Sistema de Información Urbana del Ministerio de Fomento
} 


\section{“1. GRANDES ÁREAS URBANAS}

Se han delimitado un total de 86 áreas mayores de 50.000 habitantes (uni o plurimunicipales) que agrupan un total de 753 municipios en los que viven más de 32 millones de habitantes según el Padrón Municipal de Habitantes de 2016, es decir, en el 9,3\% de los municipios españoles viven el 68,9\% del total de la población. En términos de superficie, el conjunto de estas áreas ocupa tan solo el 9,6\% del territorio Nacional. Constituye el primer rango en nuestro panorama urbano y está compuesto, tanto por las grandes ciudades de nuestro país, como por las principales aglomeraciones urbanas. De las 86 áreas, 20 abarcan un sólo término municipal, mientras que las 66 restantes están compuestas por varios municipios, constituyendo, pues, éstas, las auténticas aglomeraciones urbanas españolas.

\section{PEQUEÑAS ÁREAS URBANAS}

Entre las que podemos distinguir dos subestratos:

a) Por un lado, las ciudades entre 20.000 y 50.000 habitantes, no incluidas en el primer nivel (GRANDES ÁREAS URBANAS). Son en total 121 municipios, que suponen un $7,2 \%$ de la población y un $5,6 \%$ de superficie.

b) Por otro lado, tendríamos los municipios urbanos entre 5.000 y 20.000 habitantes, si bien este segundo sub-estrato requiere un análisis más pormenorizado.

La clasificación estadística española tradicional determina como urbano, "el conjunto de entidades de población con 10.001 o más habitantes". Sin embargo, esta clasificación enmascara muchas situaciones que no son propiamente urbanas.

El conjunto de municipios entre 5.000 y 20.000 habitantes no incluidos en el primer nivel (GRANDES ÁREAS URBANAS), suma un total de 624 municipios. A estos, se les han aplicado cuatro filtros con las siguientes características:

-El primer filtro hace referencia a la población del núcleo. Nuestra especial configuración territorial presenta algunos casos (sobre todo en el norte y en algunas zonas montañosas) en que la estructura de los asentamientos responde a una concepción multinuclear, de forma que la población se encuentra dispersa en numerosos asentamientos y entidades menores de población, si bien la asignación estadística de población se referencia a un solo municipio. Así, solo se han tenido en cuenta para este primer análisis aquellos municipios cuya población en núcleo superase los 10.000 habitantes. Para la determinación de la población nuclear se ha utilizado el Nomenclátor de 2016, restando del total de población asignado a cada municipio, la que aparece bajo el epígrafe "población en diseminado". La 
aplicación de este primer filtro elimina 430 municipios y reduce, por tanto, la cantidad inicial, 624, a 194.

-En segundo lugar, de estos 194 municipios se han eliminado aquellos cuya evolución demográfica en el periodo 1960-2016 resultase negativa, es decir, que hayan perdido población, y por lo tanto, manifiesten una tendencia a bajar del umbral de los 10.000 habitantes. Este segundo filtro provoca la exclusión de 36 municipios, con lo que la cantidad ya se reduce a 158.

-En tercer lugar, se ha tenido en cuenta la población activa por sectores económicos. Es evidente, y así consta en numerosos estudios, que uno de los principales indicadores de urbanización, es el peso del sector servicios. El umbral de referencia que hemos empleado es comparar los niveles porcentuales de población activa dedicada al sector servicios (comercio y otros servicios), con el porcentaje de población activa dedicada a este sector del ámbito 2 (ciudades entre 20.000 y 50.000 habitantes no incluidas en el ámbito 1). Todos aquellos municipios que lo igualasen o lo superasen quedarían incluidos en nuestro ámbito. Este tercer filtro reduce el número de municipios a 29, es decir, excluye 129 del conjunto total que nos quedaba después de la aplicación de los dos filtros anteriores.

-En cuarto lugar y una vez aplicados estos filtros, y estudiando con detenimiento los municipios que habían quedado fuera de la clasificación, se constató que, en algunos casos, quedaban fuera términos municipales de importancia en el sector turístico, por lo que se decidió aplicar un indicador de "potencial de acogida". Para ello, se tuvo en cuenta el número de viviendas secundarias y vacías. El indicador consiste en multiplicar el número de viviendas secundarias por el índice de ocupación medio de España (2,52), y sumarle la población de derecho en núcleo del municipio en 2016. De este modo, obtenemos una estimación de la capacidad de acogida del municipio para población flotante estacional. Todos aquellos que sobrepasasen el umbral de 15.000 habitantes, quedarían incluidos en el ámbito. Con la aplicación de este filtro se recuperan un total de 168 municipios.

-El balance total de la aplicación de los filtros nos da un ámbito de 198 municipios de entre 5.000 y 20.000 habitantes".

En el estudio realizado en el presente trabajo de investigación, se han analizado alguna de las grandes áreas urbanas y es inevitable, una vez estudiadas, asimilar el concepto de Área Urbana, definida por el Ministerio de Fomento, al sistema de ciudades español y sus áreas de influencia 


\subsubsection{Los canales de relación - Los flujos - El Sistema de Comunicación}

Como se ha definido en el apartado 3.4.1 Antecedentes dentro de los componentes del sistema territorial utilizado en la Ordenación del Territorio se encuentran los denominados "canales de relación" y, de igual modo, uno de los conceptos básicos en la estructura del sistema de ciudades es el de "flujo". En ambos casos se consideran como tales los movimientos o intercambios de personas, mercancías, energía, comunicación, etcétera.

En el desarrollo de este trabajo se ha considerado la red de carreteras de España como elemento básico que forma dichas canales de relación o flujos considerados en la definición de los sistemas referenciados en el párrafo anterior y como elemento fundamental para el análisis de la localización en la accesibilidad a núcleos de población. Aunque dentro de los canales de relación y flujos deben incluirse las restantes infraestructuras, para la realización del estudio se ha considerado que el trazado de la red ferroviaria puede considerarse en la práctica superpuesto al de la red de carreteras, por lo que se ha optado por utilizar esta última como referencia exclusiva.

La red de carreteras de España está formada tanto por la denominada Red de Carreteras del Estado (en adelante RCE), como por las carreteras gestionadas por la Comunidades Autónomas y Diputaciones. Puesto que, tal y como se ha recogido en el apartado 3.4.1 Antecedentes del presente punto, la función de estas infraestructuras lineales, es el transporte de persona y mercancías, se considera que constituyen un elemento fundamental en el sistema de la conexión entre las diferentes ciudades.

\subsubsection{El sistema urbano-territorial: conclusión}

De acuerdo con lo expresado en el presente apartado, siguiendo a Fernández Güell se define el sistema urbano-territorial como el formado por el Sistema urbano español y sus áreas de influencia, conectado mediante la red de comunicación que genera unos flujos de conexión, estructurándose así la red urbana a nivel estatal. Reproduciendo los modelos gravitacionales antes citados en el sistema urbano- territorial se establece la jerarquía de cada uno de sus elementos en función del poder de atracción de cada una de las grandes áreas urbanas.

En definitiva, en el contexto de este trabajo, se define el sistema urbano-territorial como la compleja estructura formada por las áreas urbanas y las infraestructuras de 
conexión que las unen, configurándose dichas áreas como conjuntos de entidades de población, formadas por uno o más municipios, dotadas de una fuerza demográfica y económica que destaca entre otras entidades de población, y que generan zonas de influencia en los territorios próximos.

\subsection{LA INCIDENCIA DE LA LOCALIZACIÓN EN LA VALORACIÓN DE SUELO: CONCLUSIONES}

Los nuevos estudios económicos que describen las fuerzas centrípetas que llevan a la aglomeración o las fuerzas centrífugas que llevan a la dispersión, facilitan el entendimiento de la formación de las ciudades, así como las relaciones entre diferentes áreas urbanas, lo que tiene una relación inequívoca con el concepto de sistema urbano-territorial.

Como se puede observar existe una correlación entre el factor de corrección por accesibilidad a núcleos de población $\mathbf{u}_{1}$, en el que el factor determinante es la población de cualquier asentamiento humano, las denominadas "aglomeraciones" y el sistema urbano-territorial.

Con el análisis de los resultados que se obtengan del cálculo del factor de accesibilidad a núcleos de población $\mathbf{u}_{1}$ en la presente investigación se procederá a llegar a alguna conclusión sobre el sentido de dicho factor. 



\section{METODOLOGÍA}

\subsection{ANTECEDENTES DEL CÁLCULO DEL FACTOR DE CORRECCIÓN POR LOCALIZACIÓN (FL) EN EL SUELO RURAL SEGÚN EL RVLS 2011}

En el estudio que precedió al presente trabajo de investigación se realizó un análisis práctico del cálculo de los factores de corrección por localización, que se expone a continuación con carácter preliminar.

Con carácter inicial se realizó el estudio aplicado al Municipio de Leganés, aplicándose sus resultados al análisis práctico de diferentes puntos del territorio nacional con distintas densidades de población, cuyo desarrollo se llevó a cabo desde ámbitos con una densidad baja a otros con poblaciones muy superiores.

\subsubsection{Aplicación al municipio de Leganés (Madrid)}

En el primer análisis desarrollado en el municipio de Leganés (Madrid), se tomaron como referencia tres puntos: un punto al Norte, otro en el Centro del municipio y otro al Sur. Dicho análisis se hizo de forma manual, a partir de otras tantas localizaciones virtuales de suelo hipotéticamente valorado, con el fin de conocer la variación el factor de localización FL dentro del municipio, para posteriormente pormenorizar el cálculo a nivel de cada parcela.

Se pretendía así analizar la variación del factor de corrección por accesibilidad a núcleos de población $\left(\mathbf{u}_{1}\right)$ en cada uno de dichos puntos, todo ello con referencia a un mismo término municipal. Puesto que Leganés colinda con Madrid al norte, el valor de $\mathbf{u}_{1}$ obtuvo un valor superior en el punto denominado "Norte" y, sobre todo, en el punto denominado "Centro".

Para el cálculo del factor $\mathbf{u}_{1}$ se adoptó como origen de la medición un punto en el Centro del municipio con coordenadas geográficas $\left(40,327616^{\circ},-3,779146^{\circ}\right)$; un punto en el Sur con coordenadas geográficas $\left(40,293959^{\circ},-3,774790^{\circ}\right)$; y un punto al Norte con coordenadas geográficas $\left(40,365541^{\circ},-3,721961^{\circ}\right)$.

Para el cálculo de $\mathrm{P}_{1}$ se trazó, sobre plano, un círculo de radio $4 \mathrm{Km}$., de forma que, utilizando los datos facilitados por el INE se consideró la cantidad de población incluida en los núcleos a los que afectaba dicho círculo.

Para el cálculo de $\mathrm{P}_{2}$ se trazó, sobre el mismo plano, un círculo de radio $40 \mathrm{Km}$., de 
igual modo que para el valor anterior y, una vez obtenido el número total de habitantes, se restó del valor de $\mathrm{P}_{1}$, obteniendo el número de habitantes de los núcleos de población situados a más de $4 \mathrm{Km}$. y menos de $40 \mathrm{Km}$.

Con los datos obtenidos se procedió al cálculo del factor de corrección por accesibilidad a núcleos de población $\mathbf{u}_{1}$ utilizando la fórmula del artículo 17.2 del RVLS 2011, resultando los valores que se muestran en la Tabla 4.1:

VALOR $\mathbf{u}_{1}$

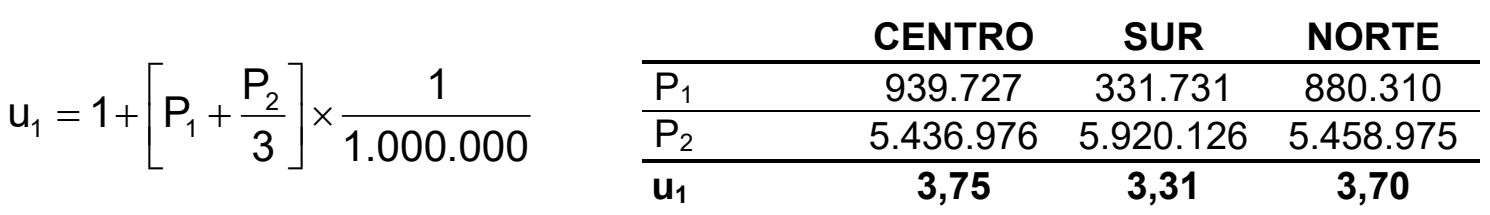

Tabla 4.1. Resultados $u_{1}$ en Leganés. (fuente: elaboración propia)

Se puede observar que los resultados obtenidos evidenciaban que la utilización de la metodología planteada por el RVLS 2011 para el cálculo del coeficiente del Factor de Corrección por Localización conduce a que en todas las localizaciones del término municipal se superaba ampliamente el límite máximo previsto de forma inicial en el RVLS 2011. ${ }^{12}$

\subsubsection{Aplicación a otros municipios}

Una vez analizados los resultados obtenidos en el Municipio de Leganés, se estimó necesario localizar suelos donde la variación de la densidad de población, al menos en un radio de $40 \mathrm{Km}$., resultará diferente en cada uno de ellos.

Para ello se utilizó un mapa de España donde se representaban las densidades poblacionales $^{13}$ (Figura 4.1), y se localizaron diferentes emplazamientos objeto del estudio, dotados de diferentes densidades de población.

\footnotetext{
12 Es necesario mencionar que en el momento de la realización del análisis al que se refiere el presente punto, no se había pronunciado el TC en su Sentencia del 141/2014, de 11 de septiembre de 2014, sobre la inconstitucionalidad del "límite del doble" fijado en el RVLS 2011.

${ }^{13}$ http://alarcos.inf-cr.uclm.es/per/fruiz/pobesp/map/espania.htm\#densidad
} 


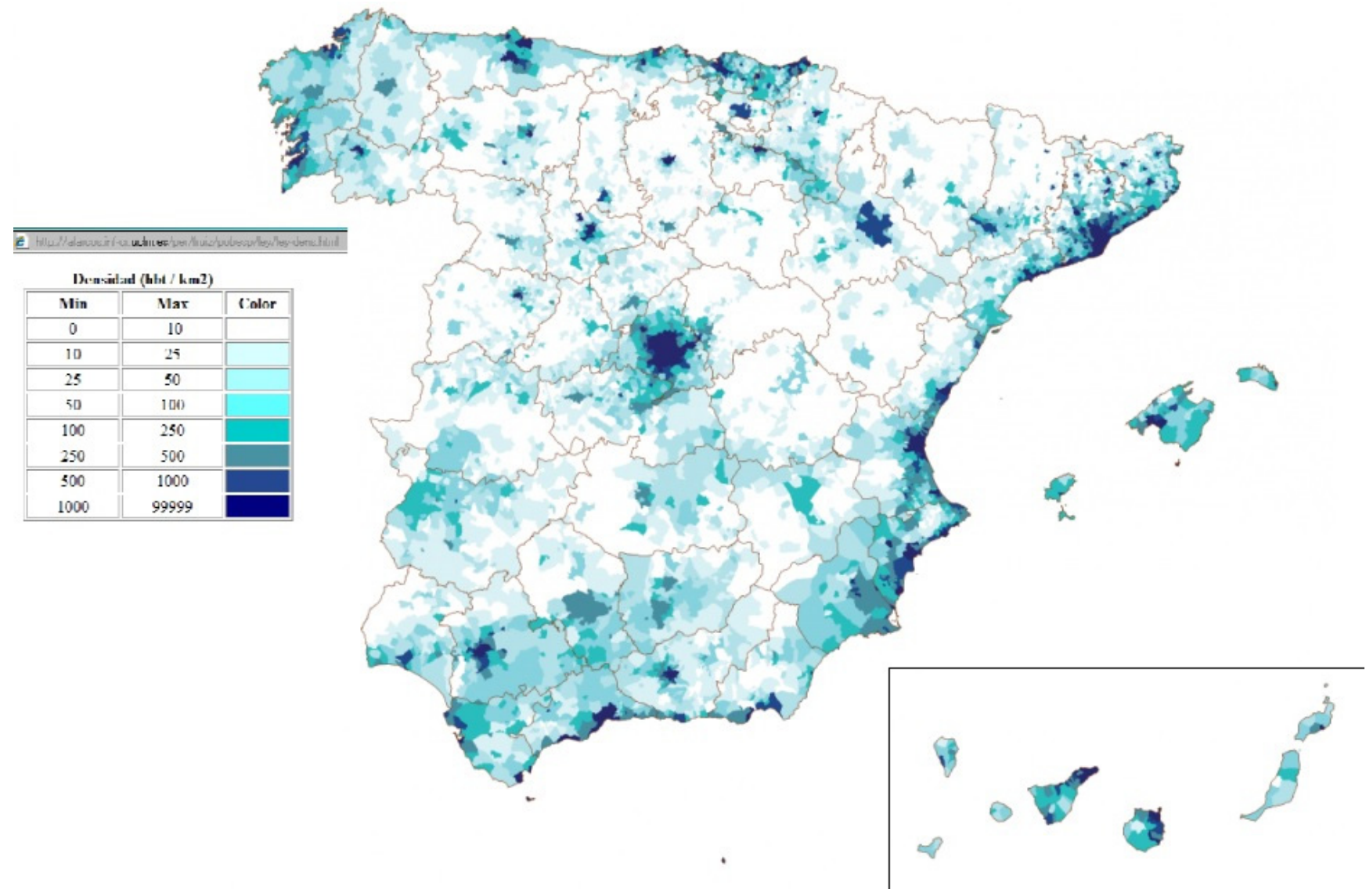

Figura 4.1. Mapa de España de densidades de población (fuente: http://alarcos.infcr.uc/m.es/per/fruiz/pobesp/map/espania.htm\#densidad y elaboración propia)

Para este nuevo cálculo se estimó que los suelos objeto de valoración estarían situados en las siguientes ubicaciones:

- Layna (Soria) (Figura 4.2), ámbito con densidad poblacional muy baja, con coordenadas geográficas $\left(41,099444^{\circ},-2,303333^{\circ}\right)$

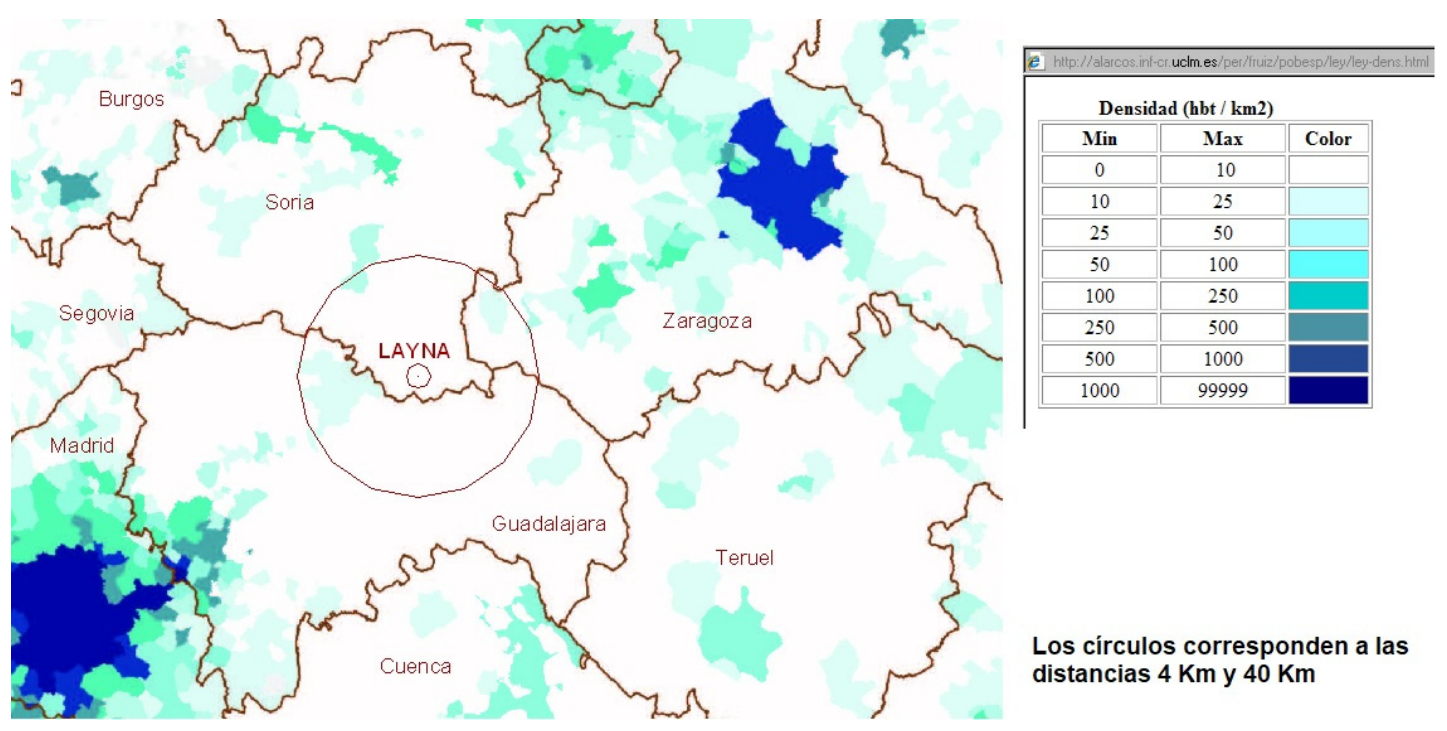

Figura 4.2. Ubicación de Layna (fuente: elaboración propia) 
- Alares (Toledo), (Figura 4.3), con densidad poblacional superior a la de Layna e inferior al municipio de Leganés y coordenadas geográficas (40, $\left.293959^{\circ},-4,727489^{\circ}\right)$

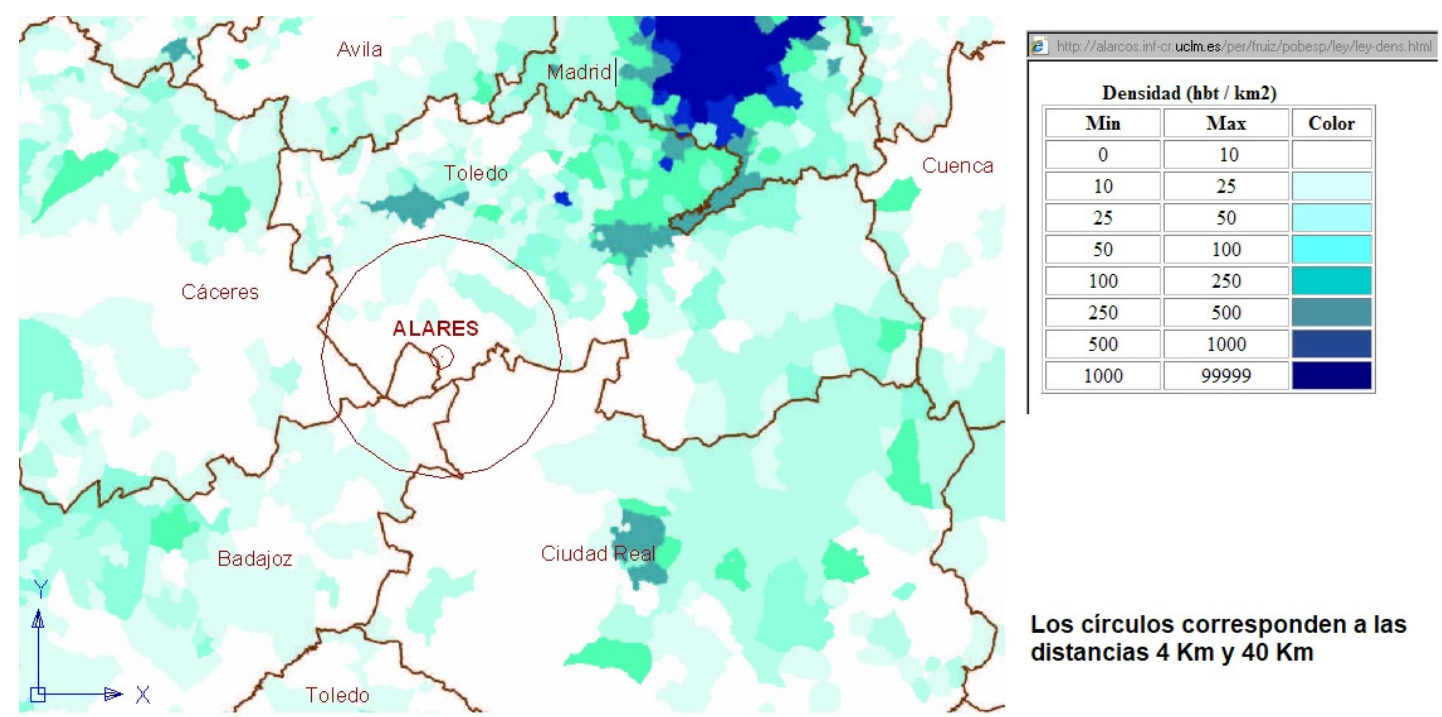

Figura 4.3. Ubicación de Alares (fuente: elaboración propia)

- Tembleque (Toledo) (Figura 4.4), con densidad poblacional superior a la de Alares e inferior a la del municipio de Leganés y coordenadas geográficas son $\left(39,700499^{\circ},-3,509466^{\circ}\right)$

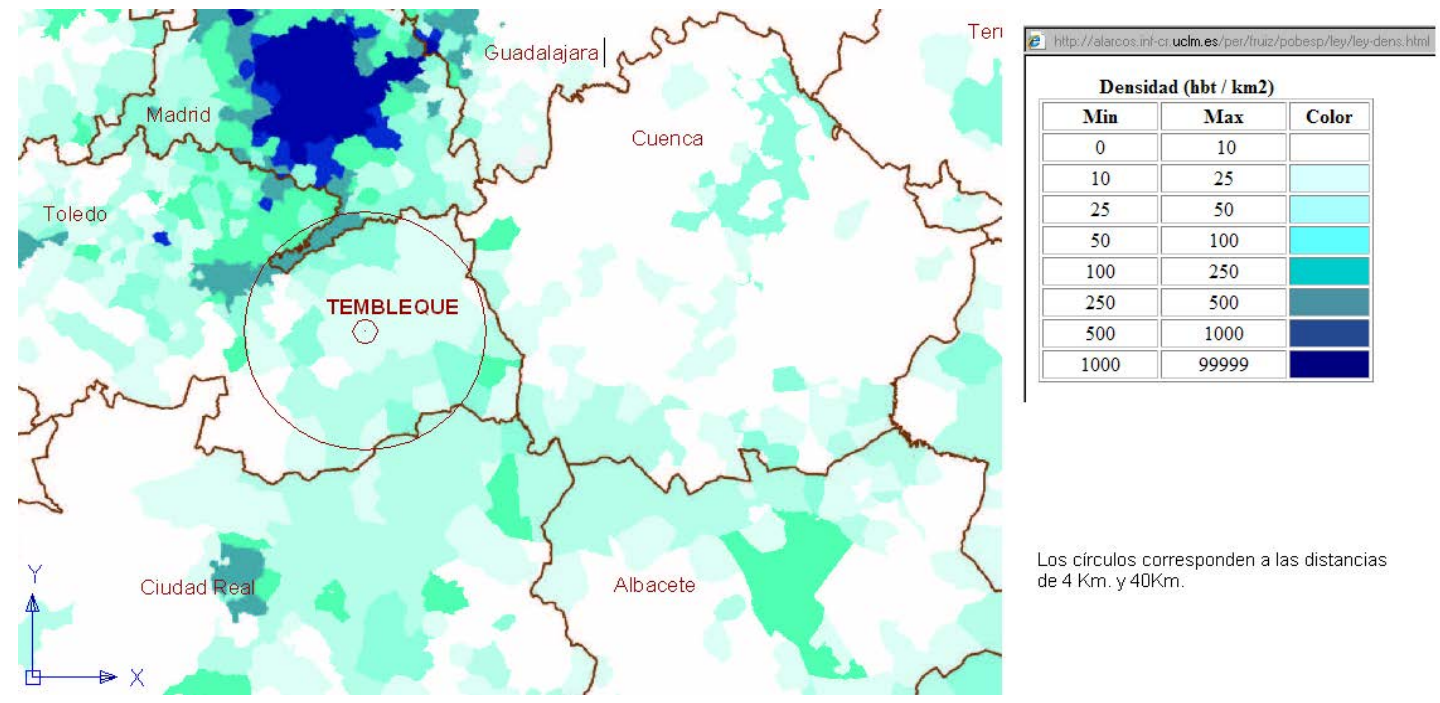

Figura 4.4. Ubicación de Tembleque (fuente: elaboración propia)

- Almagro (Ciudad Real) (Figura 4.5), con densidad poblacional superior a los anteriores estudiados, pero inferior a la del municipio de Leganés, cuyas coordenadas geográficas son $\left(38,894419^{\circ},-3,714429^{\circ}\right)$ 


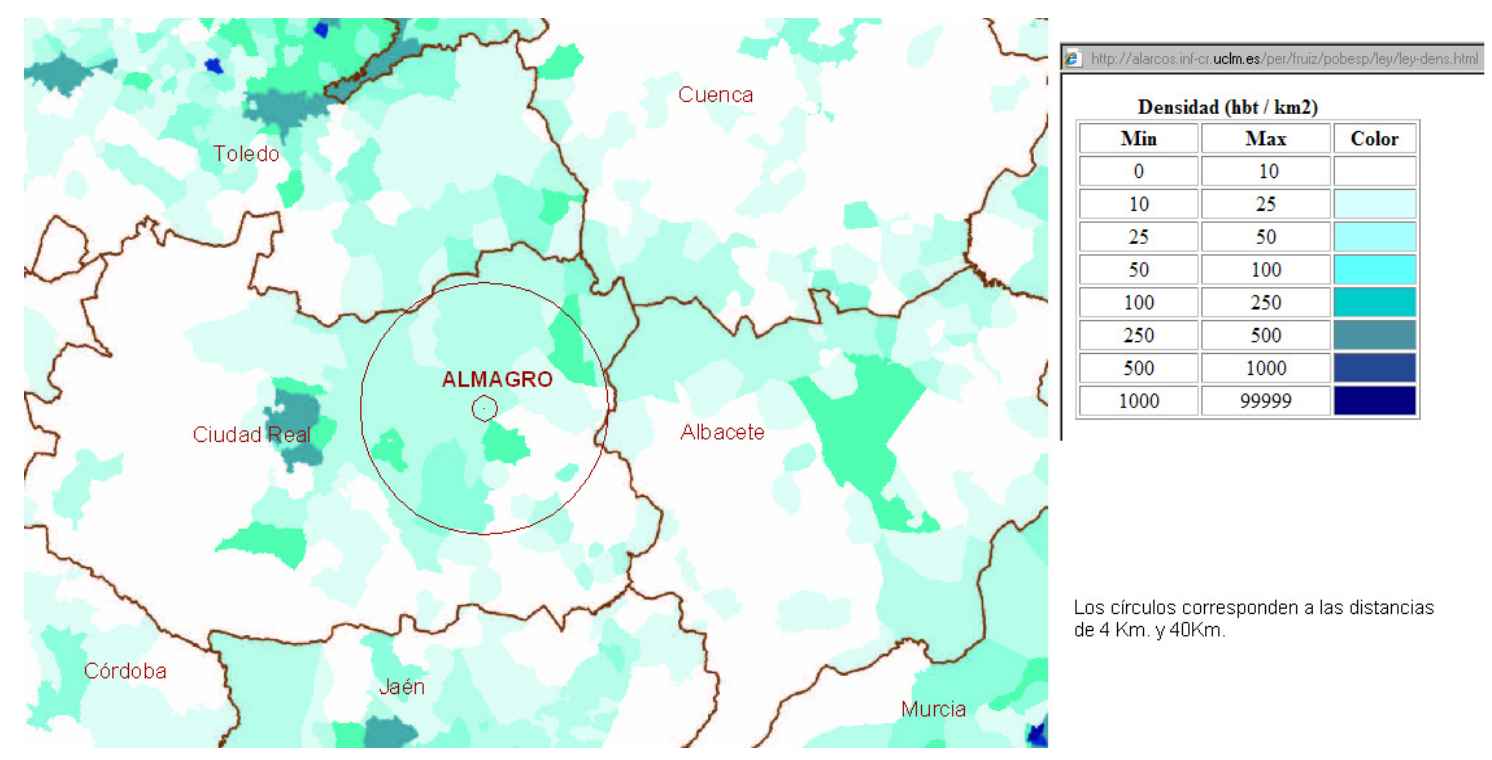

Figura 4.5. Ubicación de Almagro (fuente: elaboración propia)

Córdoba (Figura 4.6) con coordenadas geográfica son $\left(37,889940^{\circ}\right.$, $\left.4,785596^{\circ}\right)$

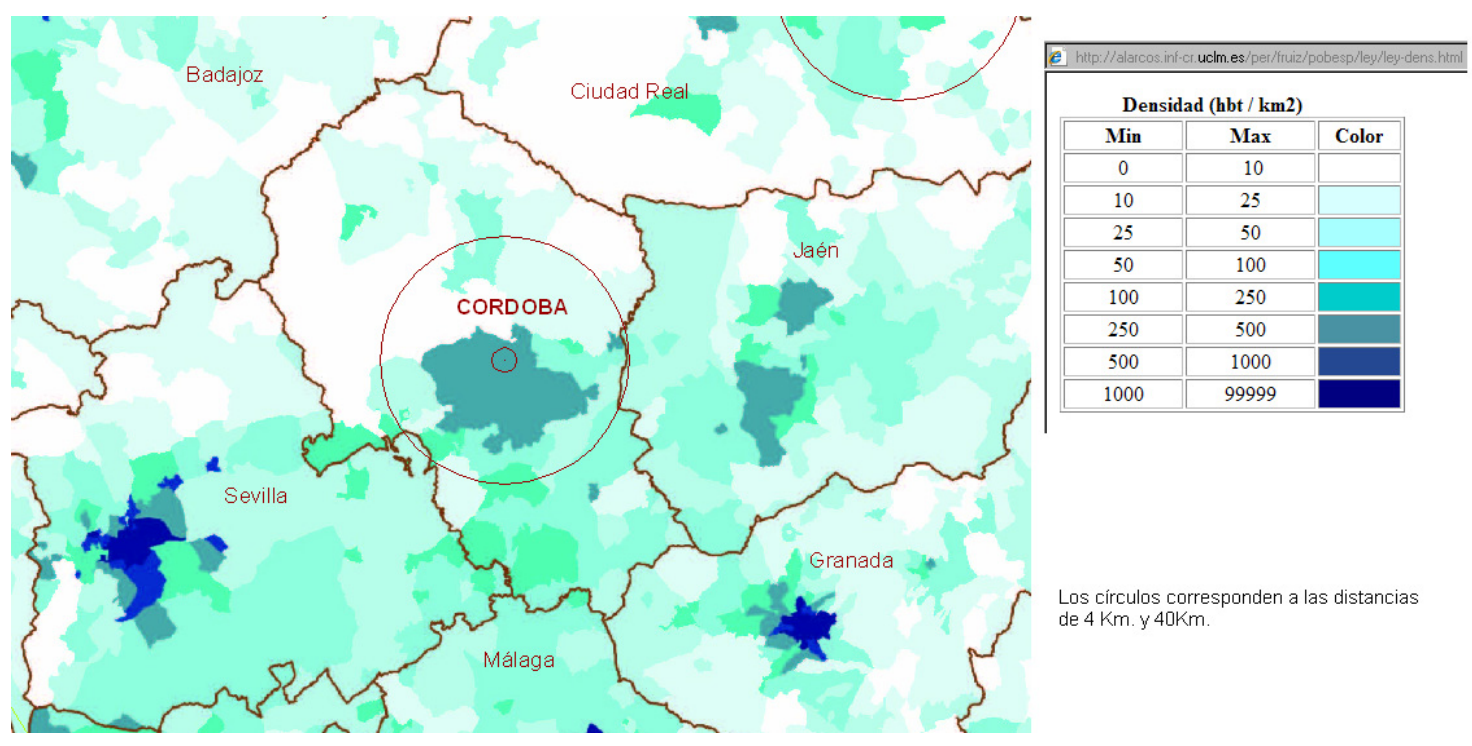

Figura 4.6. Ubicación de Córdoba (fuente: elaboración propia)

En la Tabla 4.2 pueden verse los distintos resultados del factor de localización obtenidos para cada una de las ubicaciones estudiadas:

- En el caso de Layna, el valor de $\mathbf{u}_{1}$ es el mínimo posible $(1,00)$. En Alares, Tembleque y Almagro se puede observar que, al resultar un valor prácticamente igual a la unidad, el número de habitantes no tiene en este caso relevancia real en cuanto a la aplicación del factor. 
- En el caso de Córdoba se incrementa ligeramente el valor del factor $\mathbf{u}_{1}$.

\begin{tabular}{cccccc} 
& LAYNA & ALARES & TEMBLEQUE & ALMAGRO & CÓRDOBA \\
\hline $\mathrm{P}_{1}$ & 1.909 & 95 & 2.390 & 8.855 & 298.839 \\
\hline $\mathrm{P}_{2}$ & 17.813 & 29.360 & 301.898 & 293.604 & 180.894 \\
\hline $\mathbf{u}_{1}$ & $\mathbf{1 , 0 0 7 8}$ & $\mathbf{1 , 0 0 9 8}$ & $\mathbf{1 , 1 0 3}$ & $\mathbf{1 , 1 0 6 7}$ & $\mathbf{1 , 3 5 9 1}$
\end{tabular}

Tabla 4.2. Valores de $u_{1}$ en otros municipios (fuente: elaboración propia)

\subsubsection{Conclusiones de los antecedentes del cálculo del factor de corrección}

Una vez obtenido el factor de corrección por accesibilidad a núcleos de población $\mathbf{u}_{1}$ en distintos puntos del territorio nacional se pudo observar que el coeficiente $\mathbf{u}_{1}$ siempre tiene un valor superior a 1 , aunque el incremento registrado tenga tan solo una magnitud infinitesimal.

El resumen de los datos obtenidos son los siguientes:

\begin{tabular}{ccccccc} 
& LEGANÉS & LAYNA & ALARES & TEMBLEQUE & ALMAGRO & CÓRDOBA \\
\hline $\mathrm{P}_{1}$ & 939.727 & 1.909 & 95 & 2.390 & 8.855 & 298.839 \\
\hline $\mathrm{P}_{2}$ & 5.436 .976 & 17.813 & 29.360 & 301.898 & 293.604 & 180.894 \\
\hline $\mathbf{u}_{\mathbf{1}}$ & $\mathbf{3 , 7 5}$ & $\mathbf{1 , 0 0 7 8}$ & $\mathbf{1 , 0 0 9 8}$ & $\mathbf{1 , 1 0 3}$ & $\mathbf{1 , 1 0 6 7}$ & $\mathbf{1 , 3 5 9 1}$
\end{tabular}

Tabla 4.3. Valores de $u_{1}$ de los puntos de estudio previo (fuente: elaboración propia)

Con la ayuda del mapa de España que refleja las densidades de población (Figura 4.1 del apartado 4.1.2 Aplicación a otros municipios), se representaron las ubicaciones en las que el coeficiente corrector $\mathbf{u}_{1}$ tendrían un valor superior a $2^{14}$. Para ello, se trazaron círculos de $4 \mathrm{Km}$. de radio representándose en la Figura 4.7 las ubicaciones donde el valor a aplicar al coeficiente $\mathbf{u}_{1}$ sería superior a $2^{14}$, esto es, aquellas en las que el factor de localización por accesibilidad a núcleos de población duplica, al menos, el resultado de la capitalización de las rentas de la explotación en el suelo rural. Como puede apreciarse, son los entornos próximos a las áreas metropolitanas de los municipios de Madrid, Barcelona, Sevilla y Valencia los que representan valores superiores.

\footnotetext{
${ }^{14}$ Representado por el límite máximo establecido por la Ley 8/2007 y anulado posteriormente por la STC 141/2014. 


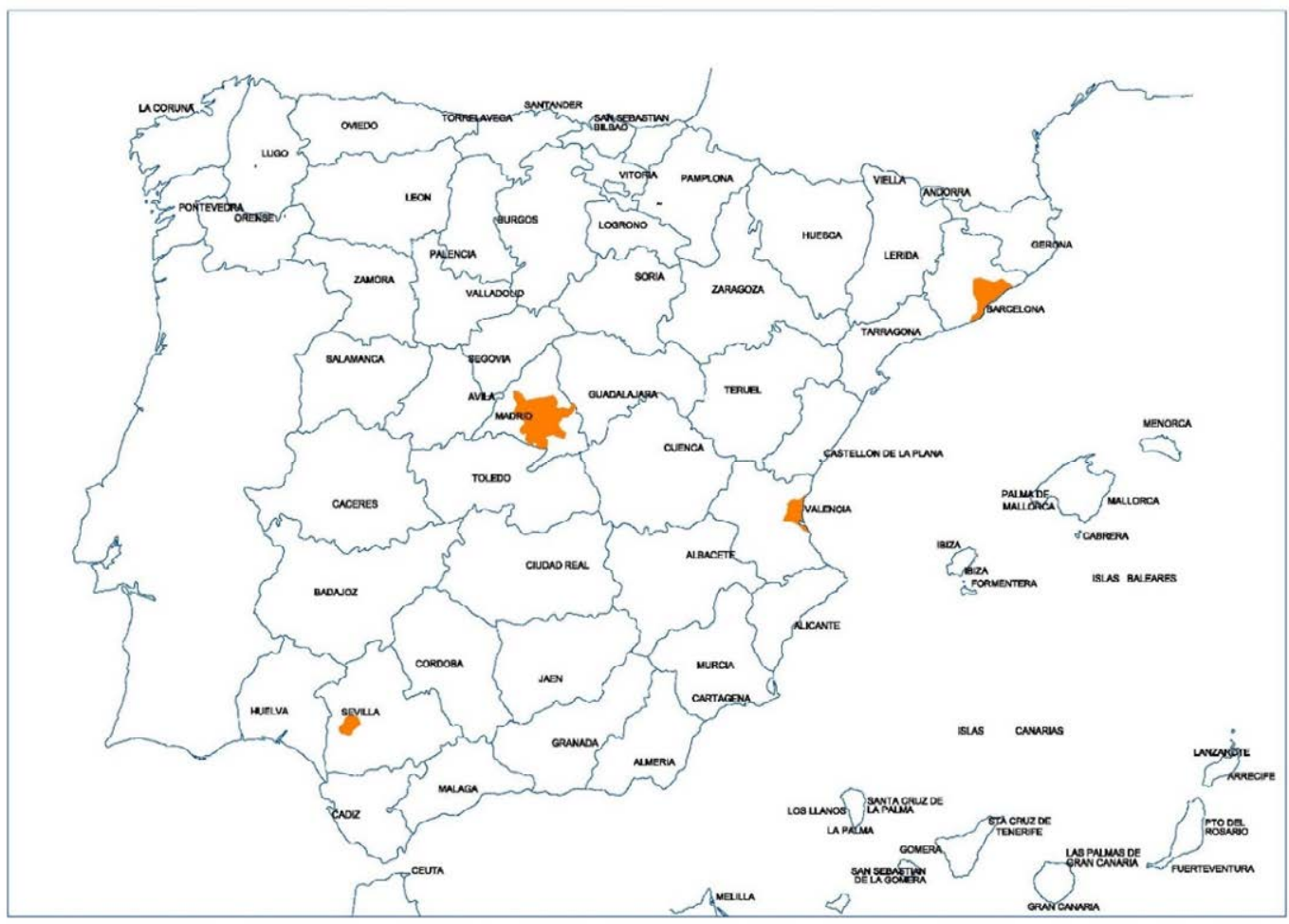

Figura 4.7. Valores de $u_{1}$ superiores a 2 en color naranja (fuente: elaboración propia)

En el estudio preliminar al que nos estamos refiriendo se analizaron también los resultados del cálculo del factor de localización de acuerdo con la formulación regulada en el Anteproyecto del RVLS 2011; de ello resultaba un mapa de España en el que se representaban los valores de $\mathbf{u}_{1}$ superiores a $2^{14}$ (Figura 4.8).

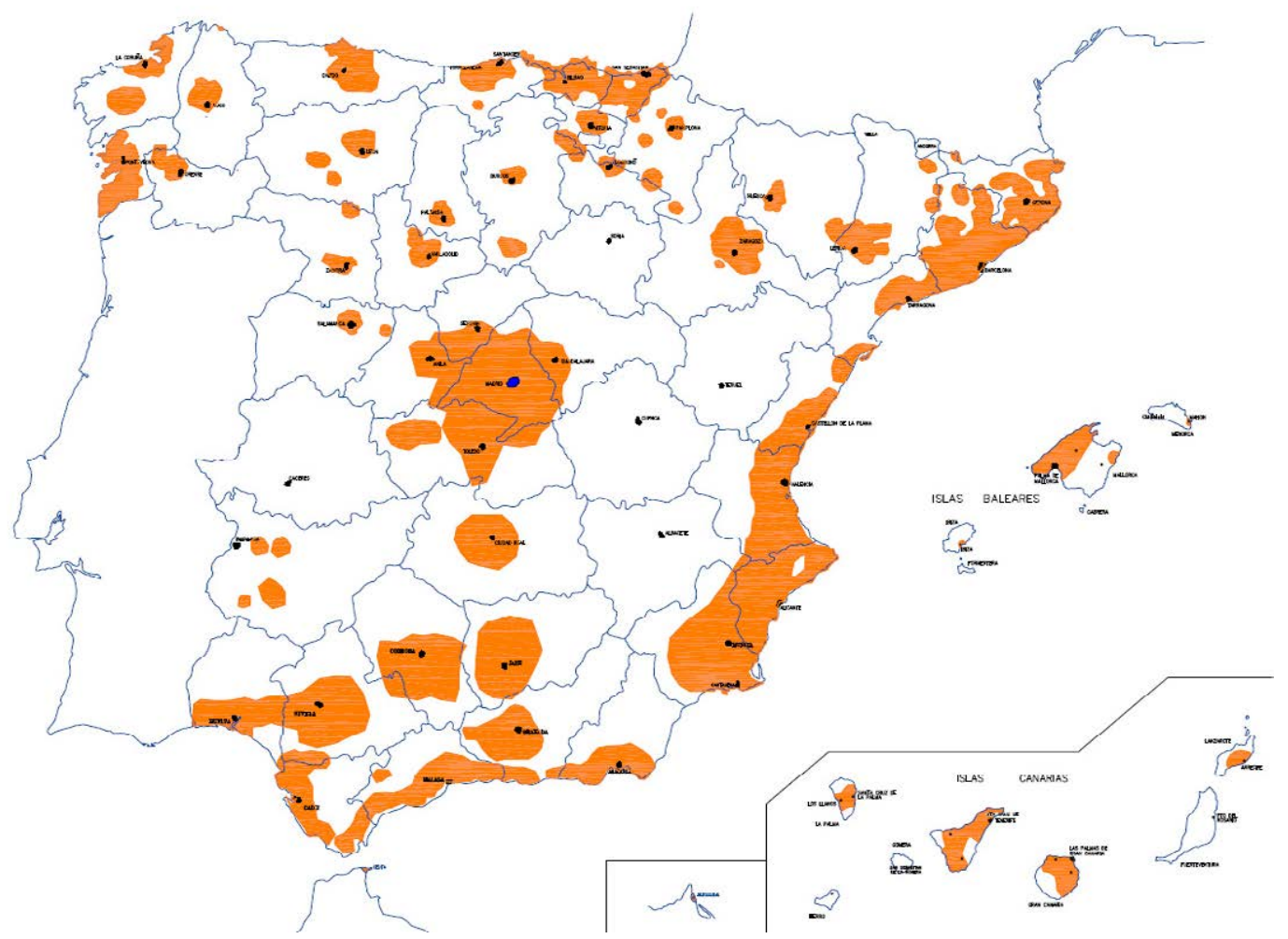

Figura 4.8. Valores de $u_{1}$ superiores a 2 en color naranja, según el Anteproyecto del RVLS 2011 (fuente: elaboración propia) 
Una cuestión relevante observada en el análisis preliminar es que ni el Anteproyecto del RVLS 2011, ni el propio Reglamento, reflejan el problema planteado con las localizaciones próximas a las fronteras y, de forma específica, si se debería tener en cuenta la población de los núcleos de población de nuestros países vecinos -Francia y Portugal- y con fronteras comunes con España. En concreto, la exclusión de la población de la localidades francesas y portuguesas próximas a las localizaciones españolas limítrofes, podrían derivar en una reducción ficticia del valor del coeficiente, que no refleja el valor añadido de la atracción de la población extranjera más próxima.

\subsection{LÍNEA METODOLÓGICA PARA EL CÁLCULO DEL FACTOR POR ACCESIBILIDAD A NÚCLEOS DE POBLACIÓN EN ESPAÑA}

Tras la experiencia de este análisis preliminar, realizado por medios manuales, se concluyó que para analizar con mayor precisión la evolución del factor de localización en función de la accesibilidad a núcleos de población era necesario realizar un estudio aplicado a la totalidad del territorio nacional. Para ello, el método manual utilizado no resultaba ni útil ni operativo.

En consecuencia, se consideró la posibilidad de utilizar una herramienta mucho más eficiente que el mero cálculo manual, en concreto un Sistema de Información Geográfica (SIG), resultado de la aplicación de las denominadas Tecnologías de la Información (TI) a la gestión de la Información Geográfica (IG)

En la actualidad gran parte de la información que utilizamos en nuestra vida diaria está georreferenciada; esto permite que a dicha información se le pueda asignar una posición geográfica, lo que facilita, a su vez, más información sobre la misma, relativa a su localización. Este aspecto resulta de vital interés en la investigación que se pretende realizar.

Una de las definiciones más significativas de los SIG la hace Bouille (1978), que definía de manera ilustrativa el SIG, como el "modelo informatizado del mundo real, descrito en un sistema de referencia ligado a la Tierra, establecido para satisfacer unas necesidades de información específicas respondiendo, del mejor modo posible, a un conjunto de preguntas concreto".

Un SIG, tal y como lo definían Burrough, P.A. y McDonnell, R. (1998), es "un potente conjunto de herramientas para recoger, almacenar, recuperar, transformar y visualizar datos geoespaciales del mundo real para un conjunto particular de propósitos" 
Una de las múltiples características de los SIG es que no se trata de una herramienta simplemente destinada a un almacenamiento de información geográfica, sino que permite analizar la información incluida en cada uno de los proyectos, así como realizar y obtener consultas de forma eficaz y rápida sobre la información contenida.

Por otro lado, con ayuda de la herramienta del SIG se ha realizado un estudio geoestadístico, generando una superficie continua a partir de un conjunto de puntos dispersos (interpolación espacial). La interpolación espacial generará superficies de fenómenos continuos en el espacio, realizando una predicción de los valores mediante la utilización del concepto de vecindad espacial. Esto permitirá obtener un valor a partir de un grupo de valores reales vecinos.

El flujo de trabajo desarrollado en esta investigación para la consecución de los objetivos, se representa en la Tabla 4.4. Inicialmente se delimita el área de estudio y se crea una base de datos (población, municipios...) que serán representados posteriormente en un SIG. Seguidamente se realiza el cálculo de los valores $P_{1}, P_{2}$ y $\mathbf{u}_{1}$, así como su geolocalización, para crear un modelo de superficie usando métodos geoestadísticos. 


\section{METODOLOGÍA}
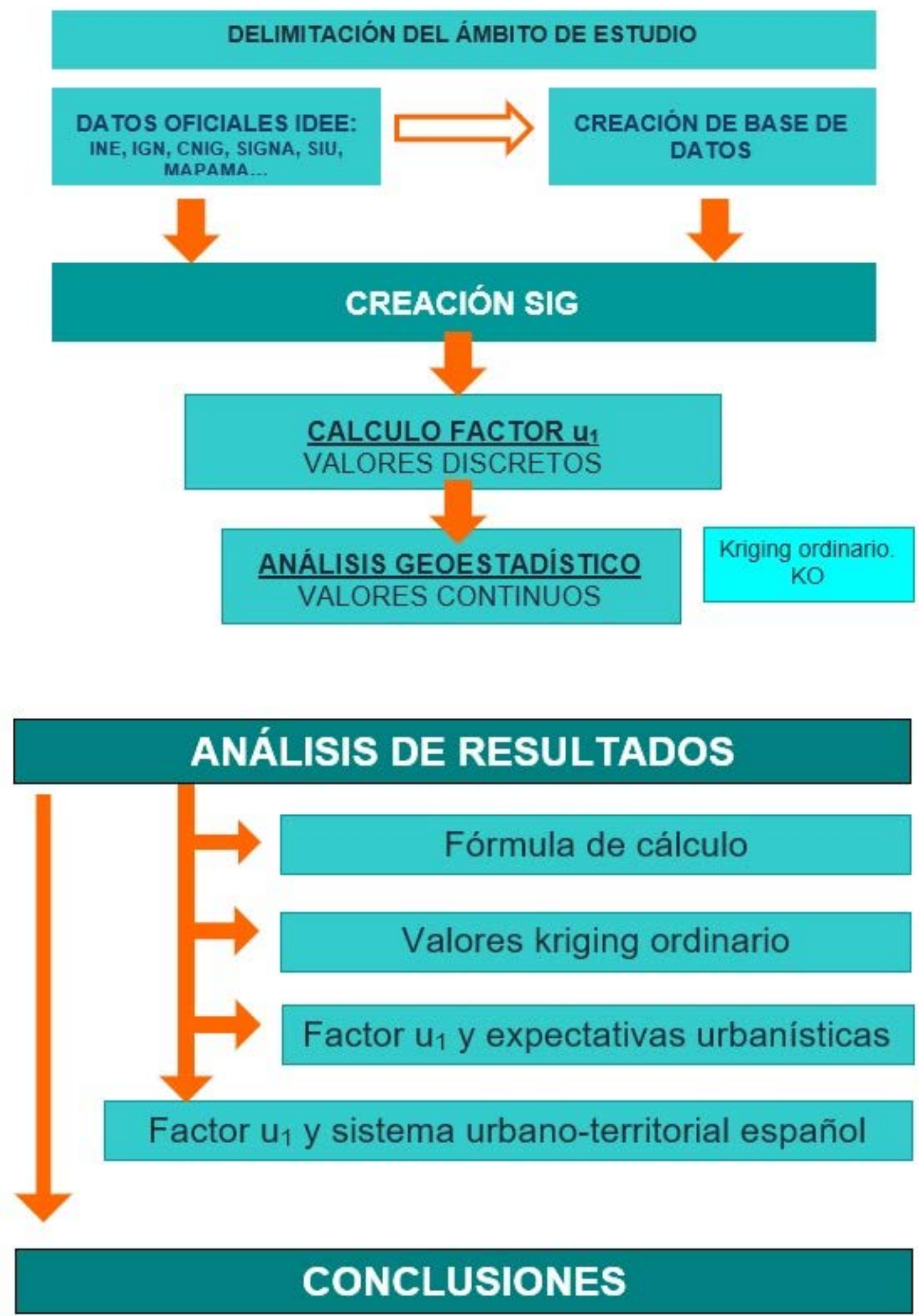

Tabla 4.4. Flujo de trabajo desarrollado en el estudio (fuente: elaboración propia) 


\subsubsection{Datos utilizados en el análisis}

Existen diferentes infraestructuras de datos espaciales (IDEs) disponibles para la descarga de datos. Una IDE integra datos, metadatos, servicios web (WMS, WFS, WCS ...) e información de tipo geográficos para promover su uso. Su objetivo es compartir la información geográfica en la red y ponerla a disposición de los usuarios. La información geográfica gestionada por una IDE se presenta en distintos formatos: ortofoto, imágenes de satélites, mapas, capas sig, etcétera.

La mayoría de la información necesaria para crear la base de datos del proyecto se ha descargado del portal de acceso a la información geográfica IDEE (Infraestructura de Datos Espaciales de España Figura 3.9). En dicho portal todos los datos son de acceso libre y se descargan de distintos organismos a través de sus portales IDE estatales, autonómicos o locales:

- Catálogo de metadatos de la Infraestructura de datos Espaciales de España del Ministerio de Fomento (IDE)

- Centro de Descargas del Centro Nacional de Información Geográfica (CNIG) del Instituto Geográfico Nacional (IGN) del Ministerio de Fomento.

- Sistema de Información Geográfica Nacional de España del IGN del Ministerio de Fomento (SIGNA).

- Sistema de Información Urbanística del Ministerio de Fomento (SIU)

- Banco de datos de la Naturaleza (BDN) del Ministerio de Agricultura, Alimentación y Medio Ambiente. 


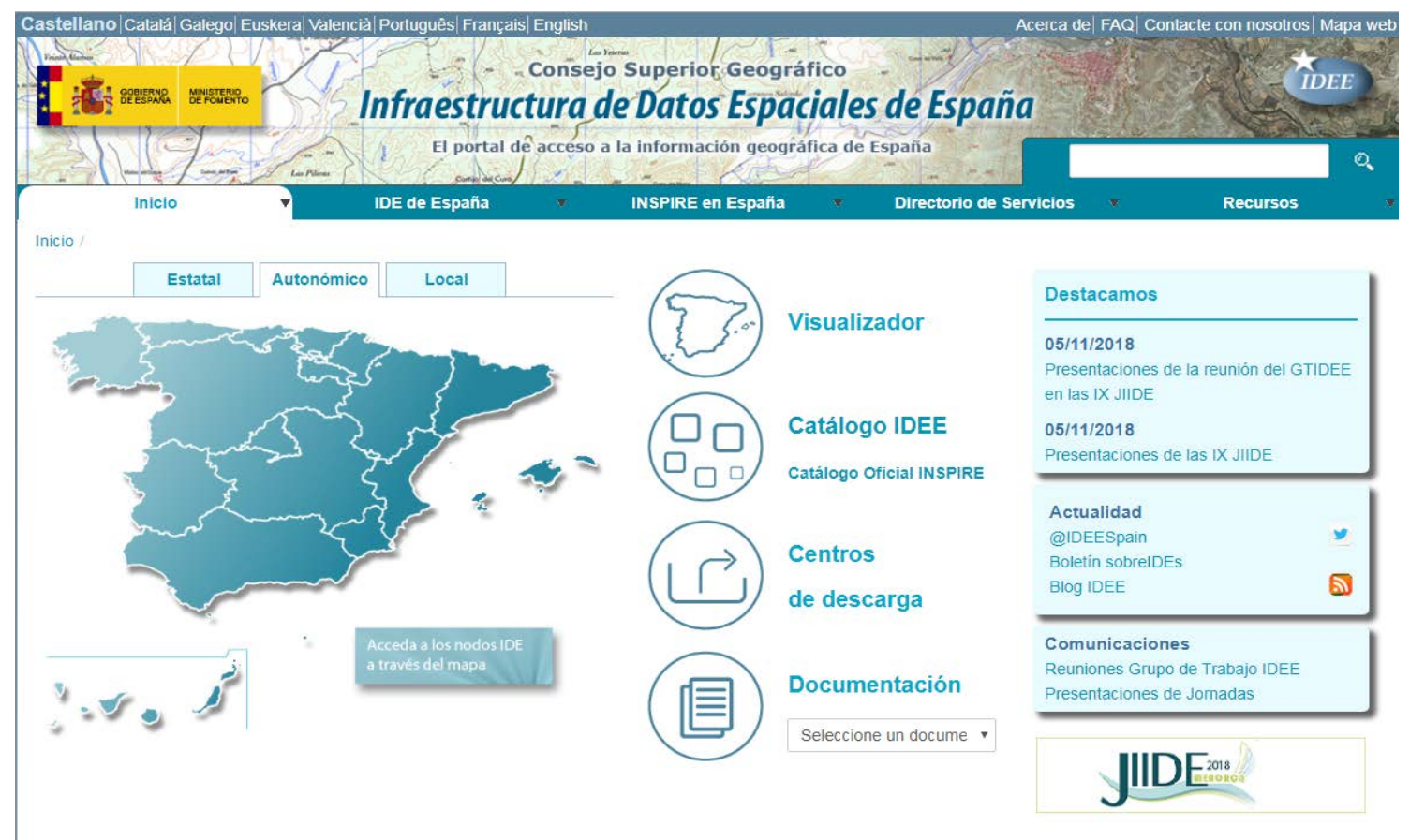

Figura 4.9. Infraestructura de datos espaciales (fuente: http://www.idee.es/)

Para la elaboración del SIG utilizado en este trabajo se han descargado datos de los siguientes organismos:

- Base cartográfica (Comunidades Autónomas, Provincias y Municipios). Datos fecha de referencia julio de 2015

- Datos de población de Municipios, Núcleos de Población y diseminado. Datos el Censo de población de 2011, último Censo publicado por el INE.

- Infraestructuras (Autopistas, Autovías, Carreteras, etc). Datos fecha de referencia julio de 2015

- Estaciones de ferrocarril. Datos fecha de referencia julio de 2015

- Aeropuertos. Datos fecha de referencia julio de 2015

- Puertos. Datos fecha de referencia julio de 2015

- Zonas Arqueológicas (SIGNA)

- Jardines Históricos (SIGNA)

- Parques Naturales (MAPAMA)

- LIC (MAPAMA)

- ZEPA (MAPAMA)

\subsubsection{Creación de la Base de Datos}

Para la creación del SIG y posterior análisis espacial se ha construido una base de datos con la información descargada. Los atributos de esta base de datos han sido catalogados según su geometría y ámbito de aplicación. En la Tabla 4.5 puede verse el nombre abreviado de los atributos, así como su descripción, tipo y categorización. 


\begin{tabular}{|c|c|c|c|c|c|}
\hline NOMBRE & GEOMETRÍA & ETIQUETA & DESCRIPCIÓN & TIPO & FUENTE \\
\hline $\mathrm{X}$ & Punto & $\begin{array}{c}\text { Coordenada } \\
\text { X }\end{array}$ & $\begin{array}{c}\text { Localización } \\
\text { geográfica. } \\
\text { Coordenada } \\
\text { horizontal. El } \\
\text { sistema utilizado } \\
\text { es: Sistema de } \\
\text { proyección (UTM). }\end{array}$ & Numérica & IGN \\
\hline Y & Punto & $\begin{array}{c}\text { Coordenada } \\
Y\end{array}$ & $\begin{array}{l}\text { Localización } \\
\text { geográfica. } \\
\text { Coordenada } \\
\text { vertical. El sistema } \\
\text { utilizado es: } \\
\text { (UTM). }\end{array}$ & Numérica & IGN \\
\hline$P_{1}$ & Punto & \begin{tabular}{|c|}
$\begin{array}{c}\text { Cantidad de } \\
\text { población a } 4 \\
\text { Km de cada } \\
\text { punto. }\end{array}$ \\
\end{tabular} & $\begin{array}{c}\text { Cantidad de } \\
\text { población a } 4 \mathrm{Km} \\
\text { de cada punto. }\end{array}$ & Numérica & $\begin{array}{c}\text { Elaboración } \\
\text { propia }\end{array}$ \\
\hline $\mathrm{P}_{2}$ & Punto & $\begin{array}{l}\text { Cantidad de } \\
\text { población a } \\
40 \mathrm{Km} \text { de } \\
\text { cada punto. }\end{array}$ & $\begin{array}{c}\text { Cantidad de } \\
\text { población a } 40 \mathrm{Km} \\
\text { de cada punto. }\end{array}$ & Numérica & $\begin{array}{l}\text { Elaboración } \\
\text { propia }\end{array}$ \\
\hline $\mathrm{u}_{1}$ & Punto & $\begin{array}{c}\text { Factor } \\
\text { corrección }\end{array}$ & \begin{tabular}{|c|}
$\begin{array}{c}\text { Valor del factor de } \\
\text { corrección }\end{array}$ \\
\end{tabular} & Numérica & $\begin{array}{c}\text { Elaboración } \\
\text { propia }\end{array}$ \\
\hline $\mathrm{Mu}$ & Polígono & Municipios & $\begin{array}{c}\text { Delimitación de los } \\
\text { Municipios de } \\
\text { España }\end{array}$ & Categórica & IGN \\
\hline CCAA & Polígono & $\begin{array}{c}\text { Comunidades } \\
\text { Autónomas }\end{array}$ & $\begin{array}{c}\text { Delimitación de las } \\
\text { Comunidades } \\
\text { Autónomas. }\end{array}$ & Categórica & IGN \\
\hline $\mathrm{Pr}$ & Polígono & Provincias & $\begin{array}{c}\text { Provincias de } \\
\text { España }\end{array}$ & Categórica & IGN \\
\hline PL & Polígono & $\begin{array}{l}\text { Países } \\
\text { Limítrofes }\end{array}$ & $\begin{array}{c}\text { Países colindantes } \\
\begin{array}{c}\text { Portugal, Francia y } \\
\text { Marruecos }\end{array} \\
\end{array}$ & Categórica & IGN \\
\hline PobNu & Polígono & $\begin{array}{c}\text { Cantidad de } \\
\text { Población }\end{array}$ & $\begin{array}{l}\text { Población } \\
\text { Entidades }\end{array}$ & Numérica & INE \\
\hline PobPL & Polígono & $\begin{array}{l}\text { Cantidad de } \\
\text { Población }\end{array}$ & $\begin{array}{l}\text { Población de los } \\
\text { países limítrofes, } \\
\text { Francia y Portugal }\end{array}$ & Numérica & INE \\
\hline DPob & Polígono & $\begin{array}{l}\text { Densidad de } \\
\text { Población }\end{array}$ & & Numérica & INE \\
\hline $\mathrm{AU}$ & Polígono & $\begin{array}{c}\text { Áreas } \\
\text { urbanas }\end{array}$ & $\begin{array}{l}\text { Delimitación de } \\
\text { Áreas urbanas }\end{array}$ & Categórica & SIU \\
\hline SUC & Polígono & $\begin{array}{l}\text { Suelo urbano } \\
\text { consolidado }\end{array}$ & Delimitación SUC & Categórica & SIU \\
\hline SUNC & Polígono & \begin{tabular}{|c|} 
Suelo urbano \\
No \\
consolidado \\
\end{tabular} & $\begin{array}{l}\text { Delimitación } \\
\text { SUNC }\end{array}$ & Categórica & SIU \\
\hline
\end{tabular}




\begin{tabular}{l|c|c|c|l|c}
\hline SUS & Polígono & $\begin{array}{c}\text { Suelo } \\
\text { urbanizable } \\
\text { sectorizado }\end{array}$ & Delimitación SUS & Categórica & SIU \\
\hline SUNS & Polígono & $\begin{array}{c}\text { Suelo } \\
\text { urbanizable } \\
\text { no } \\
\text { sectorizado }\end{array}$ & $\begin{array}{c}\text { Delimitación } \\
\text { SUNS }\end{array}$ & Categórica & SIU \\
\hline SNU & Polígono & $\begin{array}{c}\text { Suelo no } \\
\text { urbanizable }\end{array}$ & Delimitación SNU & Categórica & SIU \\
\hline Corredores & Líneas & $\begin{array}{c}\text { Carreteras, } \\
\text { autopistas, } \\
\text { autovías }\end{array}$ & Red de Carreteras & Categórica & IGN \\
\hline
\end{tabular}

Tabla 4.5.-Base de datos con las propiedades de los atributos del estudio (fuente: elaboración propia)

Con esta base de datos espacial se procedido a calcular, estudiar y analizar los datos obtenidos que constituyen el contenido de esta investigación.

\subsubsection{Creación del Sistema de Información Geográfica (SIG)}

La base de datos descrita en el punto anterior se ha georreferenciado en un Sistema de Información Geográfica. El software utilizado ha sido ArcGIS en su versión 10.6, que consiste en un sistema de información que conecta mapas, aplicaciones y datos en este caso, distancias y número de habitantes- y permite una gestión más eficiente del proceso de tomas de decisiones. El ámbito de trabajo abarca la totalidad del territorio nacional. Previamente a realizar los procesos de análisis todos los datos se pusieron en el mismo sistema de referencia para poder realizar posteriormente las consultas.

\subsubsection{Puntos para el cálculo}

Para el cálculo del factor $\mathbf{u}_{1}$ se creó inicialmente una malla de 50 x $50 \mathrm{Km}$. por lo que, colocando un punto en la intersección de las líneas de la cuadrícula, se obtuvieron 392 puntos (Figura 4.10). Se tomó esta dimensión inicial de la malla para evitar interferencias entre los círculos que era necesario trazar con un radio de $40 \mathrm{Km}$ para la obtención del valor $\mathrm{P}_{2}$ de la fórmula del cálculo del coeficiente $\mathbf{u}_{1}$. 


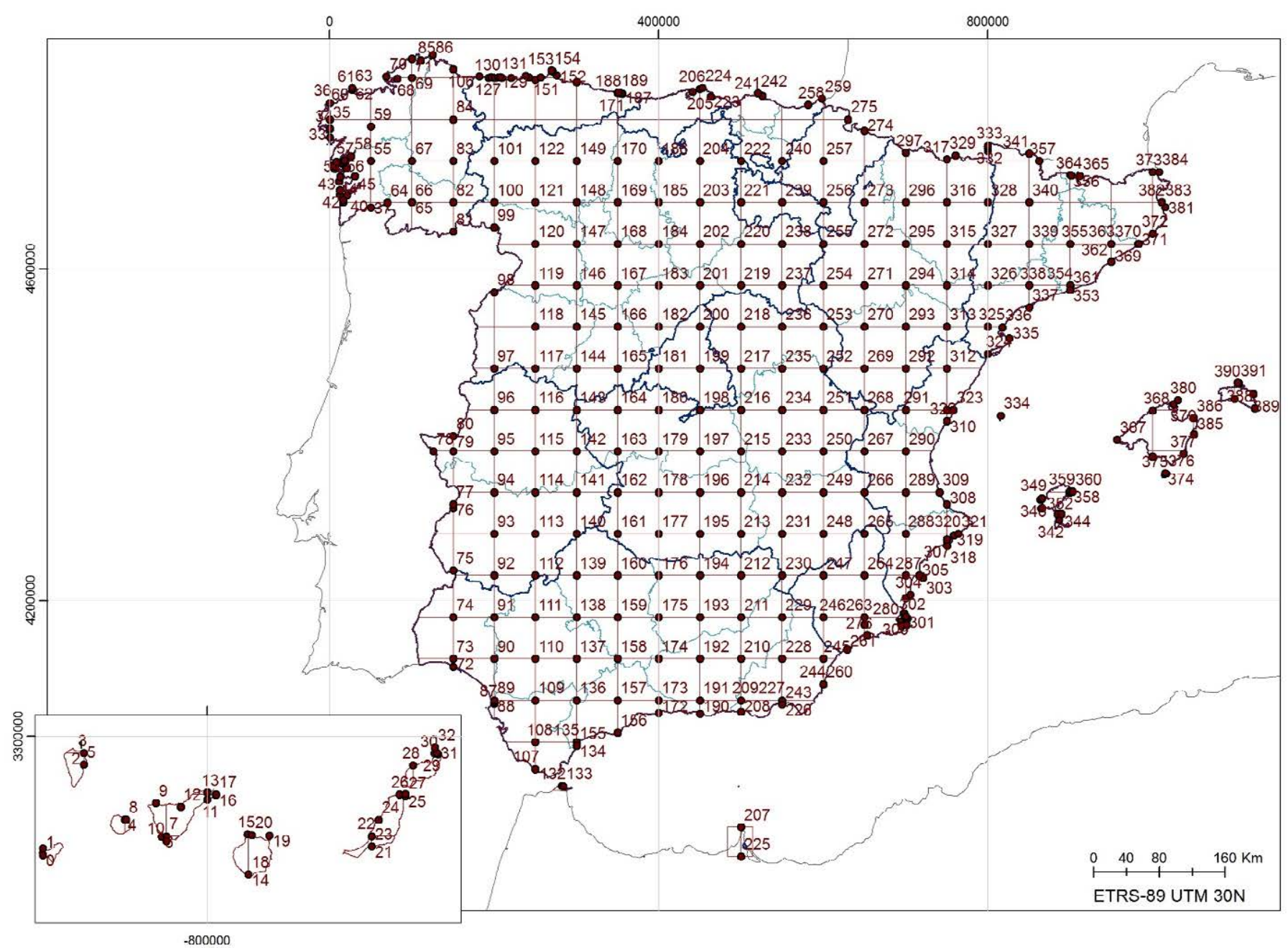

Figura 4.10. - Cuadrícula 50x50 y 392 puntos (fuente: elaboración propia)

Posteriormente, para el estudio del factor de corrección por accesibilidad a núcleos de población $\mathbf{u}_{1}$ se introdujeron nuevos puntos en los centroides de la malla inicial de $50 \mathrm{x}$ $50 \mathrm{Km}$ y se crearon nuevas mallas consistentes en módulos de distintas dimensiones

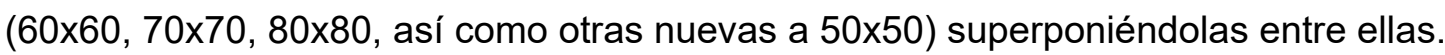

En el cuadro adjunto, se recogen los diferentes puntos y cuadrículas en diferentes fases del desarrollo de la investigación, y en la Figura 4.11, se aprecian las distintas cuadrículas:

\begin{tabular}{cccc} 
Otros & Cuadrícula & \multicolumn{1}{c}{ Puntos } & No de puntos $^{\circ}$ \\
\hline Puntos iniciales & & & 8 \\
\hline & $50 \times 50$ & Vértice cuadrícula & 392 \\
\hline $60 \times 60$ & Vértice cuadrícula & 168 \\
\hline $60 \times 60$ & Centroides cuadrícula & 175 \\
\hline $70 \times 70$ & Vértice cuadrícula & 115 \\
\hline $70 \times 70$ & Centroides cuadrícula & 121 \\
\hline
\end{tabular}




\begin{tabular}{lclc}
\hline & $80 \times 80$ & Vértice cuadrícula & 223 \\
\hline 10 poca población & & & 10 \\
\hline nueva cuadrícula & $50 \times 50$ & Vértice cuadrícula & 219 \\
\hline nueva cuadrícula & $50 \times 50$ & Centroides cuadrícula & 212 \\
\hline Cercano a ciudades & & & 133 \\
\hline Cercano a ciudades & & & 200 \\
\hline TOTAL & & 1.976
\end{tabular}

Tabla 4.6. Puntos obtenidos para el cálculo de $\boldsymbol{u}_{1}$ (fuente: elaboración propia)
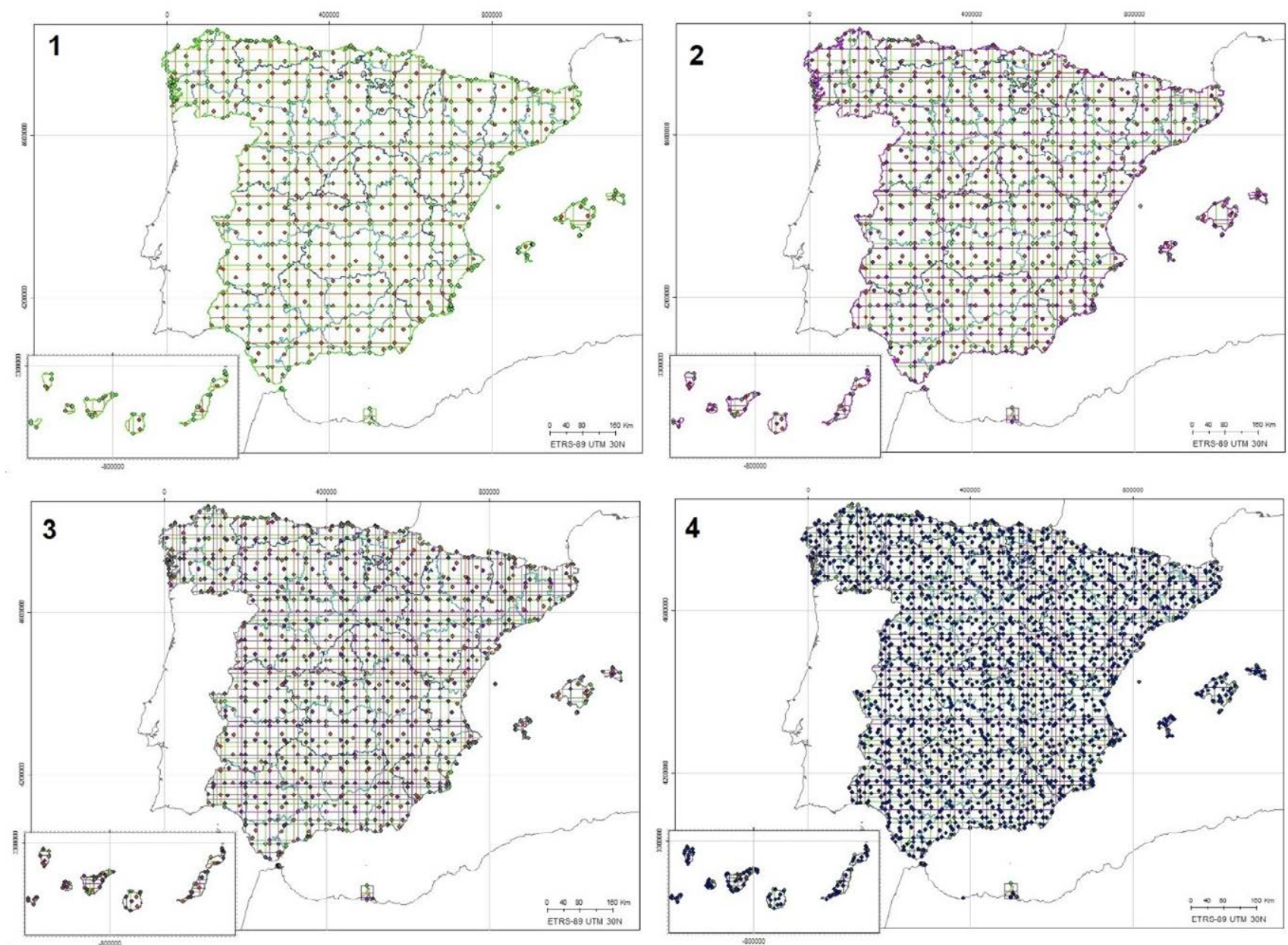

Figura 4.11.- Distintas cuadrículas en el desarrollo:

1.- Cuadrícula $50 \times 50$ vértices y $60 \times 60$ vértices y centroides.

2.- igual que 1 y $70 \times 70$ vértices y centroides.

3.- igual que 2 y $80 \times 80$ vértices.

4.- igual que 3 y nuevo $50 \times 50$ vértices y centroides

(fuente: elaboración propia)

De los 1.976 puntos resultantes se descartaron 140 puntos por interferir en los cálculos a realizar, además de los puntos repetidos, resultando un total de 1.836 puntos. 


\subsubsection{Población}

En el cálculo del factor $\mathbf{u}_{1}$ el dato de población requerido es el del número de habitantes situados a las distancias reguladas en el artículo 24.2 del RVLS 2011 de las diferentes ubicaciones, no la densidad de población que exista en el entorno de dicha ubicación.

La utilización del número de habitantes simplifica los cálculos, pero dificulta la representación gráfica de los resultados, a diferencia de las densidades de población, cuyo cálculo se realiza en una extensión concreta, fácilmente representable mediante una cartografía temática de coropletas (Figura 4.12). Ello permite una forma de cartografiado cuantitativo para la representación de fenómenos discretos asociados a unidades de enumeración (provincias, regiones, comunidades autónomas...), a las que se aplican símbolos superficiales de acuerdo con su valor.

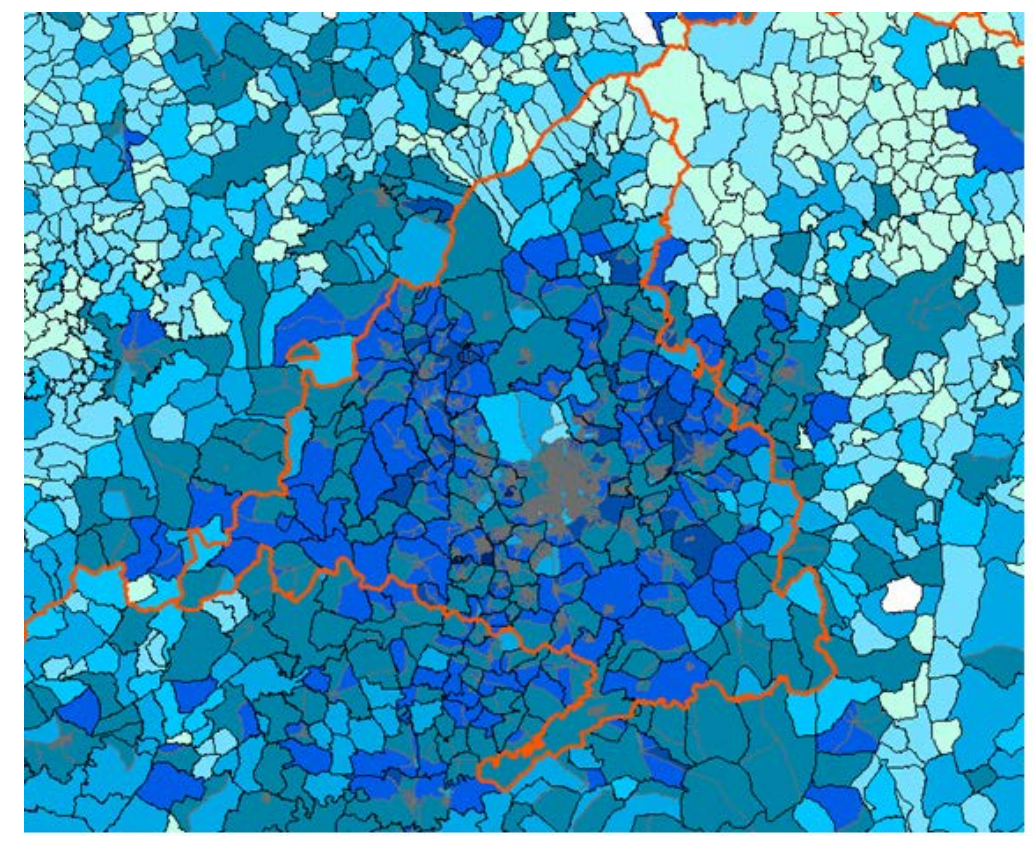

\section{Densidad población ( $n^{\circ}$ habitantes)}

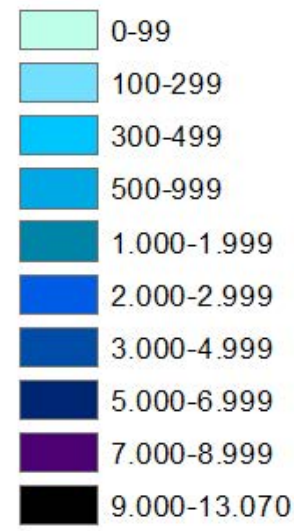

Figura 4.12. Coropletas población Comunidad de Madrid y alrededores (fuente: elaboración propia)

Por otro lado, debido a que el cálculo del factor de corrección $\mathbf{u}_{1}$ se debe considerar aplicado a una posición concreta y que la cantidad de habitantes se toma dentro de unas distancias determinadas (4 y $40 \mathrm{Km}$.), ha sido necesario determinar la ubicación real de la población en el espacio físico, con el fin de no interferir en los resultados a obtener.

Por ello se han utilizado los datos estadísticos proporcionados por el Instituto Nacional de Estadística (INE) y, en concreto se ha utilizado el Censo de población de 2011, que 
es el último Censo publicado por el INE.

EI INE facilita los datos de población, en diferentes unidades poblacionales, que define en su informe metodológico estandarizado de la siguiente forma ${ }^{15}$ :

"Entidad singular: se entiende por entidad singular de población cualquier área habitable del término municipal, habitada o excepcionalmente deshabitada, claramente diferenciada dentro del mismo, y que es conocida por una denominación específica que la identifica sin posibilidad de confusión.

Núcleo de población: se considera núcleo de población a un conjunto de al menos diez edificaciones, que están formando calles, plazas y otras vías urbanas. Por excepción, el número de edificaciones podrá ser inferior a 10, siempre que la población que habita las mismas supere los 50 habitantes. Se incluyen en el núcleo aquellas edificaciones que, estando aisladas, distan menos de 200 metros de los límites exteriores del mencionado conjunto, si bien en la determinación de dicha distancia han de excluirse los terrenos ocupados por instalaciones industriales o comerciales, parques, jardines, zonas deportivas, cementerios, aparcamientos y otros, así como los canales o ríos que puedan ser cruzados por puentes. Las edificaciones o viviendas de una entidad singular de población que no pueden ser incluidas en el concepto de núcleo se consideran en diseminado. Una entidad singular de población puede tener uno o varios núcleos, o incluso ninguno, si toda ella se encuentra en diseminado. Ninguna vivienda puede pertenecer simultáneamente a dos o más núcleos, o a un núcleo y un diseminado.

Diseminado: las edificaciones o viviendas de una entidad singular de población que no pueden ser incluidas en el concepto de núcleo de población se consideran en diseminado.

Entidad colectiva: como unidad intermedia entre la entidad singular de población y el municipio existen, en algunas regiones, agrupaciones de entidades singulares, (parroquias, hermandades, concejos, diputaciones, y otras), que conforman una entidad colectiva de población con personalidad propia y un origen marcadamente histórico.

De este modo, en el estudio de la población se han considerado 34.180 unidades poblaciones formadas por entidades singulares, núcleos de población, diseminados y entidades colectivas.

\section{${ }^{15}$ Fuente:}

http://www.ine.es/dyngs/INEbase/es/operacion.htm?c=Estadistica_C\&cid=1254736177010\&menu=metodo logia\&idp=1254734710990\# 
A diferencia de la metodología utilizada en los estudios preliminares, en los que solamente se tenía en cuenta la población de los núcleos de población facilitados por el INE, los cálculos obtenidos en la presente investigación resultan más exactos, al tomar toda la información disponible sobre el número de habitantes, considerando todas las entidades de población que recoge el INE. Como puede apreciarse en la Figura 4.13 el mayor número de entidades de población se localiza, tal y como veremos más adelante, en la zona de Madrid, Barcelona, Valencia y Sevilla.

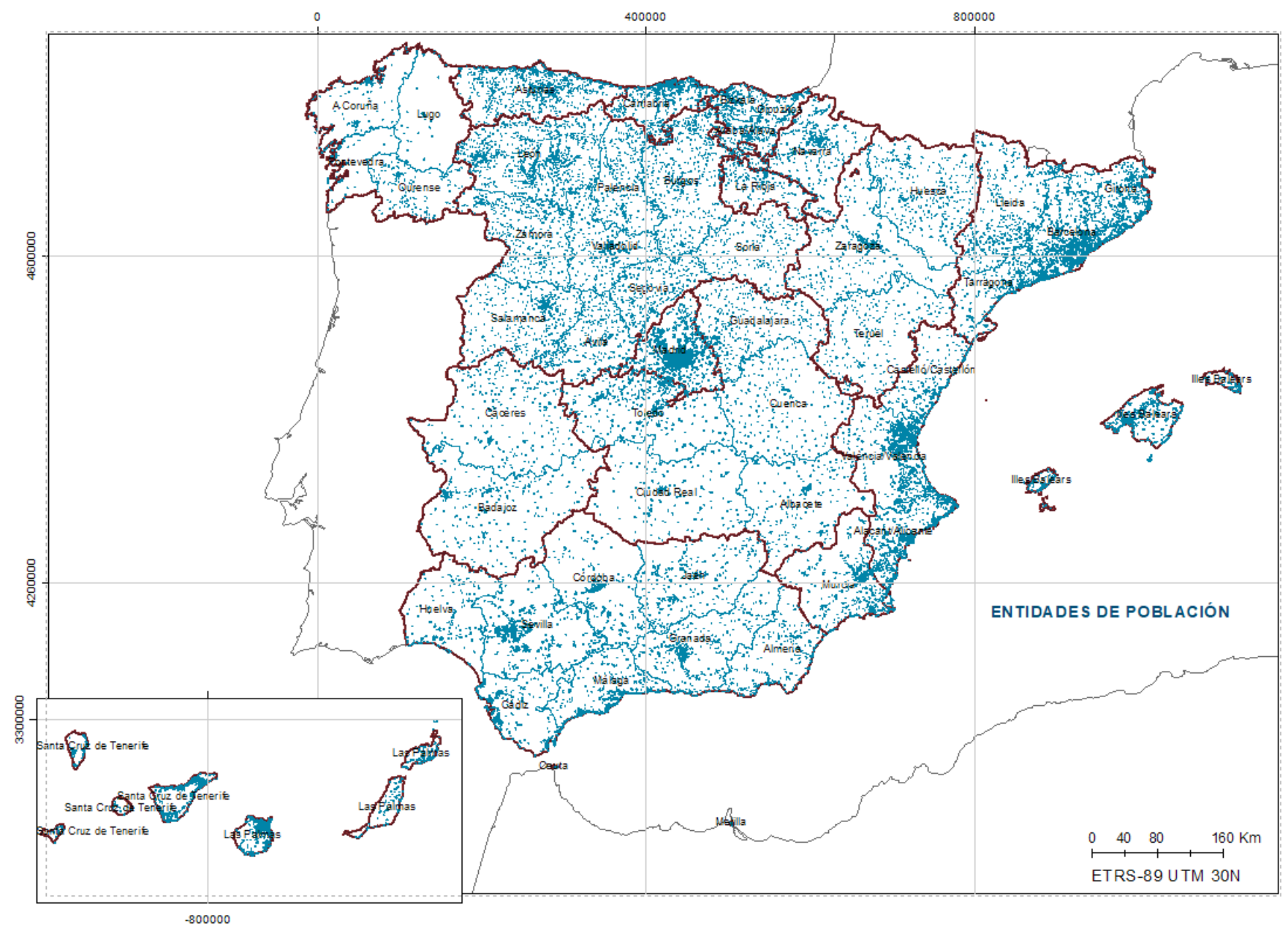

Figura 4.13. Entidades de población España (fuente: elaboración propia)

Del mismo modo que se obtuvo la información de España a través del IDEE para la obtención de los datos de población y entidades de poblacionales se utilizaron los portales IDE de Francia y Portugal. Así se obtuvieron datos para el estudio sobre el número de habitantes situados en los países limítrofes, que permitieran detectar la influencia de la población no situada en territorio español. 


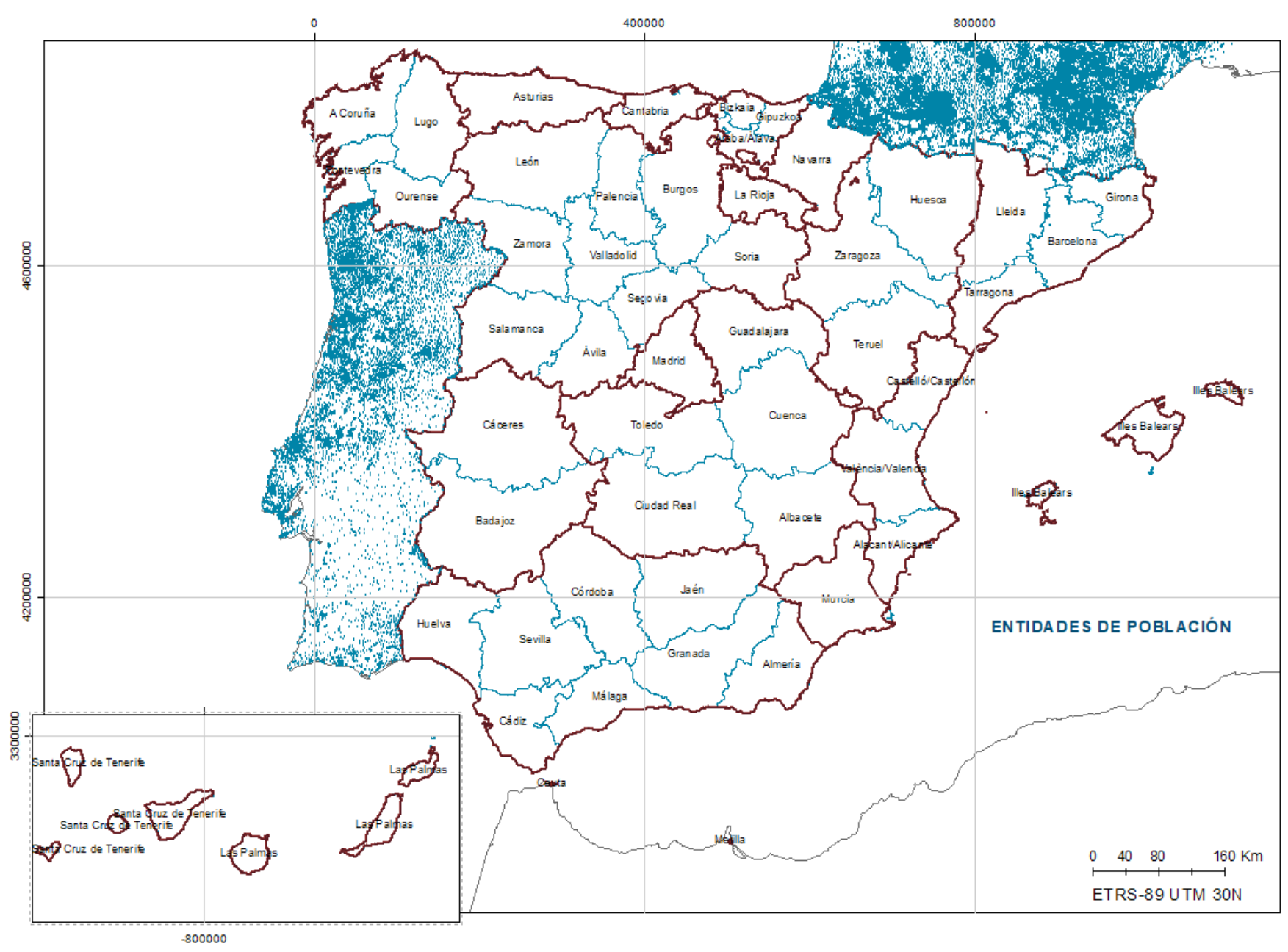

Figura 4.14. Entidades de población Francia y Portugal (fuente: elaboración propia)

\subsubsection{Clasificación urbanística del suelo}

Para poder analizar si el valor alcanzado para el factor de corrección $\mathbf{u}_{1}$ se corresponde con el incremento generado por las expectativas urbanísticas en el valor de suelo en situación básica rural, se ha analizado la relación existente con la clasificación urbanística del suelo. Para ello, se ha utilizado la información facilitada por el Ministerio de Fomento a través del Sistema de Información Urbana (SIU).

EI SIU es un sistema público general e integrado de información que, en cumplimiento de la Disposición adicional primera del TRLSRU 2015, se ha desarrollado por el Ministerio de Fomento en colaboración con las Comunidades Autónomas con el principal objetivo de promover la transparencia en materia de suelo y urbanismo en toda España.

Este Sistema ofrece en la actualidad información urbanística de 4.157 municipios que representan el $92,2 \%$ de la población y el $99,9 \%$ de las áreas urbanas. 
Para llevar a cabo el análisis del incremento de valor generado por las expectativas de desarrollo futuro, se ha partido de las siguientes clasificaciones urbanísticas de suelo:

- Suelo urbano consolidado (en adelante SUC).

- Suelo urbano no consolidado (en adelante SUNC).

- Suelo urbanizable sectorizado (en adelante SUS).

- Suelo urbanizable no sectorizado (en adelante SUNS).

No se ha considerado el Suelo no urbanizable (en adelante SNU) ya que, si bien esta clase urbanística de suelo es objeto de valoración mediante la capitalización de la renta por tratarse de suelo en situación básica rural, no genera potencialmente, por su propia naturaleza, expectativa urbanística alguna.

Por otro lado, se ha considerado el suelo urbano consolidado (SUC) en el análisis, ya que, a pesar de tratarse de una clasificación urbanística que el TRLSRU 2015 la considera de forma implícita en situación básica urbanizada y en consecuencia, en su valoración no se tiene en cuenta el factor de corrección por accesibilidad a núcleos de población $\mathbf{u}_{1}$, parece razonable considerar que esta clase urbanística de suelo debería tener el mayor valor del factor de localización, al tratarse de un suelo donde podrían ser mayores las expectativas urbanísticas, por estar ya desarrollado.

La información disponible en el SIU no permite realizar el análisis de la relación del factor $\mathbf{u}_{1}$ con las expectativas urbanísticas extendido a todo el territorio nacional, como hubiera sido deseable. Como se ha indicado, el SIU dispone de información urbanística de 4.157 municipios, que representan el 51,2\% del total de los existentes, que cuentan con el $92,2 \%$ de la población de España, por lo que la clasificación urbanística del suelo de la diferencia ( $48,8 \%$ de los municipios) no está recogida en el SIU. Por ello, tal y como se observa en la Figura 4.15, hay diferentes zonas del mapa en las que no se representa la clasificación urbanística de suelo. 


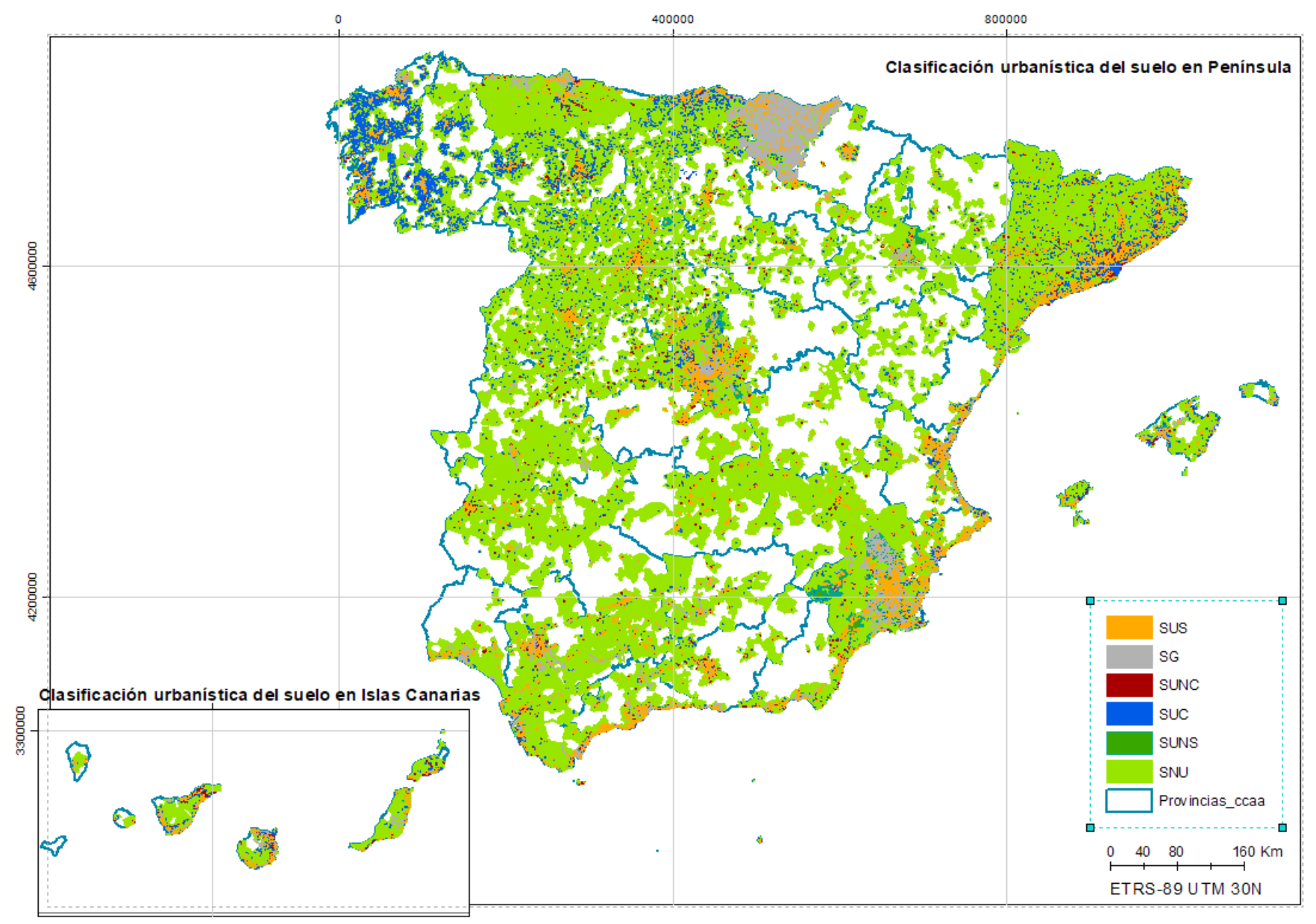

Figura 4.15 Datos facilitados SIU sobre clasificación de suelo (fuente: elaboración propia)

\subsubsection{4 Áreas urbanas}

Como se recogía en el apartado 3.4.3 en la investigación realizada se han tomado las "grandes áreas urbanas" de acuerdo con la denominación atribuida por el Ministerio de Fomento, que están formadas por municipios o conjuntos de municipios de al menos 50.000 habitantes. Tal y como se recoge en el SIU, se han incluido Soria y Teruel dentro de estas áreas, debido a su condición de capitales de provincia, a pesar de tener una cantidad de población inferior a 50.000 habitantes en el año 2010 , ya que actúan como verdaderos centros urbanos de su entorno.

Del total de los 8.125 municipios existentes en el año $2.016,753$ forman parte de las 86 "grandes áreas urbanas", con un total de 32 millones de habitantes. ${ }^{16} \mathrm{Si}$ bien la cantidad de municipios que conforman las grandes áreas urbanas suponen un $9.27 \%$ de los municipios españoles, el porcentaje de población que contienen es del 69,08\%. En la Figura 4.16. se puede observar la distribución de estas áreas categorizadas por

16 Datos obtenidos http://atlasau.fomento.gob.es/. Correspondiente al documento "Áreas urbans en España 2017" 
la cantidad de población. Se han categorizado en 3 clases, las que tienen una población entre 1.000.000 de habitantes y el máximo (6.018.681) en la que se encuentran 4 grandes áreas urbanas, Madrid, Barcelona, Valencia y Sevilla.

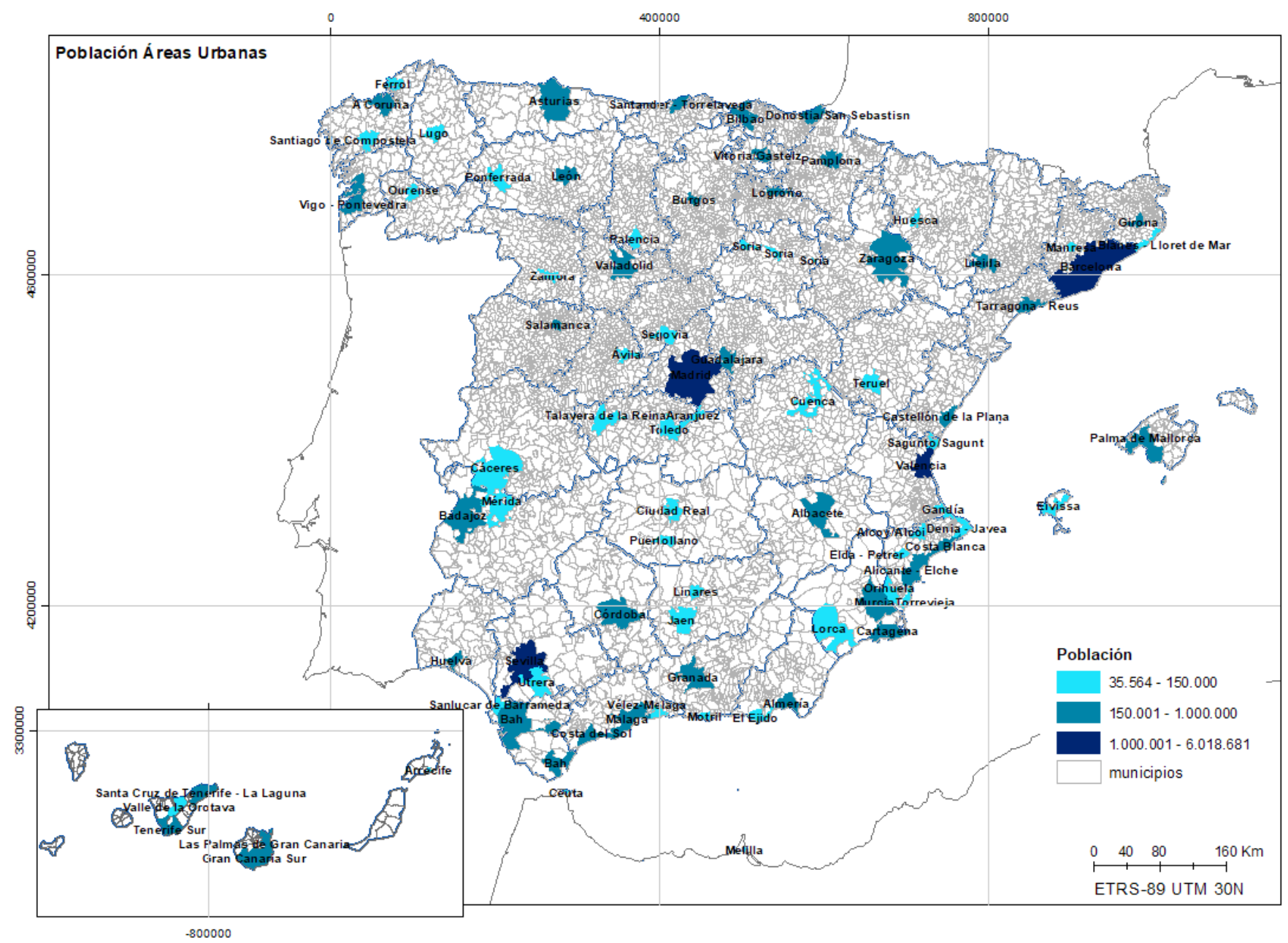

Figura 4.16. Áreas urbanas del territorio nacional categorizadas por población (fuente: elaboración propia)

Igualmente se han categorizado en segmentos con los siguientes criterios:

1. Por su extensión superficial en $\mathrm{Ha}$, donde se observa que las grandes áreas urbanas con mayor extensión superficie son Madrid, Barcelona y Zaragoza. Figura 4.17.1

2. Por su densidad de población medida en habitantes por Ha, destacando las grandes áreas de Ceuta y Melilla, debido a que son las de menor extensión superficial, seguidas de Arrecife (con una situación muy similar a Ceuta y Melilla), Valencia y Madrid. 

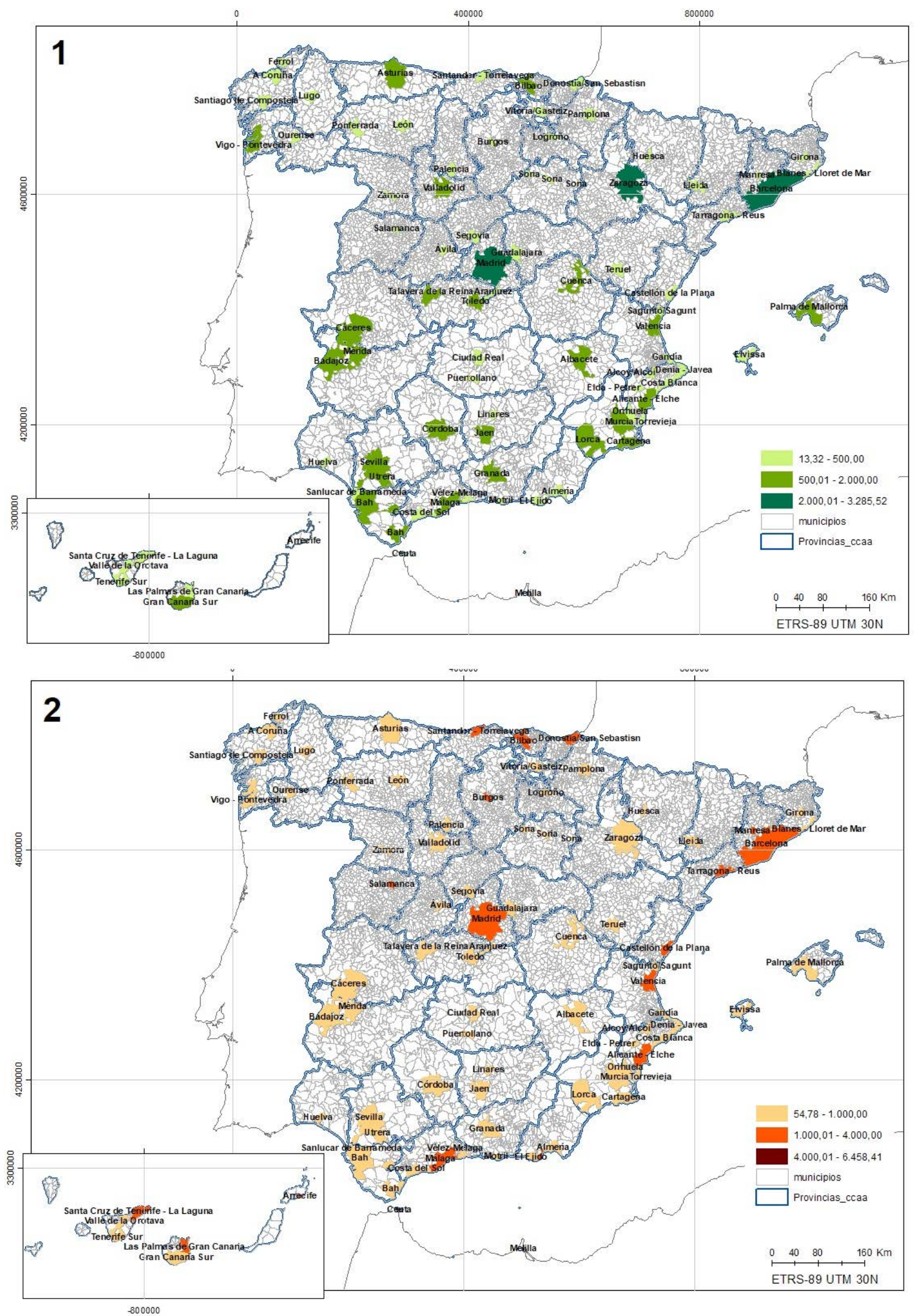

Figura 4.17. Áreas urbanas del territorio nacional categorizadas por: 1.-superficie (Ha) y 2.densidad (habitantes/Ha) (fuente: elaboración propia) 
En la distribución espacial de la densidad de población (número de habitantes/Ha) de grandes áreas urbanas se observa que gran número de ellas están situadas en la costa.

\subsubsection{Canales de relación - Flujos - El Sistema de Comunicación}

Tal y como se ha indicado en el apartado 3.4.4 el sistema de carreteras en España está formado tanto por las carreteras del Estado como por las gestionadas por la Comunidades Autónomas y Diputaciones.

En este estudio se ha tomado la red de Carreteras del Estado como simplificación al sistema de comunicaciones ya que se estima que su capacidad y potencial de conexión es fundamental en la estructura del sistema de conexiones y, por tanto, suficiente para el análisis de los resultados.

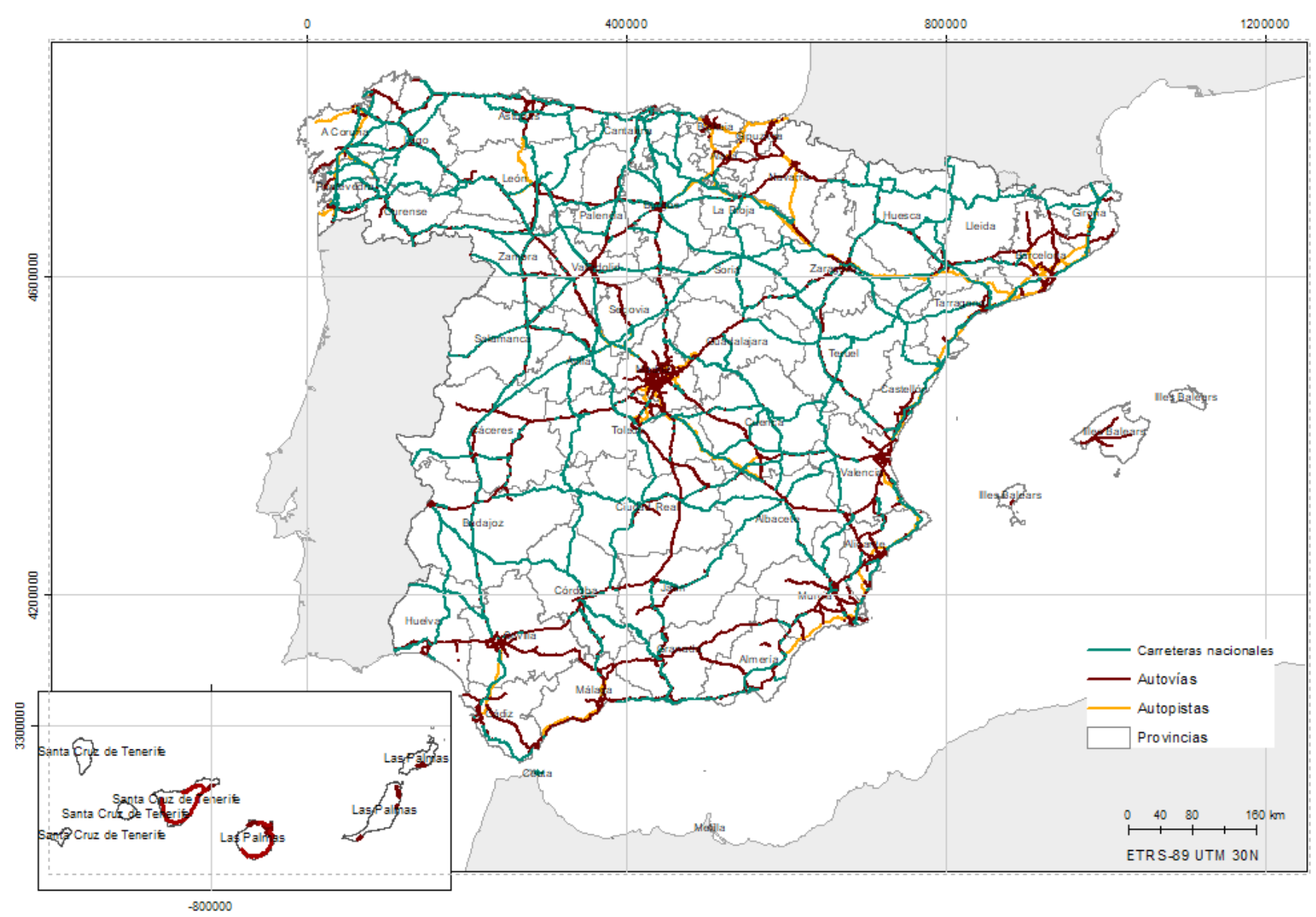

Figura 4.18. Canales de relación - Flujos - Sistema de Comunicación (fuente: elaboración propia) 


\subsubsection{Análisis geoestadístico y espacial}

La geoestadística es una rama de la estadística aplicada que se especializa en el análisis y la modelación de la variabilidad espacial en ciencias de la tierra. Los métodos empleados en este trabajo para la estimación del factor de corrección $\mathbf{u}_{1}$ corresponden al análisis geoestadístico (Díaz Viera 2002).

La geoestadística se define como el estudio de fenómenos regionalizados, es decir, fenómenos que extienden en el espacio y que presentan una cierta continuidad (Emery 2000).

La información almacenada en la base de datos ha sido fundamental para la categorización espacial del factor de corrección $\mathbf{u}_{1}$, partiendo de estadísticos preliminares de primer orden como la media, rango, desviación estándar, etcétera. Los valores que adquieren estos parámetros en el presente estudio se exponen en la sección de resultados. A continuación, se realizó una modelización de la variabilidad espacial del factor de corrección $\mathbf{u}_{1}$, utilizando lo que se conoce como semivariograma experimental, que se ha obtenido por estimación a partir de los datos de una muestra y nos indica la variación de la correlación entre los datos en función de la distancia. El estimador más común se basa en el método de los momentos, también puede escribirse mediante la expresión siguiente (Cressie 1990):

$$
Y(h)=\frac{1}{2|N(h)|_{N(h)}} \sum\left(Z\left(x_{i}\right)-Z\left(x_{j}\right)\right)^{2}, h \in R^{d}
$$

Donde:

$$
\begin{aligned}
& Z\left(x_{i}\right)=\text { valor de la variable en el punto } x_{i} \\
& Z\left(x_{i}\right)=\text { valor de la variable en el punto } x_{j} \\
& N(h)=\left\{\left(x_{i}, x_{j}\right) / x_{i}-x_{j}=h ; i, j=1, \ldots, n\right\} \\
& |N(h)|=\text { número de pares distintos. }
\end{aligned}
$$

La expresión del semivariograma experimental nos permite cuantificar la continuidad espacial para una serie de distancias de separación y direcciones. Cualquier función que dependa de la distancia y de la dirección no necesariamente es un semivariograma válido $\mathrm{y}$, por lo tanto, no puede utilizarse directamente para obtener estimaciones espaciales krigeadas ya que no necesariamente cumple las condiciones que todo semivariograma debe satisfacer. La solución que se adopta ante estas limitaciones de los semivariogramas experimentales es la utilización de un semivariograma teórico que represente lo más fielmente posible la estructura de 92 
dependencia espacial que muestran los datos disponibles (la realización observada); o, en otras palabras: ajustar la representación semivariográfica experimental a una teórica que garantice el buen funcionamiento del proceso posterior de estimación espacial.

A la hora de elegir el modelo de semivariograma teórico que mejor adapta al experimental es importante tener en cuenta que, sobre todo, debe recoger el comportamiento en el origen y a grandes distancias de este último. No importa tanto la forma analítica concreta del semivariograma como el hecho de que respete las principales características del fenómeno. Por orden de importancia, éstas son: el "efecto pepita", la pendiente en el origen, el alcance, las mesetas y las anisotropías". (Montero y Larraz 2008)

\subsubsection{Características y tipologías de semivariogramas teóricos}

Un semivariograma teórico o modelo es una función matemática que "representa" el semivariograma real del fenómeno. Las características básicas del semivariograma son:

- Alcance: distancia para la cual se estabiliza el variograma. Representa la "zona de influencia" de un dato y es la distancia a partir de la cual no hay correlación.

- Meseta: valor constante que toma el semivariograma a distancias mayores al alcance.

- Efecto Pepita: valor del semivariograma en el origen.

Los modelos básicos más usados se desarrollan construyendo matemáticamente una función aleatoria y calculando su semivariograma teóricamente, imponiéndose la condición de función condicionada positiva (Moral García 2003). Estos son:

- Modelo esférico

$$
\gamma(h)=\left\{\begin{array}{l}
\frac{m}{2}\left[3\left(\frac{h}{a}\right)-\left(\frac{h}{a}\right)^{3}\right] \text { si } 0 \leq h<a \\
m \text { si } h=a
\end{array}\right.
$$

Siendo $\mathrm{m} \mathrm{y} \mathrm{a}$, constantes positivas, el valor de la meseta $(\mathrm{m})$ y del alcance (a), respectivamente. 
- Modelo exponencial

$$
\gamma(h)=m\left(1-e^{-\frac{h}{a}}\right) \text { si } h>0
$$

Siendo $\mathrm{m}$ y a, constantes positivas, el valor de la meseta $(\mathrm{m})$ y del alcance (a), respectivamente.

- Modelo gaussiano

$$
\gamma(h)=m\left(1-e^{-\frac{h^{2}}{a^{2}}}\right) \text { si } h \geq 0
$$

Siendo h y a, constantes positivas, el valor de la meseta $(\mathrm{m})$ y del alcance (a), respectivamente.

Posteriormente se ha llevado a cabo un análisis de estimación de la variable "Factor de corrección $\mathbf{u}_{1}$ " mediante una interpolación espacial de los resultados, con el fin de conseguir una superficie continua con las estimaciones, lo que permite conocer valores de la variable indicada allí donde no fue muestreada. La interpolación de datos ofrece la ventaja de proyectar mapas o superficies continuas a partir de datos discretos (Johnston et al. 2001). La precisión en el mapa generado, a partir de las características a estudiar, depende en gran medida de la estructura espacial de los datos. Se estima que donde más fuerte es la correlación espacial de los valores de la variable en estudio, mejor es la calidad del mapeo (Kravchenko 2003).

\subsubsection{Krigeado}

Una completa introducción del kriging fue dada por Cressie (1990). El problema de la estimación de los atributos, en los lugares no muestreados, se favorece de forma especial cuando se considera la existencia de un modelo de dependencia espacial. Las variables naturales se distribuyen en el espacio de una forma continua, de acuerdo con la ley de Tobler: "Todas las cosas están relacionadas entre sí, pero las cosas más próximas en el espacio tienen una relación mayor que las distantes" (Tobler 1970), lo cual suele cumplirse en la naturaleza.

El kriging (bautizado así en honor de uno de los precursores de la geoestadística, Daniel Krige), método que permite estimar el valor de un punto o de un bloque a partir de los valores observados en los puntos circundantes, tomando en cuenta su configuración geométrica y la estructura espacial de la regionalización. 
El kriging se apoya en la interpretación de la variable regionalizada como una realización de una función aleatoria, de la cual se tiene un modelo de covarianza o variograma. Se trata de buscar, entre los estimadores formados por las combinaciones lineales ponderadas de los datos, aquel que presente las "mejores" propiedades (en este caso, ausencia de sesgo y varianza del error mínima, que constituye el criterio de precisión escogido)

El kriging presenta varias ventajas sobre las técnicas de interpolación deterministas (método del inverso de las distancias, splines, interpolación por el vecino más cercano, regresión polinomial, ...). Por una parte, entrega una estimación precisa e insesgada de la magnitud buscada, que toma en cuenta no solo las informaciones de naturaleza geométrica (número y configuración de los sitios con datos), sino también las informaciones estructurales contenidas en el modelo variográfico. Por otra parte, permite apreciar cuantitativamente la precisión de la estimación, con ayuda de una varianza de estimación, lo que no es posible sin recurrir a un modelo estocástico.

En este trabajo, nos interesa el Kriging puntual, es decir, que la cantidad a estimar no es otra cosa que el valor puntual desconocido $z(x 0)$ en un punto no muestreado $x 0$ (también puede hacerse en un punto ya muestreado). En general, el kriging puntual es efectuado no solo en un punto, sino en todos los nodos de una malla regular que cubre la zona de interés.

\section{A.- Krigeado ordinario}

Se supone que, a la escala de la vecindad de kriging, la regionalización es una realización de una función aleatoria $Z$ estacionaria de orden dos, con esperanza $\mathrm{m}$ constante y con una función de covarianza $\mathrm{C}$. Suponiendo que $\mathrm{m}$ es desconocida.

Las etapas del kriging son:

- Linealidad: el estimador de $Z$ en un punto $x_{0}$ se determina mediante:

$$
Z^{*}\left(x_{0}\right)=\sum_{i=1}^{n} \lambda_{i} Z\left(x_{i}\right)
$$

- Autorización: no existe restricción efectiva en el marco estacionario

- Insesgo: la esperanza del error de estimación vale:

$$
E\left[Z^{*}\left(x_{0}\right)-Z\left(x_{0}\right)\right]=\sum_{i=1}^{n} \lambda_{i} E\left[Z^{*}\left(x_{i}\right)\right]-E\left[Z\left(x_{0}\right)\right]=m\left(\sum_{i} \lambda_{i}-1\right)
$$


Ahora bien, siendo $\mathrm{m}$ desconocida, el único medio de garantizar el insesgo del error es imponiendo la condición de universalidad:

$$
\sum_{i} \lambda_{i}=1
$$

Esta igualdad asegura que, en el caso en que todos los datos son iguales a una misma constante, el valor estimado restituirá esta constante.

- Optimalidad: hay que minimizar la varianza del error de estimación, que se desarrolla de la siguiente forma, con la ayuda de la función de covarianza C:

$$
\operatorname{var}\left[Z^{*}\left(x_{0}\right)-Z\left(x_{0}\right)\right]=C(0)+\sum_{i=1}^{n} \sum_{j=1}^{n} \lambda_{i} \lambda_{j} C\left(x_{i}-x_{j}\right)-2 \sum_{i=1}^{n} \lambda_{i} C\left(x_{i}-x_{0}\right)
$$

Ahora, es necesario minimizar esta cantidad bajo la restricción que impone la condición de insesgo, a saber:

$$
\sum_{i} \lambda_{i}=1
$$

Para resolver este problema de minimización bajo restricción, se aplica la técnica de los multiplicadores de Lagrange, de la siguiente manera:

$$
\begin{aligned}
& \operatorname{var}\left[Z^{*}\left(x_{0}\right)-Z\left(x_{0}\right)\right] \\
& \quad=C(0)+\sum_{i=1}^{n} \sum_{j=1}^{n} \lambda_{i} \lambda_{j} C\left(x_{i}-x_{j}\right)-2 \sum_{i=1}^{n} \lambda_{i} C\left(x_{i}-x_{0}\right)+2 \mu\left(\sum_{i} \lambda_{i}-1\right)
\end{aligned}
$$

y se minimiza la función de las $n+1$ variables $\lambda 1, \ldots \lambda n, \mu$. Calculando las $n+1$ derivadas parciales de esta función y luego anulándolas, se obtiene el sistema:

$$
\begin{gathered}
\frac{\partial}{\partial \lambda_{i}}=0 ; \sum_{j=1}^{n} \lambda_{j} C\left(x_{i}-x_{j}\right)+\mu=C\left(x_{i}-x_{0}\right), \quad \forall i=1, \ldots, n \\
\frac{\partial}{\partial \mu}=0 ; \sum_{i=1}^{n} \lambda_{i}=1 . \text { Condición de insesgo }
\end{gathered}
$$

Este sistema puede ser expresado en forma matricial como:

$$
\left(\begin{array}{ccccc}
C(0) & C\left(x_{1}-x_{2}\right) & \ldots & C\left(x_{1}-x_{n}\right) & 1 \\
C\left(x_{2}-x_{1}\right) & C(0) & \ldots & C\left(x_{2}-x_{n}\right) & 1 \\
\ldots & \ldots & \ldots & \ldots & \ldots \\
C\left(x_{n}-x_{2}\right) & C\left(x_{n}-x_{2}\right) & \ldots & C(0) & 1 \\
1 & 1 & 1 & 1 & 0
\end{array}\right) \cdot\left(\begin{array}{c}
\lambda_{1} \\
\lambda_{2} \\
\ldots \\
\lambda_{n} \\
\mu
\end{array}\right)=\left(\begin{array}{c}
C\left(x_{1}-x_{0}\right) \\
C\left(x_{2}-x_{0}\right) \\
\ldots \\
C\left(x_{n}-x_{0}\right) \\
1
\end{array}\right)
$$


Siendo el variograma una herramienta equivalente a la covarianza, a partir de la relación: $\gamma(\mathrm{h})=\mathrm{C}(0)-\mathrm{C}(\mathrm{h})$, se puede elegir utilizarlo en lugar de la función de covarianza. Las ecuaciones de kriging pasan a ser:

$$
\left\{\begin{array}{l}
\sum_{i=1}^{n} \lambda_{j} \gamma\left(x_{i}-x_{j}\right)+\mu=\gamma\left(x_{i}-x_{0}\right), \forall i=1, \ldots, n \\
\sum_{i=1}^{n} \lambda_{i}=1
\end{array}\right.
$$

Esto es:

$$
\left(\begin{array}{ccccc}
\gamma(0) & \gamma\left(x_{1}-x_{2}\right) & \ldots & \gamma\left(x_{1}-x_{n}\right) & 1 \\
\gamma\left(x_{2}-x_{1}\right) & \gamma(0) & \ldots & \gamma\left(x_{2}-x_{n}\right) & 1 \\
\ldots & \ldots & \ldots & \ldots & \ldots \\
\gamma\left(x_{n}-x_{2}\right) & \gamma\left(x_{n}-x_{2}\right) & \ldots & \gamma(0) & 1 \\
1 & 1 & 1 & 1 & 0
\end{array}\right) \cdot\left(\begin{array}{c}
\lambda_{1} \\
\lambda_{2} \\
\ldots \\
\lambda_{n} \\
\mu
\end{array}\right)=\left(\begin{array}{c}
\gamma\left(x_{1}-x_{0}\right) \\
\gamma\left(x_{2}-x_{0}\right) \\
\ldots \\
\gamma\left(x_{n}-x_{0}\right) \\
1
\end{array}\right)
$$

La solución viene dada por:

$$
\lambda=\Gamma^{-1} \cdot \Gamma_{0}
$$

Varianza del error de estimación:

$$
V\left[X^{*}\left(x_{0}\right)-X\left(x_{0}\right)\right] \rightleftarrows=\sum_{i=1}^{n} \lambda_{i} \gamma\left(x_{i}-x_{0}\right)+\mu
$$

Esta interpolación se ha realizado en nuestro estudio, debido a que es recomendada para patrones de puntos de una región, con el fin de obtener resultados más razonables (Ghiasi y Nafisi 2016). Así los valores discretos de $\mathbf{u}_{1}$ se han convertido en valores continuos en el territorio español

\section{B.- Método de validación cruzada}

Una vez seleccionado el semivariograma teórico como aquel que mejor ajusta los datos disponibles representados en el semivariograma experimental, es preciso validar el proceso de ajuste realizado ya que en el caso de haber llevado a cabo un ajuste defectuoso los resultados obtenidos del proceso posterior de krigeado no serán todo lo buenos que sería deseable. A estos fines el procedimiento más utilizado es el denominado "validación cruzada"

El principio de validación cruzada, también llamado "leave-one-out method", consiste en estimar $\mathrm{Z}\left(\mathrm{x}_{\mathrm{i}}\right)$ en cada localización muestral $\mathrm{xi}, \mathrm{i}=1, \ldots, \mathrm{n}$ a partir de las 
observaciones correspondientes a las $n-1$ localizaciones restantes, $Z\left(x_{j}\right), j \neq i$, como si $Z\left(x_{i}\right)$ fuera desconocido. Mediante este procedimiento, en cada localización $x_{i}$ se dispone de una estimación $Z^{*}\left(x_{i}\right)$ y de una varianza del error de estimación, $\boldsymbol{\sigma}_{\boldsymbol{k}_{\boldsymbol{i}}}^{2}$. Como $Z\left(x_{i}\right)$ es conocido, se puede calcular el error de estimación $E i=Z^{*}\left(x_{i}\right)-Z\left(x_{i}\right)$, así como el error estandarizado $\mathrm{e}_{\mathrm{i}}=\mathrm{E}_{\mathrm{i}} / \boldsymbol{\sigma}_{\boldsymbol{k}_{\boldsymbol{i}}}$ (Montero y Larraz 2008).

\subsection{SUMARIO Y CONCLUSIONES}

Con la metodología planteada en el presente trabajo se pretende realizar no solamente el cálculo de los valores del factor $\mathbf{u}_{1}$ sino el análisis de los resultados obtenidos para la elaboración de la investigación planteada.

Todas las fuentes de datos utilizadas son abiertas, y gracias a eso ha sido posible realizar la investigación, contrastar las hipótesis y alcanzar los objetivos planteados. En particular para la ciencia, es de vital importancia contar con datos que hagan posible la investigación y permitan avanzar en el conocimiento.

Se han empleado datos vectoriales descargados del INE, SIU y CNIG. Se ha usado principalmente la base cartográfica de comunidades autónomas, provincias y municipios, datos de población de municipios, núcleos de población y diseminado; datos el Censo de población de 2.011, último Censo publicado por el INE y datos de infraestructuras viarias: autopistas, autovías, carreteras, etc; En cuanto a la evaluación de estas fuentes, no han supuesto ningún coste económico para el proyecto, han sido fácilmente accesibles, no se ha requerido ningún registro y han resultado idóneas en relación a resoluciones, formato y extensión.

Es importante remarcar el potencial que supone para un país tener fuentes de datos institucionales abiertas. Los casos del Catastro y el PNOA de España, que recibió un premio de la ONU en 2013, o el repositorio EarthExplorer de la NASA, son claros ejemplos de ello. Hay que mostrar que, lejos de suponer un perjuicio para el país, contribuyen a su desarrollo y a su posicionamiento internacional.

En esta investigación se ha llevado a cabo un análisis de estimación de la variable "Factor de corrección $\mathbf{u}_{1}$ " mediante una interpolación espacial de los resultados, con el fin de conseguir una superficie continua con las estimaciones, lo que permite conocer valores de la variable indicada allí donde no fue muestreada. La interpolación de datos ofrece la ventaja de proyectar mapas o superficies continuas a partir de datos discretos. La precisión en el mapa generado, a partir de las características a estudiar, 
depende en gran medida de la estructura espacial de los datos. La interpolación seleccionada ha sido el kriging al presentar ventajas sobre las técnicas de interpolación deterministas. Por una parte, entrega una estimación precisa e insesgada de la magnitud buscada, que toma en cuenta no solo las informaciones de naturaleza geométrica (número y configuración de los sitios con datos), sino también las informaciones estructurales contenidas en el modelo variográfico. Por otra parte, permite apreciar cuantitativamente la precisión de la estimación, con ayuda de una varianza de estimación, lo que no es posible sin recurrir a un modelo estocástico. 



\section{APLICACIÓN DE LA METODOLOGÍA EN ESPAÑA}

\subsection{CÁLCULO INICIAL}

Para comenzar se ha procedido a estudiar los puntos a los que se ha hecho referencia en el apartado 4.1 Antecedentes del cálculo del Factor de Corrección por Localización (FL) en el suelo rural según el RVLS 2011.

En este punto es necesario mencionar que como se dijo en dicho apartado el análisis inicial sobre mapas diseñados para ser impresos poseía ciertas limitaciones. Por un lado, el análisis de la información que proporcionaban era visual, esto es, "analógico", con la limitación que esto conlleva, y por otro, el soporte físico de los planos también incorporaba una serie de limitaciones, tales como la escala a la que se podían representar.

Sin embargo, la utilización de un SIG permite la posibilidad de realizar un análisis de forma digital y automática, tomando gran importancia los atributos asociados a los datos que se deben utilizar. Todo ello permite realizar operaciones de medición y de análisis de manera más rápida y sencilla que las mismas tareas realizadas sobre un mapa donde difícilmente se obtendrían los mismos resultados, si bien el proceso preparatorio de la información requiere un laborioso trabajo

En las siguientes tablas se han recogido los datos obtenidos mediante la metodología inicial (la denominada "analógica") en la Tabla 5.1, representándose los datos obtenidos mediante la utilización del SIG en la Tabla 5.2. Se puede observar que los datos obtenidos mediante el SIG difieren muy poco de los datos obtenidos en el trabajo inicial. No obstante, como se ha mencionado en el párrafo anterior, los últimos datos obtenidos son precisos y exactos.

\begin{tabular}{ccccccc} 
& LEGANÉS & LAYNA & ALARES & TEMBLEQUE & ALMAGRO & CÓRDOBA \\
\hline $\mathrm{P}_{1}$ & 939.727 & 1.909 & 95 & 2.390 & 8.855 & 298.839 \\
\hline $\mathrm{P}_{2}$ & 5.436 .976 & 17.813 & 29.360 & 301.898 & 293.604 & 180.894 \\
\hline $\mathbf{u}_{\mathbf{1}}$ & $\mathbf{3 , 7 5}$ & $\mathbf{1 , 0 0 7 8}$ & $\mathbf{1 , 0 0 9 8}$ & $\mathbf{1 , 1 0 3}$ & $\mathbf{1 , 1 0 6 7}$ & $\mathbf{1 , 3 5 9 1}$
\end{tabular}

Tabla 5.1. Datos iniciales antecedentes previos (fuente: elaboración propia)

\begin{tabular}{ccccccc} 
& LEGANÉS & LAYNA & ALARES & TEMBLEQUE & ALMAGRO & CÓRDOBA \\
\hline $\mathrm{P}_{1}$ & 766.748 & 49 & 89 & 2.307 & 780 & 303.928 \\
\hline $\mathrm{P}_{2}$ & 5.599 .474 & 17.484 & 31.219 & 212.726 & 277.643 & 505.459 \\
\hline $\mathbf{u}_{1}$ & $\mathbf{3 , 6 3 3}$ & $\mathbf{1 , 0 0 5 9}$ & $\mathbf{1 , 0 1 0 5}$ & $\mathbf{1 , 0 7 3 2}$ & $\mathbf{1 , 0 9 3 3}$ & $\mathbf{1 , 4 7 2 4}$
\end{tabular}

Tabla 5.2. Datos calculados en el SIG (fuente: elaboración propia) 
Al margen de los datos numéricos obtenidos, el detalle de las imágenes generadas mediante el SIG evidencia la mayor precisión en los cálculos realizados y los resultados obtenidos.

Se adjuntan imágenes de cada uno de los puntos en los que se obtiene el valor $\mathbf{u}_{1} \mathbf{y}$, además, puesto que la herramienta de trabajo lo permite, se han representado también las entidades de población que se localizan próximas a cada uno de dichos puntos y de las que se obtienen los datos de población necesarios para el cálculo del factor de corrección $\mathbf{u}_{1}$ en el estudio.
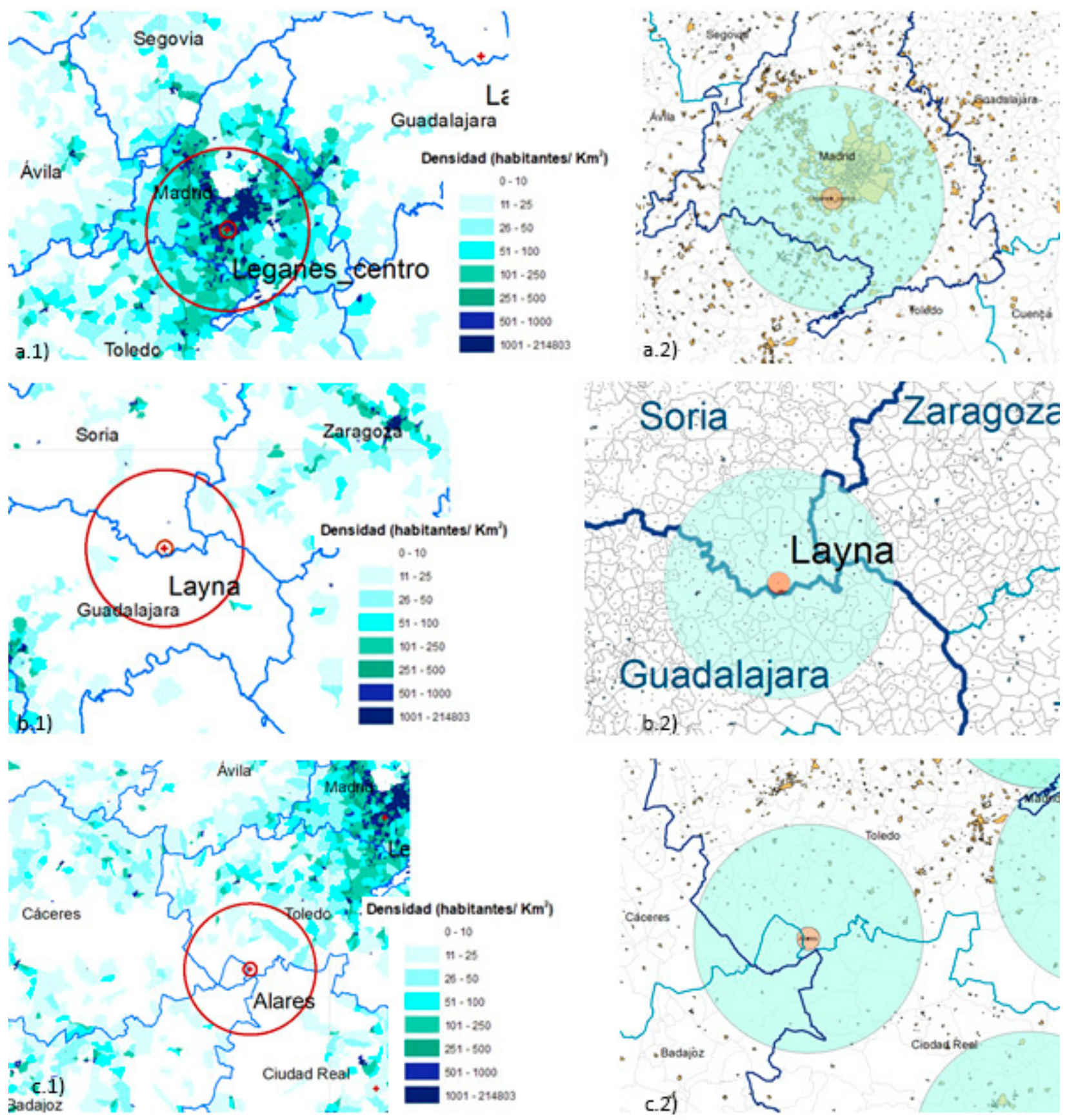

Figura 5.1. x.1) Densidad de población y x.2) entidades de población de: a Leganés, b Layna y c Alares. (fuente: elaboración propia) 

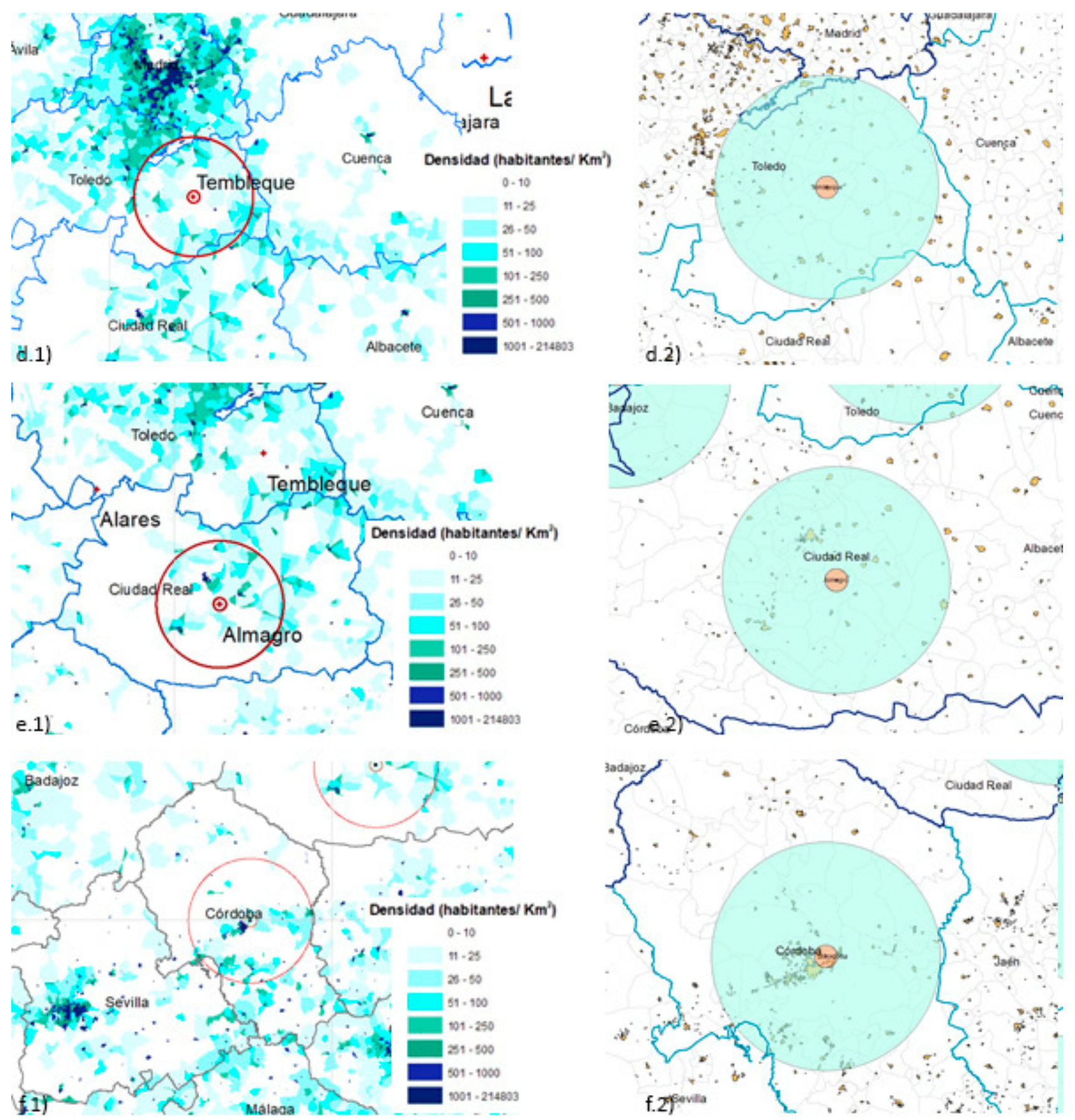

Figura 5.2. x.1) Densidad de población y x.2) entidades de población de: d Tembleque, e Almagro y Córdoba. (fuente: elaboración propia)

\subsection{VALORES DISCRETOS DEL FACTOR $U_{1}$ (1.836 PUNTOS)}

Partiendo de los datos de población facilitados por el INE como base para el cálculo de factor $\mathbf{u}_{1}$ se procedió a representar los valores de $\mathrm{P}_{1}$ y $\mathrm{P}_{2}$, de acuerdo con la fórmula del artículo 17.2 del RVLS 2011 en mapas representativos de todo el territorio nacional (Figura 5.3). En la representación se han tomado los valores de población existentes a partir de 100.000 habitantes ya que en esos puntos se obtienen los mayores valores de $\mathbf{u}_{1}$, evitando de este modo que el exceso de información y representación gráfica 
desvirtúe la información que se quiere representar.

De los 1.836 puntos a representar, en unos 1.785 puntos el valor de $\mathrm{P}_{1}$ es inferior a 100.000 habitantes. Por otro lado, unos 1.187 puntos representan un valor de $P_{2} / 3$ inferior a 100.000 habitantes.

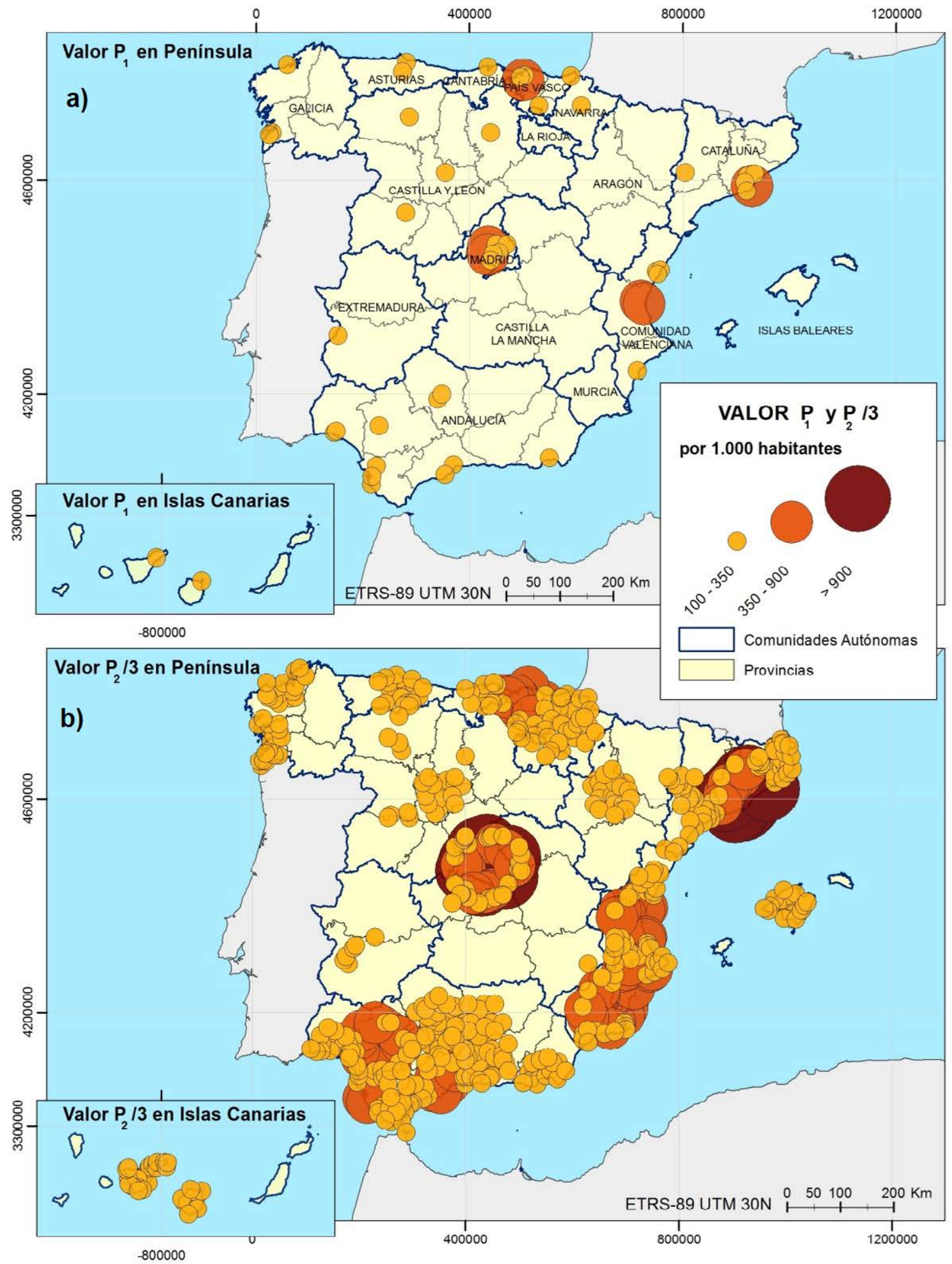

Figura 5.3.a) Valor de $P_{1}$ (número de habitantes a una distancia de $4 \mathrm{Km}$.), b) valor $P_{2} / 3$ (número de habitantes situados a más de $4 \mathrm{Km}$. y a menos de $40 \mathrm{Km}$.) (fuente: elaboración propia) 
Una vez conocidos los valores de $\mathrm{P}_{1}$ y $\mathrm{P}_{2} / 3$ se calculó el valor de $\mathbf{u}_{1}$, de acuerdo con la fórmula del artículo 17.2 RVLS 2011, representado en un mapa de todo el territorio nacional los valores obtenidos (Figura 5.4).

Del mismo modo que se clasificaron los valores de cada uno de los $\mathrm{P}_{\mathrm{x}}$ para que su representación fuera lo más clara posible en el mapa del territorio nacional, los valores de $\mathbf{u}_{1}$ también se clasificaron con criterios estadísticos para que su representación resultara suficientemente representativa. De este modo se crearon 7 intervalos con el valor de $\mathbf{u}_{1}$ de acuerdo con la siguiente tabla:

\begin{tabular}{lccc}
$\begin{array}{c}\text { Clasificación valores } \\
\mathbf{u}_{1}\end{array}$ & $\mathbf{N .}^{\circ}$ de puntos & $\begin{array}{c}\text { Porcentaje } \\
\%\end{array}$ \\
\hline 1 & $1-1,05$ & 1.175 & $64,00 \%$ \\
\hline 2 & $1,06-1,20$ & 317 & $17,27 \%$ \\
\hline 3 & $1,21-1,50$ & 239 & $13,02 \%$ \\
\hline 4 & $1,51-2,00$ & 68 & $3,70 \%$ \\
\hline 5 & $2,01-2,50$ & 10 & $0,54 \%$ \\
\hline 6 & $2,51-3,00$ & 17 & $0,93 \%$ \\
\hline 7 & $3,00-3,82$ & 10 & $0,54 \%$ \\
\hline TOTAL & & $\mathbf{1 . 8 3 6}$ & $\mathbf{1 0 0} \%$
\end{tabular}

Tabla 5.3. Clasificación de los valores de $u_{1}$, número de puntos en cada una de las clases (fuente: elaboración propia)

Como se puede observar, en la mayor parte de los puntos -el $64 \%$ - se obtienen valores situados entre 1 y 1,05 .

En la Figura 5.4 se representan los valores de los 1.836 puntos. 


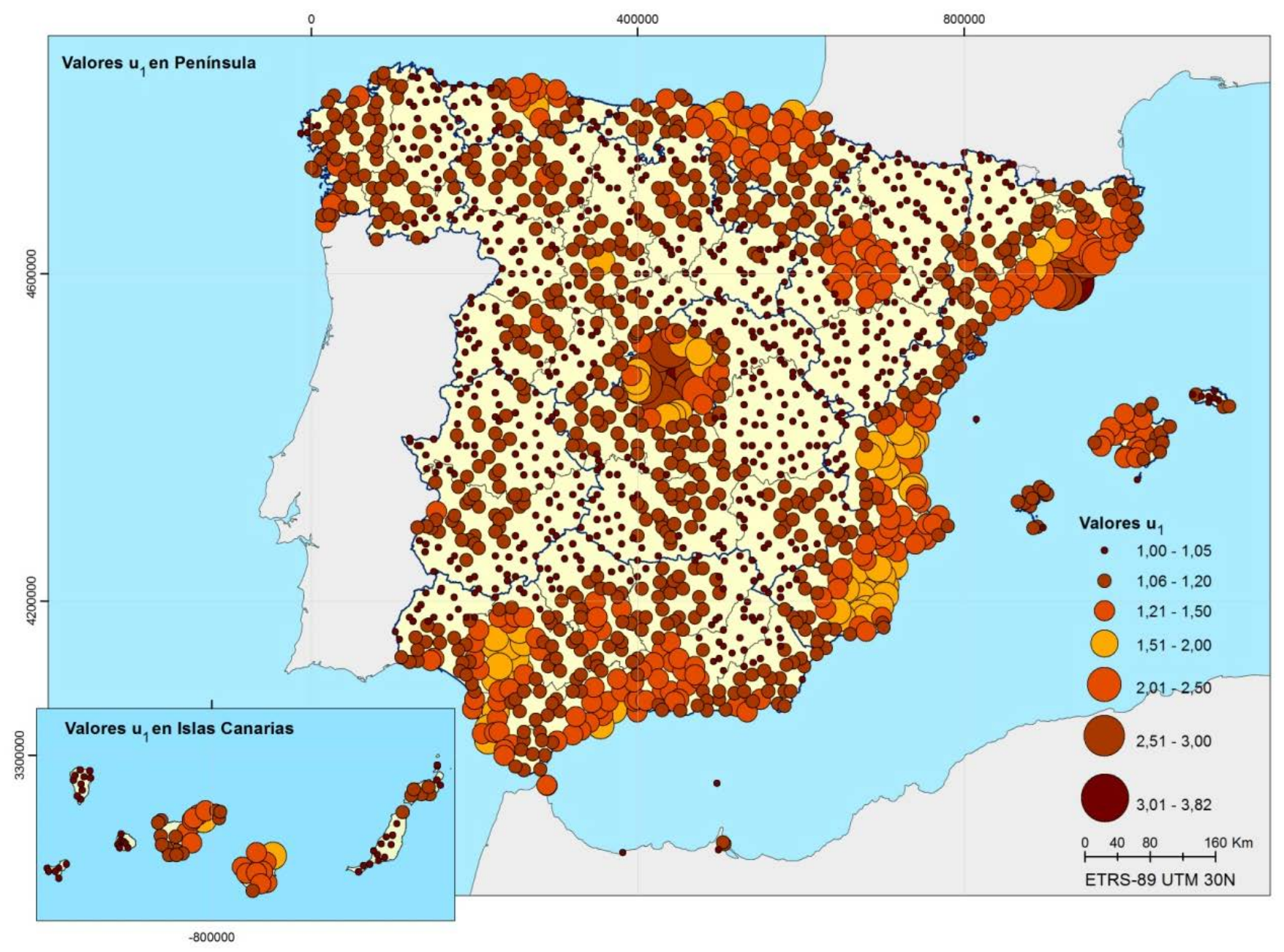

Figura 5.4. Distribución del valor del factor de corrección por accesibilidad a núcleos de población $u_{1}$. Representación en cada uno de los 1836 puntos (fuente: elaboración propia)

\subsection{VALORES CONTINUOS DEL FACTOR U 1 . GEOESTADÍSTICA}

Partiendo del análisis realizado en los 1.836 puntos, se procedió a realizar un estudio geoestadístico de los valores obtenidos para crear un modelo de superficie continua con los valores del factor de corrección $\mathbf{u}_{1}$ en todo el territorio nacional.

\subsubsection{Geoestadística. Resultados}

Los datos estadísticos de partida de la muestra de estudio, obtenidos en relación con la variable "Factor de corrección $\mathbf{u}_{1}$ " son los siguientes:

PARÁMETROS MUESTRAS

\begin{tabular}{lc} 
MÍNIMO & 1836 \\
\hline MÁXIMO & 3,82 \\
\hline MEDIA & 1,15 \\
\hline
\end{tabular}


RANGO

2,67

\begin{tabular}{lc}
\hline CUARTIL Q1 & 1,03 \\
\hline MEDIANA Q2 & 1,06 \\
\hline CUARTIL Q3 & 1,16 \\
\hline DESVIACIÓN ESTÁNDAR & 0,29 \\
\hline COEFICIENTE VARIACIÓN & $24,82 \%$ \\
\hline ERROR TÍPICO DE LA MEDIA & 0,007 \\
\hline TABLA T (95\%) & 1,96 \\
\hline LÍMITE INFERIOR & 1,14 \\
\hline LÍMITE SUPERIOR & 1,16 \\
\hline
\end{tabular}

Tabla 5.4. Estadísticos preliminares de la variable "Factor de corrección u1" (fuente: elaboración propia)

Dentro del estudio exploratorio de los datos se busca si hay tendencias globales del factor en estudio. Para ello se realizó el gráfico de tendencia global del factor $\mathbf{u}_{1}$ sobre los planos este-oeste $(\mathrm{X}-\mathrm{Z})$ y norte-sur $(\mathrm{Y}-\mathrm{Z})$, concluyendo que hay una débil tendencia global en la dirección este-oeste (Figura 5.5).

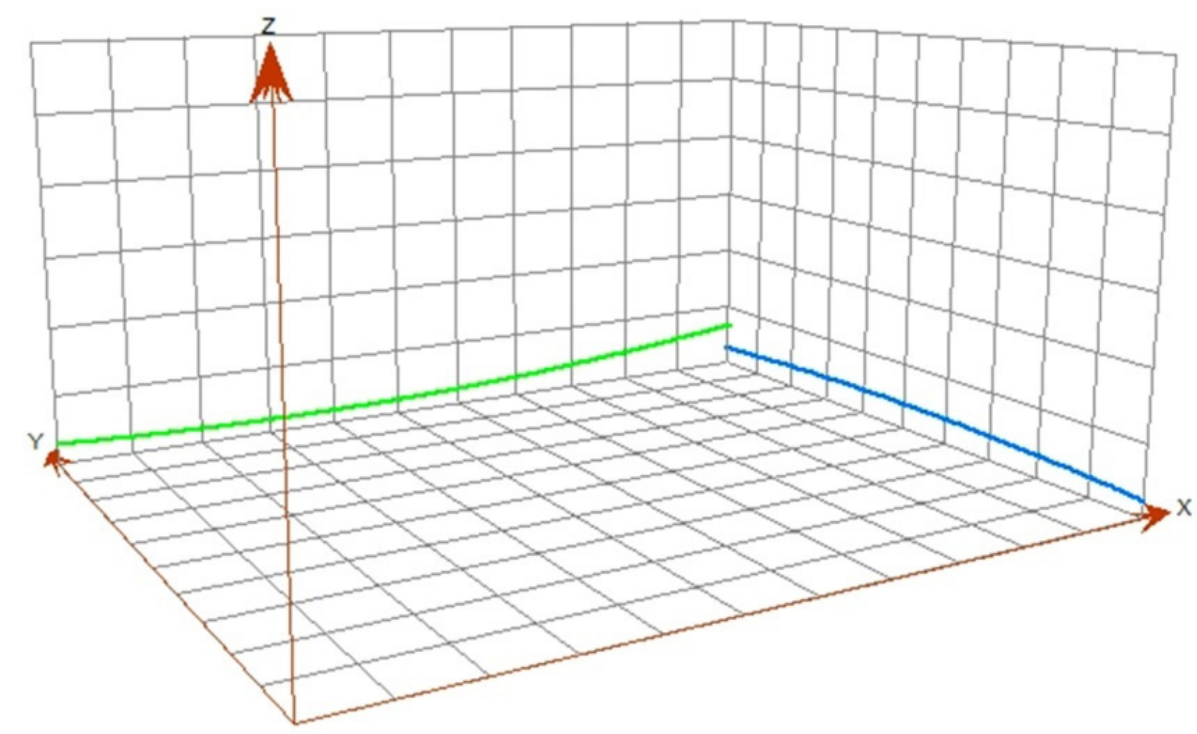

Figura 5.5. Tendencia global "muy débil" lineal de los puntos del Factor de corrección u (línea azul: NS, línea verde: WE) (fuente: elaboración propia)

El primer paso para trabajar con una función geoestadistica de interpolación, en nuestro caso, con el kiging Ordinario es concretar Para encontrar el mejor el modelo de semivariograma experimental que definiera la continuidad espacial de los valores de la variable "Factor de corrección $\mathbf{u}_{1}$ ", se utilizó el programa SGEMS porque nos permite el ajuste del semivariograma experimental al teórico de forma manual, ya que una primera aproximación al teorico se realiza "a primera vista" (Wackernagel 2013), porque generalmente no es tan importante lo bien que se ajusta el semivariograma teorico a la secuencia de puntos experimentales como que recoja bien el comportamiento cerca del origen y las condiciones de continuidad y de 
estacionariedad asociadas a la función aleatoria (Montero y Larraz 2008).

Cuando se genera el semivariograma, debido la gran cantidad de datos que se emplean, el gráfico que lo representa mediante una nube de puntos se congestiona en exceso y se complica la interpretación. Para reducir el número de puntos en el semivariograma experimental se lleva a cabo un proceso de agrupación de aquellos pares de localizaciones presentes en el semivariograma en base a la distancia entre ellos. El control de las condiciones en que se va a realizar este proceso de agrupación se realiza mediante la modificación del tamaño y número de intervalos (Lag size, Number of Lags)

En este estudio se realizaron diferentes pruebas cambiando el tamaño del lag, o distancia de separación entre cada par de valores, así como el número de lags, adoptándose diferentes azimut (angulo formado etc et..) para estudiar una posible anisotropía que reflejase variaciones dependientes de las distintas direcciones espaciales. De los resultados del estudio, pudo comprobarse la inexistencia de anisotropía en el modelo, ya que a partir de distintos azimut no se observan cambios significativos en el variograma o semivariograma teórico. En la Figura 4.6 se representa el ajuste al modelo exponencial. Por otra parte, se ajustó el variograma experimental a los modelos teóricos: esférico, exponencial y gaussiano. Los parámetros obtenidos en los distintos modelos variográficos se muestran en la Tabla 5.5 .
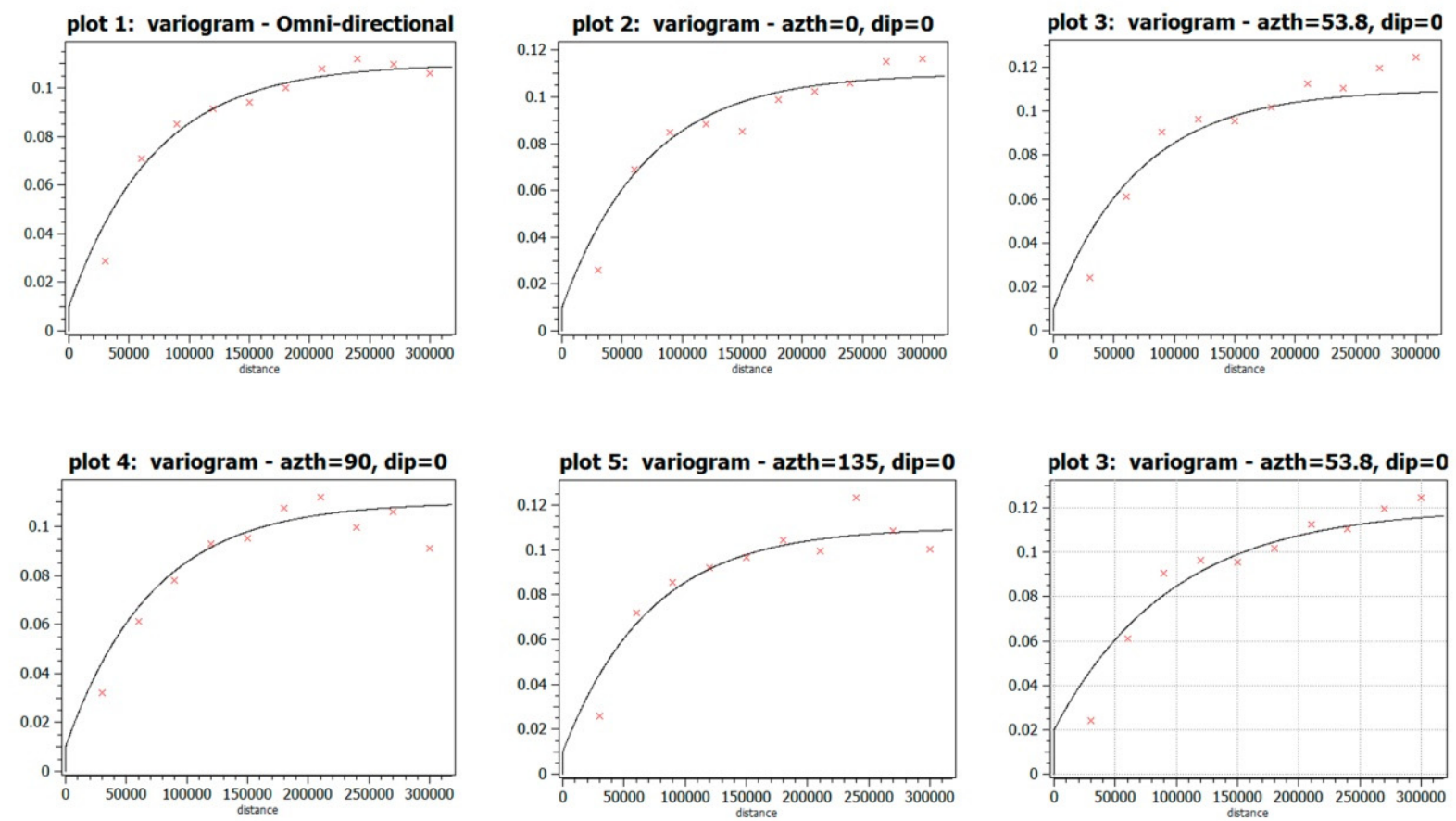

Figura 5.6. Modelo de semivariograma exponencial con distintos azimuts (fuente: elaboración propia) 
El estudio de la interpolación mediante el kriging ordinario se realizó con el software ArcMap, ya que este programa realiza un estudio de los errores de las estimaciones del modelo utilizado. Para realizar dicha interpolación se partió de los parámetros del variograma teórico realizado con SGEMS.

A continuación se exponen la características de los diferentes variogramas teóricos, para ello se utizó el software ArcMap:

VARIOGRAMAS

\begin{tabular}{lccc}
\cline { 2 - 4 } Datos & ESFÉRICO & EXPONENCIAL & GAUSSIAN \\
\hline Vecinos máximos & 5 & 5 & 5 \\
\hline Vecinos mínimos & 2 & 2 & 2 \\
\hline Sector & 4 & 4 & 4 \\
\hline Dirección & 0 & 0 & 0 \\
\hline Alcance o rango & 204000 & 213000 & 156000 \\
\hline Nugget & 0 & 0,01 & 0 \\
\hline Sill parcial & 0,1 & 0,1 & 0,01 \\
\hline$N^{\circ}$ Lag & 10 & 10 & 10 \\
\hline Tamaño lag & 30000 & 30000 & 30000 \\
\hline
\end{tabular}

Tabla 5.5. Definición de los variogramas (fuente: elaboración propia)

El nugget o "efecto pepita", que detecta las varianzas no explicadas en el modelo, nos indica el comportamiento cerca del origen, poniendo de manifiesto la semejanza de los datos muy próximos; es decir, refleja la continuidad o regularidad de la variable a pequeña escala, por lo que en nuestro caso nos indica que la variable "Factor de corrección $\mathbf{u}_{1}$ " es regular a distancias cortas. El valor del rango (por ejemplo 213.000 m., caso exponencial) nos indica que hasta esa distancia los puntos están relacionados. Además, el valor "sill parcial" nos indica el máximo valor promedio de la diferencia al cuadrado de los valores del "Factor de corrección $\mathbf{u}_{1}$ " entre dos puntos separados por una distancia de $213.000 \mathrm{~m}$. a partir de la cual dicho valor es constante y su magnitud es 0,1 .

En la Tabla 5.6 se exponen los resultados de la validación cruzada como comprobación de la validez del modelo kriging ordinario, tomando como criterio para seleccionar el mejor modelo predictivo el menor error cuadrático medio (RMSE), observándose que hay muy pocas diferencias entre el modelo esférico y el exponencial. 


\begin{tabular}{lccc} 
& \multicolumn{3}{c}{ KRIGING ORDINARIO } \\
\cline { 2 - 4 } & ESFÉRICO & EXPONENCIAL & GAUSSIAN \\
\hline Validación cruzada & 1836 & 1836 & 1836 \\
\hline $\mathrm{M}^{\circ}$ de muestras & 0,0001 & 0,0001 & 0,0019 \\
\hline Media de la predicción de los errores & 0,059 & 0,058 & 0,13 \\
\hline Root mean Square Error (RMSE) & 1,02 & 1,01 & 1,05 \\
\hline Standardized error & enc
\end{tabular}

Tabla 5.6. Validación cruzada del modelo kringing ordinario según distintos semivariogramas (fuente: elaboración propia)

Una vez seleccionado el modelo variográfico exponencial, se procedió a realizar la interpolación del kriging ordinario, ya que los datos cumplían los requisitos de dicha interpolación, cuyo resultado se puede ver en la Figura 3.25, donde se observa que los mayores valores del factor de corrección $\mathbf{u}_{1}$ se encuentran en los emplazamientos donde también existe el mayor número de habitantes, tal y como se refleja en la Figura 5.7 .

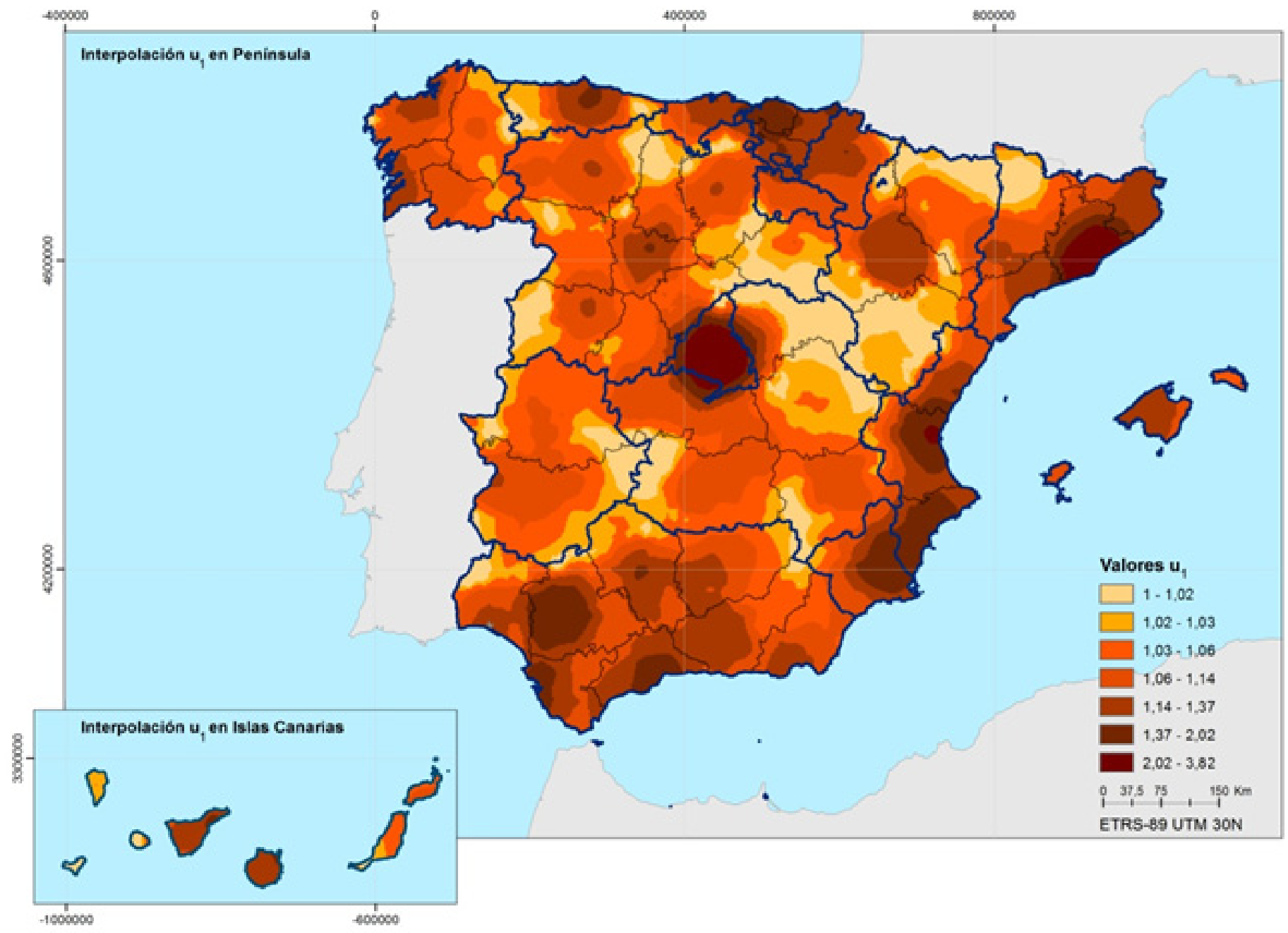

Figura 5.7. Interpolación de kriging ordinario de la variable "Factor de corrección u1" (fuente: elaboración propia) 


\subsection{VALIDACIÓN DE LOS VALORES DEL FACTOR $U_{1}$}

Para validar la interpolación realizada con el kriging se ha superpuesto, en el mismo mapa, los 1.836 puntos de la malla y la interpolación. A los puntos se les ha categorizado en el mismo valor de $\mathbf{u}_{1}$ que las zonas proporcionadas en el kriging para poder comprobar los valores. En la Figura 5.8 puede observarse como no existen casi desviaciones entre el valor discreto y continuo, validándose así geométricamente el modelo.

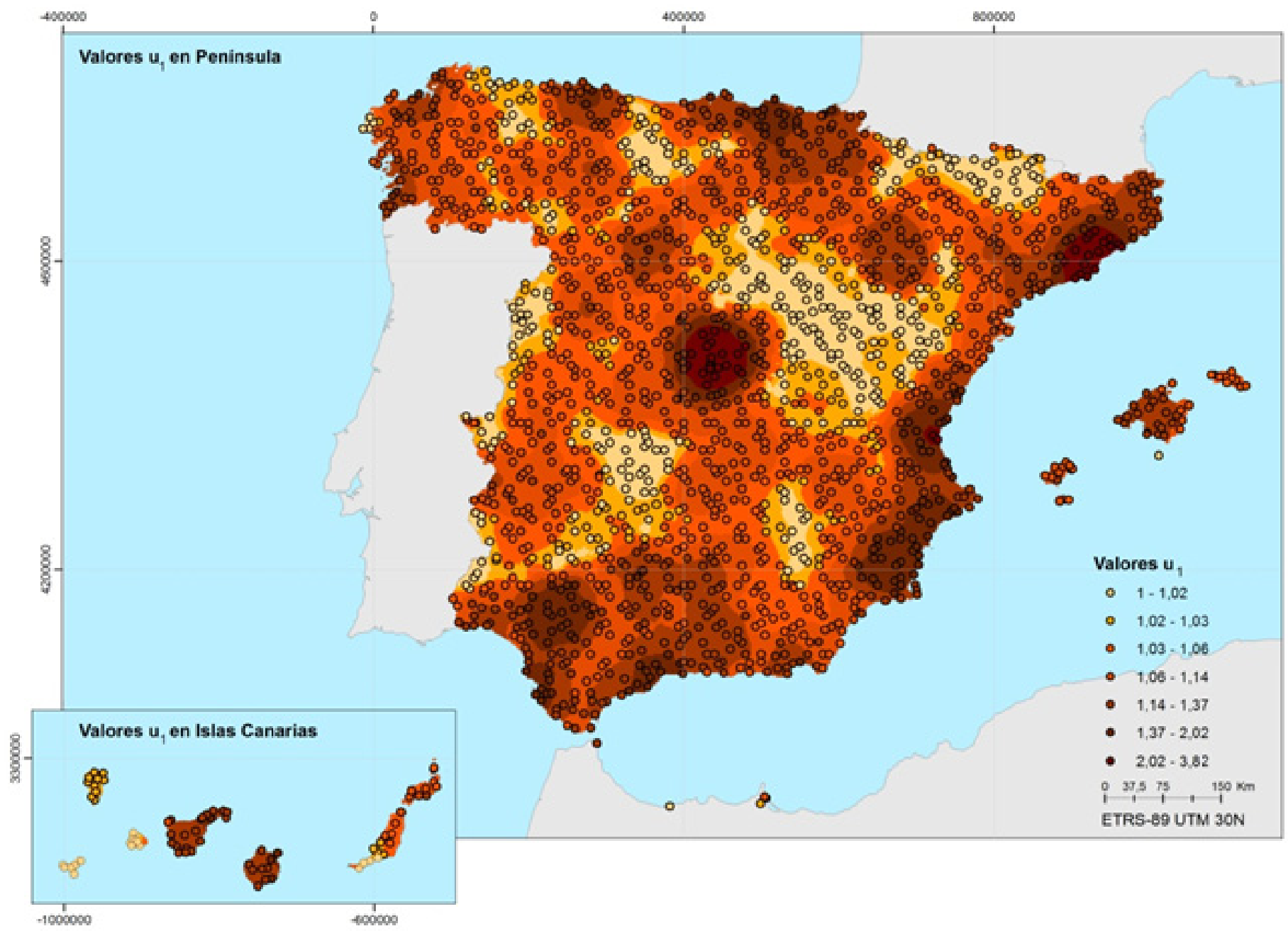

Figura 5.8. Zonificación obtenida con la interpolación kriging ordinario superpuesto el valor del "Factor de corrección u1" (fuente: elaboración propia)

\subsection{APLICACIÓN DE LA METODOLOGÍA: CONCLUSIONES}

Una vez aplicada la metodología elegida para el cálculo del factor de corrección $\mathbf{u}_{1}$ se puede constatar, que si bien, el proceso inicial es muy laborioso y requiere seleccionar los valores a utilizar de forma muy precisa, permite estudiar y analizar de forma clara los resultados logrando de este modo que los mismo sean fiables. 



\section{ANÁLISIS Y DISCUSIÓN DE RESULTADOS: LA ACCESIBILIDAD A NÚCLEOS DE POBLACIÓN}

\subsection{LAS RELACIONES ENTRE LOS ELEMENTOS DE LA FORMULA DEL ARTÍCULO 17.2 RVLS 2011}

Una vez obtenidos los datos discretos del factor $\mathbf{u}_{1}$, se ha realizado, con la fórmula de cálculo definida en el RVLS 2011, un análisis de la incidencia de cada uno de los componentes de la fórmula $\left(\mathrm{P}_{1}\right.$ y $\left.\mathrm{P}_{2} / 3\right)$ y su relación con el valor de $\mathbf{u}_{1}$.

Para ello se ha utilizado un gráfico de superficies (Figura 6.1) compuesto por:

- Eje vertical: valores homogeneizados de 0-1 de cada uno de los componentes de la fórmula $\mathbf{u}_{1}, \mathrm{P}_{1}$ y $\mathrm{P}_{2} / 3$.

- Eje horizontal: cada uno de los puntos 1.836 estudiados.

- Serie de datos: representación de los valores homogenizados $\mathbf{u}_{1}$ en cada uno de los 1.836 puntos (en color verde oscuro), $\mathrm{P}_{1}$ (en color naranja) y $\mathrm{P}_{2} / 3$ (en color verde más claro), relacionados entre sí.

Se observa que la representación de los valores de $\mathrm{P}_{1}$ no coincide con la representación de los valores de $\mathbf{u}_{1}$, ya que en algunos de los puntos el valor de ambos es radicalmente diferente ya sea superior o inferior. Sin embargo, la representación de los valores de $\mathrm{P}_{2} / 3$ genera una superficie paralela y similar a la superficie que representa los valores $\mathbf{u}_{1}$, con lo que se concluye que los valores que más influyen en el factor $\mathbf{u}_{1}$ son los de número de habitantes situados a $40 \mathrm{Km}$. del punto estudiado.

Este es el resultado esperado, ya que el número de habitantes situados a una distancia de $4 \mathrm{Km}$. en el punto analizado es muy inferior al número de habitantes situados a $40 \mathrm{Km}$. 


\section{COMPARACION VALORES}

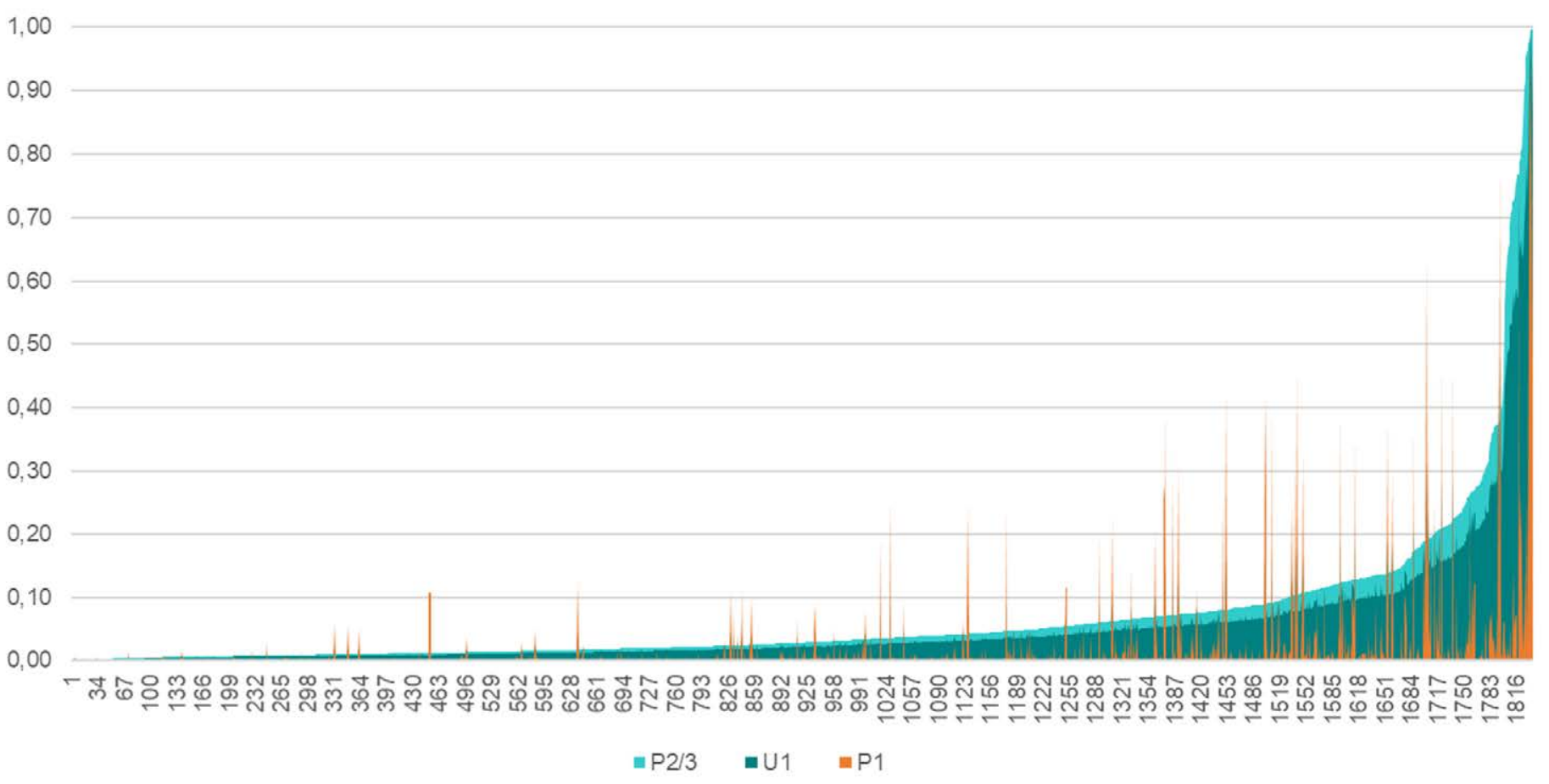

Figura 6.1 Comparación valores $P_{1}, P_{2} / 3$ y $u_{1}$ (fuente: elaboración propia)

\subsection{VALORES KRIGING}

Siguiendo con los datos discretos obtenidos en el cálculo, y observando los valores obtenidos, se ha estudiado su normalidad y simetría. En cuanto a la normalidad de los datos, figurados en la tabla de la Figura 6.2 se puede concluir que no siguen una distribución normal y que la estructura de los valores del factor $\mathbf{u}_{1}$ respecto la media tiene una asimetría positiva, es decir, que la cola de la distribución se alarga para valores superiores a la media. Esto quiere decir que el $86 \%$ de los valores del factor $\mathbf{u}_{1}$ son inferiores a 1,28 , por lo que el valor de $\mathbf{u}_{1}$ no es homogeneo en el territorio español. En la cola de la distribución, con frecuenca muy baja aparecen los valores máximos. En la Figura 6.2 pueden verse los intervalos realizados para el histograma con el límite superior e inferior y las frecuencias ablsolutas y relativas. 


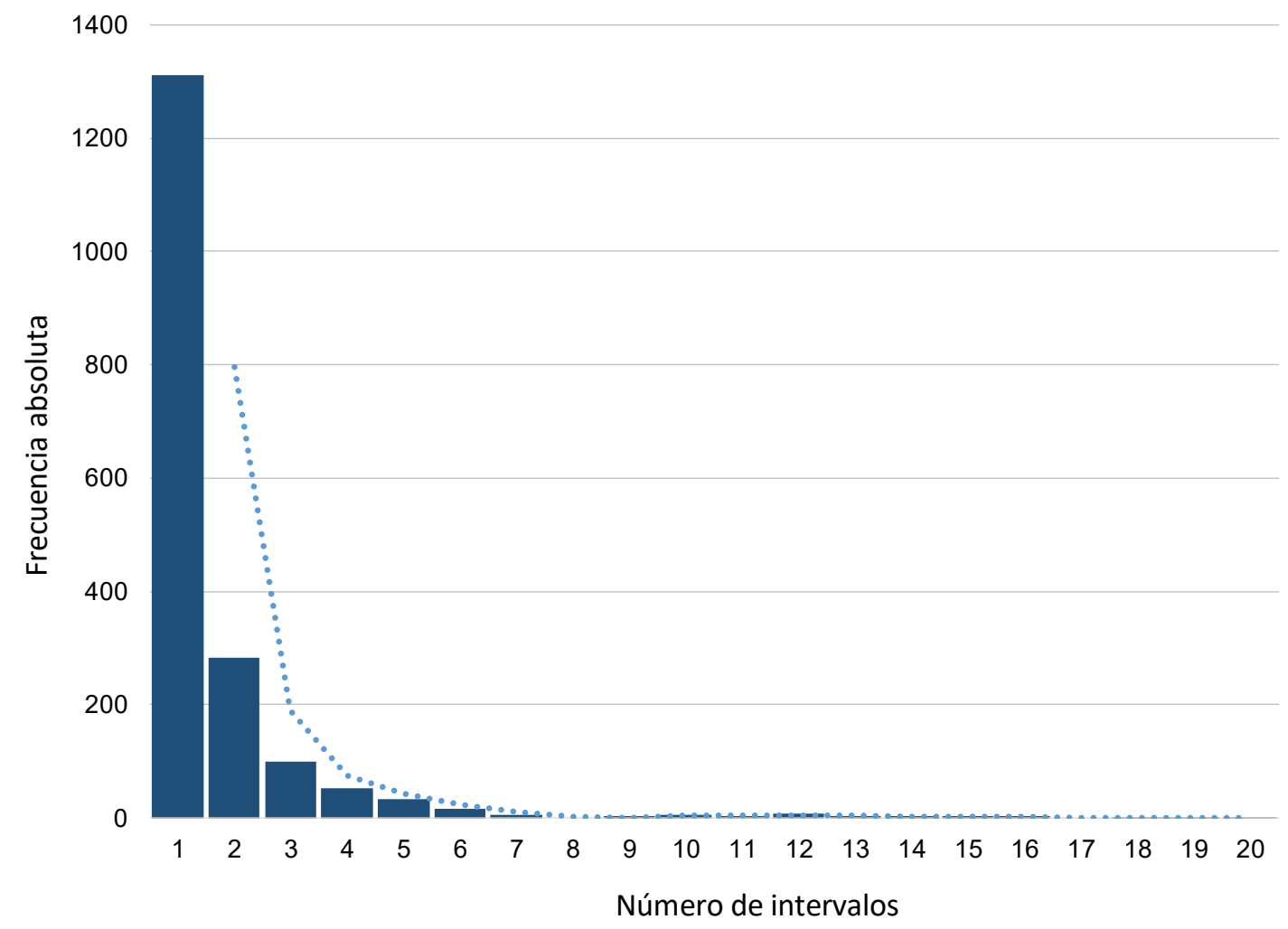

Figura 6.2 Histograma con los valores discretos del facto u1. (fuente: elaboración propia)

\begin{tabular}{ccccc}
$\begin{array}{c}\text { Número de } \\
\text { intervalos }\end{array}$ & $\begin{array}{c}\text { Límite } \\
\text { inferior }\left(\mathbf{u}_{1}\right)\end{array}$ & $\begin{array}{c}\text { Límite } \\
\text { superior }\left(\mathbf{u}_{1}\right)\end{array}$ & $\begin{array}{c}\text { Frecuencia } \\
\text { absoluta }\end{array}$ & $\begin{array}{c}\text { Frecuencia } \\
\text { relativa }\end{array}$ \\
\hline 1 & 1 & 1,14 & 1310 & $71,43 \%$ \\
\hline 2 & 1,14 & 1,28 & 283 & $15,43 \%$ \\
\hline 3 & 1,28 & 1,42 & 99 & $5,40 \%$ \\
\hline 4 & 1,42 & 1,56 & 52 & $2,84 \%$ \\
\hline 5 & 1,56 & 1,7 & 33 & $1,80 \%$ \\
\hline 6 & 1,7 & 1,84 & 16 & $0,87 \%$ \\
\hline 7 & 1,84 & 1,98 & 5 & $0,27 \%$ \\
\hline 8 & 1,98 & 2,12 & 0 & $0,00 \%$ \\
\hline 9 & 2,12 & 2,26 & 3 & $0,16 \%$ \\
\hline 10 & 2,26 & 2,4 & 6 & $0,33 \%$ \\
\hline 11 & 2,4 & 2,54 & 4 & $0,22 \%$ \\
\hline 12 & 2,54 & 2,68 & 7 & $0,38 \%$ \\
\hline 13 & 2,68 & 2,82 & 4 & $0,22 \%$ \\
\hline 14 & 2,82 & 2,96 & 3 & $0,16 \%$ \\
\hline 15 & 2,96 & 3,1 & 3 & $0,16 \%$ \\
\hline 16 & 3,1 & 3,24 & 3 & $0,16 \%$ \\
\hline 17 & 3,24 & 3,38 & 0 & $0,00 \%$ \\
\hline 18 & 3,38 & 3,52 & 1 & $0,05 \%$ \\
\hline 19 & 3,52 & 3,66 & 1 & $0,05 \%$ \\
\hline 20 & 3,66 & 3,8 & 1 & $0,05 \%$ \\
\hline
\end{tabular}

Tabla 6.1 Intervalos y frecuencias del factor u1(fuente: elaboración propia) 
Los valores máximos de $\mathbf{u}_{1}$, con escas frecuencia, corresponden a las zonas de la Comunidad de Madrid y de Barcelona y su área metropolitana. (imagen de la Figura $6.3)$

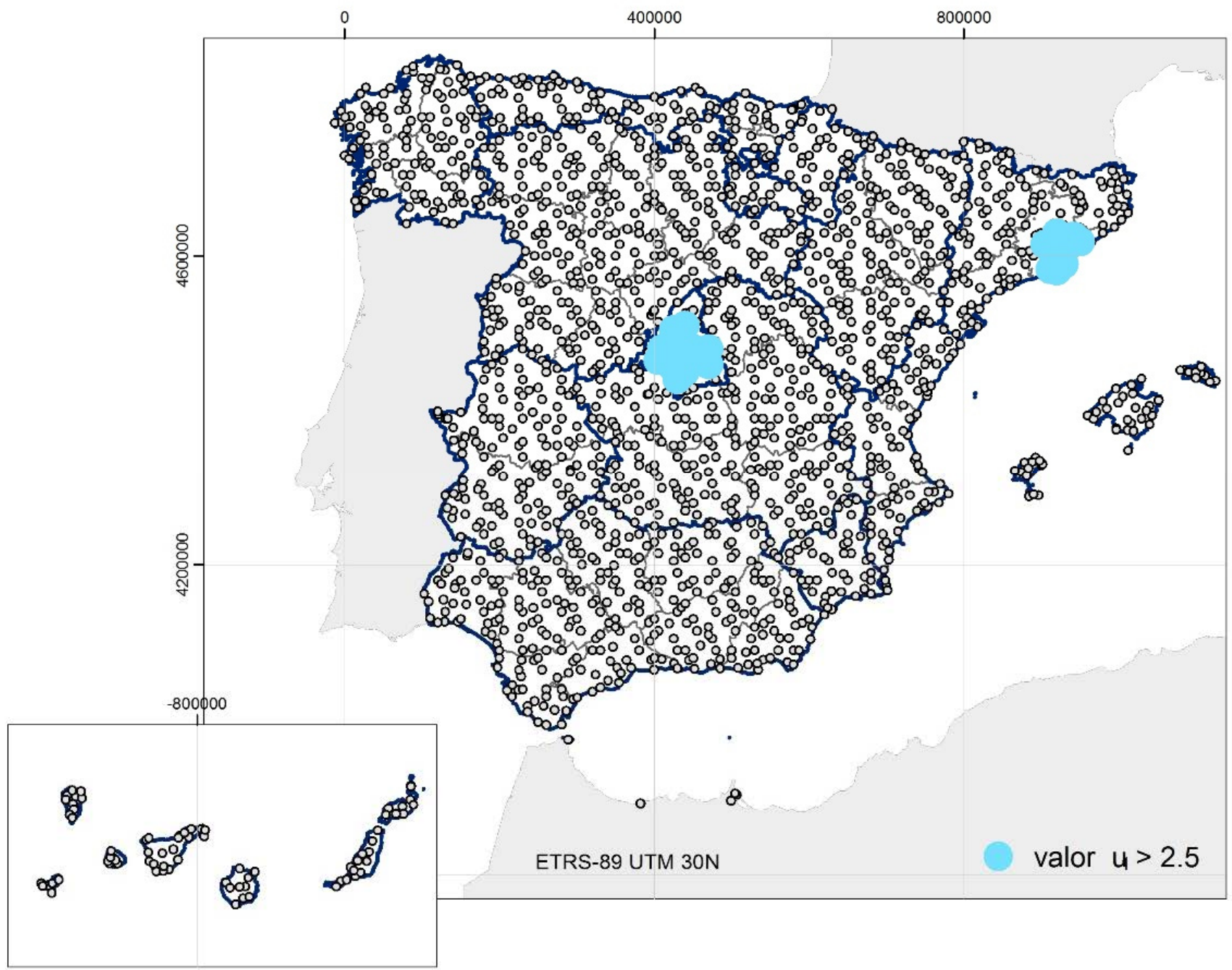

Figura 6.3. Representación de los valores de $u_{1}$ más altos en el mapa (fuente: elaboración propia)

Los valores continuos calculados y su representación gráfica permiten un estudio y análisis de los resultados obtenidos. En primer lugar, permiten conocer el valor del factor $\mathbf{u}_{1}$ en cualquier punto del territorio nacional, además de conseguir una visión del conjunto, en la que se observan las variaciones del valor dependiendo de su ubicación geográfica.

Se ha podido analizar de este modo qué elementos son los determinantes en la variación del valor del factor $\mathbf{u}_{1} \mathrm{y}$, a su vez, se ha podido constatar qué representan estos valores obtenidos del factor $\mathbf{u}_{1}$. Por un lado, como es lógico, los mayores valores del factor $\mathbf{u}_{1}$ se encuentran donde hay mayor número de población como foco de la 
ubicación del valor creándose un halo en torno al punto, que como veremos, puede tratarse de la zona de influencia de estos focos.

Llama la atención que, al margen de localizarse los focos en las grandes concentraciones de población (Madrid, Barcelona, Valencia, Sevilla...), también se emplazan los mayores valores de $\mathbf{u}_{1}$ a lo largo de la costa de levante, así como en la costa cantábrica. Esta circunstancia es relevante porque en la costa, a diferencia de las áreas interiores de la península, no existe población en la superficie del mar, a pesar de lo cual los valores que se obtienen del factor $\mathbf{u}_{1}$, son muy elevados.

Por otro lado, hay que tener en cuenta que la obtención de los diferentes valores del factor $\mathbf{u}_{1}$ implica su aplicación al valor resultante de la capitalización de las rentas de la explotación en el suelo en situación básica rural, incrementándolo.

Por ello se ha analizado qué cantidad de suelo (tanto en superficie como en porcentaje) del territorio nacional se encuentra en cada uno de los segmentos del valor del factor $\mathbf{u}_{1}, \mathrm{y}$ asimismo se ha reflejado qué incremento en el valor de suelo supone cada una de dichas categorías, resultando los datos que figuran en la Tabla 6.2.

\begin{tabular}{lcccc}
\multicolumn{2}{c}{ CATEGORÍA } & SUPERFICIE $\left(\mathbf{K m}^{2}\right)$ & $\%$ & INCREMENTO VALOR SUELO \\
\hline 1 & $1,00-1,02$ & $55.010,99$ & $11 \%$ & $0-2 \%$ \\
\hline 2 & $1,02-1,03$ & $67.000,21$ & $14 \%$ & $2-3 \%$ \\
\hline 3 & $1,03-1,06$ & $111.069,13$ & $23 \%$ & $3-6 \%$ \\
\hline 4 & $1,06-1,14$ & $130.497,02$ & $27 \%$ & $6-14 \%$ \\
\hline 5 & $1,14-1,37$ & $88.875,26$ & $18 \%$ & $14-37 \%$ \\
\hline 6 & $1,37-2,02$ & $30.816,52$ & $6 \%$ & $37-102 \%$ \\
\hline 7 & $2,02-3,82$ & $8.905,87$ & $2 \%$ & $102-237 \%$ \\
\hline TOTAL & $\mathbf{4 9 2 . 1 7 5 , 0 0}$ & $\mathbf{1 0 0} \%$ &
\end{tabular}

Tabla 6.2. Superficie en categorías de $u_{1}$ e incremento de valor de suelo (fuente: elaboración propia)

Como consecuencia de ello se observa que el $11 \%$ del territorio nacional tiene un valor del factor $\mathbf{u}_{1}$ situado en la categoría correspondiente al segmento 1 , alcanzando una magnitud situada entre 1 y 1,02 , lo que supone un incremento en el valor del suelo de la capitalización de las rentas hasta un $2 \%$. Por otra parte, el $14 \%$ del territorio nacional alcanza un valor del factor $\mathbf{u}_{1}$ localizado en la categoría 2 con una magnitud situada entre 1,02 y 1,03 , resultando un incremento en el valor del suelo entre un 2 y un $3 \%$. El $23 \%$ del territorio nacional tiene un valor del factor $\mathbf{u}_{1}$ localizado en la 
categoría 3 con magnitudes entre 1,03 y 1,06, resultando un incremento en el valor del suelo entre un 3 y un $6 \%$. El $27 \%$ del territorio nacional tiene un valor del factor $\mathbf{u}_{1}$ localizado en la categoría 4 con magnitudes entre 1,06 y 1,14, resultando un incremento en el valor del suelo calculado mediante la capitalización de las rentas situado entre un 6 y un $14 \%$. El 18\% del territorio nacional tiene un valor del factor $\mathbf{u}_{1}$ localizado en la categoría 5 con magnitudes entre 1,14 y 1,37 , resultando un incremento en el valor del suelo entre un 14 y un $37 \%$. El $6 \%$ del territorio nacional tiene un valor del factor $\mathbf{u}_{1}$ localizado en la categoría 6 con magnitudes entre 1,37 y 2,02, resultando un incremento en el valor del suelo entre un 37 y un $102 \%$. Finalmente, el $2 \%$ del territorio nacional tiene un valor del factor $\mathbf{u}_{1}$ localizado en la categoría 7 con magnitudes entre 2,02 y 3,82, resultando un incremento en el valor del suelo entre un 102 y un $237 \%$.

La mayoría del territorio nacional (92\% de su superficie) se encuentra entre los valores del factor $\mathbf{u}_{1} 1,00$ y 1,37 , mientras que solamente al $2 \%$ del suelo español se le aplicaría un factor entre el 2,02 y el máximo 3,82. Como veremos en el desarrollo del presente trabajo, este dato contrasta con los valores de población de España.

\subsection{ACERCA DEL FACTOR U $\mathrm{U}_{1}$ Y LAS EXPECTATIVAS URBANÍSTICAS}

Una vez realizado el estudio del valor del factor $\mathbf{u}_{1}$, en todo el territorio español, se ha procedido a analizar si realmente el mayor valor de dicho factor llevaba implícita la consideración de expectativas urbanísticas, tal y como habían concluido diferentes autores $^{17}$ a los que se ha hecho referencia en el apartado 2.5 del presente documento.

Para ello se ha llevado a cabo un análisis de la relación existente entre los valores del factor $\mathbf{u}_{1}$ y la clasificación urbanística de suelo en cada una de las localizaciones geográficas correspondientes.

En este sentido, es necesario recordar que el TRLSRU 2015 prescinde de la técnica urbanística de la clasificación de suelo, tal y como se ha indicado en el precedente apartado 2.4.1 Legislación de aplicación, distinguiendo dos situaciones básicas de suelo, con una finalidad: "Debe valorarse lo que hay, no lo que el plan dice que debe haber en un futuro incierto" (Preámbulo del TRLS 2008, de 20 de junio). Esta distinción entre clasificación del suelo y situaciones básicas ha transformado el sistema de valoración existente hasta la entrada en vigor de la Ley 8/2007 en España.

\footnotetext{
${ }^{17}$ Ana María de la Encarnación, Álvaro Jiménez Bueso.
} 
Para analizar la relación existente entre la magnitud del factor de localización y la clasificación urbanística, se ha realizado una superposición de la información obtenida sobre la clasificación urbanística de suelo (apartado 4.2.3.3 Clasificación urbanística del suelo) con los valores continuos del factor $\mathbf{u}_{1}$ realizados mediante el Kriging Ordinario (KO).

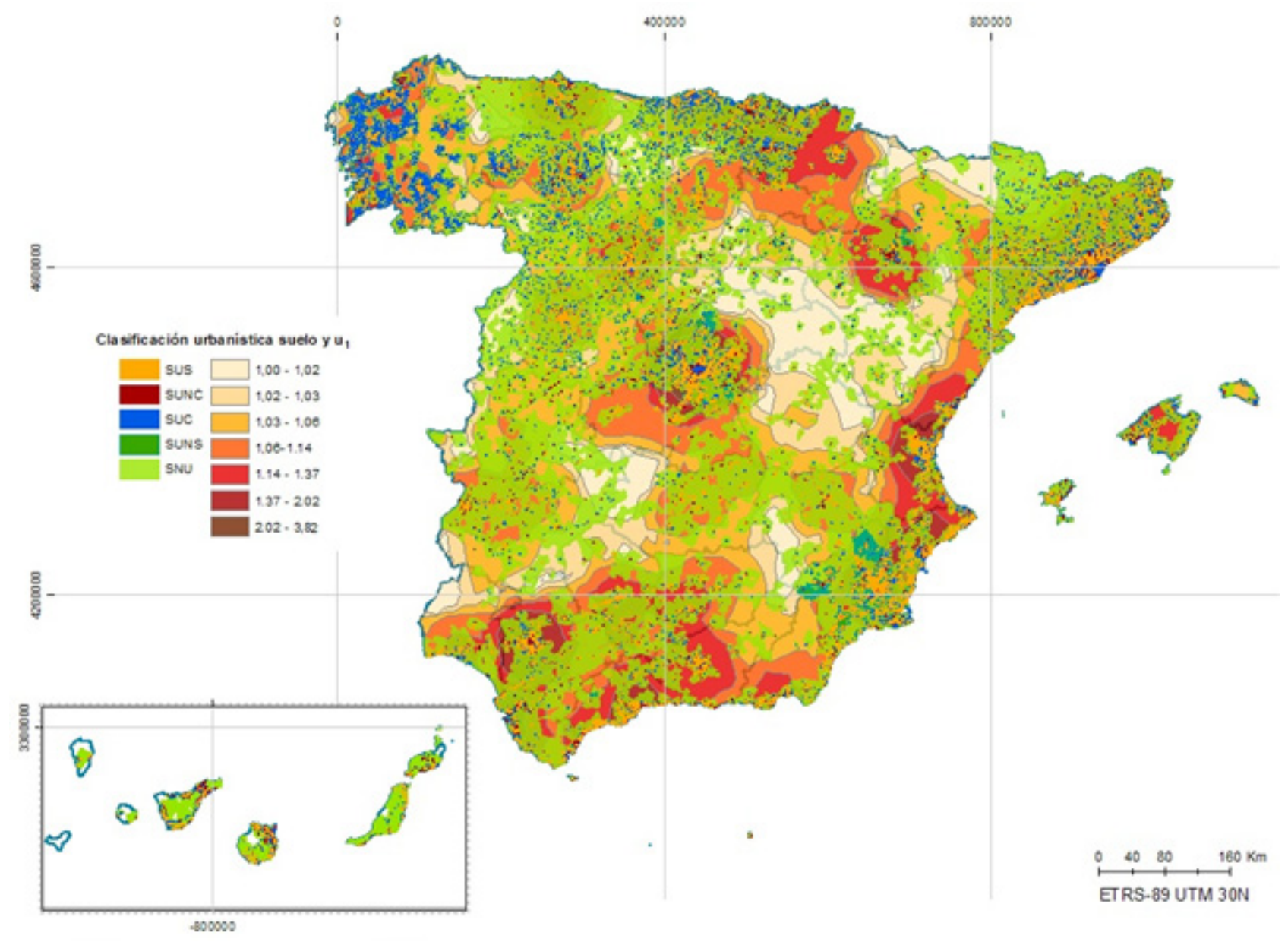

Figura 6.4 KO con valores de un y clasificación y categorías urbanísticas del suelo de la Comunidad de Madrid (fuente: elaboración propia)

Tal y como se indica en el apartado 4.2.3, el SIU ofrece en la actualidad información urbanística de 4.157 municipios (de los 8119 existentes, en la fecha de actualización de los datos utilizados), en los que se localiza el $92,2 \%$ de la población. Puesto que los datos obtenidos a partir del SIU no están referidos a la totalidad del territorio nacional, no ha sido posible hacer extensivo el análisis a todo el territorio español. Por ello, ha parecido procedente llevar a cabo la investigación en aquellas Comunidades Autónomas en las que se dispone de la totalidad de la información sobre la clasificación urbanística del suelo, con el fin de realizar un análisis fiable. Las Comunidades objeto de análisis son: Madrid, Cataluña y Murcia. 
El motivo de la elección de la Comunidad de Madrid y Cataluña se debe a que en ambas se han obtenido los mayores valores del factor de corrección $\mathbf{u}_{1}$, así como el mayor número de habitantes en cada una de las ciudades más representativas (Madrid y Barcelona). Las diferencias existentes entre una y otra son, por un lado, que la Comunidad de Madrid se encuentra en el centro de la península, mientras que la catalana linda con el litoral y el límite fronterizo de Francia; por otro lado, Madrid es una Comunidad uniprovincial, mientras Cataluña dispone de cuatro provincias.

Por su parte, la Región de Murcia tiene unos valores del factor de corrección $\mathbf{u}_{1}$ bastante elevados, a pesar de no encontrarse entre las Comunidades de mayor número de población, como es el caso de la de Madrid y Cataluña. Además, al igual que Cataluña linda con el litoral y al igual que Madrid se trata de una Comunidad uniprovincial. Lo que todas tienen en común es que se dispone de la clasificación urbanística del suelo (a partir de los datos del SIU) del 100\% de su superficie, dato necesario para el análisis a realizar.

Es necesario mencionar que las clasificaciones de suelo que se han adoptado en el presente análisis son:

- Suelo urbano consolidado (SUC). Si bien en esta clase y categoría urbanística de suelo no es de aplicación el factor de corrección $\mathbf{u}_{1}$, parece lógico que, suponiendo que la aplicación de $\mathbf{u}_{1}$ llevara implícita la consideración de expectativas, en esta clase y categoría de suelo, los valores que se obtuvieran deberían ser muy superiores que, en el resto de las clases y categorías urbanística de suelo de un municipio, por tratarse de un suelo "finalista"18. Por ello ha parecido interesante considerarlo, para comparar el valor obtenido en dicha clase y categoría frente al resto de las mismas que deberían tener valores muy inferiores.

- Suelo urbano no consolidado (SUNC). En esta clase y categoría urbanística de suelo, en la mayoría de los casos es de aplicación el factor de corrección $\mathbf{u}_{1}$, puesto que la valoración de los mismos se realizará considerando que se trata de suelo en situación básica rural.

- Suelo urbanizable sectorizado (SUS)

- Suelo urbanizable no sectorizado (SUNS)

18 Término coloquial utilizado para referirse a suelos en los que el derecho a edificar no requiere de ningún deber en referencia a tramitación de planeamiento urbanístico o en referencia a la actividad de ejecución urbanística. 
En las dos últimas clases de suelo será más habitual el uso del factor de corrección $\mathbf{u}_{1}$, ya que tanto el TRLSRU 2015 como el Reglamento de valoraciones que lo desarrolla definen claramente la situación básica de dichos suelos y, como consecuencia, el método de valoración aplicable (capitalización de las rentas y corregido con la aplicación del Factor de Localización).

\subsubsection{Factor $u_{1}$ y expectativas en la Comunidad de Madrid}

La elección de la Comunidad de Madrid (en adelante CM) se debe a que el SIU facilita una información completa sobre la clasificación urbanística de la totalidad de su territorio.

Se puede comprobar que la mayor superficie de suelo tiene la clasificación urbanística de Suelo No Urbanizable (SNU), se observa también que los núcleos de cada uno de los municipios tienen gran cantidad de suelos clasificados y categorizados como Suelo Urbano Consolidado (SU). Destaca también sobre todo en los municipios que rodean Madrid los suelos clasificados y categorizados como Suelos Urbanizables Sectorizados (SUS).

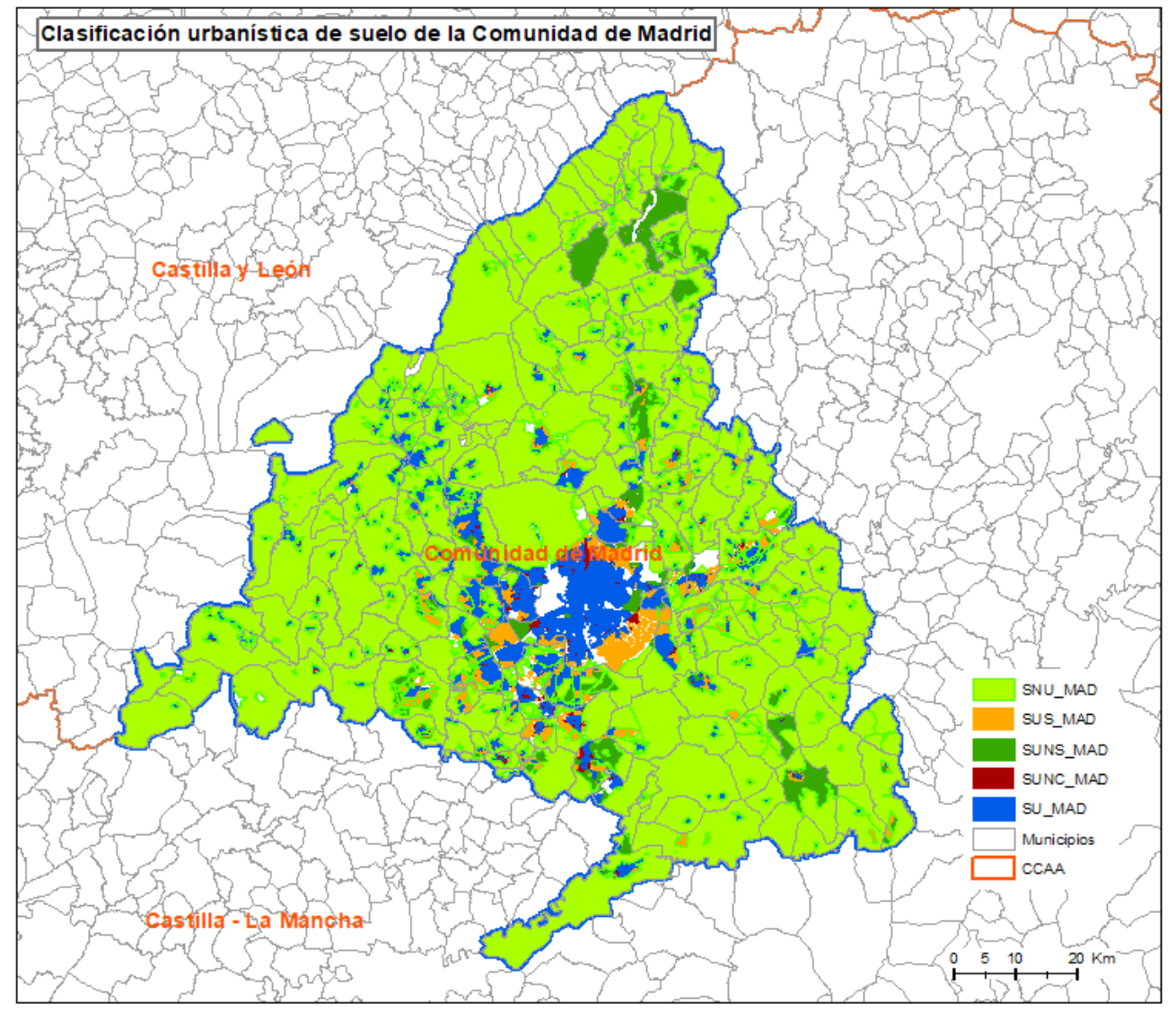

Figura 6.5 Clasificación urbanística del suelo de la Comunidad de Madrid (fuente: elaboración propia) 
Para analizar la relación entre la clasificación urbanística y los valores continuos de $\mathbf{u}_{1}$ obtenidos a partir del Kriging Ordinario se han superpuesto ambos datos, observando que el mayor porcentaje de superficie de suelo (60\%) de la Comunidad se localiza sobre la categoría 7 del factor $\mathbf{u}_{1}$ (valores de 2,02 a 3,82), de acuerdo con la Tabla 6.2. Seguidamente en la categoría 6 (valores de 1,37 a 2,02) de las relacionadas en dicha tabla se localiza el $22,71 \%$ de la superficie de suelo. El resto de suelo se distribuye en las restantes categorías del factor $\mathbf{u}_{1}$. Los datos aquí recogidos se pueden observar en la Figura 6.6.

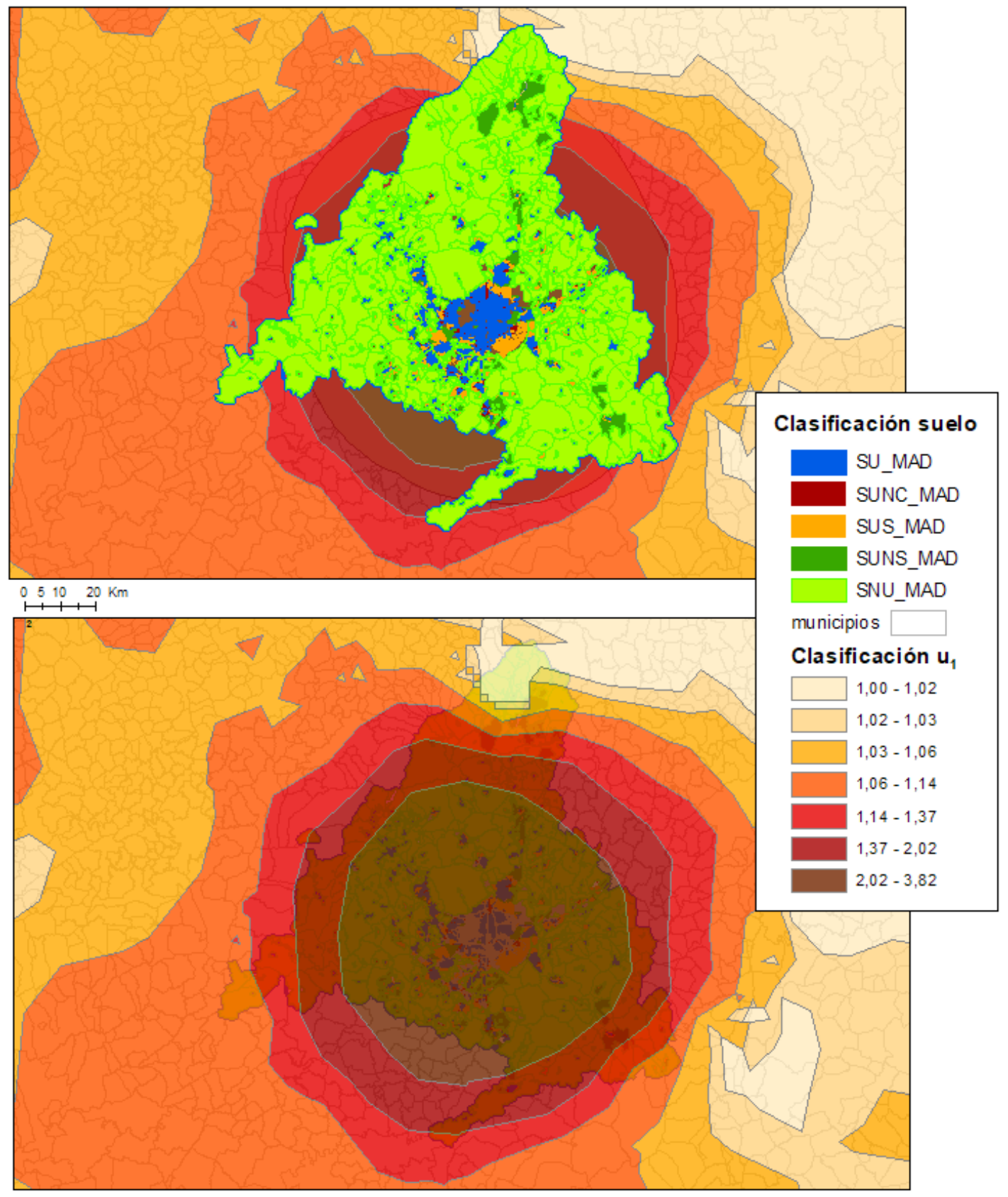

Figura 6.6. Superposición de clasificación urbanística del suelo de la Comunidad de Madrid y valores $u_{1}$ (fuente: elaboración propia) 
Puesto que el valor del factor $\mathbf{u}_{1}$ está directamente relacionado con la cantidad de población de las diferentes ubicaciones, se incluye la Figura 6.7, en la que se puede comprobar la densidad de población y el número de habitantes localizados en cada uno de los municipios de la Comunidad de Madrid.

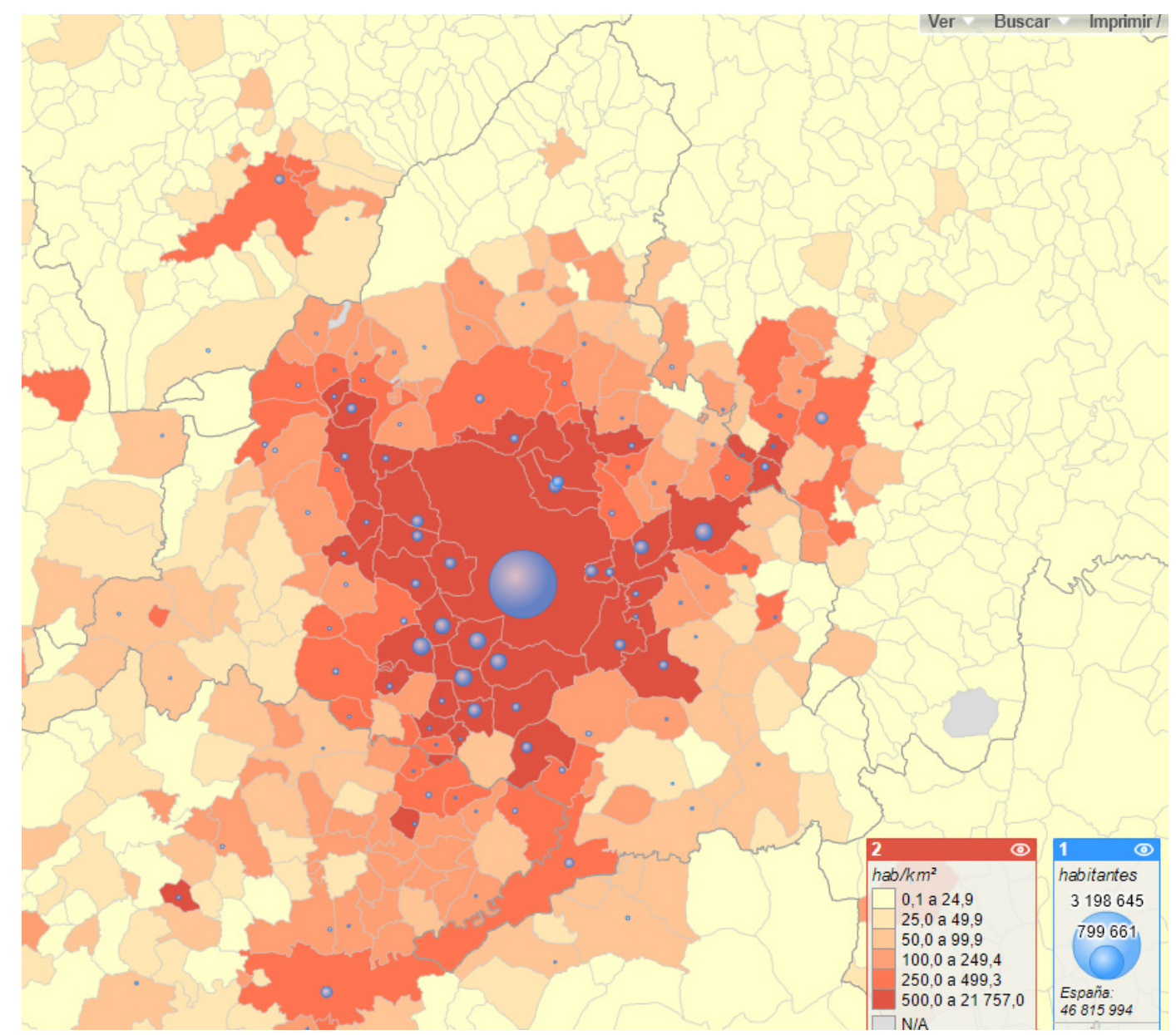

Figura 6.7. Densidad de población y número de habitantes de la Comunidad de Madrid (fuente: Atlas Digital de la Áreas Urbanas Ministerio de Fomento)

En la Tabla 6.3 se puede observar la cantidad de superficie existente en cada una de las categorías del factor $\mathbf{u}_{1}$ y la superficie de las clases y categorías urbanísticas de suelo analizadas.

Para realizar una aproximación a la conexión entre el factor de corrección $\mathbf{u}_{1}$ y las expectativas urbanísticas se ha realizado un estudio de la relación entre el valor de $\mathbf{u}_{1}$ dentro de la segmentación elegida en el KO y la cantidad de suelo (medida en superficie) de cada una de las clasificaciones urbanísticas que se han referenciado en el apartado 4.2.3.3 Clasificación urbanística del suelo. De este modo lo que se pretende es averiguar si realmente la aplicación del factor $\mathbf{u}_{1}$ conlleva el plusvalor 
originado por las expectativas urbanísticas.

\begin{tabular}{|c|c|c|c|c|c|c|c|}
\hline \multicolumn{2}{|c|}{ CATEGORÍA } & \multirow{2}{*}{$\begin{array}{c}\text { SUPERFICIE } \\
\mathbf{( H a )}\end{array}$} & \multirow{2}{*}{$\begin{array}{c}\% \\
2,46 \%\end{array}$} & \multirow{2}{*}{$\begin{array}{c}\begin{array}{c}\text { SUC } \\
\mathbf{H a}\end{array} \\
122,03\end{array}$} & \multirow{2}{*}{$\begin{array}{c}\begin{array}{c}\text { SUNC } \\
\mathrm{Ha}\end{array} \\
0\end{array}$} & \multirow{2}{*}{$\begin{array}{c}\text { SUS } \\
\mathrm{Ha}\end{array}$} & \multirow{2}{*}{$\begin{array}{c}\begin{array}{c}\text { SUNS } \\
\text { Ha }\end{array} \\
481,18\end{array}$} \\
\hline 1 & $1,00-1,02$ & & & & & & \\
\hline 2 & $1,02-1,03$ & $6.267,77$ & $0,78 \%$ & 29,55 & 0 & 26,98 & 324,43 \\
\hline 3 & $1,03-1,06$ & $14.494,65$ & $\%$ & 132,89 & 2,28 & 32,23 & $3.459,92$ \\
\hline 4 & $1,06-1,14$ & $33.737,56$ & $4,20 \%$ & 306,32 & 19,51 & 567,63 & $4.453,77$ \\
\hline 5 & $1,14-1,37$ & $64.502,43$ & $8,04 \%$ & $1.217,72$ & 265,93 & 195,31 & $5.107,07$ \\
\hline 6 & $1,37-2,02$ & $182.278,78$ & $22,71 \%$ & $5.447,76$ & 364,68 & $1.646,27$ & $3.805,11$ \\
\hline 7 & $2,02-3,82$ & $481.543,44$ & $60,00 \%$ & $62.384,21$ & $4.426,08$ & $35.561,74$ & $14.399,76$ \\
\hline & & $802.557,78$ & $100 \%$ & $\begin{array}{c}69.640,48 \\
8,68 \%\end{array}$ & $\begin{array}{c}5.078,48 \\
0,63 \%\end{array}$ & $\begin{array}{c}38.030,16 \\
4,74 \%\end{array}$ & $\begin{array}{c}32.031,23 \\
3,99 \%\end{array}$ \\
\hline
\end{tabular}

Tabla 6.3. Categorías $u_{1}$ y clasificación de suelo (fuente: elaboración propia)

Para lleva a cabo dicho estudio se han representado los valores obtenidos en unos gráficos de columnas o barras en los que se pueden comparar 3 valores diferentes:

- Clasificación de los valores de $\mathbf{u}_{1}$ en las 7 categorías definidas.

- Clases y categorías urbanísticas del suelo: suelo urbano consolidado (SUC), suelo urbano no consolidado (SUNC), suelo urbanizable sectorizado (SUS) y suelo urbanizable no sectorizado (SUNS)

- Valor homogenizado de la superficie de suelo. Se ha homogenizado el valor de las superficies de suelo en cada una de las clases y categorías urbanísticas de suelo entre 0 y 1 , para poder comparar los resultados.

En el estudio en la Comunidad de Madrid (6.495.551 habitantes) se obtuvo el siguiente diagrama:

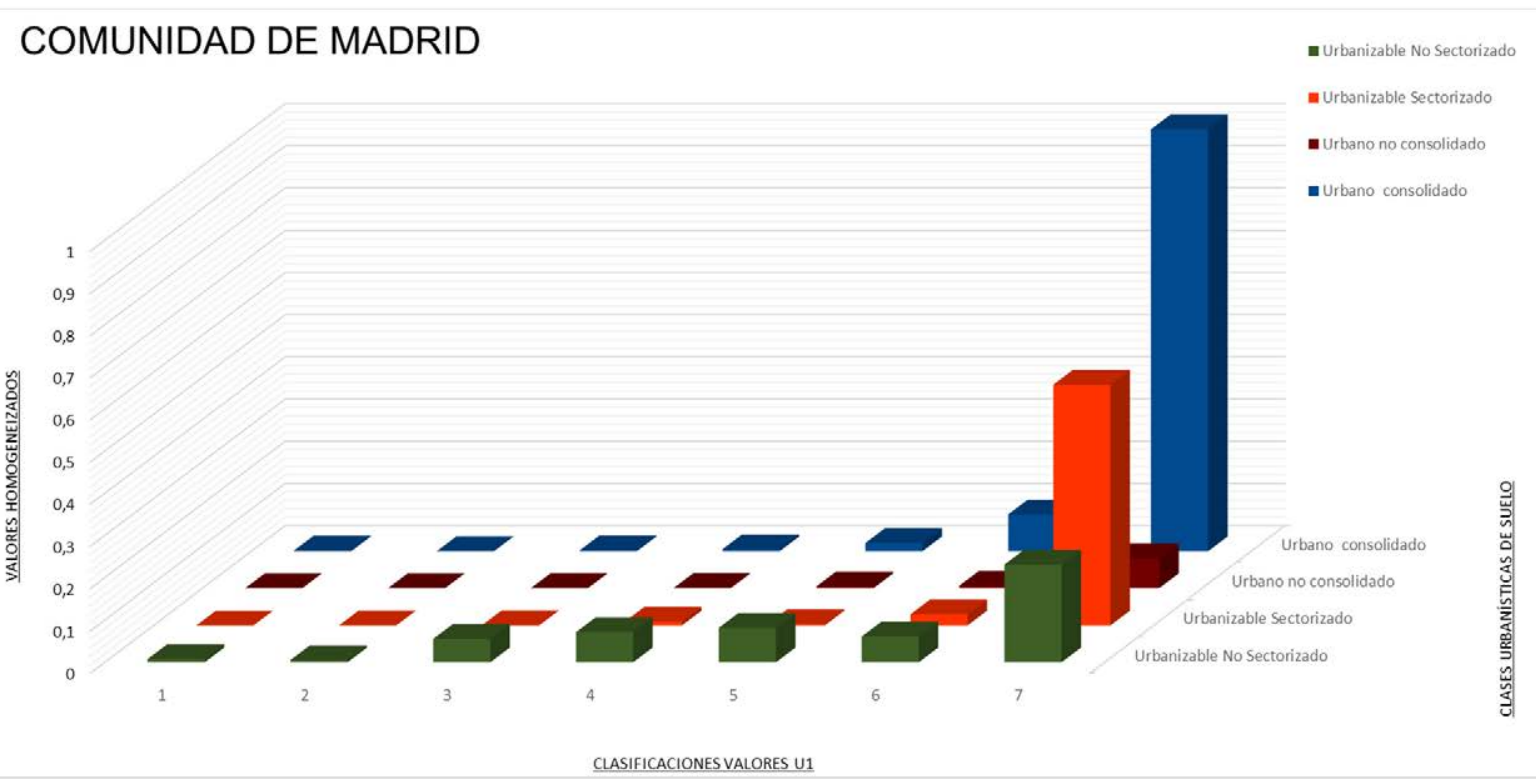

Figura 6.8. Diagrama de columnas clasificación de suelo, clasificación de u1 y superficie en Comunidad Madrid (fuente: elaboración propia) 
En este diagrama se observa que la gran mayoría de los valores de $\mathbf{u}_{1}$ se encuentran en la clase 7 de la Tabla 6.2, donde las magnitudes de aquellos oscilan entre 2,02 y 3,82. El suelo urbanizable no sectorizado (SUNS) tiene valores en otras categorías de $\mathbf{u}_{1}$, situadas entre la 2 a 7 . Todas y cada una de las clases y sus categorías de suelo tienen asignado el mismo valor del coeficiente $\mathbf{u}_{1}$. El suelo urbano consolidado (SUC) es la categoría con mayor cantidad de superficie y la que presenta una menor superficie es el suelo urbano no consolidado.

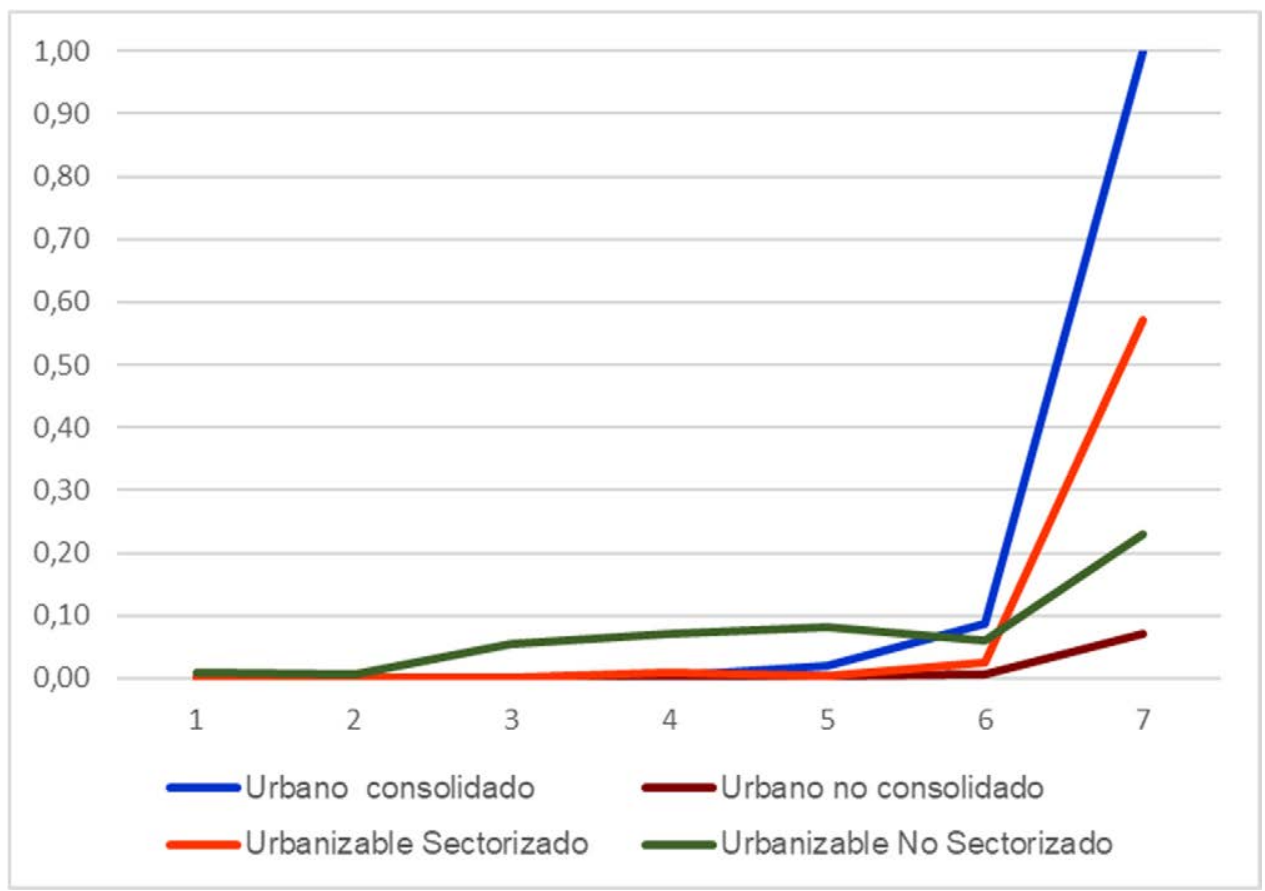

Figura 6.9. Diagrama de líneas clasificación suelo, calificación de u1 y superficie en CM (fuente: elaboración propia)

Se realizó posteriormente el estudio en diferentes municipios de la Comunidad de Madrid con diferente número de habitantes:

- Madrid (3.207.747 habitantes)

- Leganés (186.995 habitantes)

- Aranjuez (57.728 habitantes)

- Robledo de Chavela (4.137 habitantes)

Se han obtenido los siguientes diagramas: 

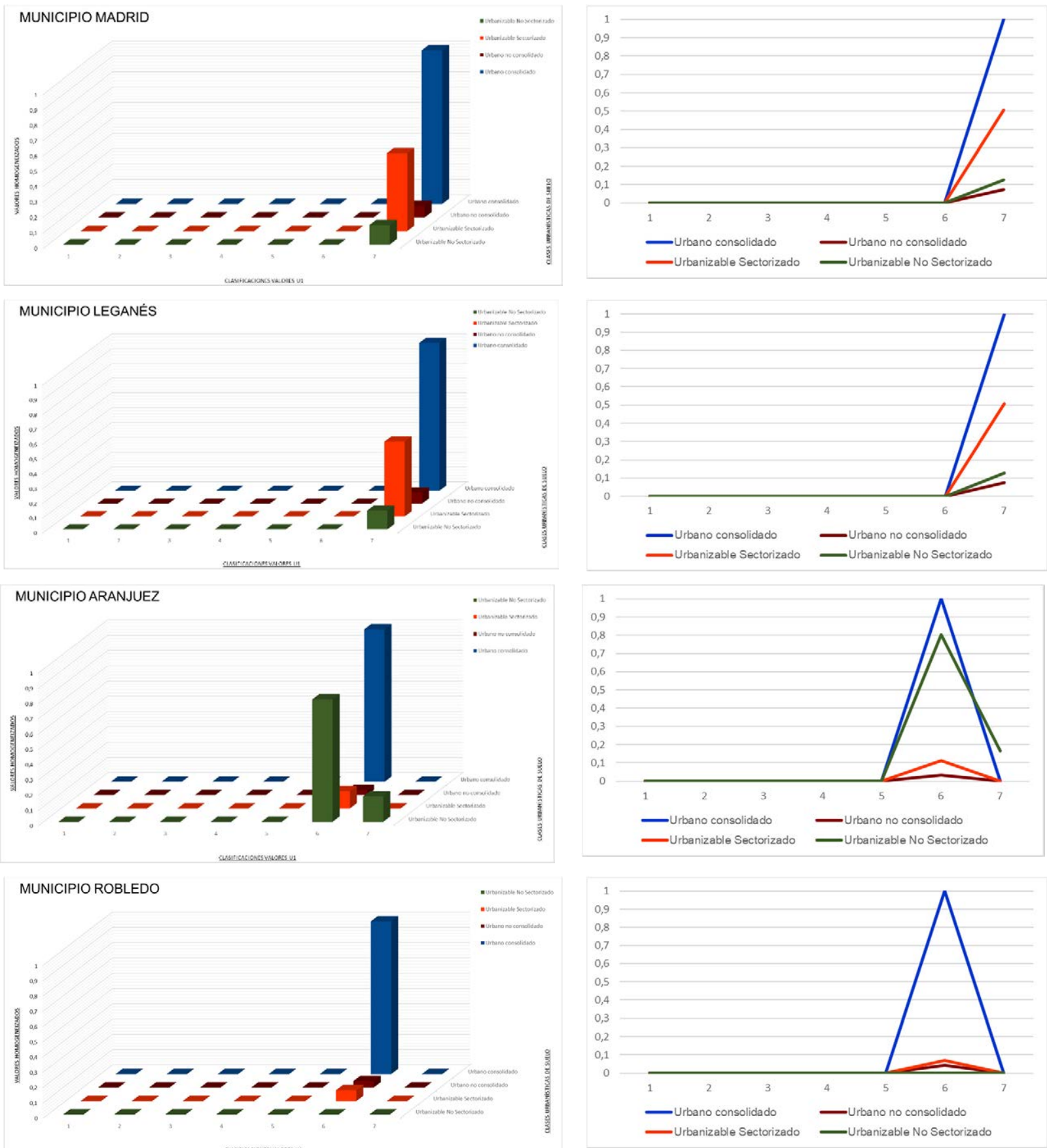

Figura 6.10. Diagrama de columnas y líneas clasificación de suelo, clasificación de u y superficie en municipios de Madrid, Leganés, Aranjuez y Robledo de Chavela (fuente: elaboración propia)

Se observa que los valores obtenidos en Madrid y Leganés son similares entre sí y, a su vez, son también análogos a los del conjunto de la Comunidad de Madrid. Únicamente difieren en que en estos dos municipios solamente se obtienen valores en la clase 7 de los valores de $\mathbf{u}_{1}$, mientras que en el conjunto de la Comunidad de Madrid también se obtienen valores en las clases $3,4,5$ y 6 de los valores de $\mathbf{u}_{1}$, localizados sobre todo en el SUNS. 
En Aranjuez se obtienen valores, sobre todo, en la clase 6 de valor $\mathbf{u}_{1}$ y en la clase 7 solamente en el SUNS.

En Robledo de Chavela se obtienen unos valores similares a Aranjuez, aunque no se obtienen valores para el SUNS, debido a que el planeamiento general que ordena el municipio está regulado por unas Normas Subsidiarias de Planeamiento que, en consecuencia, no disponen de la clasificación urbanística de suelo urbanizable no sectorizado.

Además, se ha analizado la situación de otros municipios, cada uno de ellos en una de las clasificaciones del valor $\mathbf{u}_{1}$ :

- Patones (502 habitantes). Predominantemente categoría 5.

- Cenicientos (2.091 habitantes). Predominantemente categoría 4.

- Robledillo de la Jara (102 habitantes). Predominantemente categoría 4.

- La Hiruela (51 habitantes). Predominantemente categoría 2.

- Robregordo (60 habitantes). Predominantemente categoría 1.

MUNICIPIO PATONES

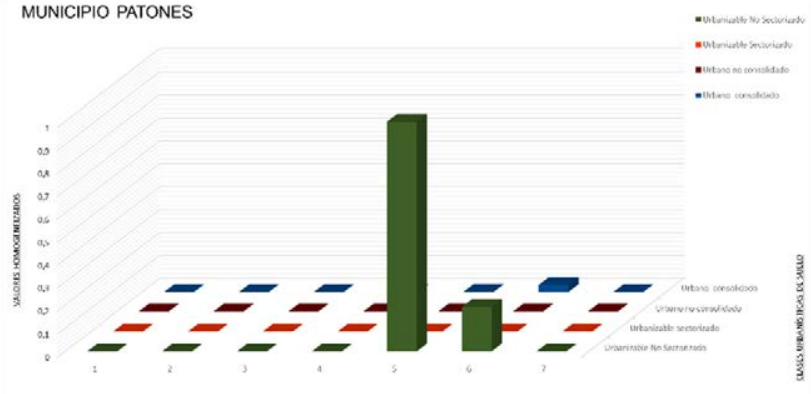

MUNICIPIO CENICIENTOS

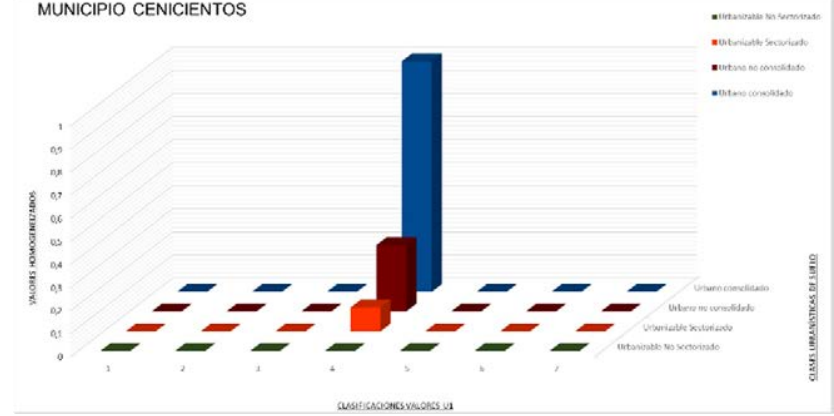

MUNICIPIO ROBLEDILLO DE LA JARA

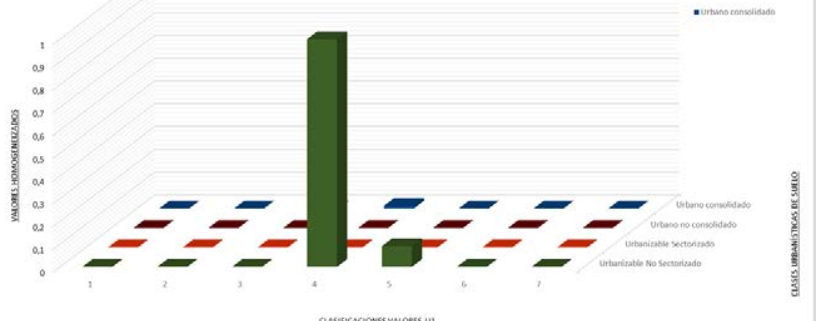

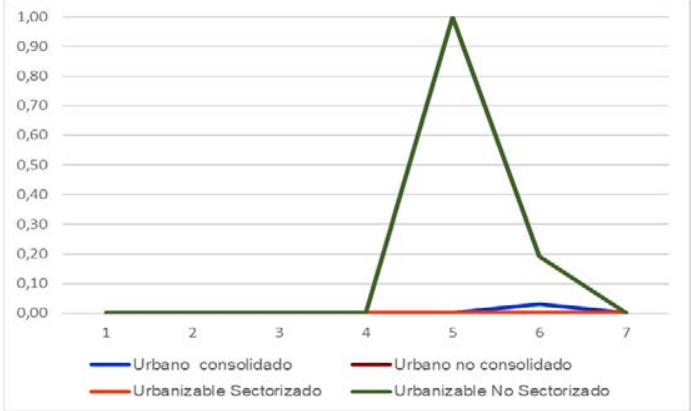

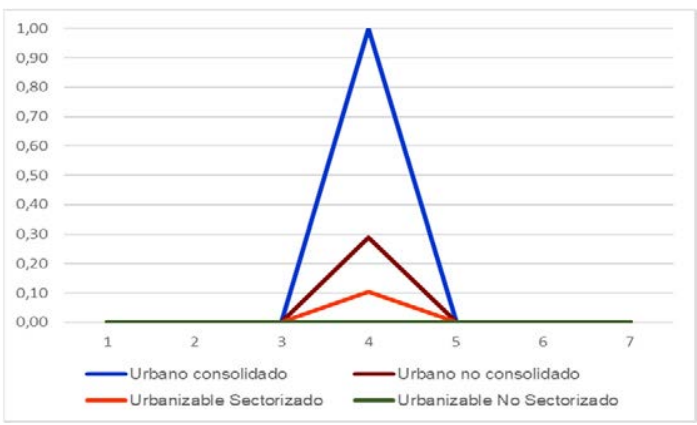

-Urbanizable Sectorizado Urbanizable No Sectorizado

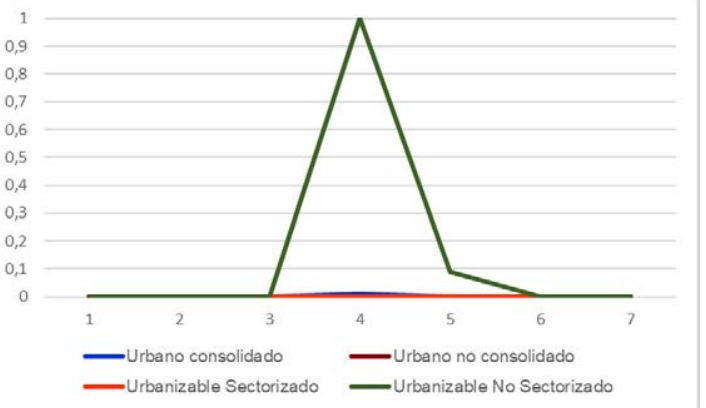



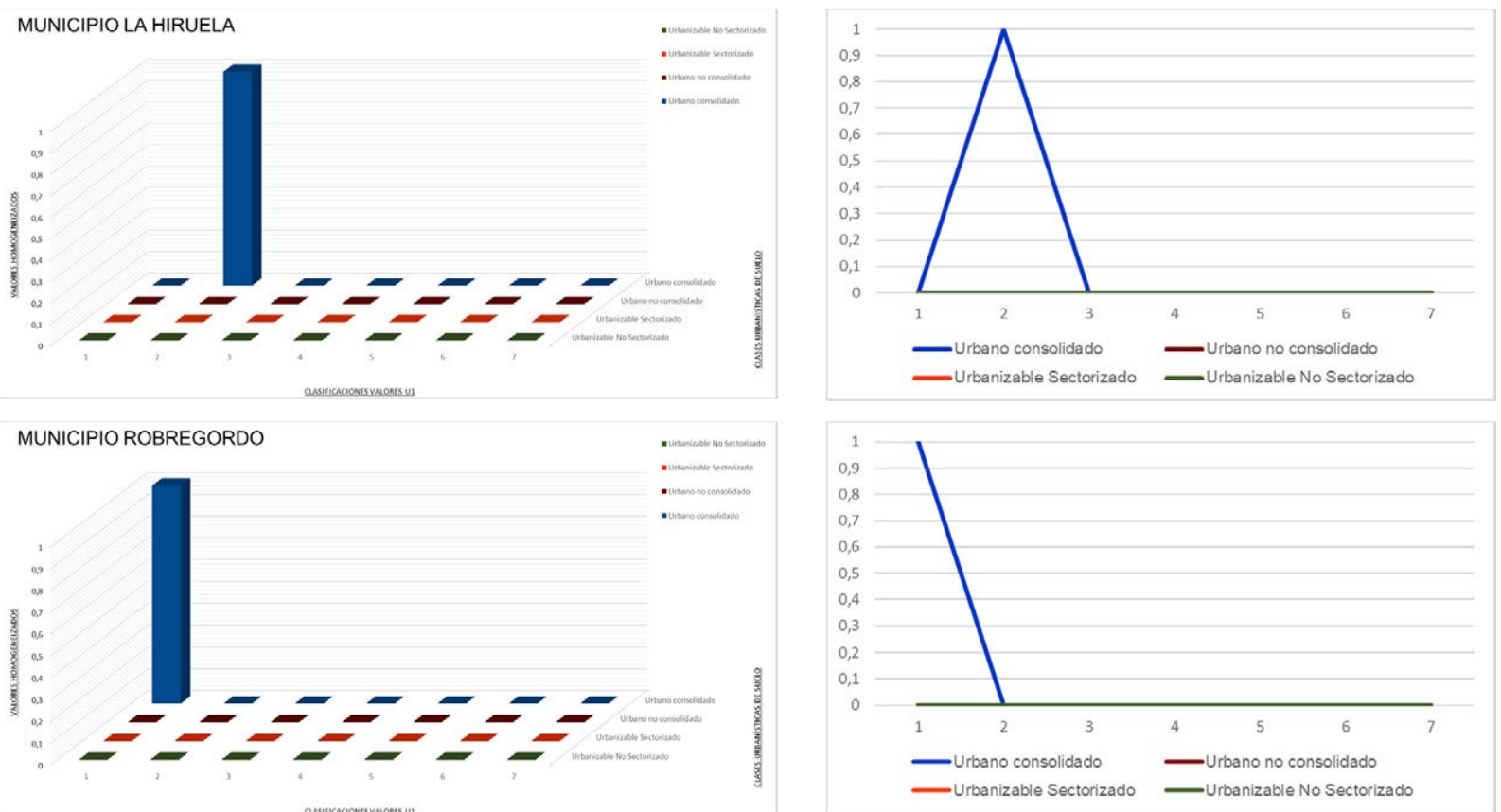

Figura 6.11. Diagrama de columnas clasificación de suelo, clasificación de $u_{1}$ y superficie en municipios de Patones, Cenicientos, Robledillo de la Jara, Prádena, La Hiruela y Robregordo (fuente: elaboración propia)

En lo referente a la clasificación de suelo de cada uno de los municipios estudiados es necesario señalar que Patones y Robledillo de la Jara son los únicos municipios estudiados en los que la mayor parte del suelo es Suelo Urbanizable No Sectorizado (SUNS). Esta clasificación y categorización del suelo tiene su origen en una determinación del planeamiento general correspondiente, que en ambos casos se trata de Normas Subsidiarias de Planeamiento (en adelante NNSS) aprobadas definitivamente ambas en el año 1992, sino que viene motivada por una modificación legislativa. En los suelos de dichos municipios que en la actualidad tienen la clasificación y categorización de SUNS, las NNSS de sus respectivos municipios los clasificaban y categorizaban como Suelo No Urbanizable Común. Pero con la entrada en vigor de la Ley 9/2001 y en aplicación de la Disposición Transitoria primera, a los suelos con dicha clasificación y categorización se les aplicaría automáticamente el régimen establecido para los suelos que la Ley definía como SUNS.

Para obtener una visión de conjunto, se representan en la Figura 6.12 tres mapas en los que se observa la clasificación de suelo, los valores de las diferentes categorías del factor de corrección $\mathbf{u}_{1}$ y la densidad de población en toda la Comunidad de Madrid en cada uno de los municipios estudiados.

En la Figura 6.12 se puede observar cómo en aquellos municipios situados próximos a Madrid y, en general a su área de influencia, en los que la densidad de población es 
bastante elevada, se obtienen asimismo elevados valores del factor de corrección $\mathbf{u}_{1}$, situados en el entorno de a la categoría 6 (valores de 1,37 a 2,02) y 7 (valores de 2,02 a 3,82). Por su parte, los municipios como Patones, Cenicientos, Robledillo de la Jara, Prádena, La Hiruela y Robregordo están situados a mucha distancia del área de influencia de Madrid y su área de influencia, siendo muy reducida la densidad de población de los municipios próximos, reduciéndose así los valores del factor de corrección $\mathbf{u}_{1}$, a medida que crece la distancia que les separa del foco de Madrid.

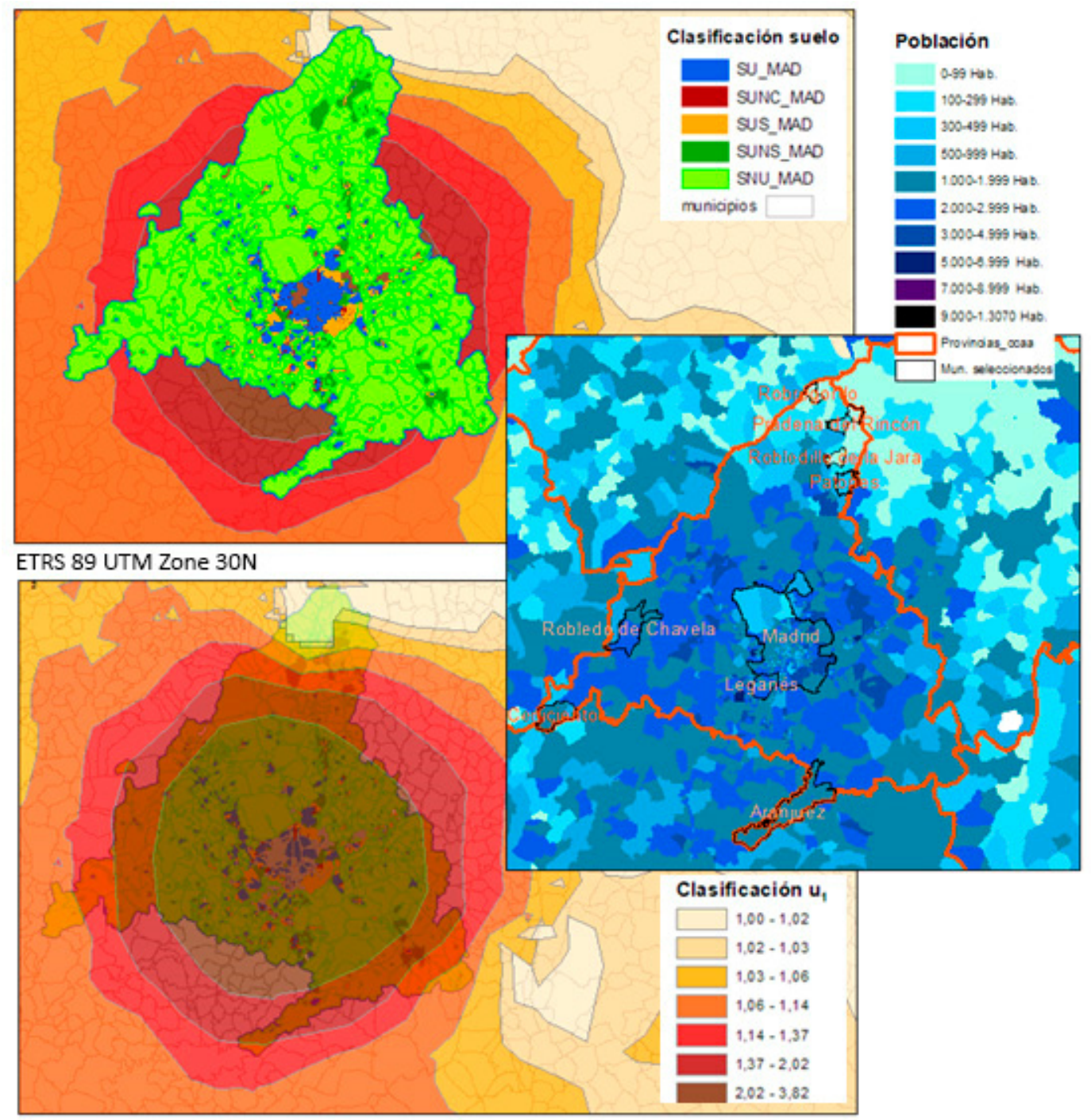

Figura 6.12. Superposición de clasificación urbanística del suelo de la Comunidad de Madrid, valores u y cantidad de población, municipios estudiados marcados en densidad de población (fuente: elaboración propia)

Por otro lado, puesto que la clasificación urbanística del suelo es asignada por el planeamiento general de cada municipio como determinación estructurante de la ordenación, en la Figura 6.13 se han representado dicho planeamiento, así como el año de su aprobación. 


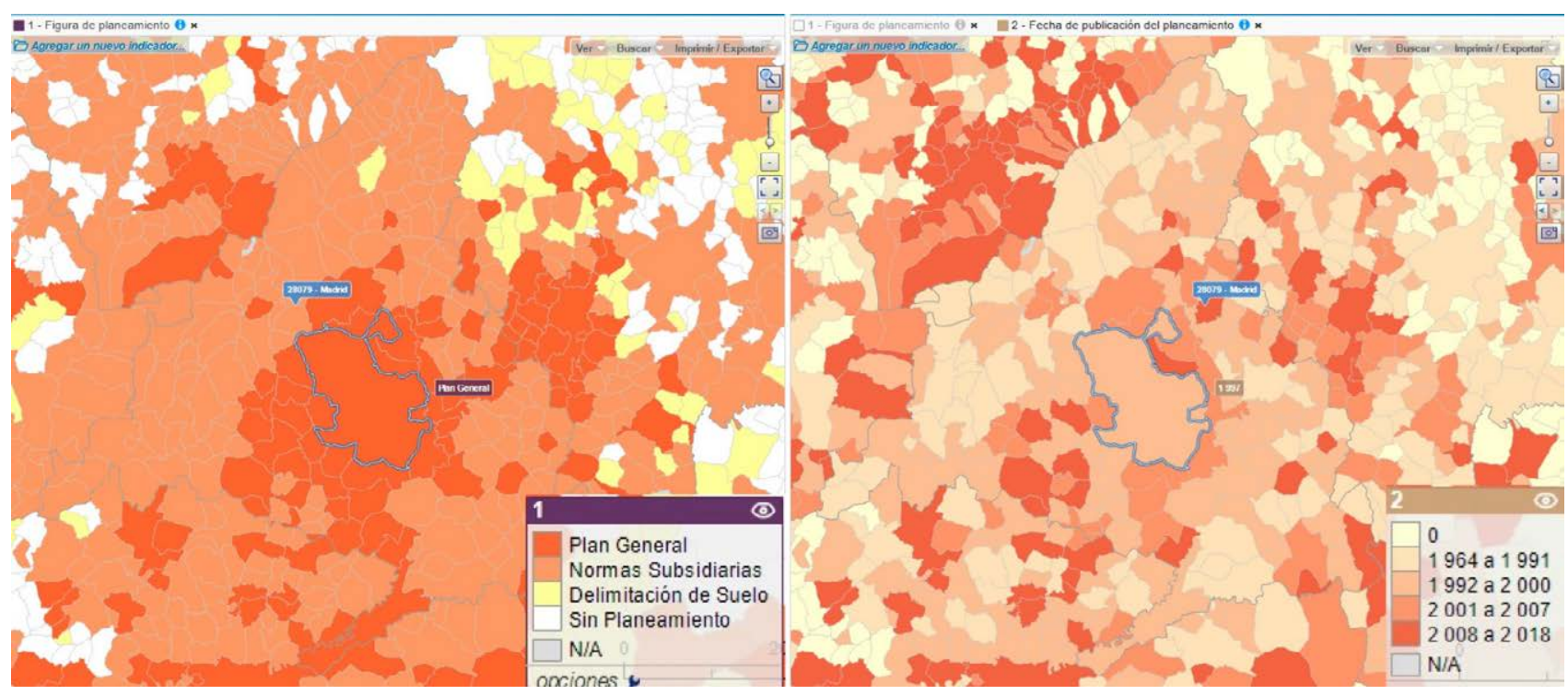

Figura 6.13. 1) Instrumentos planeamiento general-

2) Fecha de publicación del planeamiento de la Región de Murcia

Además, en la Tabla 6.4 se ha recogido para cada municipio estudiado, la categoría del factor de corrección $\mathbf{u}_{1}$ en la que se encuentra, la cantidad de habitantes, la extensión superficial de cada uno de ellos, el porcentaje de superficie en la totalidad de la Comunidad de Madrid y la superficie de suelo en cada una de las clasificaciones y categorías urbanísticas de suelo: SUC, SUNC, SUS y SUNS. Se ha incluido también la fecha de aprobación del Planeamiento General de cada uno de dichos municipios.

\begin{tabular}{|c|c|c|c|c|c|c|c|c|c|}
\hline Municipio & $\begin{array}{c}\text { Categoría } \\
\mathrm{u}_{1} \\
\end{array}$ & $\begin{array}{l}\text { Población } \\
\text { habitantes }\end{array}$ & $\begin{array}{c}\text { SUPERFICIE } \\
\left(\mathbf{k m}^{2}\right)\end{array}$ & $\%$ & $\begin{array}{l}\text { SUC } \\
\mathbf{k m}^{2}\end{array}$ & $\begin{array}{c}\text { SUNC } \\
\mathbf{k m}^{2}\end{array}$ & $\begin{array}{l}\text { SUS } \\
\mathbf{k m}^{2}\end{array}$ & $\begin{array}{c}\text { SUNS } \\
\text { km² }^{2}\end{array}$ & $\begin{array}{c}\text { Planea. } \\
\text { fecha }\end{array}$ \\
\hline Madrid & 7 & 3.165 .541 & 605,30 & 7,54 & 157,06 & 11,63 & 79,43 & 19,87 & 1997 \\
\hline Leganés & 7 & 187.173 & 43,10 & 0,54 & 10,07 & 0,00 & 8,15 & 0,69 & 2000 \\
\hline Aranjuez & 6 & 57.932 & 201,10 & 2,51 & 8,33 & 8,15 & 0,95 & 8,06 & 1996 \\
\hline $\begin{array}{l}\text { Robledo de } \\
\text { Chavela }\end{array}$ & 6 & 4.137 & 93,00 & 1,16 & 0,00 & 0,69 & 0,36 & 0,00 & 1990 \\
\hline Patones & 5 & 502 & 34,47 & 0,43 & 1,1 & 0 & 0 & 40,03 & 1988 \\
\hline Cenicientos & 4 & 2.091 & 68,24 & 0,85 & 0,93 & 0,27 & 0,09 & 0 & 1991 \\
\hline $\begin{array}{l}\text { Robledillo de } \\
\text { la Jara }\end{array}$ & 4 & 102 & 21,00 & 0,26 & 0,52 & 0 & 0 & 50,41 & 1992 \\
\hline La Hiruela & 2 & 51 & 17,15 & 0,21 & 0,14 & 0 & 0 & 0 & 1991 \\
\hline Robregordo & 1 & 60 & 18,34 & 0,23 & 1,21 & 0 & 0 & 0 & 1992 \\
\hline Total estudio & & 3.417 .589 & $1.101,70$ & 13,73 & 179,36 & 20,74 & 88,98 & 119,05 & \\
\hline TOTAL CM & & 6.495 .551 & $8.025,58$ & 100 & 696,40 & 50,78 & 380,3 & 320,31 & \\
\hline
\end{tabular}

Tabla 6.4. Valores totales comparados con la CM (fuente: elaboración propia)

En la Figura 6.14 se ha representado gráficamente el perímetro de cada uno de los municipios analizados y se ha superpuesto sobre la distribución de los valores continuos del factor de corrección $\mathbf{u}_{1}$. 


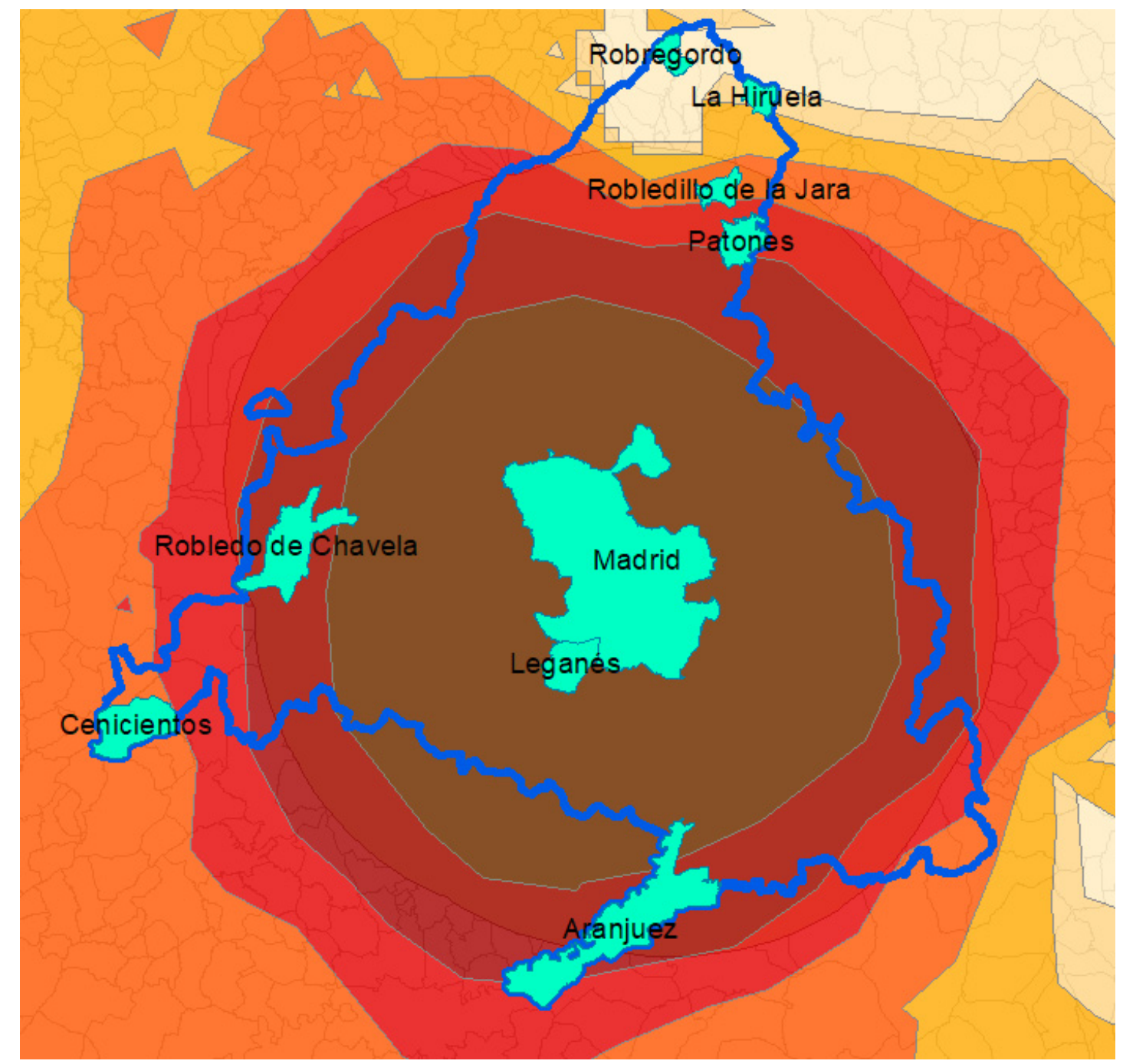

Figura 6.14. Municipios estudiados de la CM: Madrid, Leganés, Aranjuez, Robledo de Chavela, Patones, Cenicientos, Robledillo de la Jara, La Hiruela y Robregordo (fuente: elaboración propia)

\subsubsection{Conclusión Comunidad de Madrid}

Con los datos obtenidos y tras el análisis correspondiente, se observa que los resultados obtenidos son los siguientes:

- La mayoría del suelo de la Comunidad de Madrid se encuentra dentro de los valores de $\mathbf{u}_{1}$ en la categoría 7 (valores de 2,02 a 3,82). En concreto, en esta situación se encuentran 121 municipios de los 179 que integran la Comunidad.

- Sólo el 18,04 \% de la superficie de suelo de la Comunidad tiene aprovechamiento lucrativo ${ }^{19}$, de cuyo total el $8,68 \%$ tiene la clasificación urbanística de Suelo Urbano Consolidado (SUC). Esta última categoría es la

19 La expresión "aprovechamiento lucrativo" se refiere a aquellos suelos a los que el planeamiento urbanístico les atribuye aprovechamiento urbanístico. 
que tiene mayor superficie dentro de la Comunidad entre todos los suelos con usos lucrativos, mientras que el 9,36 \% restante es suelo pendiente de desarrollo (SUNC, SUS, SUNS) (Tabla 6.3).

- Dentro de todas las categorías del valor $\mathbf{u}_{1}$ se encuentran todas las clases y categorías urbanísticas de suelo de cada uno de los municipios, incluso el Suelo No Urbanizable (SNU). De tal forma que se aplica el mismo factor $\mathbf{u}_{\mathbf{1}}$ a un suelo clasificado como urbano no consolidado (SUNC) como a un suelo no urbanizable (SNU).

- Se observa que el patrón de comportamiento de los gráficos de barras de Madrid y Leganés es similar, esto es debido a que se encuentran muy próximos geográficamente e incluso Leganés se encuentra dentro del área metropolitana de Madrid. Y, como cabía esperar, en el resto de los municipios, al ir alejándose de Madrid, los valores del factor $\mathbf{u}_{1}$ van descendiendo de categoría, de forma que cuanto mayor es el alejamiento de foco atractivo de Madrid, menor es la categoría de valor $\mathbf{u}_{1}$.

Lo que más llama la atención de los resultados obtenidos es que en todos los municipios los valores del factor de corrección $\mathbf{u}_{1}$ son iguales en la totalidad del suelo dentro de cada ámbito estudiado. Es decir, que no se incrementa el valor del factor de corrección en los suelos con la proximidad de una clasificación y categorización urbanística determinada. En este caso, por ejemplo, del Suelo Urbano No Consolidado (SUNC), en la que la actividad de ejecución del planeamiento requiere menos deberes urbanísticos que en otra clase y categoría, por ejemplo, Suelo Urbanizable No Sectorizado (SUNS), en la que tanto el planeamiento necesario como la ejecución del mismo, suponen una carga mucho mayor que Suelo Urbano sin consolidar.

\subsubsection{Factor $u_{1}$ y expectativas en la Región de Murcia}

La clasificación de suelo en la Región de Murcia se representa en la Figura 6.15. Se puede comprobar que la mayor superficie de suelo tiene la clasificación urbanística de Suelo No Urbanizable (SNU), y se observa también que en la mayoría de los municipios existe gran cantidad de suelo clasificado y categorizado como Suelo Urbanizable No Sectorizado (SUNS). Lo mismo sucede en los suelos clasificados y categorizados como Suelo Urbanizable Sectorizado (SUS), estos últimos en una superficie muy inferior a la SUNS.

Parece necesario hacer una reflexión sobre la clasificación de suelo descrita en párrafo anterior ya que en todos los municipios de la Región se mantiene el mismo 
patrón en la clasificación y categorización de suelo. Tanto la legislación en materia de suelo vigente (artículo 84 de la Ley 13/2015, de 30 de marzo, de ordenación territorial y urbanística de la Región de Murcia) como la anterior (artículo 65 del Decreto Legislativo 1/2005, de 10 de junio), disponen que existirá una "categoría de suelo urbanizable "especial" para los terrenos incluidos en la huerta tradicional, con peculiaridades características de asentamientos existentes". Esta es la razón que explica la cantidad de suelo que tiene atribuida la clasificación urbanística de suelo urbanizable.

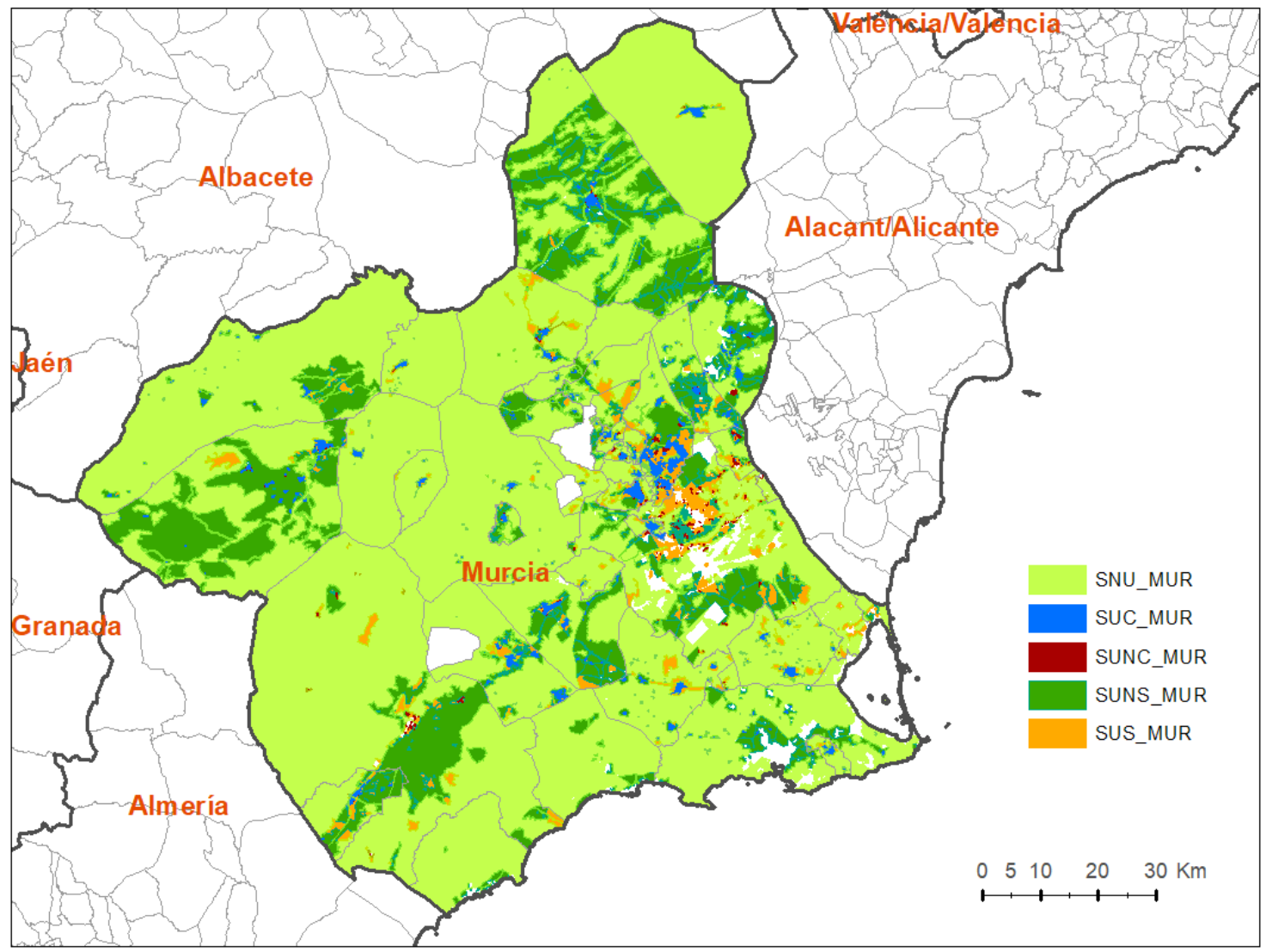

Figura 6.15 Clasificación urbanística del suelo de la Región de Murcia (fuente: elaboración propia)

Del mismo modo que se hizo en la Comunidad de Madrid, en la Región de Murcia se superponen la clasificación urbanística del suelo y los valores continuos obtenidos de $\mathbf{u}_{1}$ con el objetivo de analizar la relación entre ambos tipos de datos. Como consecuencia de ello se ha observado que el mayor porcentaje de superficie de suelo $(40,80 \%)$ de la Región se localiza sobre la categoría 6 del factor $\mathbf{u}_{1}$ (valores de 1,37 a 2,02 ). Seguidamente en la categoría 4 (valores de 1,06 a 1,14 ) se localiza el $27,41 \%$ de la superficie de suelo. El resto de suelo se distribuye entre las restantes categorías del factor $\mathbf{u}_{1}$, a excepción de la categoría 1 (valores de 1 a 1,02) donde al igual que en la categoría 7 (valores de 2,02 a 3,82), no existe ninguna superficie de suelo (Figura 6.16). 


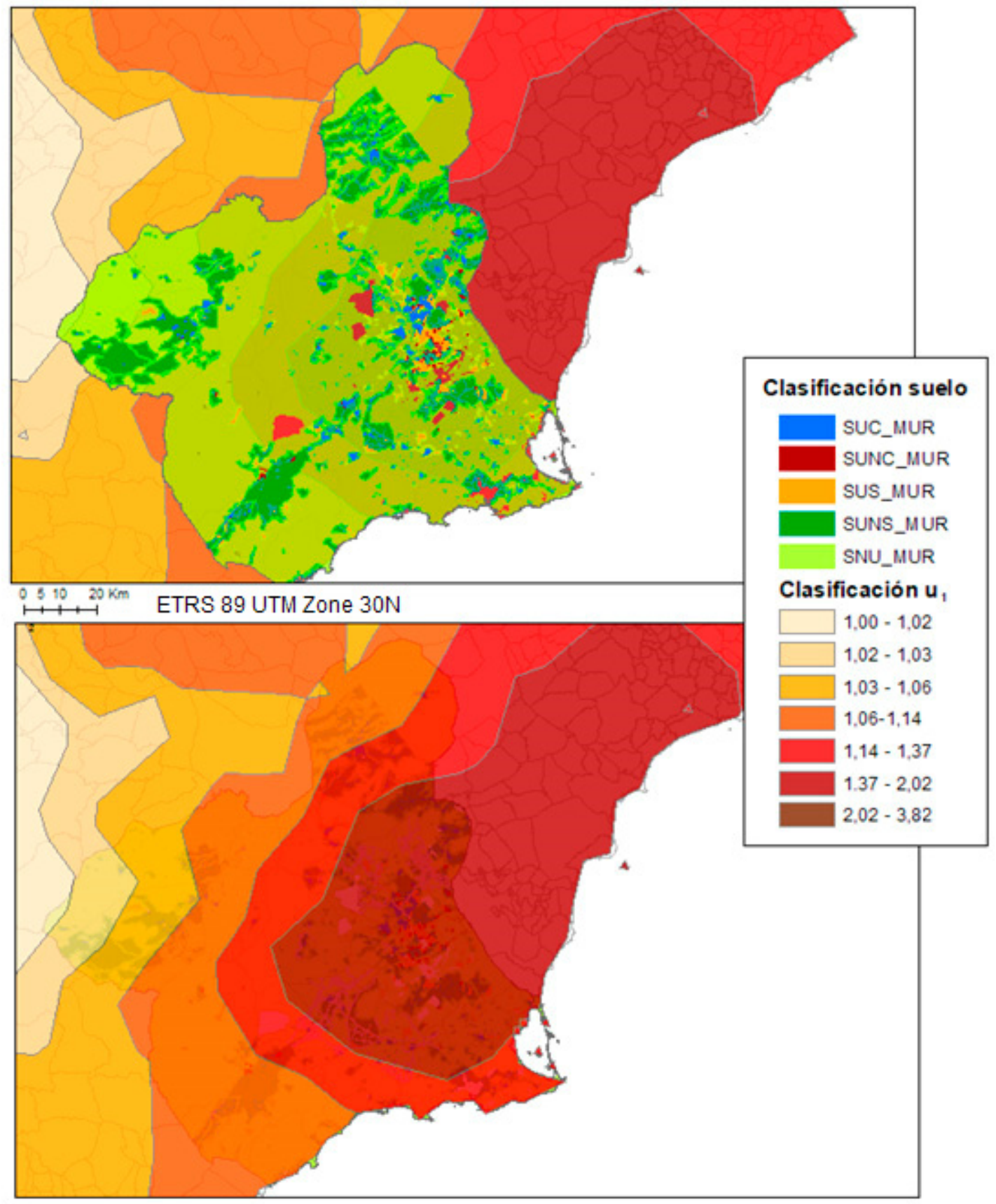

Figura 6.16. Superposición de clasificación urbanística del suelo de la Región de Murcia y valores $u_{1}$. ETRS 89 UTM (fuente: elaboración propia)

Puesto que el valor del factor $\mathbf{u}_{1}$ está directamente relacionado con la cantidad de población de las diferentes ubicaciones, en la Figura 6.17 se puede comprobar la cantidad de población existente en cada uno de los municipios de la Región de Murcia. 


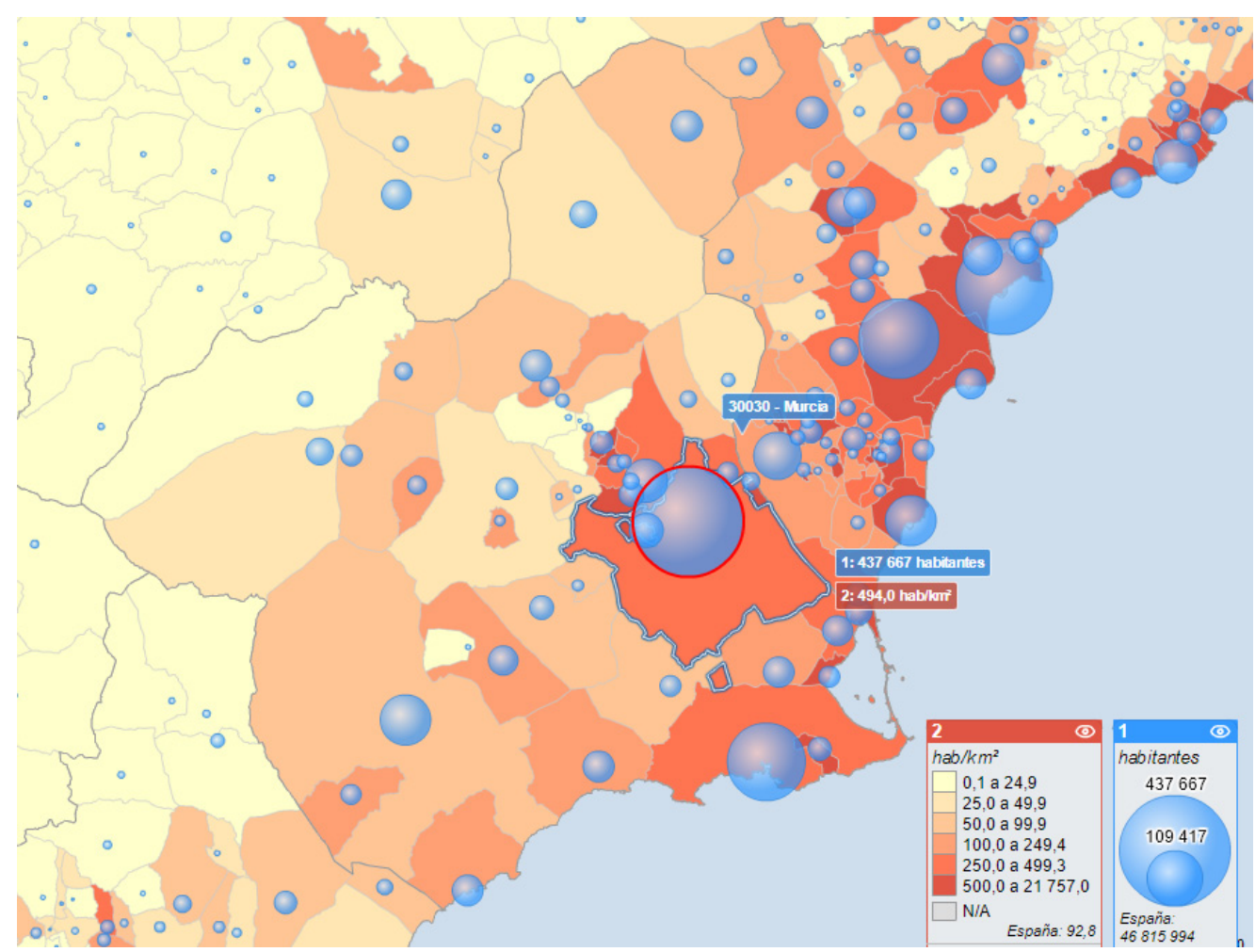

Figura 6.17. Densidad de población y número de habitantes de la Región de Murcia (fuente: ATLAS ÁREAS URBANAS SIU)

Por otra parte, en la Tabla 6.5 se puede observar la cantidad de superficie existente en cada una de las categorías del factor $\mathbf{u}_{1}$ y la superficie de cada una de las clases y categorías urbanísticas de suelo estudiadas.

Para conocer si la relación del factor $\mathbf{u}_{1}$ con el plusvalor de las expectativas, al igual que en la Comunidad de Madrid, se ha realizado un estudio de la relación entre el valor de dicho factor dentro de la segmentación elegida representada en la Tabla 6.2 y la cantidad de suelo (medida en superficie) de cada una de las clasificaciones urbanísticas que se han referenciado en el apartado 4.2.3.3 Clasificación urbanística del suelo.

\begin{tabular}{cccccccc}
\multicolumn{2}{c}{ CATEGORÍA } & $\begin{array}{c}\text { SUPERFICIE } \\
\text { (Ha) }\end{array}$ & $\begin{array}{c}\text { SUC } \\
\mathrm{Ha}\end{array}$ & SUNC & sUS & SUNS \\
\hline 1 & $1,00-1,02$ & 2.963 & $0,00 \%$ & 0,00 & 0,00 & 0,00 & 0,00 \\
\hline 2 & $1,02-1,03$ & 44.319 & $2,98 \%$ & 0,00 & 4,80 & 88,42 & $7.515,11$ \\
\hline 3 & $1,03-1,06$ & 79.204 & $10,47 \%$ & 742,51 & 96,95 & $1.492,17$ & $24.405,62$ \\
\hline 4 & $1,06-1,14$ & 361.270 & $27,41 \%$ & $2.206,57$ & 273,29 & $6.751,35$ & $60.748,02$ \\
\hline 5 & $1,14-1,37$ & 284.019 & $18,33 \%$ & $6.069,34$ & 366,95 & $4.385,72$ & $35.969,06$ \\
\hline 6 & $1,37-2,02$ & 359.538 & $40,80 \%$ & $13.165,13$ & $1.365,03$ & $25.112,85$ & $64.517,38$ \\
\hline 7 & $2,02-3,82$ & 0 & $0,00 \%$ & 0,00 & 0,00 & 0,00 & 0,00 \\
\hline \multirow{2}{*}{ TOTAL } & & $\mathbf{1 . 1 3 1 . 3 1 3}$ & $\mathbf{1 0 0 \%}$ & $\mathbf{2 2 . 1 8 3 , 5 4}$ & $\mathbf{2 . 1 0 7 , 0 2}$ & $\mathbf{3 7 . 8 3 0 , 5 1}$ & $\mathbf{1 9 3 . 1 5 5 , 1 9}$ \\
& & & $\mathbf{1 , 9 6 \%}$ & $\mathbf{0 , 1 9 \%}$ & $\mathbf{3 , 3 4 \%}$ & $\mathbf{1 7 , 0 7 \%}$
\end{tabular}

Tabla 6.5. Categorías u y clasificación de suelo Región de Murcia (fuente: elaboración propia) 
Para dicho estudio, de la misma forma que en el estudio realizado para la Comunidad de Madrid, se analizaron los valores obtenidos en unos gráficos de columnas o barras donde se comparaban los 3 valores diferentes ya definidos en el análisis de la Comunidad de Madrid: Clasificación de los valores de $\mathbf{u}_{1}$, clases y categorías urbanística y los valores homogenizados de la superficie de suelo.

En el estudio en la Región de Murcia (1.472.049 habitantes) se obtuvo el siguiente diagrama:
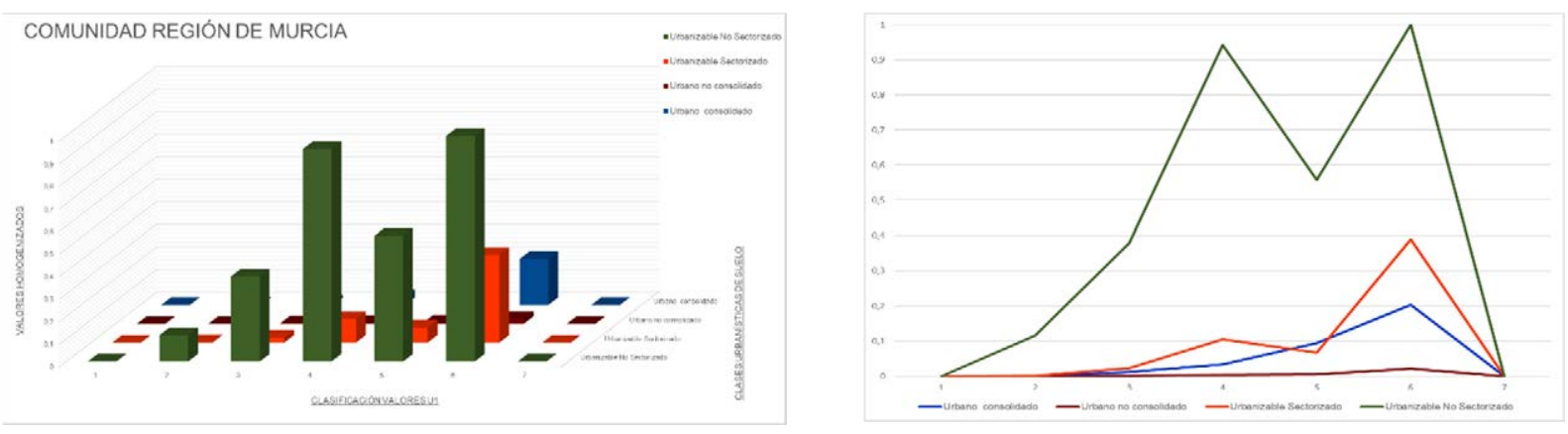

Figura 6.18. Diagrama de columnas y líneas, clasificación de suelo, clasificación de u y superficie en la Región de Murcia (fuente: elaboración propia)

Se observa que la gran mayoría de los valores de $\mathbf{u}_{1}$ se encuentran en las clases 4 y 6 , donde los valores oscilan entre 1,06-1,14 y 1,37-2,02 respectivamente, siendo en el suelo urbanizable no sectorizado (SUNS) en el que se encuentra la mayor cantidad de suelo.

A diferencia de los resultados obtenidos en la Comunidad de Madrid, las distintas categorías de suelo tienen asignados valores del coeficiente $\mathbf{u}_{1}$ en distintos intervalos. El suelo urbano consolidado (SUNC) es el suelo con menor cantidad de superficie, le sigue el suelo urbano consolidado (SUC) y el siguiente es el suelo urbanizable sectorizado (SUS).

Se realizó posteriormente un estudio del Municipio de Murcia, para comprobar si, al igual que en la Comunidad de Madrid, los resultados que se obtienen son similares al correspondiente a toda la Región, obteniendo los siguientes gráficos: 

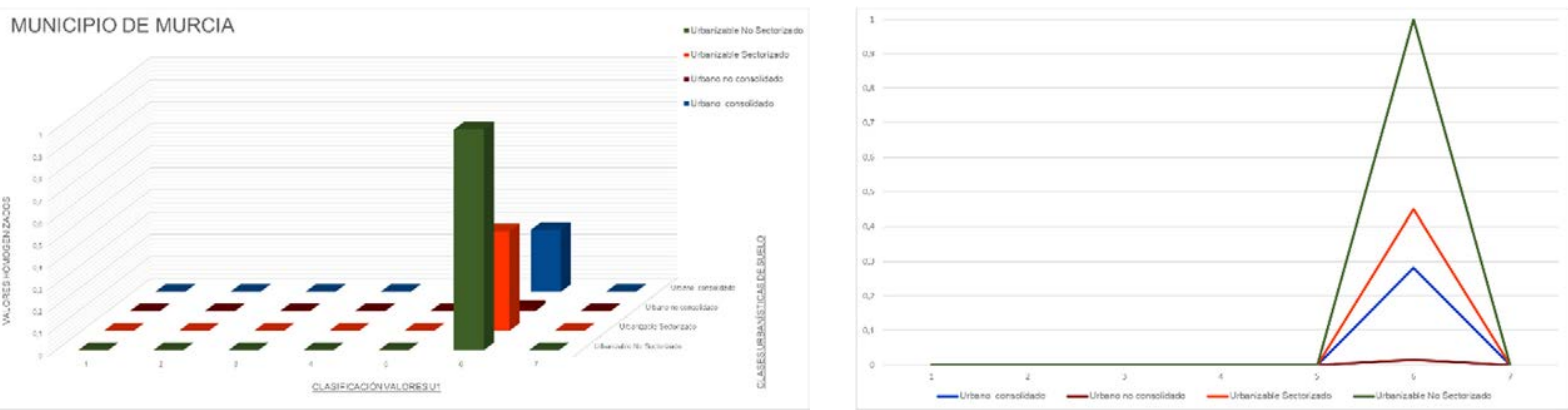

Figura 6.19. Diagrama de columnas y líneas, clasificación de suelo, clasificación de u y superficie en el Municipio de Murcia (fuente: elaboración propia)

Se observa que, a diferencia de los resultados obtenidos en la Comunidad de Madrid y sus municipios de mayor población, no existe ninguna relación entre los resultados de la Región y los del municipio de Murcia, aunque que los datos de la Región reflejan la disparidad entre los distintos municipios que la forman. Si coincide la distribución de las diferentes clases y categorías de suelo, es decir, que la mayor cantidad de suelo corresponde al Urbanizable No Sectorizado tanto en la Comunidad como en el municipio de Murcia, seguido por el Urbanizable Sectorizado y el Urbano Consolidado.

Se han representado en la Figura 6.20 tres mapas en los que se observa, la clasificación de suelo, los valores de las diferentes categorías del factor de corrección $\mathbf{u}_{1}$ y la densidad de población en toda la Región de Murcia. En la Figura se puede observar que, si bien la densidad de población en Murcia (municipio) no es demasiado elevada, en los municipios limítrofes con el sur de la Provincia de Alicante incrementa la concentración de población, lo que motiva que exista un foco en el que los valores del factor $\mathbf{u}_{1}$ son los más elevados en ese ámbito territorial. 


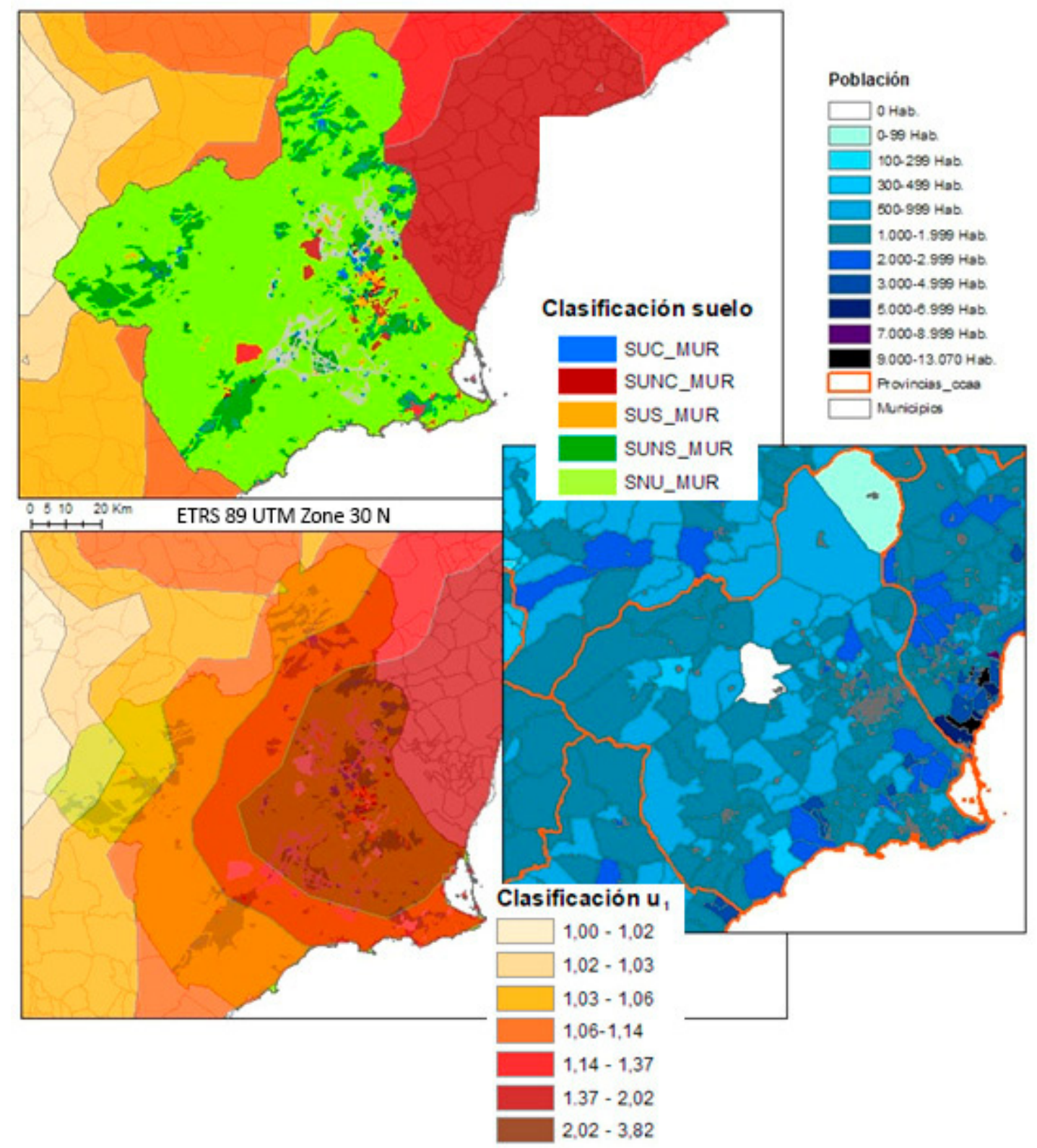

Figura 6.20. Superposición de clasificación urbanística del suelo de la Región de Murcia, valores $u_{1}$ y cantidad de población (fuente: elaboración propia)

En la Figura 6.21 se han representado tanto el planeamiento general de cada municipio de la Región de Murcia, como el año de su aprobación, lo que permite observar que hay numerosos municipios con Planes Generales como instrumento de planeamiento general. 


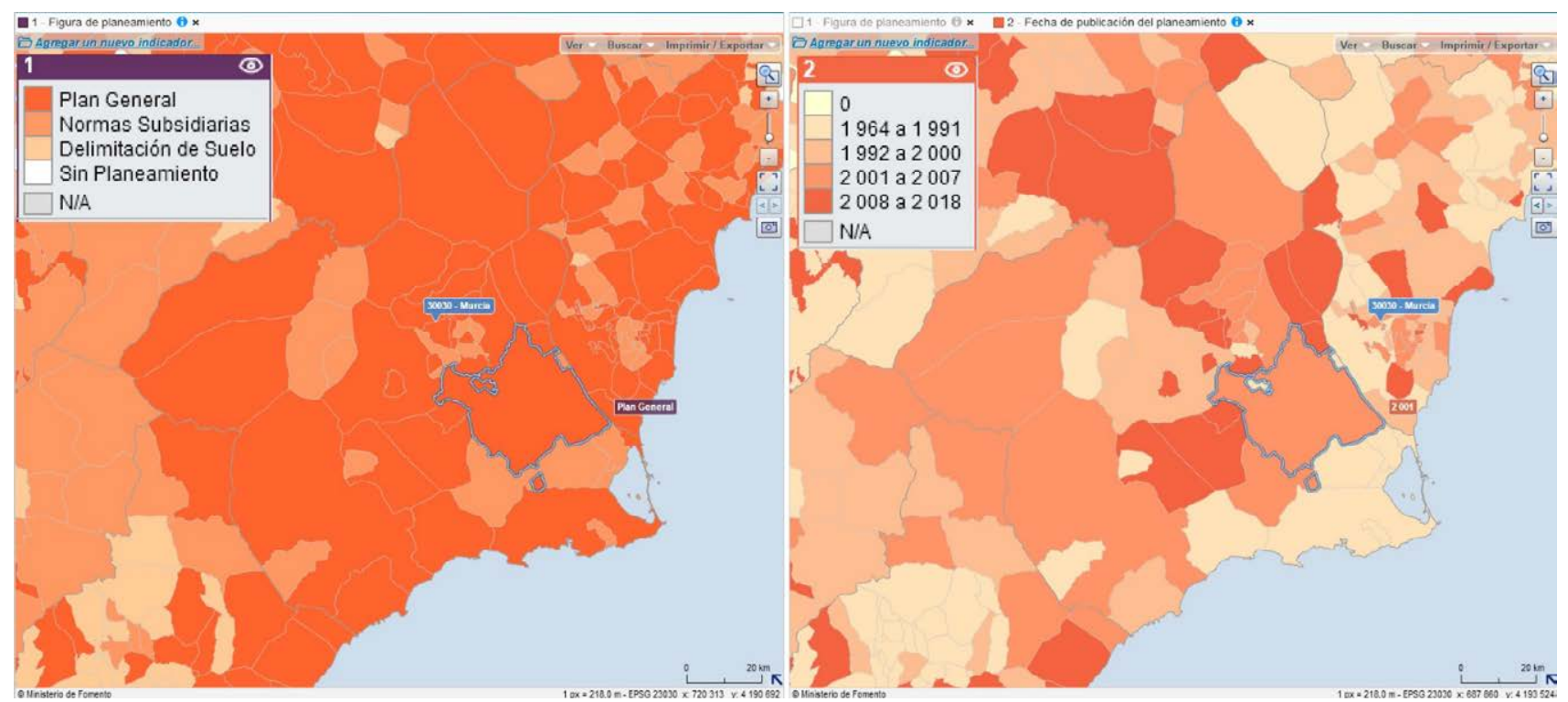

Figura 6.21. 1) Instrumentos planeamiento general.

2) Fecha de publicación del planeamiento de la Región de Murcia

En la Tabla 6.6 se ha recogido, tanto en el municipio de Murcia como en la totalidad de la Comunidad, la categoría del factor de corrección $\mathbf{u}_{1}$ correspondiente, la cantidad de habitantes, la extensión superficial de cada uno de ellos, el porcentaje de superficie en la totalidad de la Región de Murcia y la superficie de suelo en cada una de las clasificaciones y categorías urbanísticas de suelo: SUC, SUNC, SUS y SUNS. Se ha incluido también la fecha de aprobación del planeamiento general del municipio de Murcia.

\begin{tabular}{lcccccccc} 
Municipio & $\begin{array}{c}\text { Población SUPERFICIE } \\
\text { habitantes }\end{array}$ & $\begin{array}{c}\text { (Km }) \\
\left(\mathbf{K m}^{2}\right)\end{array}$ & $\begin{array}{c}\text { SUC } \\
\mathbf{K m}^{2}\end{array}$ & $\begin{array}{c}\text { SUNC } \\
\mathbf{K m}^{2}\end{array}$ & $\begin{array}{c}\text { SUS } \\
\mathbf{K m}^{2}\end{array}$ & $\begin{array}{c}\text { SUNS } \\
\mathbf{K m}^{2}\end{array}$ & $\begin{array}{c}\text { Planeamiento } \\
\text { fecha }\end{array}$ \\
\hline Murcia & 438.246 & 886,00 & 7,83 & 53,52 & 2,82 & 85,60 & 190,08 & 2001 \\
\hline
\end{tabular}

$\begin{array}{lrrrrrrr}\text { TOTAL RM } & 1.472 .049 & 11.313,10 & 100 & 221,84 & 21,07 & 378,31 & 1.931,55\end{array}$

Tabla 6.6. Valores totales comparados con la Región de Murcia (fuente: elaboración propia)

En la Figura 6.22 se ha localizado el municipio de Murcia, superponiéndolo sobre la distribución de los valores continuos del factor de corrección $\mathbf{u}_{1}$ resultado del kriging ordinario realizado.

Se observa que Murcia está localizada sobre la zona de mayor valor del factor de corrección $\mathbf{u}_{1}$, es decir en la zona de valor 6 . 


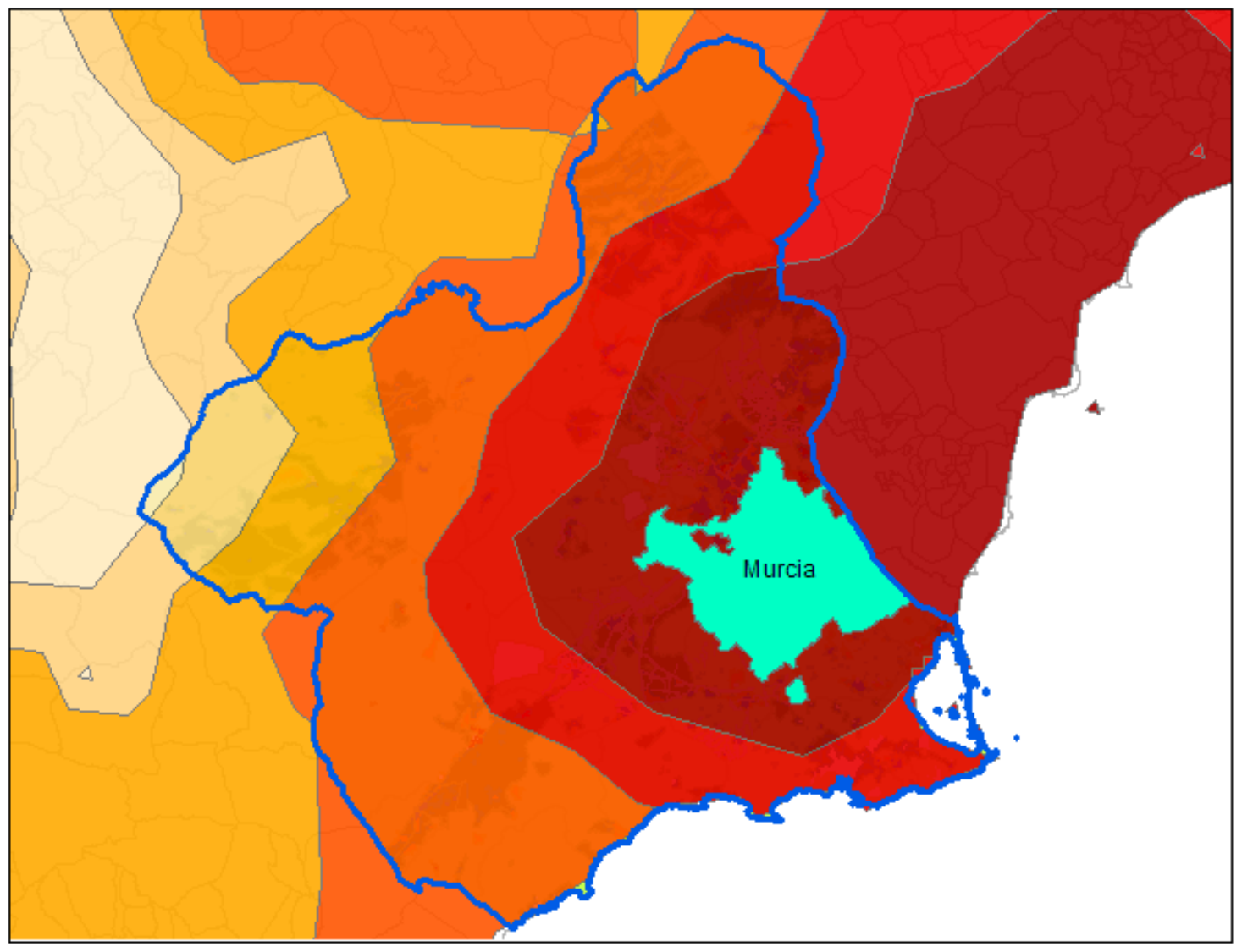

Figura 6.22. Municipios estudiados de la Región de Murcia (fuente: elaboración propia)

\subsubsection{Conclusión Región de Murcia}

A partir de los datos utilizados y tras el análisis correspondiente se han obtenido los siguientes resultados:

- Dependiendo de la situación de los municipios, los valores del factor $\mathbf{u}_{1}$ varían, por lo que en la totalidad de la Región no existe un valor único como sucede en la Comunidad de Madrid. En el municipio de Murcia se localiza el valor de $\mathbf{u}_{1}$ máximo en la región, situándose dentro de la categoría 6 (valores de 1,37 a $2,02)$.

- Sólo el 22,56 \% de la superficie de suelo de la Región tiene aprovechamiento lucrativo y, de dicho porcentaje, el 17,07 \% tiene la clasificación urbanística de Suelo Urbanizable No Sectorizado (SUNS). Esta categoría de suelo es la que tiene mayor superficie dentro de la Región, entre todos los suelos con usos lucrativos, mientas que solo el 5,49 \% restante está clasificado como SUC, SUNC y SUS. Es importante tener en cuenta que el $1,96 \%$ tiene la clasificación urbanística de Suelo Urbano Consolidado (SUC), mientras que el resto del suelo está pendiente de desarrollar.

- Se observa en la Figura 6.22 que los mayores valores de $\mathbf{u}_{1}$ se encuentran próximos a Murcia (municipio) y, a medida que nos alejamos de allí, los valores 
van disminuyendo.

- Se observa también que no existe ninguna relación entre el patrón de comportamiento de los gráficos de barras de la Región y el del municipio de Murcia.

Al igual que en los resultados obtenidos en la Comunidad de Madrid, es destacable que todas y cada una de las clases y categorías de suelo estudiadas tienen el mismo valor del factor de corrección $\mathbf{u}_{1}$.

\subsubsection{Factor $u_{1}$ y expectativas en Cataluña}

La clasificación de suelo en Cataluña se representa en la Figura 6.23. Se comprueba, al igual que en resto de las comunidades estudiadas, que la mayor cantidad de suelo está clasificado como Suelo No Urbanizable (SNU). A diferencia de las anteriores, la Comunidad catalana está formada por cuatro provincias concentrándose la mayor cantidad de suelo clasificado y categorizado como Suelo Urbano Consolidado (SUC) en la Provincia de Barcelona.

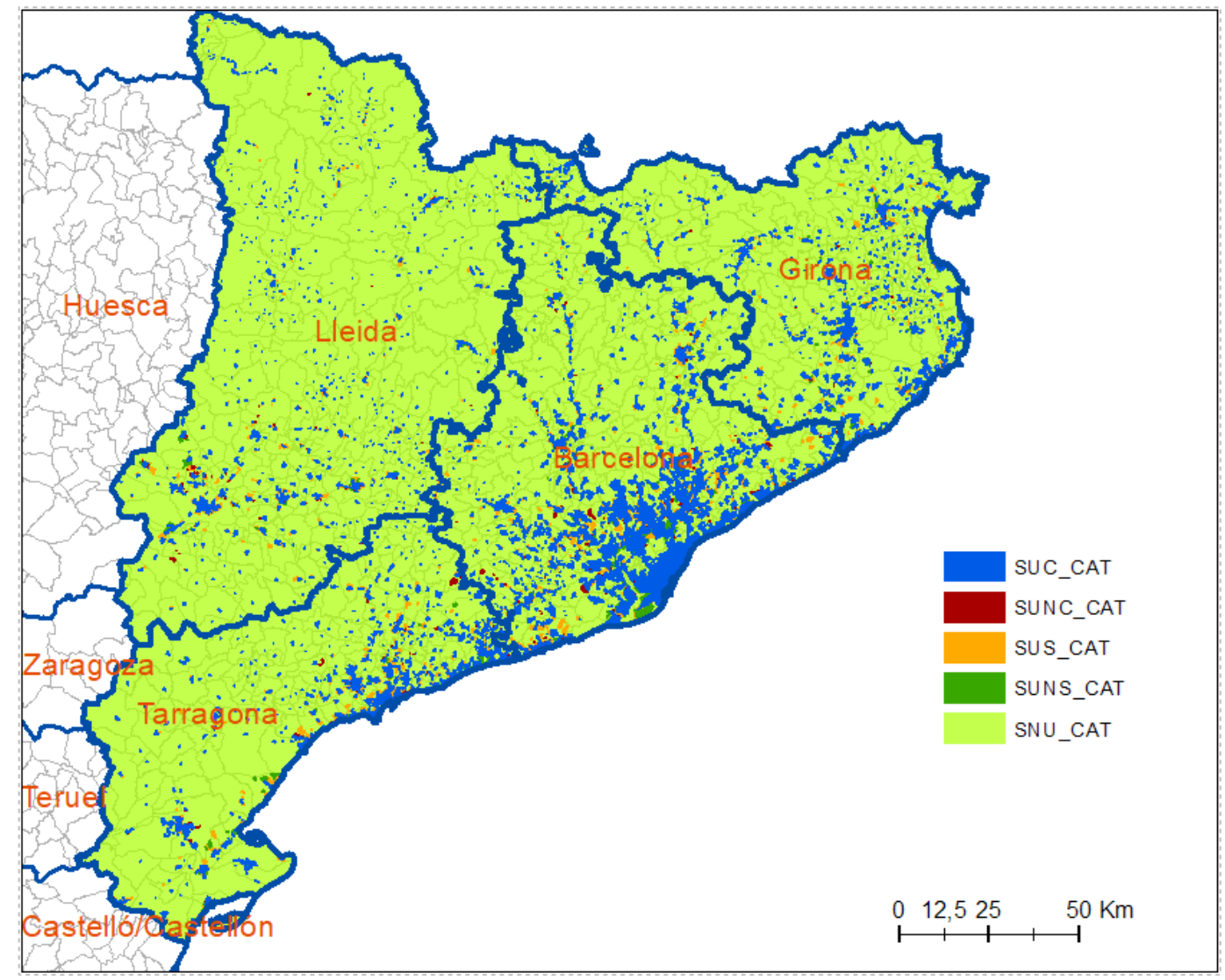

Figura 6.23 Clasificación urbanística del suelo de Cataluña (fuente: elaboración propia)

Al igual que en las anteriores Comunidades, en Cataluña se ha superpuesto la 
clasificación urbanística del suelo a los valores continuos obtenidos de $\mathbf{u}_{1}$, con el objetivo de analizar la relación entre ambos tipos de datos. Como consecuencia de ello se observa que el mayor porcentaje de superficie de suelo de Cataluña se localiza en la categoría 5 del factor $\mathbf{u}_{1}$ (valores de 1,14 a 1,37) y, seguidamente en la categoría 4 (valores de 1,06 a 1,14 ) se localiza el $27,95 \%$ de la superficie de suelo. El resto de suelo se distribuye en las otras categorías del factor $\mathbf{u}_{1}$ (Figura 6.24).

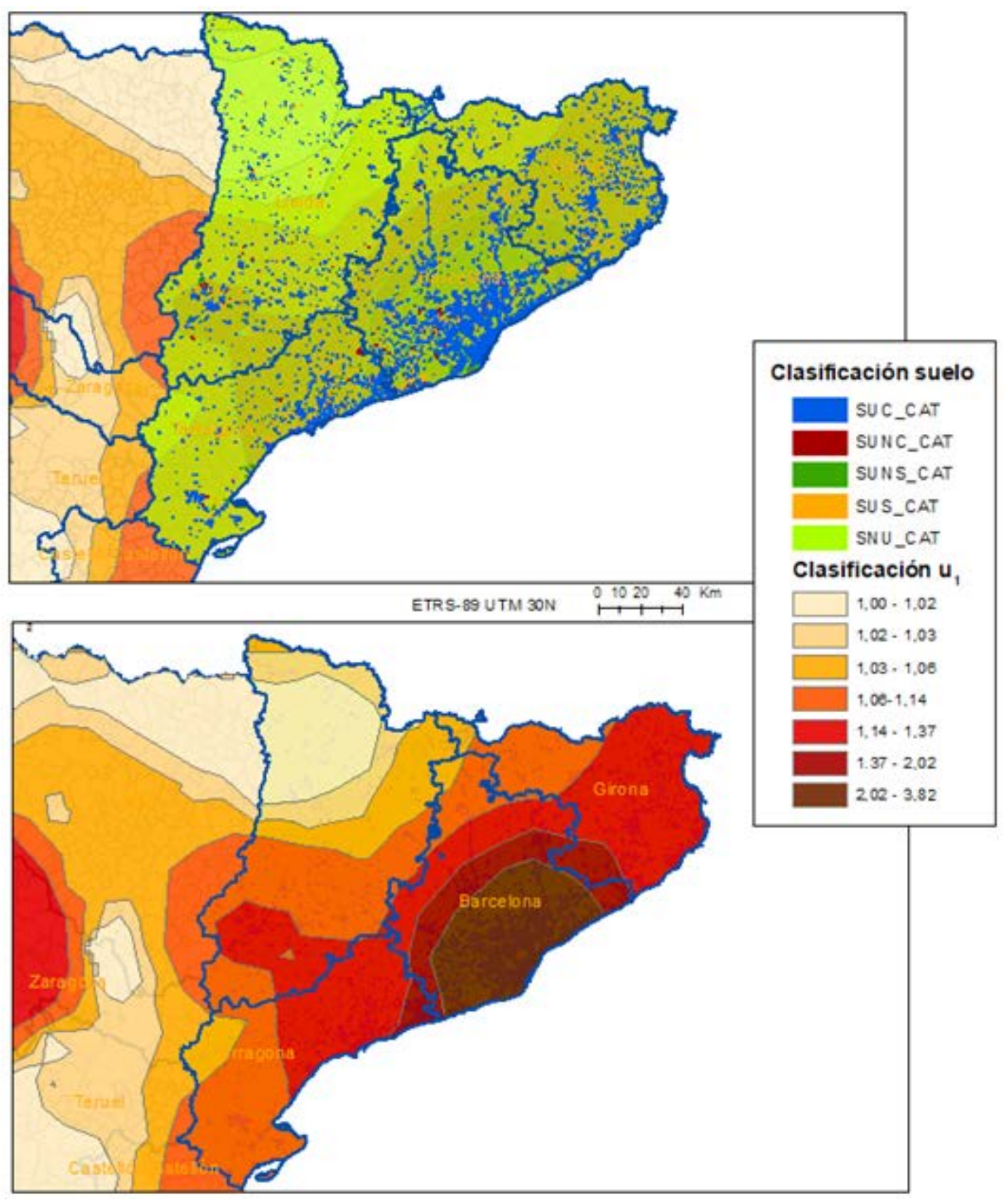

Figura 6.24. Superposición de clasificación urbanística del suelo de Cataluña y valores $u_{1}$ (fuente: elaboración propia)

Como el valor del factor $\mathbf{u}_{1}$ está directamente relacionado con la cantidad de población existente en el entorno próximo $(4 \mathrm{Km}$.) y lejano $(40 \mathrm{Km}$.) de cada una de las diferentes ubicaciones, en la Figura 6.25 puede comprobarse la cantidad de población existente en cada uno de los municipios de la Comunidad catalana y en la Figura 6.26 
se representa la cantidad de población en existente en cada provincia.

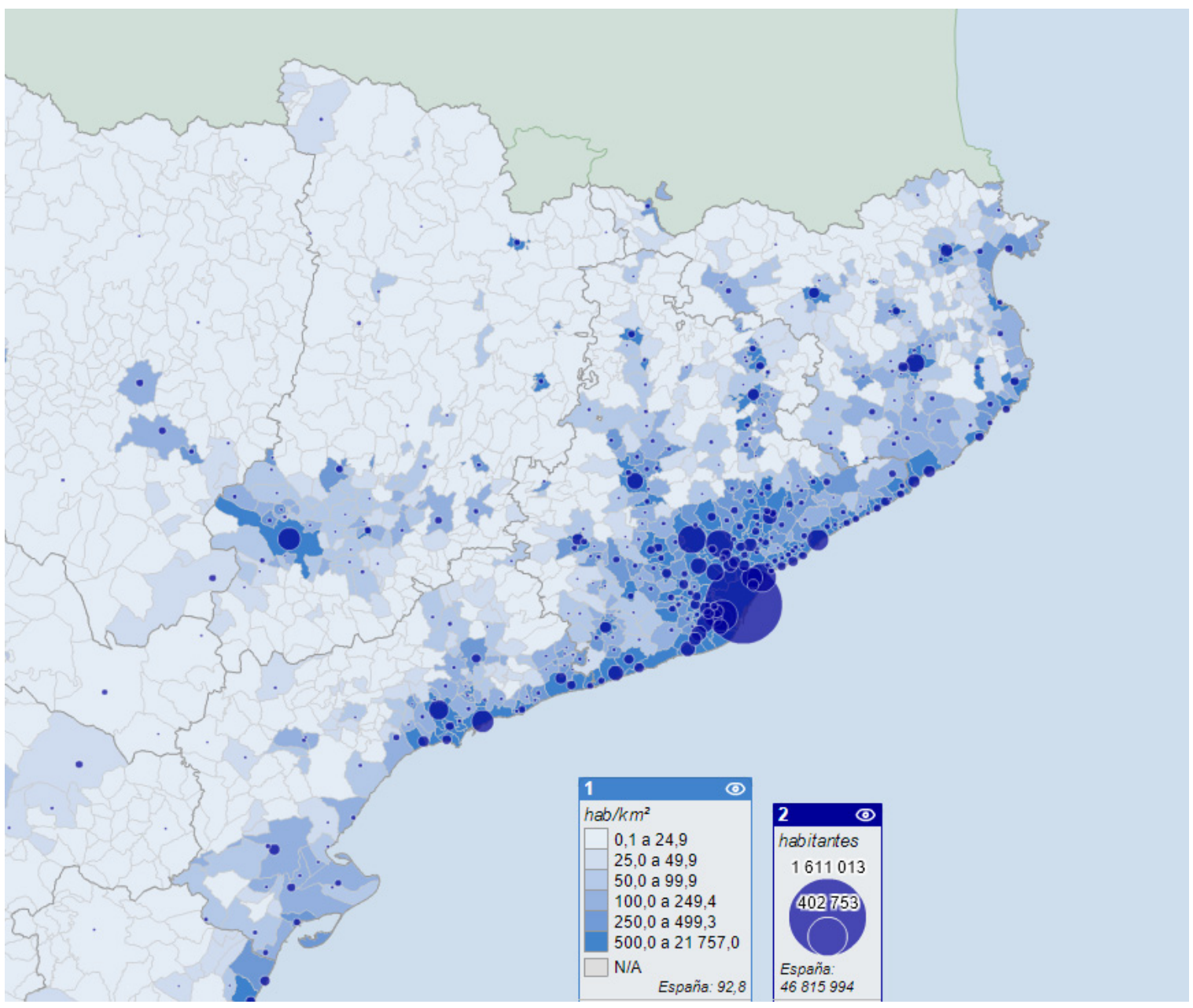

Figura 6.25. Densidad de población y número de habitantes de Cataluña (fuente: elaboración propia)

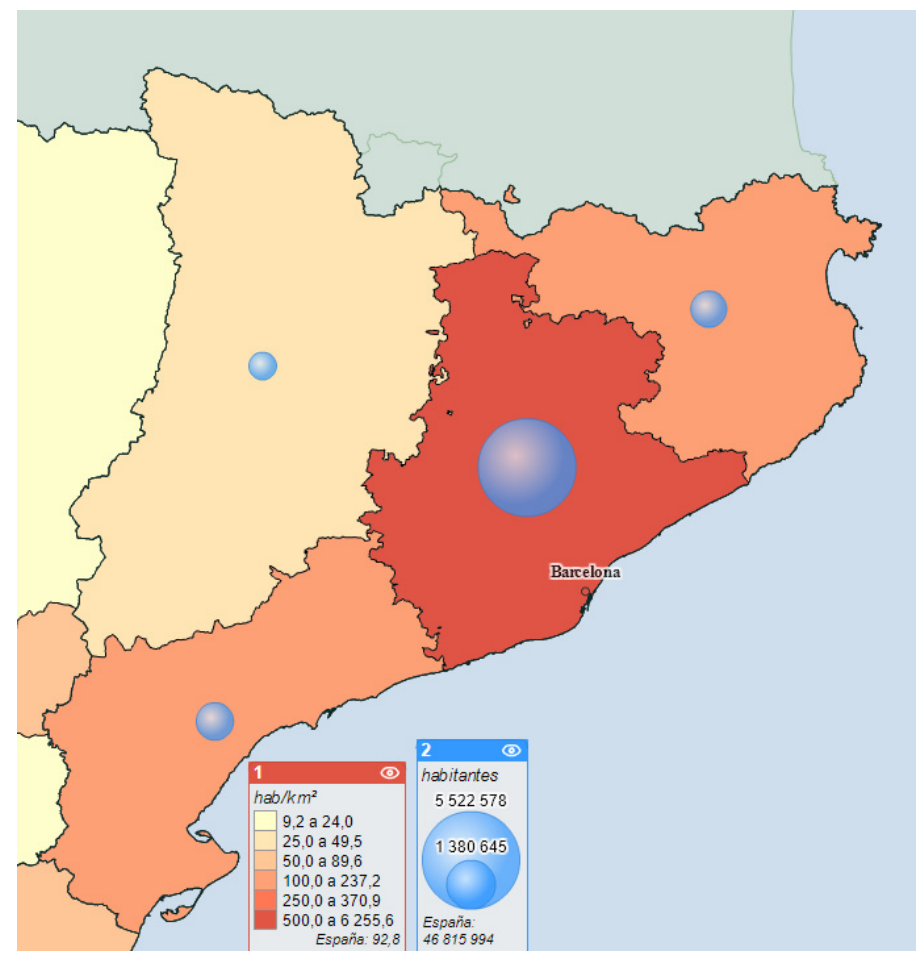

Figura 6.26. Densidad de población y número de habitantes de Cataluña, por provincias (fuente: elaboración propia) 
En la Tabla 6.7 se puede observar la cantidad de superficie existente en cada una de las categorías del factor $\mathbf{u}_{1}$ y la superficie de cada una de las clases y categorías urbanísticas de suelo estudiadas.

Para conocer la relación existente entra la magnitud del factor de corrección $\mathbf{u}_{1}$ y el plusvalor de las expectativas urbanísticas, al igual que en las anteriores Comunidades se ha realizado un estudio de la relación del valor de dicho factor dentro de la segmentación representada en la Tabla 6.2 y la cantidad de suelo (medida en superficie) existente en cada una de las clasificaciones urbanísticas que se han referenciado en el apartado 4.2.3.3 Clasificación urbanística del suelo.

\begin{tabular}{|c|c|c|c|c|c|c|c|}
\hline \multicolumn{2}{|c|}{ CATEGORÍA } & $\begin{array}{c}\text { SUPERFICIE } \\
\text { (Ha) }\end{array}$ & $\%$ & $\begin{array}{c}\text { SUC } \\
\mathrm{Ha}\end{array}$ & SUNC & SUS & SUNS \\
\hline 1 & $1,00-1,02$ & 273.043 & $8,53 \%$ & 927,26 & 45,94 & 445,80 & 23,80 \\
\hline 2 & $1,02-1,03$ & 174.944 & $5,46 \%$ & 730,27 & 85,52 & 317,08 & 2,32 \\
\hline 3 & $1,03-1,06$ & 291.998 & $9,12 \%$ & $1.853,31$ & 69,62 & 377,61 & 42,64 \\
\hline 4 & $1,06-1,14$ & 894.952 & $27,95 \%$ & $11.839,65$ & 825,34 & $5.707,75$ & $1.419,37$ \\
\hline 5 & $1,14-1,37$ & 985.454 & $30,77 \%$ & $37.237,07$ & $2.372,48$ & $17.058,77$ & $2.734,44$ \\
\hline 6 & $1,37-2,02$ & 243.574 & $7,61 \%$ & $16.217,31$ & 655,62 & $5.740,83$ & $1.170,98$ \\
\hline 7 & $2,02-3,82$ & 338.339 & $10,57 \%$ & $61.562,39$ & $2.898,15$ & $13.532,22$ & $4.807,03$ \\
\hline & & 3.202 .304 & $100 \%$ & $\begin{array}{c}130.367,27 \\
4,07 \%\end{array}$ & $\begin{array}{c}6.952,67 \\
0,22 \%\end{array}$ & $\begin{array}{c}43.180,06 \\
1,35 \%\end{array}$ & $\begin{array}{c}10.200,58 \\
0,32 \%\end{array}$ \\
\hline
\end{tabular}

Tabla 6.7. Categorías uı y clasificación de suelo (fuente: elaboración propia)

Para llevar a cabo dicho estudio, de la misma forma que en el estudio realizado para las anteriores Comunidades Autónomas, se analizaron los valores obtenidos en unos gráficos de columnas o barras donde se comparan 3 valores diferentes ya definidos en el análisis de la Comunidad de Madrid; Clasificación de los valores de $\mathbf{u}_{1}$, clases y categorías urbanística y los valores homogenizados de la superficie de suelo.

En el estudio del conjunto de la Comunidad catalana (7.553.650 habitantes) se obtuvo el siguiente diagrama: 


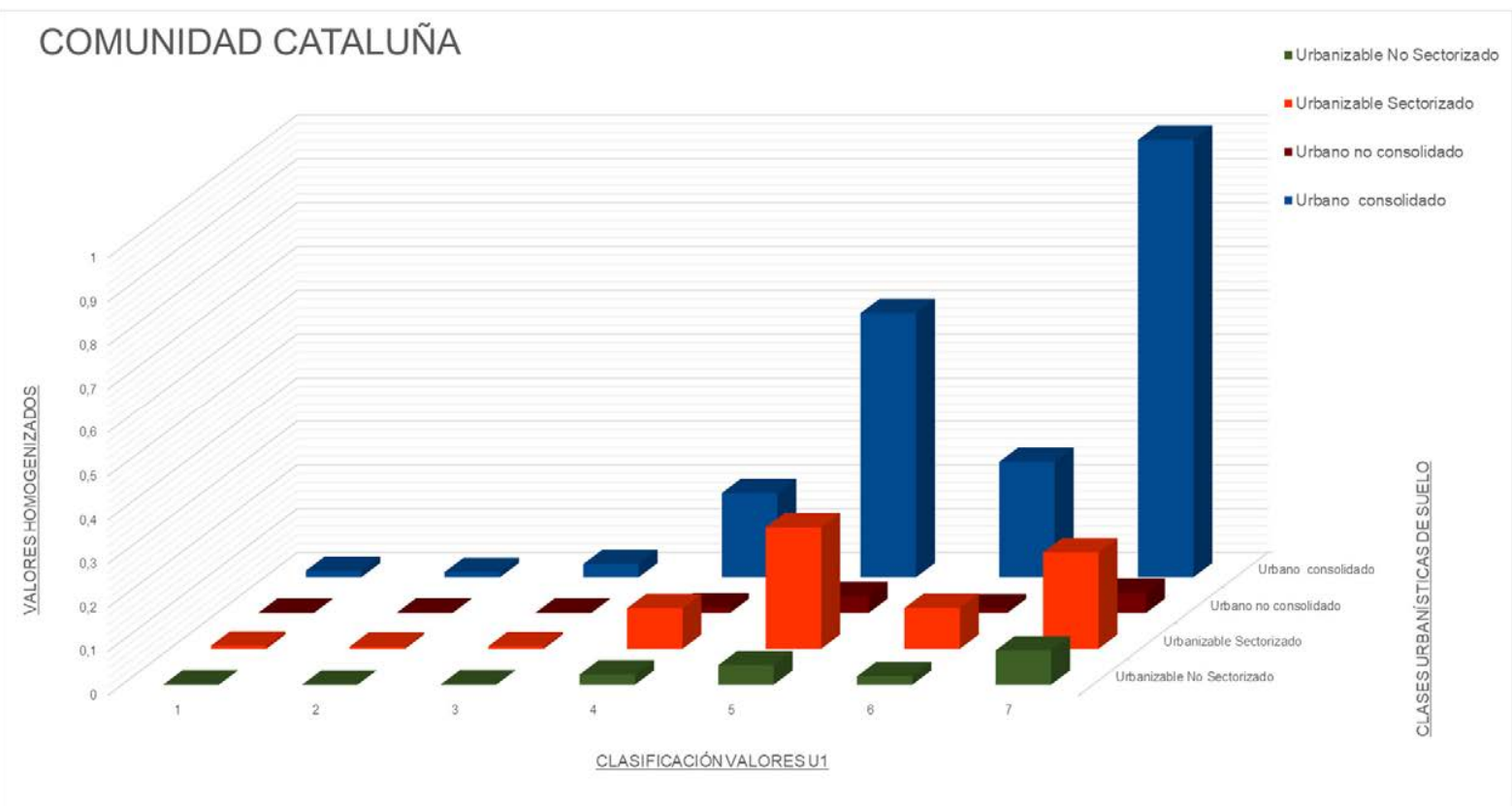

Figura 6.27. Diagrama de columnas clasificación de suelo, clasificación de $u_{1}$ y superficie en Cataluña (fuente: elaboración propia)

Se observa que la gran mayoría de los valores de $\mathbf{u}_{1}$ se encuentran repartidos entre las clases 4 y 7 , donde los valores oscilan entre 1,06 y 1,14 en el primer caso y entre 2,02 y 3,82 en el segundo, creándose dos picos en las categorías 5 y 7 , siendo el suelo urbano consolidado (SUC) en el que se obtienen valores de $\mathbf{u}_{1}$ situados en la categoría 3.

En la categoría del suelo urbano consolidado (SUC) se concentra la mayor cantidad de suelo, como sucede en la Comunidad de Madrid.

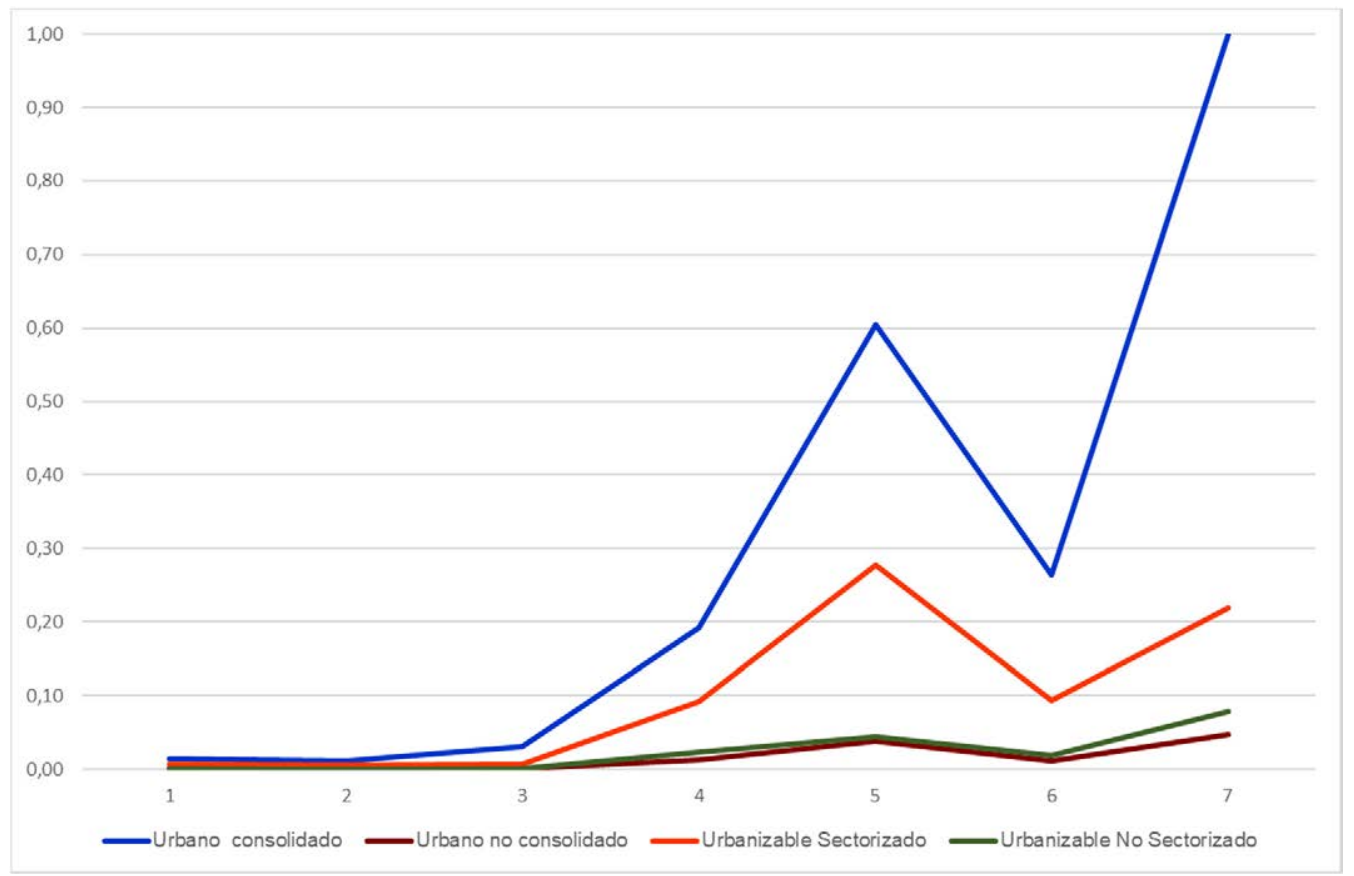

Figura 6.28. Diagrama de líneas clasificación suelo, calificación de $u_{1}$ y superficie en Cataluña (fuente: elaboración propia) 
Se ha realizado también un estudio de las distintas provincias de Cataluña, siendo su población:

- Barcelona (5.540.925 habitantes)

- Tarragona (810.178 habitantes)

- Lérida (440.915 habitantes)

- Gerona (761.632 habitantes)

Los resultados obtenidos difieren en cada una de ellas y, difieren también de los obtenidos para cada una de las Comunidades Autónomas estudiadas anteriormente, reflejándose en los siguientes gráficos:
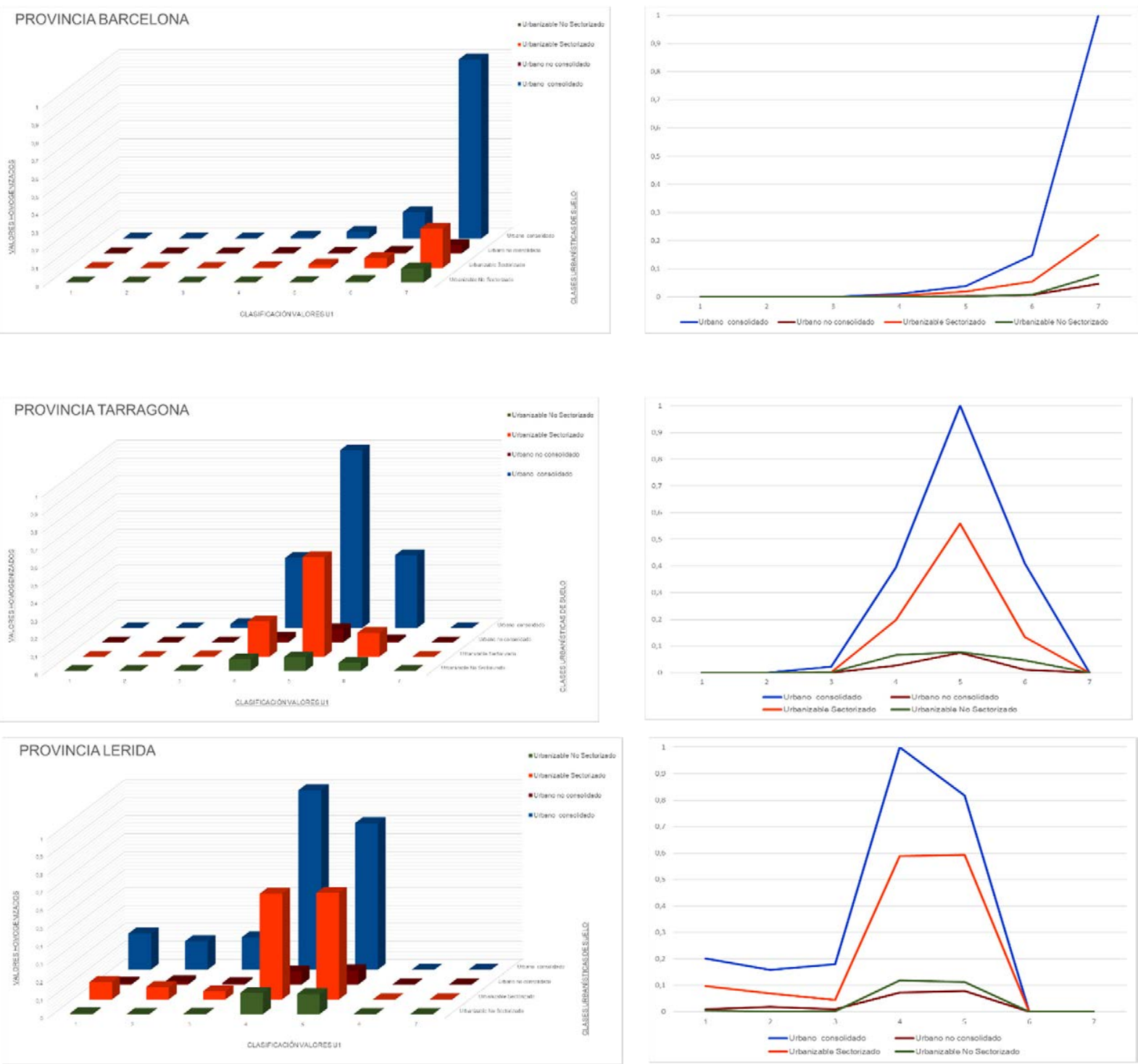

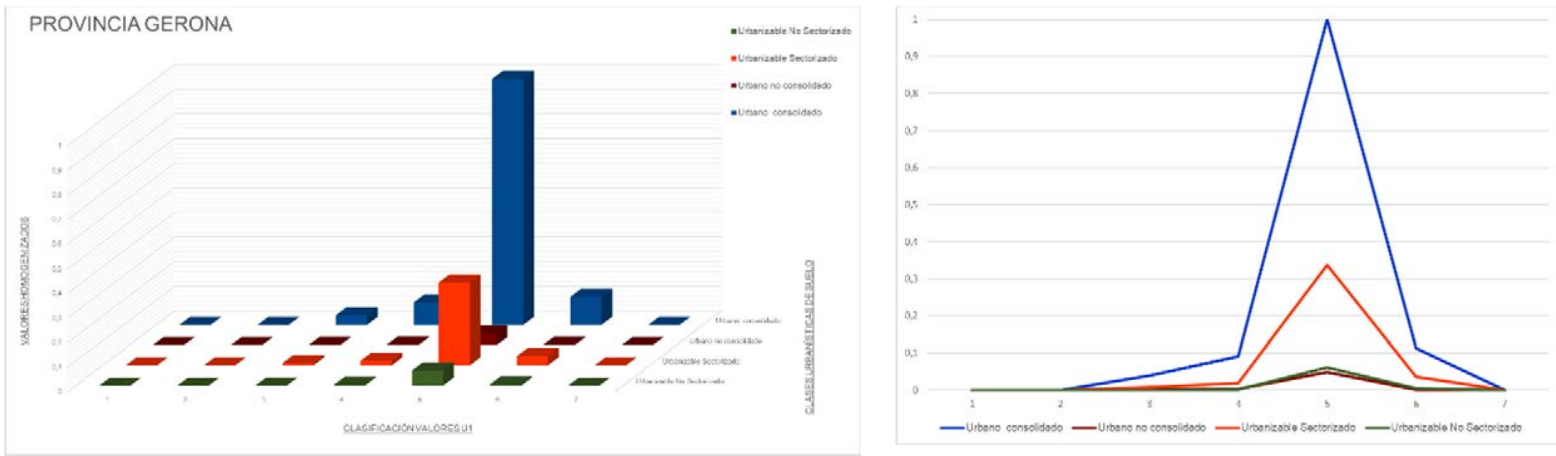

Figura 6.29. Diagrama de columnas y líneas, clasificación de suelo, clasificación de $u_{1}$ y superficie en Cataluña (fuente: elaboración propia)

Se observa en ellos que los valores obtenidos tanto en la totalidad de la Comunidad catalana como en cada una de las provincias que la integran no siguen un patrón determinado, ya que los valores obtenidos no guardan ninguna relación.

En la Figura 6.30 se han representado tres mapas en los que se observa, la clasificación de suelo, los valores de las distintas categorías del factor de corrección $\mathbf{u}_{1}$ y la densidad de población de toda la Comunidad Autónoma de Cataluña. En cuanto a la distribución de la población, en la provincia de Barcelona se concentra la mayor densidad de población, siguiéndole Tarragona y Gerona. Todas ellas son provincias que dan frente a la costa, siendo Lérida la única provincia interior y en la que, además, la densidad de población es menor en comparación con las demás provincias. 


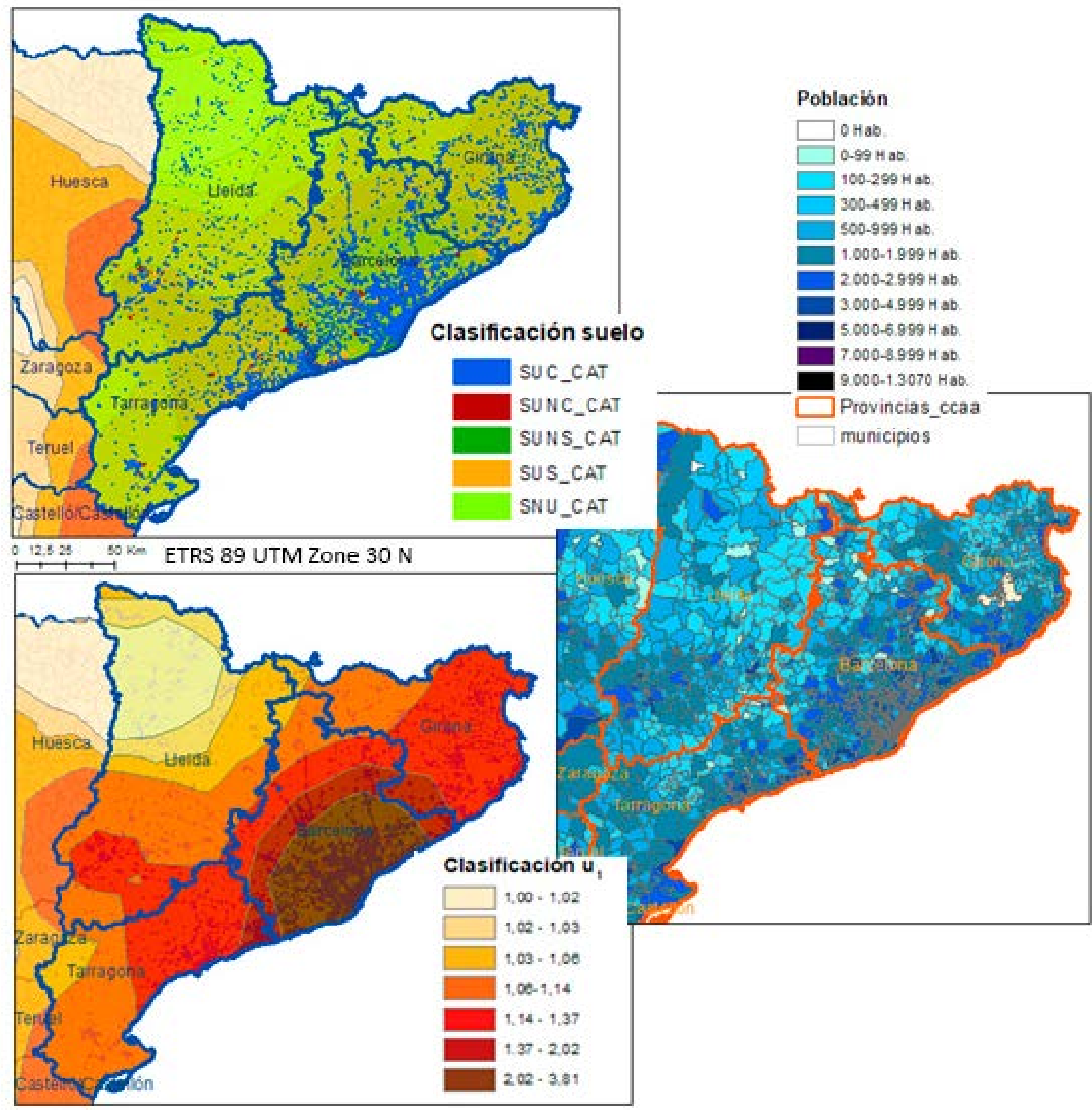

Figura 6.30. Superposición de clasificación urbanística del suelo de Cataluña, valores u y cantidad de población (fuente: elaboración propia)

Por otro lado, puesto que la clasificación urbanística de suelo es asignada por el planeamiento general de cada municipio, como determinación estructurante de la ordenación, en la Figura 6.31 se han representado tanto el planeamiento general de cada municipio como el año de su aprobación, siguiendo el procedimiento que se ha llevado a cabo en las anteriores Comunidades estudiadas. 


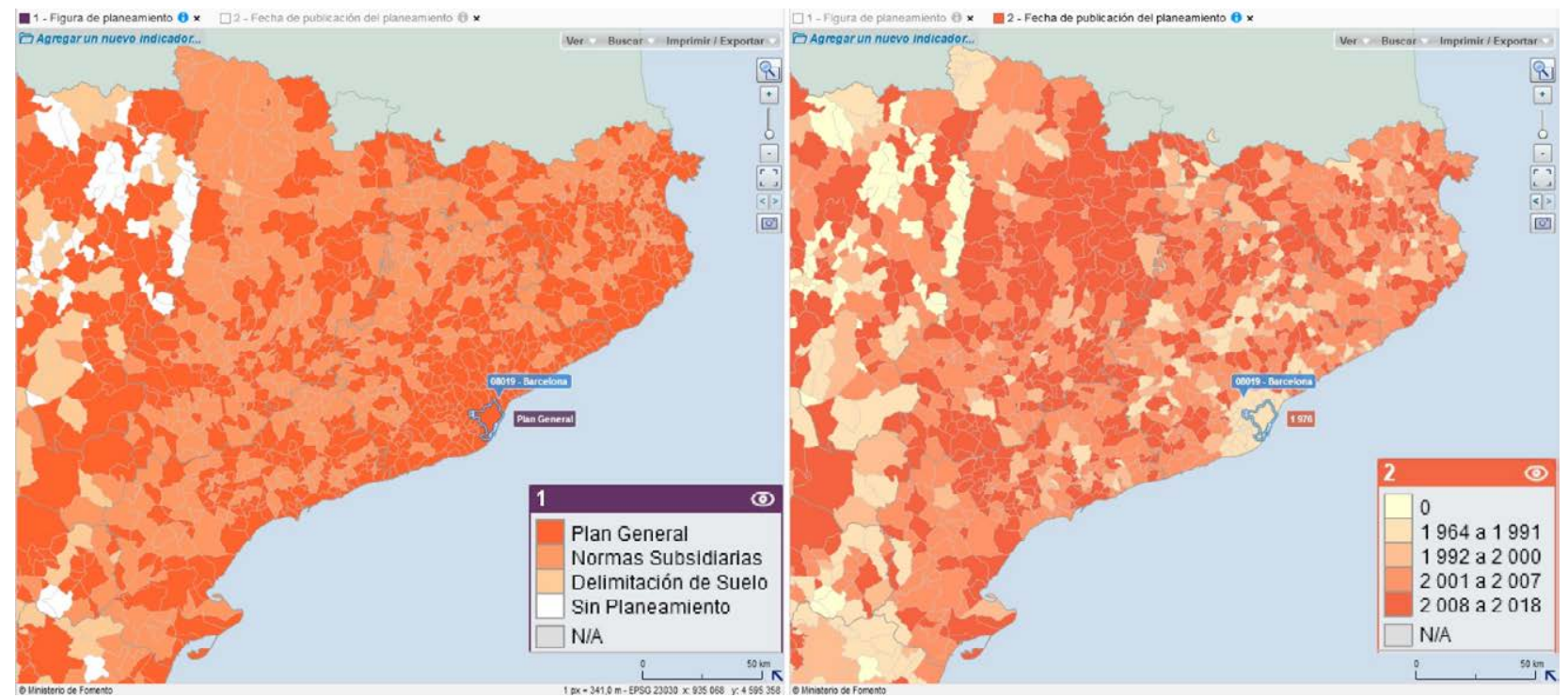

Figura 6.31. 1) Instrumentos planeamiento general.

2) Fecha de publicación del planeamiento de Cataluña

En la Tabla 6.8 se ha recogido para cada una de las provincias de Cataluña, la categoría mayoritaria del factor de corrección $\mathbf{u}_{1}$ en la que se encuentran, la cantidad de habitantes, la extensión superficial, el porcentaje de superficie en la totalidad de Cataluña y la superficie de suelo de cada una de las clasificaciones y categorías urbanísticas de suelo: SUC. SUNC, SUS y SUNS. No se ha podido incluir la fecha de aprobación del planeamiento general ya que, al estar las provincias formadas por distintos municipios, las fechas de aprobación son muy diferentes.

\begin{tabular}{lcccccccc} 
Provincia & $\begin{array}{c}\text { Categoría } \\
\mathbf{u}_{\mathbf{1}}\end{array}$ & $\begin{array}{c}\text { Población } \\
\text { habitantes }\end{array}$ & $\begin{array}{c}\text { SUPERFICIE } \\
(\mathbf{K m})\end{array}$ & $\begin{array}{c}\text { \% } \\
\mathbf{2}\end{array}$ & $\begin{array}{c}\text { SUC } \\
\mathbf{K m}^{\mathbf{2}}\end{array}$ & $\begin{array}{c}\text { SUNC } \\
\mathbf{K m}^{\mathbf{2}}\end{array}$ & $\begin{array}{c}\text { SUS } \\
\mathbf{K m}^{\mathbf{2}}\end{array}$ & $\begin{array}{c}\text { SUNS } \\
\mathbf{K m}^{\mathbf{2}}\end{array}$ \\
\hline Barcelona & 7 & 5.540 .925 & $7.728,40$ & 24,08 & 738,07 & 36,52 & 183,81 & 54,83 \\
\hline Tarragona & 5 & 810.178 & $6.302,90$ & 19,64 & 221,29 & 13,72 & 108,22 & 23,18 \\
\hline Lérida & $4-5$ & 440.915 & $12.149,70$ & 37,86 & 108,75 & 8,71 & 64,21 & 10,95 \\
\hline Gerona & 5 & 761.632 & $5.908,80$ & 18,41 & 235,57 & 10,57 & 75,56 & 13,05 \\
\hline Total estudio & & 7.553 .650 & $32.089,80$ & 100 & $1.303,67$ & 69,53 & 431,80 & 102,01 \\
\hline T. Cataluña & & $\mathbf{7 . 5 5 3 . 6 5 0}$ & $\mathbf{3 2 . 0 9 0 , 8 0}$ & $\mathbf{1 0 0}$ & $\mathbf{1 . 3 0 3 , 6 7}$ & $\mathbf{6 9 , 5 3}$ & $\mathbf{4 3 1 , 8 0}$ & $\mathbf{1 0 2 , 0 1}$
\end{tabular}

Tabla 6.8. Valores totales comparados en las provincias de Cataluña (fuente: elaboración propia)

\subsubsection{Conclusión Cataluña}

Como consecuencia del análisis realizado se obtienen los siguientes resultados en la Comunidad de Cataluña:

- La distribución espacial de los valores del factor $\mathbf{u}_{1}$ varía en cada provincia, por lo que no existe un patrón único en el conjunto de la Comunidad Autónoma. Se 
observa que el parámetro determinante para la obtención de los valores es la cantidad de población, de tal forma que, en la provincia de Barcelona, en la que se concentra la mayor población (5.540.925 habitantes), los valores del factor $\mathbf{u}_{1}$ se encuentran en la categoría 7 (valores de 2,02 a 3,82). La siguiente provincia en cantidad de habitantes es Tarragona (810.178 habitantes), en la que los valores del factor $\mathbf{u}_{1}$ se encuentran, en su mayoría, en la categoría 5 (valores de 1,14 a 1,37). Gerona es la siguiente provincia en número de habitantes (761.632 habitantes), donde los valores del factor $\mathbf{u}_{\mathbf{1}}$ también se encuentran en la categoría 5 (al igual que en Tarragona). Y, por último, en la provincia de Lérida, que es la que menor número de habitantes tiene (440.915), el valor del factor $\mathbf{u}_{1}$ sobre todo se encuentra en la categoría 4 (valores entre 1,06 a 1,14), aunque también existen bastantes valores en la categoría 5 (valores de 1,14 a 1,37). Es necesario mencionar que en esta provincia también se encuentran valores del factor $\mathbf{u}_{1}$ entre las categorías de 1 a 3 (valores de 1 a 1,06).

- Sólo el 5,94 \% de la superficie de suelo de Cataluña tiene aprovechamiento lucrativo y de dicho porcentaje el 4,06 \% tiene la clasificación urbanística de Suelo Urbano Consolidado (SUC), siendo esta clase la que tiene mayor superficie dentro de Cataluña, entre los suelos lucrativos. Tan solo el 1,88 \% restante se trata de SUNC SUS y SUNS. Es importante tener en cuenta que este porcentaje del 1,88 \% es suelo que está pendiente de desarrollar.

- Se observa en la Figura 6.30. Superposición de clasificación urbanística del suelo de Cataluña, valores $\mathbf{u}_{1}$ y cantidad de población, que los mayores valores de $\mathbf{u}_{1}$ se encuentran en la provincia de Barcelona y a medida que nos alejamos de ella los valores van disminuyendo. Lérida es la provincia que menor población tiene, por ello los valores tienden a bajar, y en ella se encuentran valores de las categorías 1 a 3 (valores de 1 a 1,06), por la poca población de esta provincia. Sin embargo, su proximidad a la provincia de Barcelona hace que los valores aumenten desde la categoría 4 (valores de 1,06 a 1,14) hasta la categoría 5 (valores de 1,14 a 1,37).

- Del mismo modo que ocurría en la Comunidad Autónoma de Madrid, Barcelona se comporta como un polo donde el valor del factor de corrección $\mathbf{u}_{1}$ tiene su valor máximo (categoría 7 valores de 3 a 3,82)

Del mismo modo que en Madrid y Murcia, en la Comunidad Autónoma Catalana, todas las clases y categorías de suelo estudiadas en los diferentes puntos, tienen el mismo valor para el factor de corrección $\mathbf{u}_{1}$. 


\subsubsection{Sobre las expectativas urbanísticas}

Analizados los datos obtenidos sobre las expectativas urbanísticas, se ha constatado que no existe una clara homogeneidad en la obtención de los resultados a nivel general. Sin embargo, en cada una de las Comunidades Autónomas en las que se ha analizado la clasificación de suelo, existe un patrón en los resultados obtenidos.

En el estudio de la Comunidad Autónoma de Madrid, tanto en su conjunto como en los municipios de Madrid y Leganés se ha comprobado que los gráficos obtenidos en el análisis son similares, tanto en los valores de $\mathbf{u}_{1}$ (que obtiene el mayor valor, dentro de la categoría 7) como en las clasificaciones urbanísticas del suelo. En el caso de municipios de menor número de habitantes, los gráficos desplazan el valor de $\mathbf{u}_{1}$ a las diferentes categorías, en función de la distancia al foco que representa el municipio de Madrid.

En la Comunidad de Madrid, de los suelos estudiados (clases y categorías de SUC, SUNC, SUS, SUNS), la mayor cantidad de suelo está clasificada como suelo urbano en su categoría de consolidado (SUC 8,68 \%) y la de menor cantidad es la de suelo urbano no consolidado (SUNC 0,63\%).

En el estudio de la Región de Murcia, los resultados obtenidos son bien diferentes a los de la Comunidad de Madrid. En lo que se refiere al valor de $\mathbf{u}_{1}$ no existe similitud en los gráficos de la Región y el del Municipio de Murcia, los valores de coeficiente en la Región tienen dos picos destacables, uno en la categoría 4 y otro en la categoría 6 , sin embargo, el Municipio de Murcia tiene sus valores dentro de la categoría 6 . De ello se desprende que existe una distinción considerable entre las zonas de la Región donde se localiza la mayor cantidad de población y aquellas en las que el número de habitantes es muy inferior.

En el estudio de Cataluña, la primera diferenciación con las anteriores Comunidades es que está formada por 4 provincias, Barcelona, Tarragona, Lérida y Gerona. En lo que se refiere al valor de $\mathbf{u}_{1}$ no existe similitud entre los gráficos de Cataluña y el de cada provincia.

En la Tabla 6.9 se representan los datos obtenidos en cada una de las Comunidades, lo que permite hacer un análisis de los datos obtenidos. 


\begin{tabular}{lccccccc} 
& $\begin{array}{c}\text { Población } \\
\text { habitantes }\end{array}$ & $\begin{array}{c}\text { SUPERFICIE. } \\
(\mathbf{k m})\end{array}$ & $\mathbf{\%}$ & $\begin{array}{c}\text { SUC } \\
\mathbf{k m}^{\mathbf{2}}\end{array}$ & $\begin{array}{c}\text { SUNC } \\
\mathbf{k m}^{\mathbf{2}}\end{array}$ & $\begin{array}{c}\text { sUS } \\
\mathbf{k m}^{\mathbf{2}}\end{array}$ & $\begin{array}{c}\text { SUNS } \\
\mathbf{k m}^{\mathbf{2}}\end{array}$ \\
\hline TOTAL CM & 6.495 .551 & $8.025,58$ & 100 & 696,40 & 50,78 & 380,3 & 320,31 \\
\hline TOTAL RM & 1.472 .049 & $11.313,10$ & 100 & 221,84 & 21,07 & 378,31 & $1.931,55$ \\
\hline TOTAL CAT & 7.553 .650 & $32.090,80$ & 100 & $1.303,67$ & 69,53 & 431,80 & 102,01 \\
\hline
\end{tabular}

Tabla 6.9. Valores totales comparados de las CCAA estudiadas (fuente: elaboración propia)

Como consecuencia de todo lo expuesto anteriormente, se puede concluir:

1. La Comunidad de Madrid y la provincia de Barcelona tienen unos resultados muy similares en los valores obtenidos para el factor $\mathbf{u}_{1}$

2. La Comunidad de Madrid y Cataluña clasifican sus suelos de modo similar, de forma que la mayor cantidad de suelo tiene la clasificación urbanística de suelo urbano en la categoría de consolidado (SUC), seguida por la del suelo urbanizable en su categoría de sectorizado (SUS). Por su parte, en la Región de Murcia la mayor cantidad de suelo tiene la clasificación urbanística de suelo urbanizable en la categoría de no sectorizado (SUNS) seguida de los suelos clasificados como urbanizables en la categoría de sectorizados (SUS), mientras que el suelo urbano consolidado en la categoría de consolidado (SUC) es la clasificación que menor cantidad de suelo tiene ${ }^{20}$.

3. En lo que se refiere a la población, tanto la Comunidad de Madrid como Provincia de Barcelona tienen una cantidad de población similar y unas clasificaciones de suelo también semejantes, con lo que los valores del factor $\mathbf{u}_{1}$ también resultan muy próximos. Sin embargo, la Región de Murcia tiene una cantidad de población muy inferior a las de las otras dos Comunidades analizadas y, además, la mayor cantidad de suelo corresponde a la categoría de SUNS. Como se ha indicado, esa clase y categoría de suelo es la que el planeamiento deja prevista para los futuros desarrollos y las huertas tradicionales de Murcia.

4. En cuanto a la fecha de aprobación de los planeamientos generales, en las distintas ubicaciones estudiadas varían considerablemente, sin seguir un patrón, ni por Comunidad ni por localización de la población. Figura 6.32

\footnotetext{
${ }^{20}$ Tal y como se recogía en el apartado 6.3.2 la explicación a la cantidad de suelo en la clase y categoría de SUNS se debe a que la legislación urbanística, clasifica así las huertas tradicionales existente en la Región de Murcia.
} 


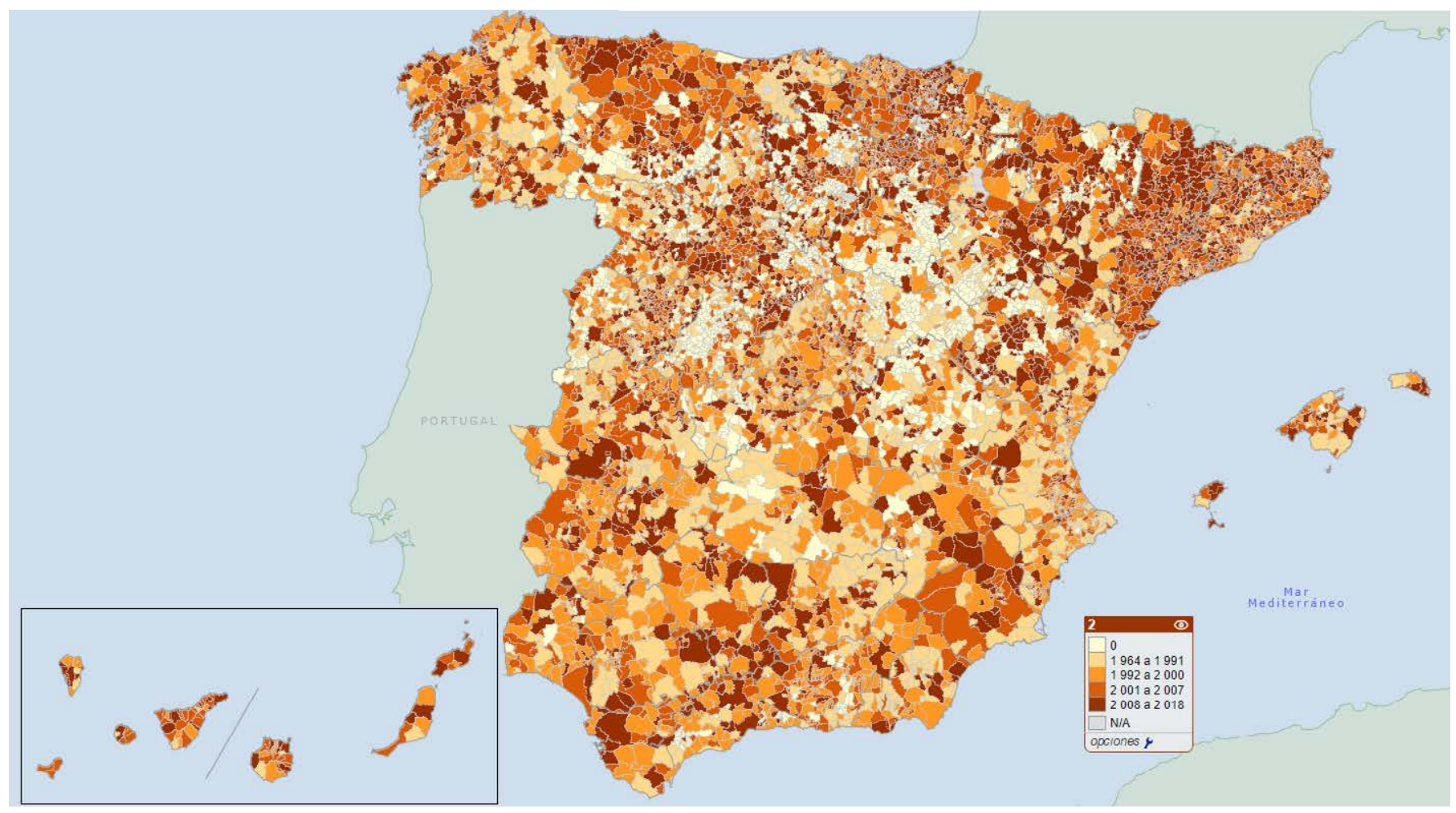

Figura 6.32. Mapa fecha publicación de planeamiento general municipal. (fuente: SIU Ministerio de Fomento)

\subsection{ACERCA DEL FACTOR U Y EL SISTEMA URBANO-TERRITORIAL ESPAÑOL}

\subsubsection{Acerca del Factor $u_{1}$ y las Áreas Urbanas}

Para analizar la relación del factor $\mathbf{u}_{1}$ con las áreas urbanas se partió de la clasificación de los valores del citado factor, a los que se han hecho referencia en 5.2 Valores discretos del factor u1 (1.836 puntos), Tabla 5.3. "Clasificación de los valores $\mathbf{u}_{1}$, número de puntos en cada una de las clases". Sobre ellos se han superpuesto las grandes Áreas urbanas definidas en el SIU, descritas en el apartado 3.4.3 Las áreas urbanas, comprobándose cómo dichas áreas están situadas en las zonas de mayor valor de $\mathbf{u}_{1}$ (Figura 6.33). 


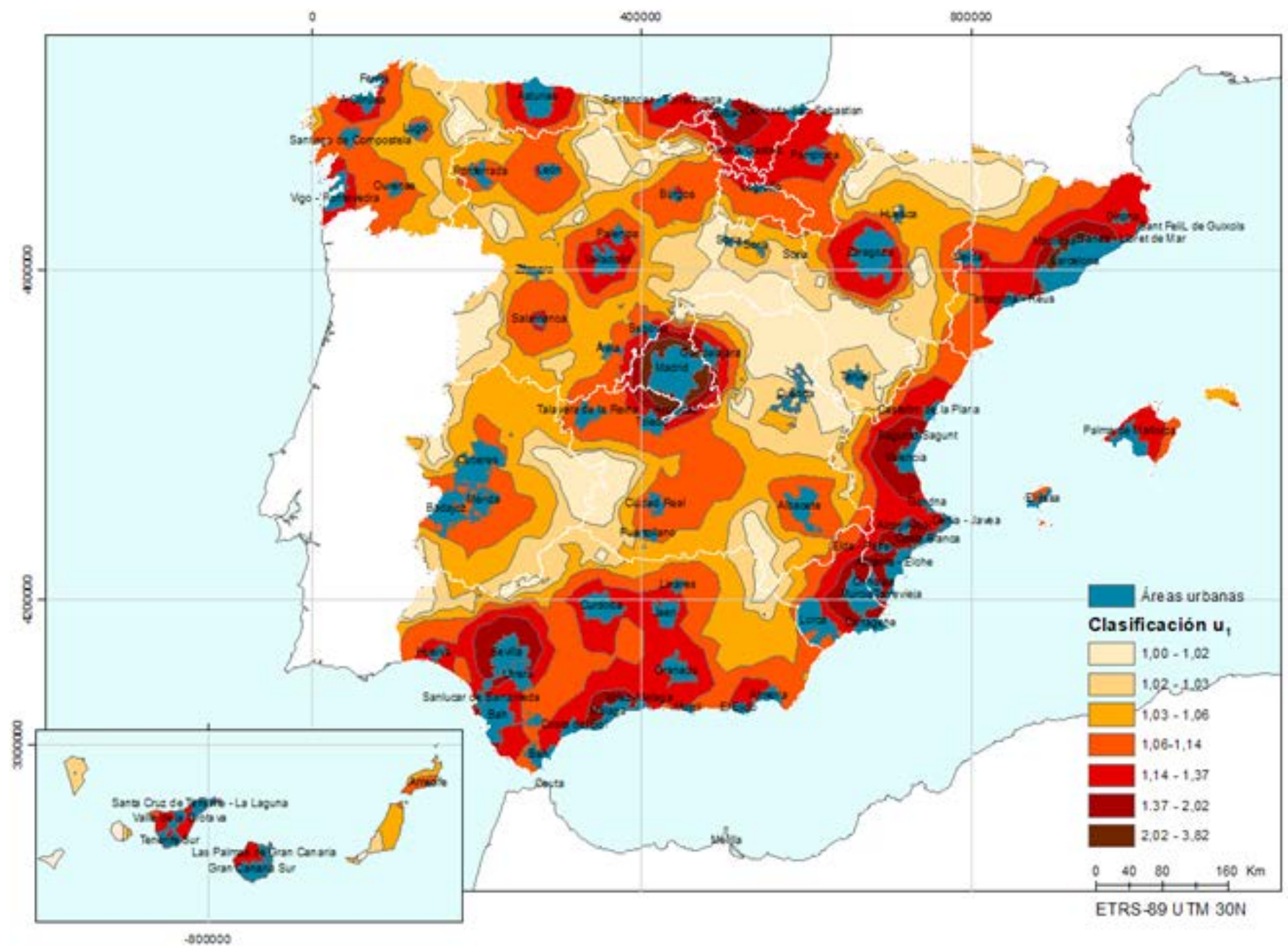

Figura 6.33. Áreas urbanas del territorio nacional (fuente: elaboración propia)

Las áreas urbanas con mayor extensión superficial (de 2.000 a $3.286 \mathrm{Ha}$ ) son Barcelona, Madrid y Zaragoza. Las áreas urbanas con mayor densidad de población son Ceuta y Melilla (4.311 Hab./Ha y $6.458 \mathrm{Hab} . / \mathrm{Ha}$, respectivamente) debido a su pequeña extensión superficial (las mínimas de todas las áreas urbanas, 19,60 Ha y $13,32 \mathrm{Ha}$ respectivamente).

Así mismo, existen otras áreas urbanas que, si bien no tienen el rango más alto de población, disponiendo de una extensión superficial dentro del menor rango (de 13 a $500 \mathrm{Ha}$ ) se encuentran entre las que tienen un rango intermedio de densidad de población (de 1.000 a $4.000 \mathrm{Hab} . / \mathrm{Ha}$ ), como es el caso de:

$\begin{array}{ll}\text { - Santa Cruz de Tenerife-La } & \text { - Santander-Torrelavega } \\ \text { Laguna } & \text { - Burgos } \\ \text { - Donostia/San Sebastián } & \text { - Salamanca } \\ \text { - Tarragona/Reus } & \text { - Manresa } \\ \text { - Castellón de la Plana } & \text { - Roquetas de Mar } \\ \text { - Las Palmas de Gran Canaria } & \text { - Arrecife. }\end{array}$


Parece necesario indicar que todas las áreas urbanas citadas se encuentran en la costa, excepto las correspondientes a Burgos, Salamanca y Manresa. Llama la atención que, en el caso del AU Zaragoza, a pesar de ser una de las de mayor extensión superficial, la densidad de población se encuentra entre las de rango más bajo.

Una vez analizadas las áreas urbanas en lo referente a su extensión superficial y densidad de población, se realizó un estudio relativo a las distintas áreas urbanas más importantes de cada una de las Comunidades Autónomas estudiadas.

\subsubsection{Factor $u_{1}$ y Área Urbana de Madrid}

El área urbana de Madrid tiene una superficie de 2.890,10 $\mathrm{Km}^{2}$ y está formada por 52 municipios. La población de toda el área urbana es de 6.047.108 habitantes.

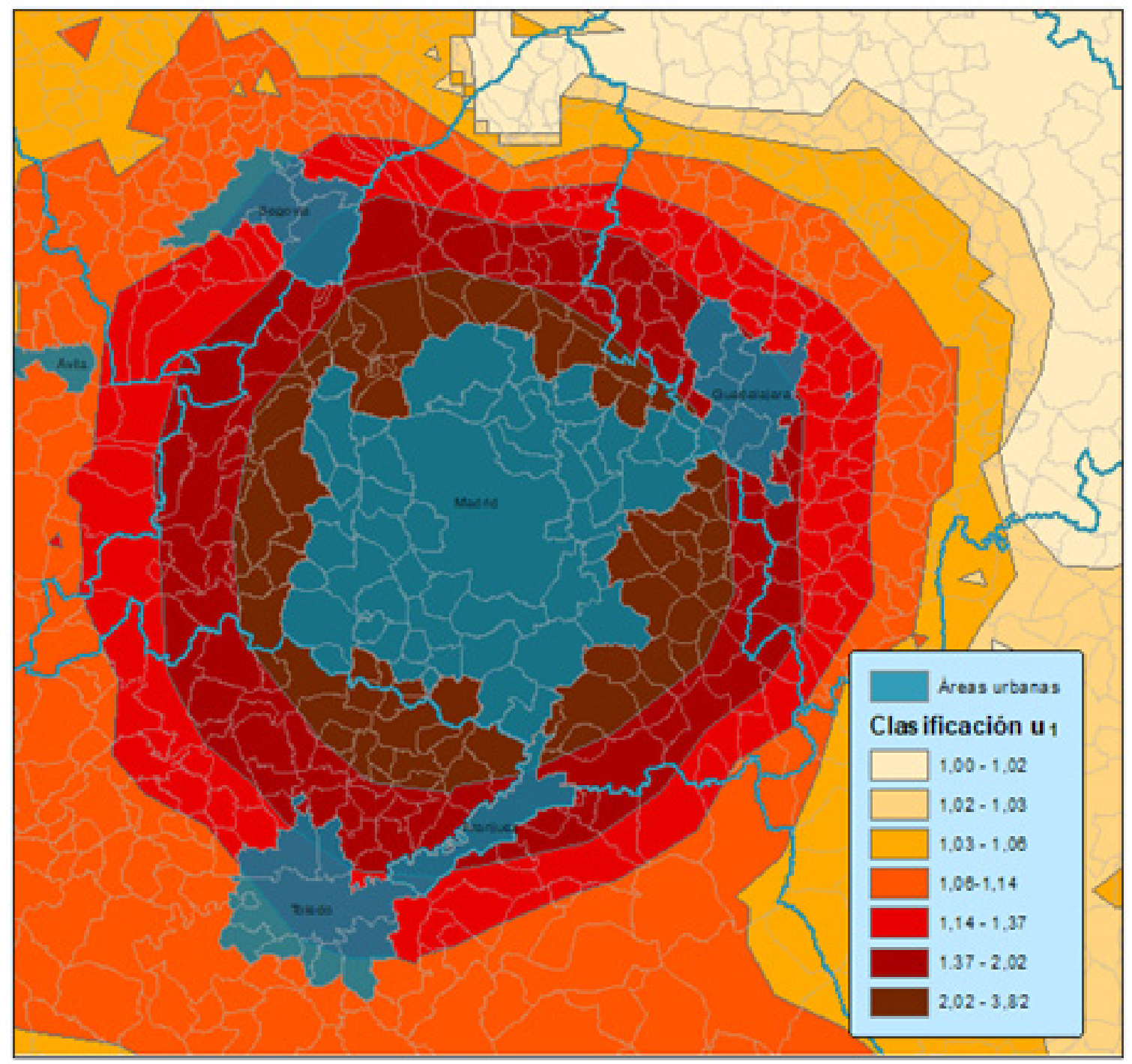

Figura 6.34. Área urbana de Madrid (fuente: elaboración propia) 
En la figura correspondiente se representa también el área urbana de Aranjuez y en ella se puede observar tanto la diferencia de la extensión, como en qué categoría del factor de corrección $\mathbf{u}_{1}$ se encuentran ambas áreas.

Con el fin de analizar las relaciones del factor $\mathbf{u}_{1}$ y la clasificación urbanística del suelo en el área urbana de Madrid, en la Figura 6.35 se representa la superposición dicha clasificación con la categorización de los valores continuos del factor de corrección.

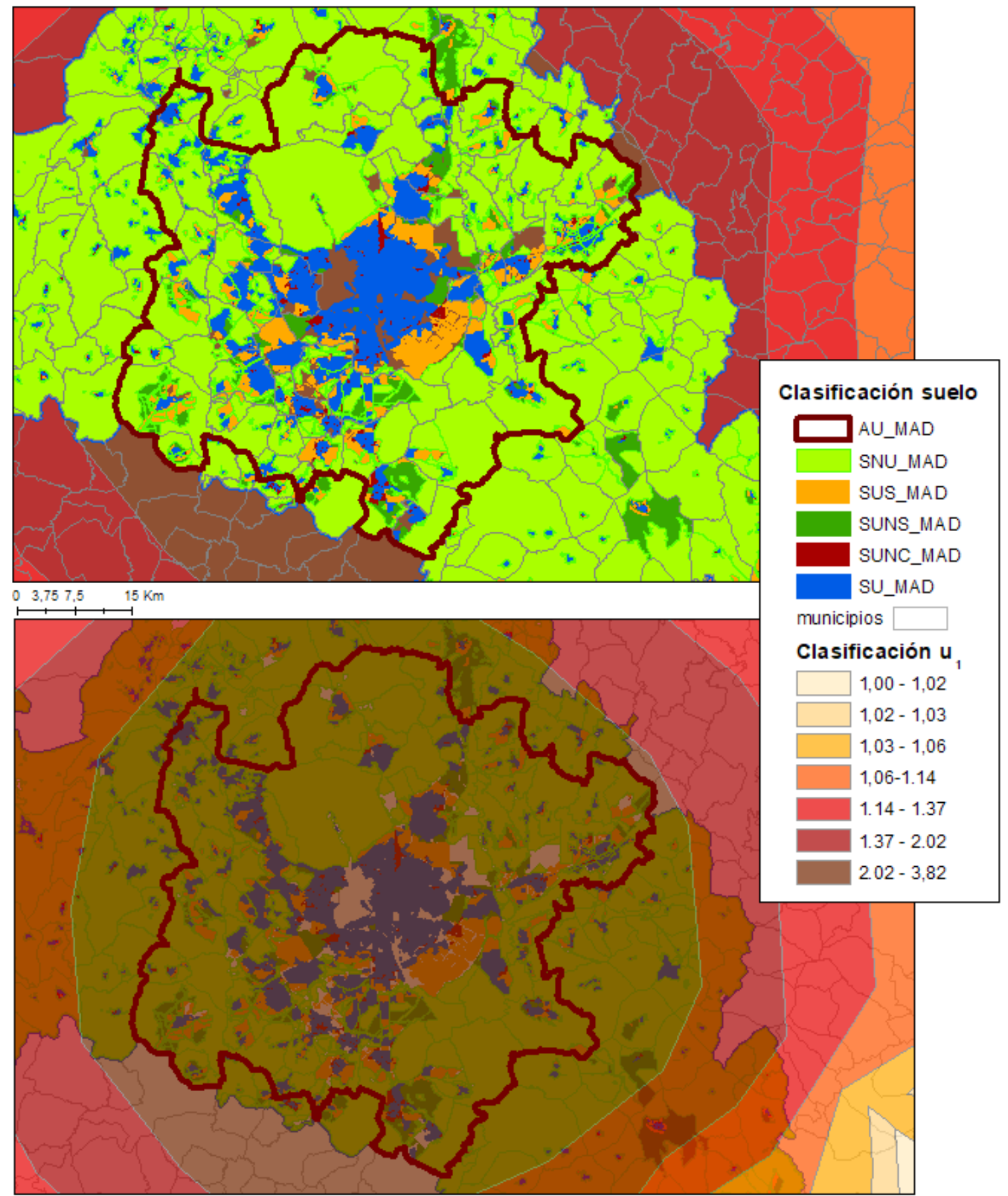

Figura 6.35. Área urbana de Madrid sobre plano de clasificación urbanística del suelo y valores de $u_{1}$ (fuente: elaboración propia) 
En la Figura 6.36 se representan las relaciones entre la clase urbanística de suelo, cantidad de suelo en cada una de ellas y el intervalo del valor del factor de corrección $\mathbf{u}_{1}$ en que se encuentran.
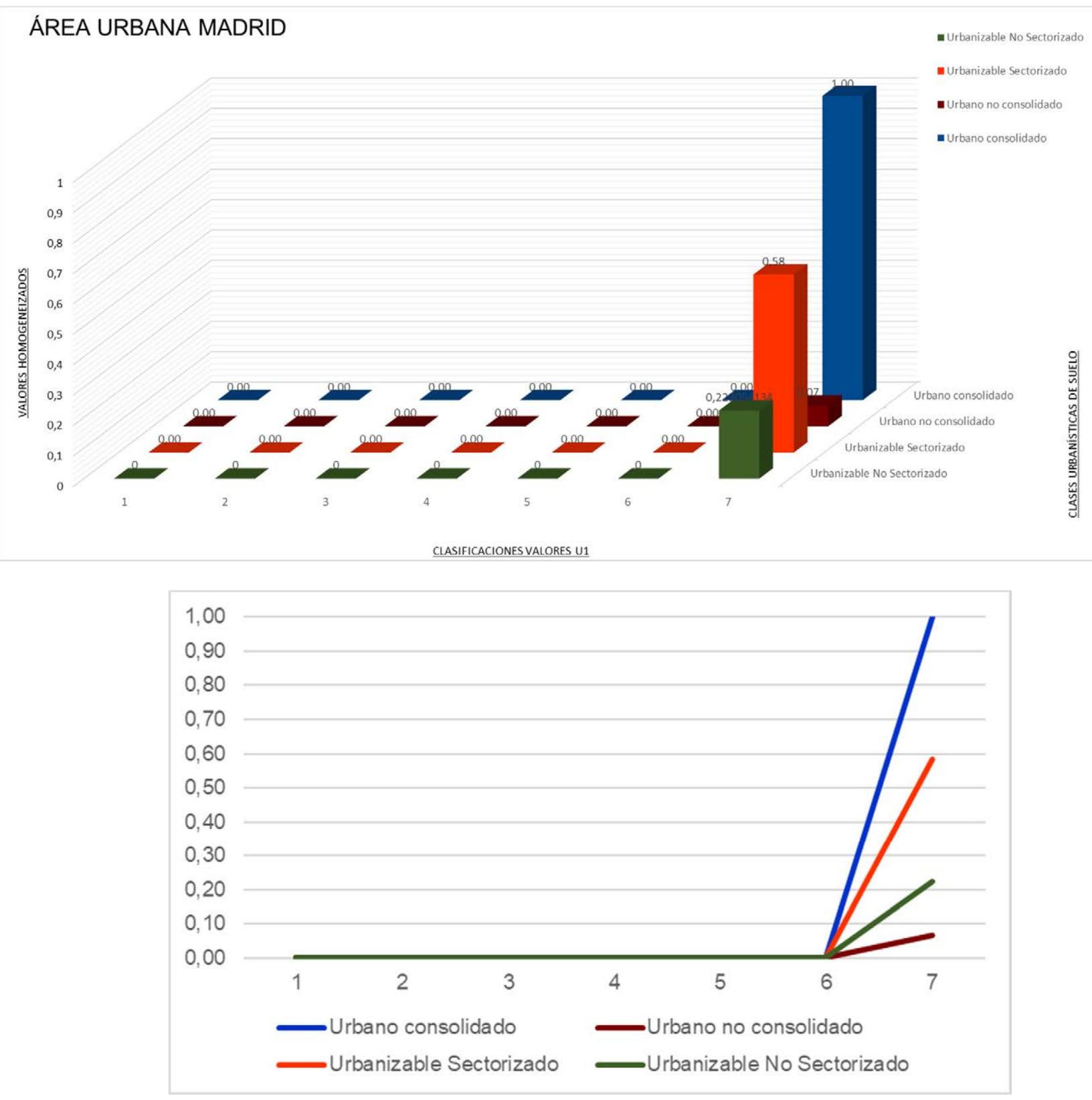

Figura 6.36. Diagrama de columnas y líneas, clasificación de suelo, clasificación de $u_{1}$ y superficie en el área urbana de Madrid (fuente: elaboración propia)

Así mismo se ha analizado la relación entre el valor del factor $\mathbf{u}_{1}$ y la cantidad de suelo de cada una de las clasificaciones urbanísticas de suelo, para conocer la relación del área urbana de Madrid con la totalidad de la Comunidad Autónoma, con los resultados expresados en la Tabla 6.10. 


\begin{tabular}{lcccccccccc} 
& $\begin{array}{c}\text { Municip } \\
\mathbf{n}^{\mathbf{0}}\end{array}$ & $\begin{array}{c}\text { SUPERFICIE } \\
\left(\mathrm{Km}^{2}\right)\end{array}$ & $\begin{array}{c}\text { \% } \\
\text { habitantes }\end{array}$ & $\begin{array}{c}\text { Población } \\
\text { hab }\end{array}$ & $\begin{array}{c}\text { SUC } \\
\mathbf{K m}^{2}\end{array}$ & $\begin{array}{c}\text { SUNC } \\
\mathbf{K m}^{2}\end{array}$ & $\begin{array}{c}\text { SUS } \\
\mathbf{K m}^{2}\end{array}$ & $\begin{array}{c}\text { SUNS } \\
\mathbf{K m}^{2}\end{array}$ \\
\hline Área Urbana & 52 & 29,05 & $2.890,10$ & 36,01 & 6.047 .108 & 93,10 & 533,45 & 36,09 & 311,92 & 118,99 \\
\hline TOTAL, CM & $\mathbf{1 7 9}$ & $\mathbf{1 0 0}$ & $\mathbf{8 . 0 2 5 , 5 8}$ & $\mathbf{1 0 0}$ & $\mathbf{6 . 4 9 5 . 5 5 1}$ & $\mathbf{1 0 0}$ & $\mathbf{6 9 6 , 4 0}$ & $\mathbf{5 0 , 7 8}$ & $\mathbf{3 8 0 , 3 0}$ & $\mathbf{3 2 0 , 3 1}$
\end{tabular}

Tabla 6.10. Valores área urbana de Madrid (fuente: elaboración propia)

Analizados los valores obtenidos en el área urbana de Madrid se observa que los resultados obtenidos de la totalidad del área urbana son similares a los obtenidos en la totalidad de la Comunidad Autónoma y prácticamente iguales a los resultantes del estudio de los municipios de Madrid y Leganés, debiendo tenerse en cuenta que este último está incluido en el área urbana de Madrid.

Los valores del factor de corrección $\mathbf{u}_{1}$ se encuentran en la categoría de mayor valor es decir en la 7 (valores de 2,02 a 3,82). El área urbana de Madrid está formada por 52 municipios que representan el $29,05 \%$ de los municipios que forman la Comunidad de Madrid.

La cantidad de habitantes que se encuentran en el área urbana es del 93\% del total de la Comunidad mientras que en lo que se refiere a la extensión superficial del área urbana, está solamente representa el $36,01 \%$ de la totalidad de la superficie de la Comunidad Autónoma.

En el área urbana el $34,62 \%$ del suelo es de uso lucrativo, el resto corresponde a Suelo no urbanizable o Sistemas Generales.

Del mismo modo que ocurría en el estudio anterior, en el área urbana de Madrid todas las categorías del factor de corrección $\mathbf{u}_{1}$ se encuentran todas las clases urbanísticas de suelo, desde el suelo urbano consolidado (SUC) hasta el suelo no urbanizable (SNU) pasando por todas las clases y categorías intermedias (SUNC, SUS, SUNS).

\subsubsection{Factor $u_{1} y$ área urbana de Murcia}

El área urbana de Murcia tiene una superficie de $1.230,9 \mathrm{Km}^{2}$ y está formada por 10 municipios. La población de toda el área urbana es de 641.743 habitantes.

En la Figura 6.37 también se representan otras áreas urbanas de la Región y se puede observar tanto la diferencia de la extensión, como la categoría del factor de corrección $\mathbf{u}_{1}$ en la que se encuentra cada una de ellas. 


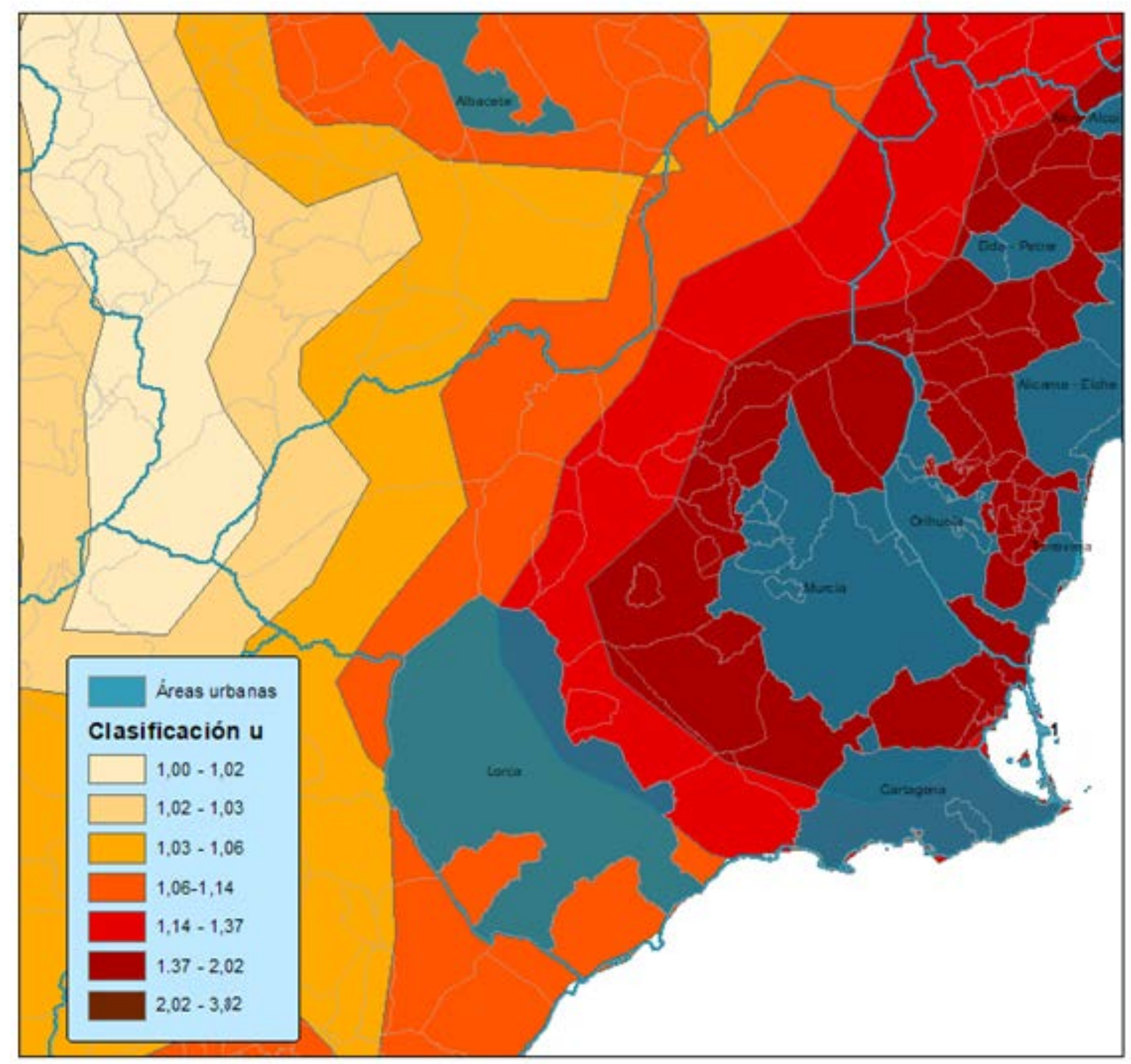

Figura 6.37. Área urbana de Murcia (fuente: elaboración propia)

Con el fin de analizar las relaciones entre el factor $\mathbf{u}_{1}$ y la clasificación urbanística de suelo en el área urbana de Murcia, también en esta ocasión se representa la superposición de dicha clasificación con la categorización de los valores continuos del factor de corrección, como puede verse en la Figura 6.38. 


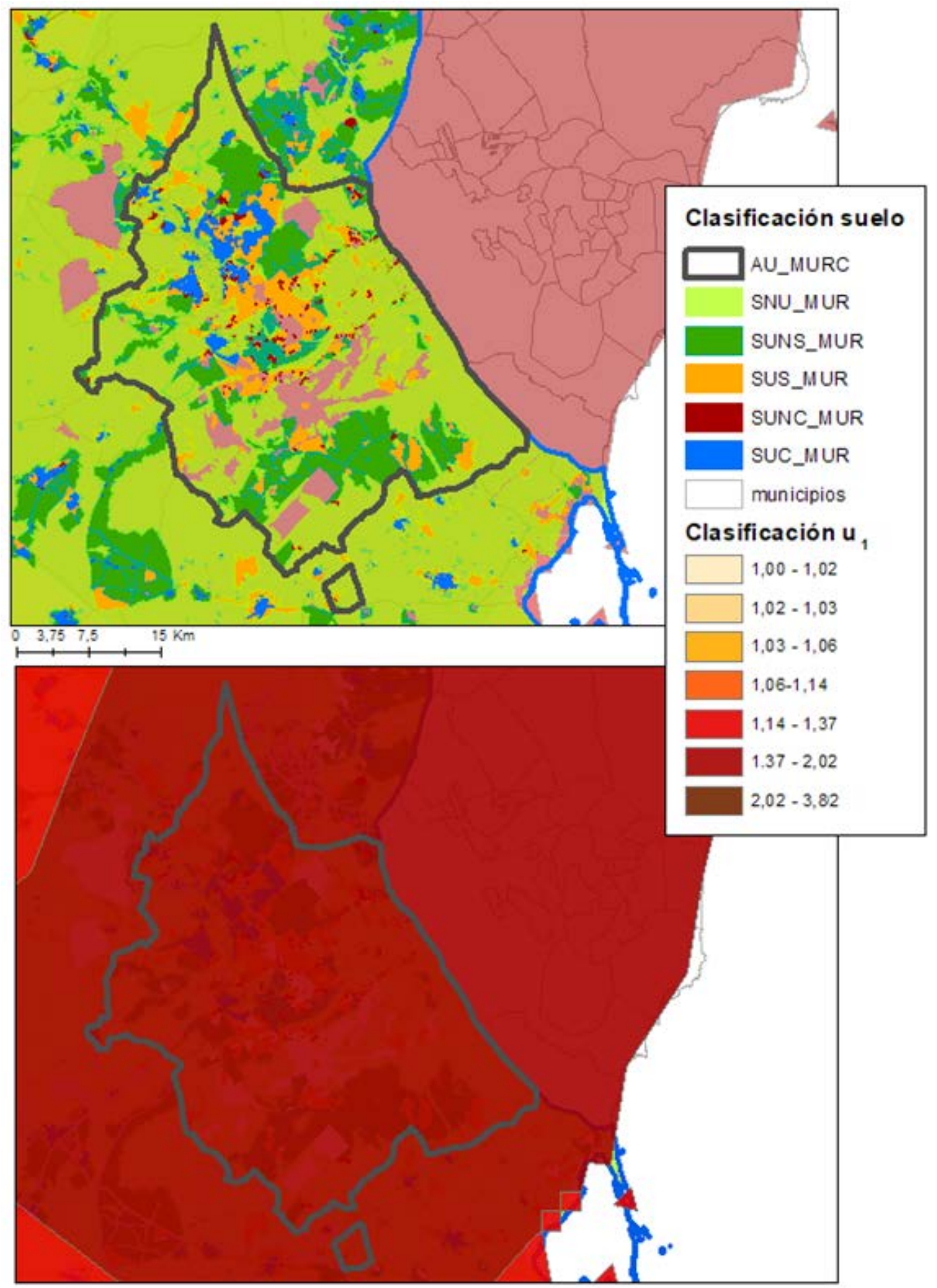

Figura 6.38. Área urbana de Murcia sobre plano de clasificación urbanística del suelo y valores de $u_{1}$ (fuente: elaboración propia)

Del mismo modo que en el apartado 6.3.2 Factor $\mathrm{u}_{1} \mathrm{y}$ expectativas en la Región de Murcia, en la Figura 6.39 se puede observar la clase urbanística de suelo, cantidad de suelo en cada una de ellas y en qué intervalo del factor de corrección $\mathbf{u}_{1}$ se encuentran. 

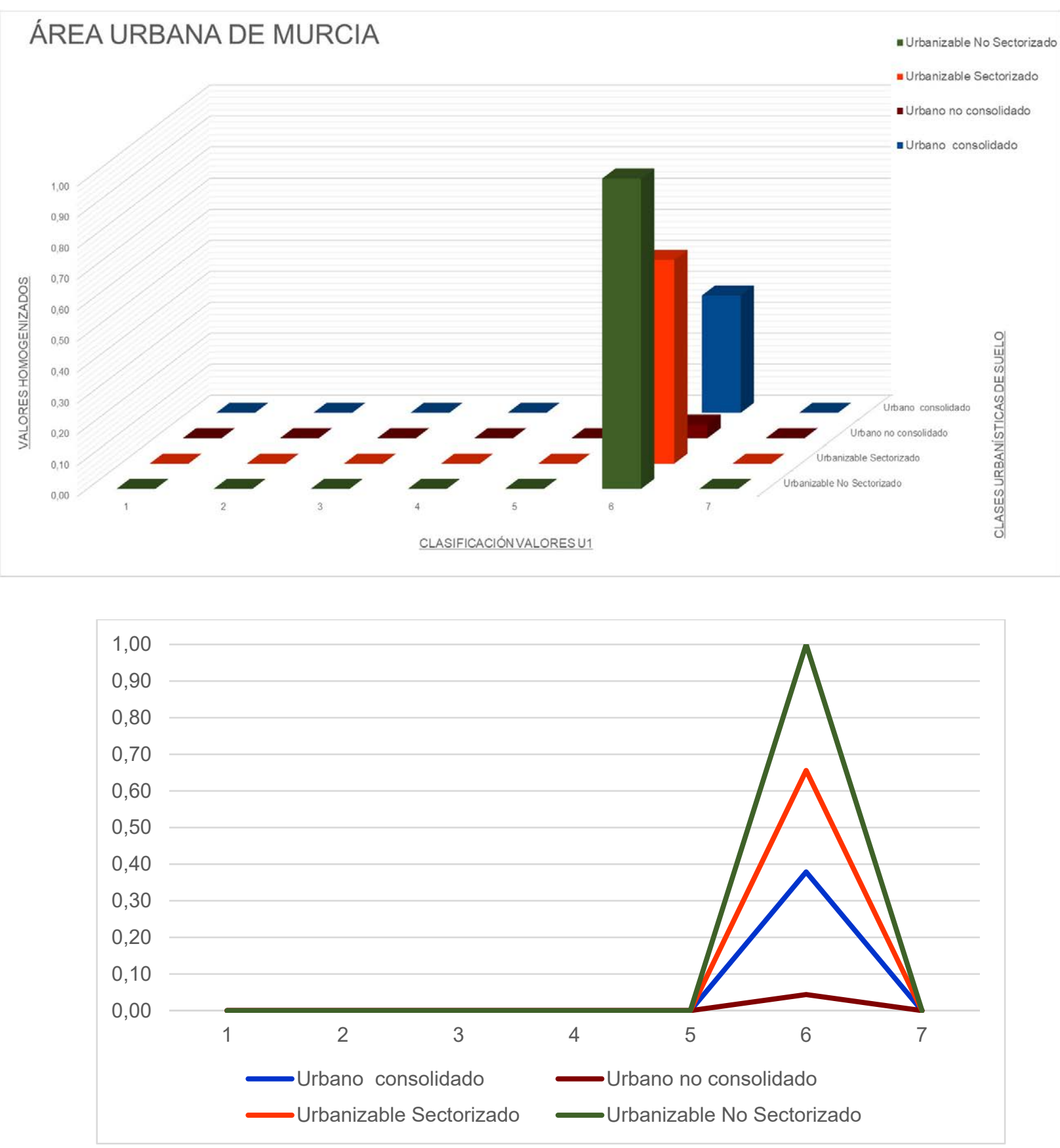

Figura 6.39. Diagrama de columnas y líneas, clasificación de suelo, clasificación de $u_{1}$ y superficie en el área urbana de Murcia (fuente: elaboración propia)

Nuevamente se ha analizado la relación entre el valor del factor $\mathbf{u}_{1}$ y la cantidad de suelo de cada una de las clasificaciones urbanísticas de suelo con el fin de conocer la relación existente entre el área urbana de Murcia y la totalidad de la Región de Murcia, obteniéndose en la Tabla 6.11 los siguientes resultados: 


\begin{tabular}{lcccccccccc} 
& $\begin{array}{c}\text { Municip } \\
\mathbf{n}^{\mathbf{0}}\end{array}$ & $\begin{array}{c}\text { SUPERFICIE } \\
\left(\mathbf{K m}^{2}\right)\end{array}$ & $\begin{array}{c}\text { Población } \\
\text { habitantes }\end{array}$ & $\begin{array}{c}\text { SUC } \\
\mathbf{K m}^{2}\end{array}$ & $\begin{array}{c}\text { SUNC } \\
\mathbf{K m}^{2}\end{array}$ & $\begin{array}{c}\text { SUS } \\
\mathbf{K m}^{2}\end{array}$ & $\begin{array}{c}\text { SUNS } \\
\mathbf{K m}^{2}\end{array}$ \\
\hline Área Urbana & 10 & 22,22 & $1.230,90$ & 10,88 & 641.743 & 43,60 & 90,19 & 10,44 & 156,19 & 238,16 \\
\hline TOTAL, RM & $\mathbf{4 5}$ & $\mathbf{1 0 0}$ & $\mathbf{1 1 . 3 1 3 , 1 0}$ & $\mathbf{1 0 0}$ & $\mathbf{1 . 4 7 2 . 0 4 9}$ & $\mathbf{1 0 0}$ & $\mathbf{2 2 1 , 8 4}$ & $\mathbf{2 1 , 0 7}$ & $\mathbf{3 7 8 , 3 7}$ & $\mathbf{1 . 9 3 1 , 5 5}$
\end{tabular}

Tabla 6.11. Valores Región de Murcia (fuente: elaboración propia)

Analizados los valores correspondientes al área urbana de Murcia se observa que los resultados son similares a los obtenidos en el municipio de Murcia.

Los valores del factor de corrección $\mathbf{u}_{1}$ se encuentran en la categoría 6 (valores de 1,37 a 2,02). El área urbana de Murcia está formada por 10 municipios que representan el $22,22 \%$ de los municipios que forman la Región.

La cantidad de habitantes que se encuentran en el área urbana es de $43,60 \%$ del total de la Región, sin embargo, la extensión superficial del área urbana corresponde con el $10,88 \%$ de la totalidad de la superficie de la regional.

En el área urbana el $40,21 \%$ del suelo es de uso lucrativo y el resto corresponde a suelo no urbanizable y Sistemas Generales. Mientras que en la totalidad de la Región el $22,56 \%$ son suelos de uso lucrativo.

\subsubsection{Factor $u_{1}$ y Área Urbana de Barcelona}

El área urbana de Barcelona tiene una superficie de $3.271,5 \mathrm{Km}^{2}$ y está formada por 165 municipios. La población de toda el área urbana es de 5.042.757 habitantes. En la Figura 6.40 se representa el área urbana de Barcelona con la división de cada uno de los 165 municipios.

En dicha figura también se representan otras áreas urbanas de Cataluña y se puede observar tanto la diferencia de tamaño como en qué categoría del factor de corrección $\mathbf{u}_{1}$ se encuentran cada una de ellas. 


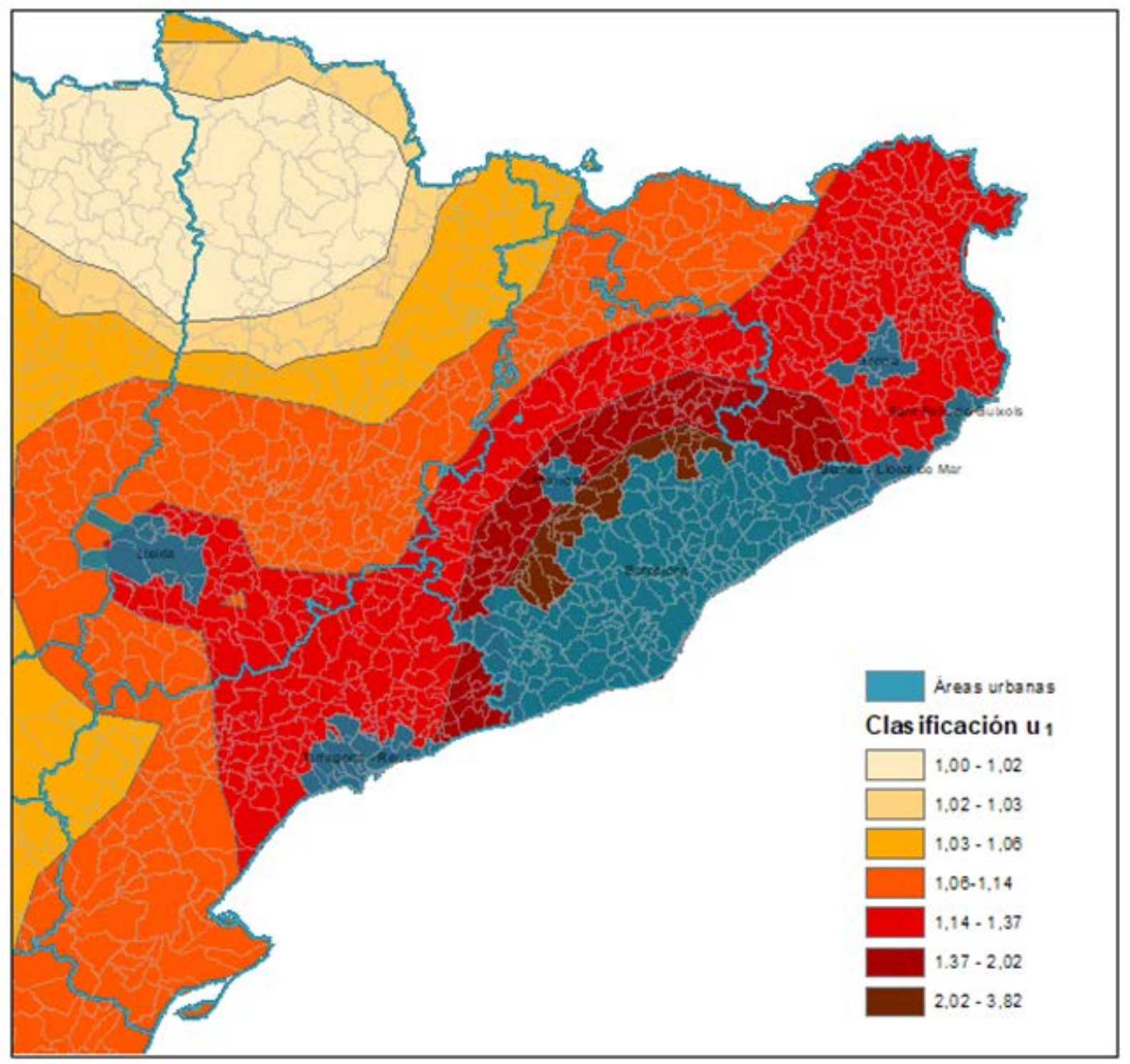

Figura 6.40. Área urbana de Barcelona (fuente: elaboración propia)

En esta ocasión se han analizado las relaciones que, en las áreas urbanas de Barcelona, Tarragona, Lérida y Gerona, existen entre el valor del factor $\mathbf{u}_{1}$, la clasificación urbanística del suelo, representándose en la Figura 6.41 la superposición de la clasificación de suelo en la totalidad del área urbana de Barcelona con la categorización de los valores continuos del citado factor de corrección. 


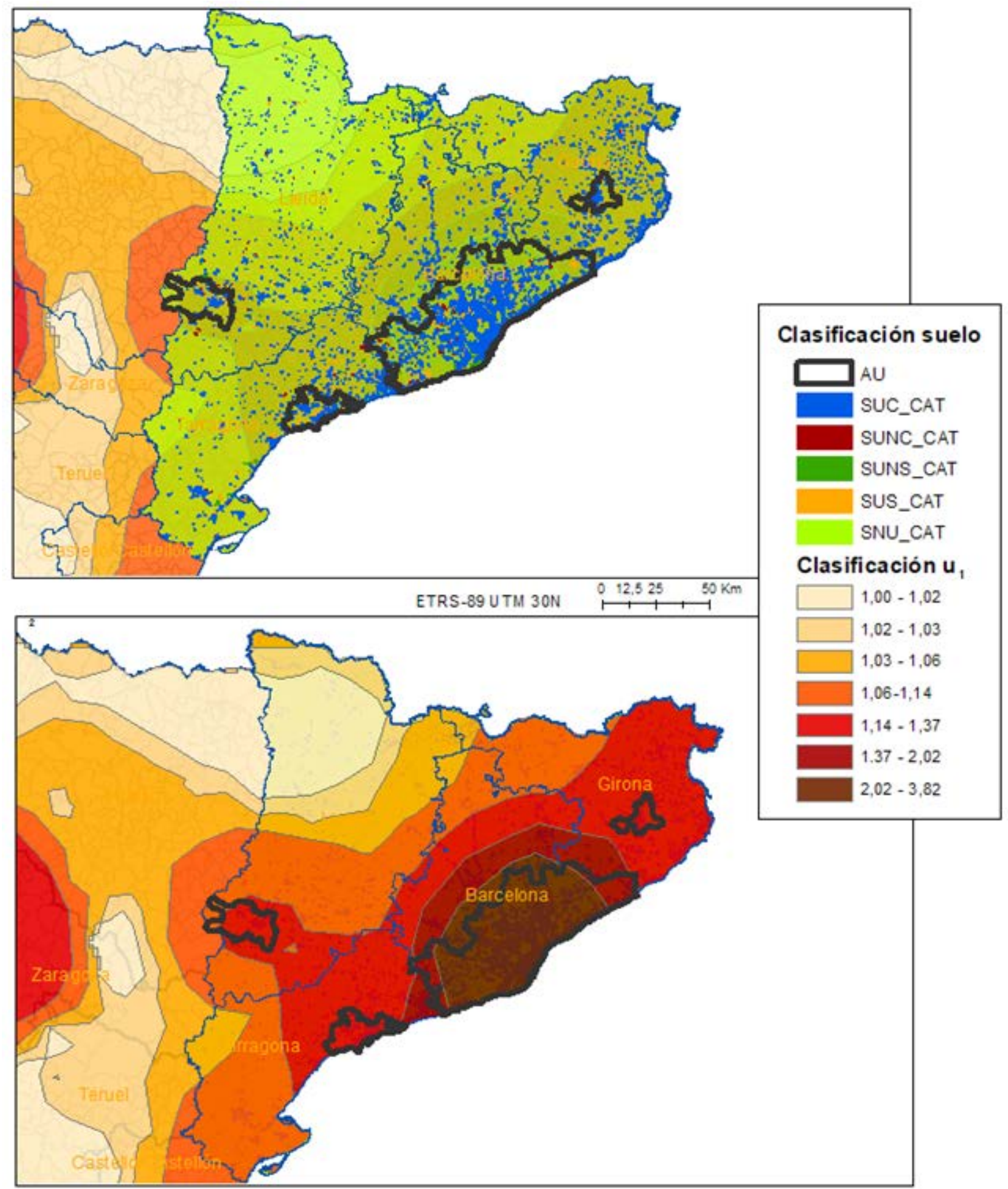

Figura 6.41. Áreas urbanas de Barcelona, Tarragona, Lérida y Gerona sobre plano de clasificación urbanística del suelo y valores de u1 (fuente: elaboración propia)

Del mismo modo que en el apartado 6.3.3 Factor $\mathrm{u}_{1} \mathrm{y}$ expectativas en Cataluña, se han analizado (Figura 6.42, 6.43, 6.44 y 6.45 ) las relaciones en cada una de las cuatro provincias entre la clase urbanística de suelo, cantidad de suelo de cada una de ellas y en qué intervalo del valor del factor de corrección $\mathbf{u}_{1}$ se encuentran. 


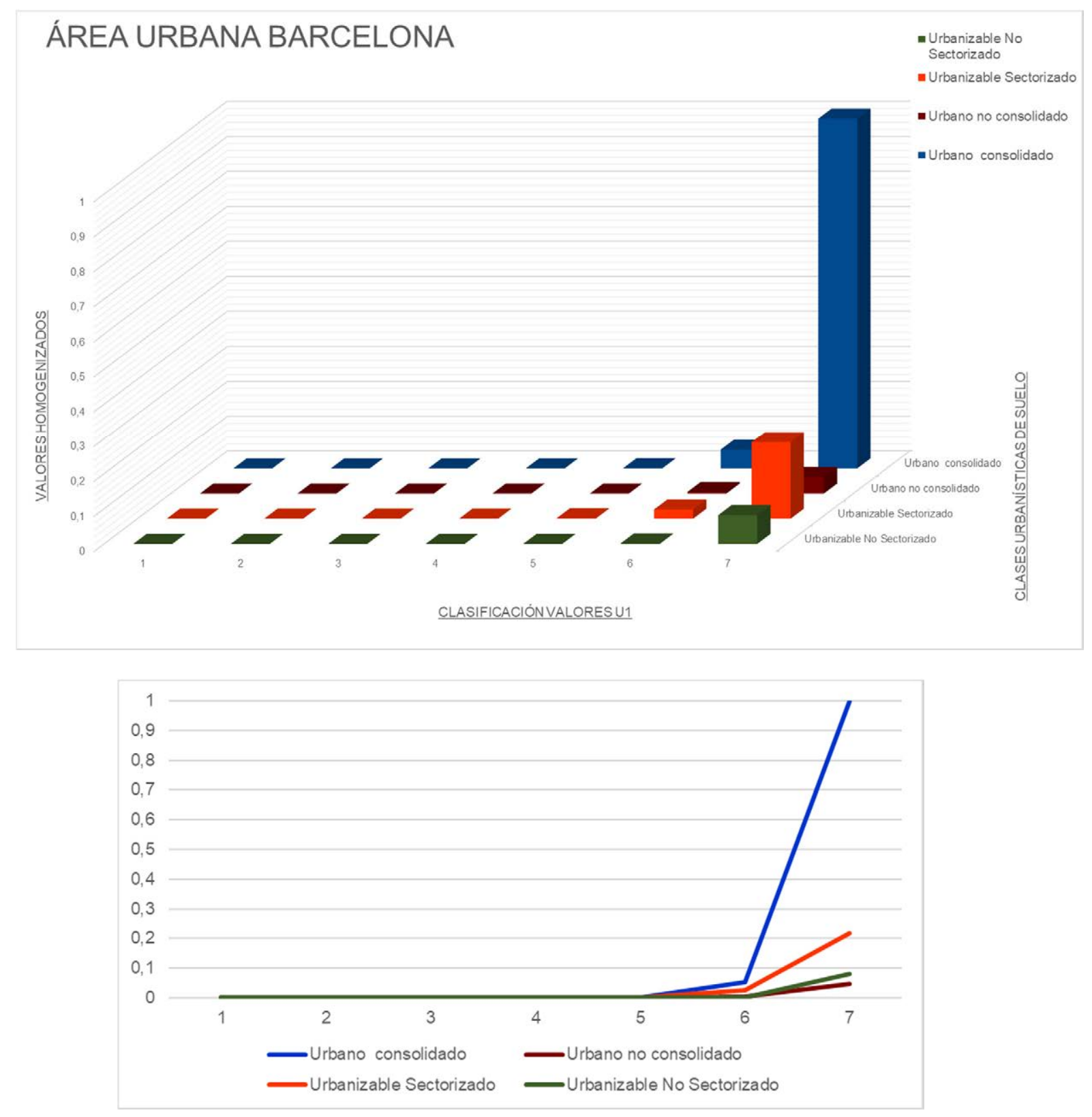

Figura 6.42. Diagrama de columnas y líneas, clasificación de suelo, clasificación de u y superficie en el área urbana de Barcelona (fuente: elaboración propia)

En estos diagramas de la Figura 6.42, correspondientes al área urbana de Barcelona, se observa que los datos obtenidos son similares a los relativos a la totalidad de la Provincia de Barcelona.

Los valores del factor de corrección $\mathbf{u}_{1}$ se encuentran en la categoría de mayor valor, es decir en la categoría 7 (valores de 2,02 a 3,82). El área urbana de Barcelona está formada por 165 municipios que representa el $17,42 \%$ de los municipios que forman la Comunidad. 

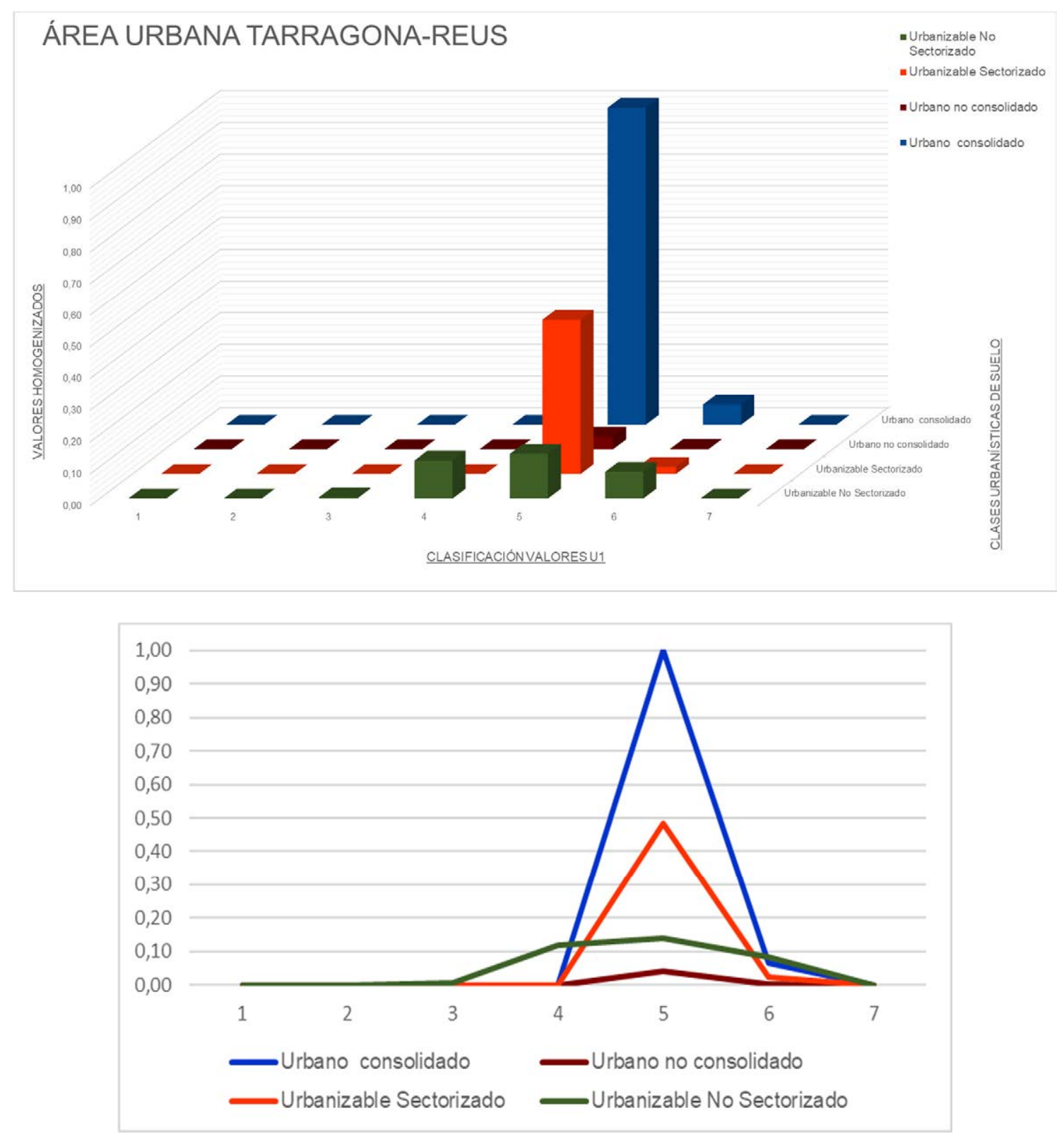

Figura 6.43. Diagrama de columnas y líneas, clasificación de suelo, clasificación de u1 y superficie en el área urbana de Tarragona (fuente: elaboración propia)

En la Figura 6.43, puede comprobarse que los datos obtenidos en el área urbana de Tarragona no presentan ninguna similitud con los datos obtenidos en la totalidad de la Provincia de Tarragona.

Los valores del factor de corrección $\mathbf{u}_{1}$ se encuentran en la categoría 5 (valores de 1,14 a 1,37). El área urbana de Tarragona está formada por 16 municipios que representa el 1,69\% de los municipios que forman la Comunidad. 

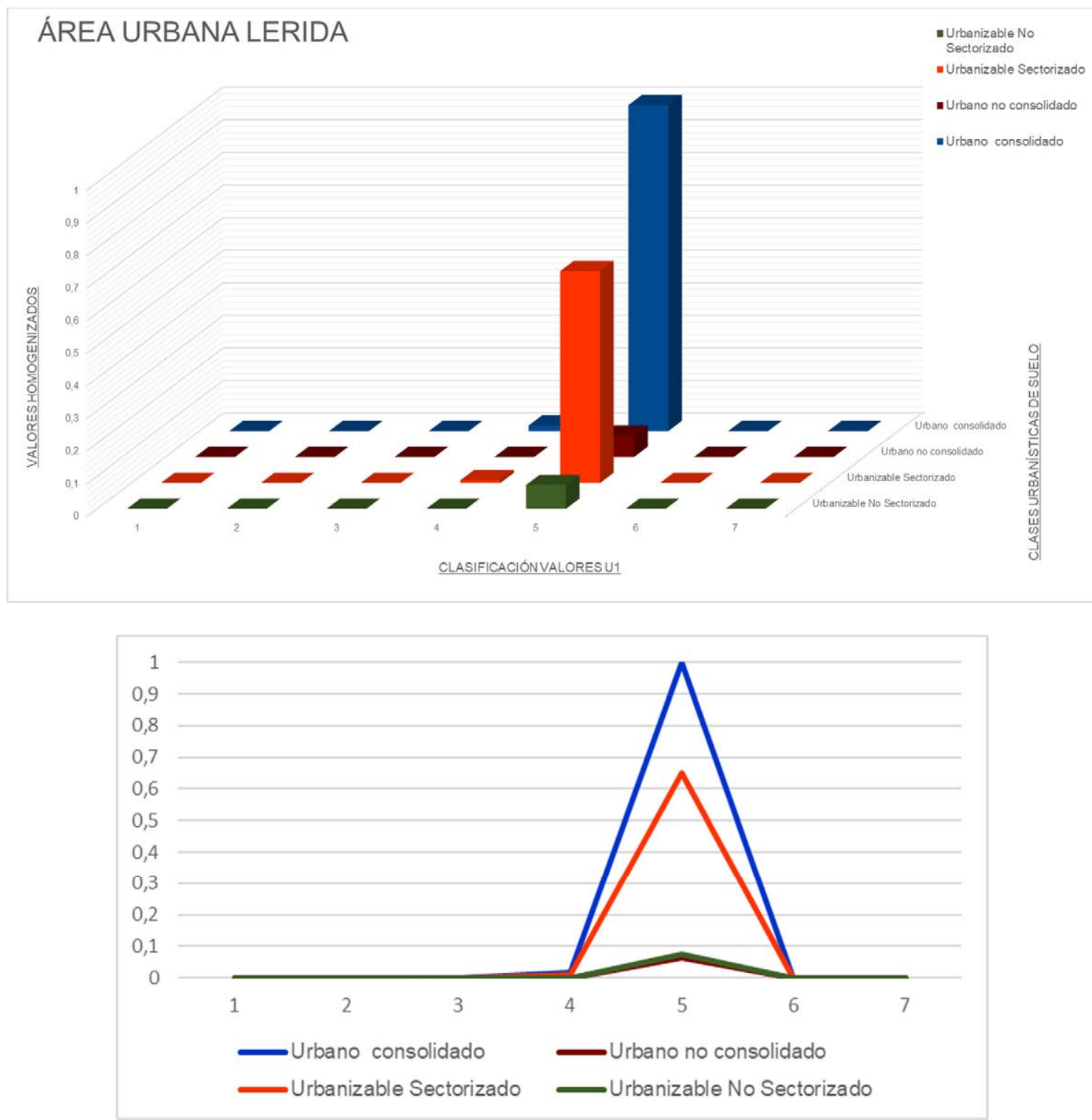

Figura 6.44. Diagrama de columnas y líneas, clasificación de suelo, clasificación de $u_{1}$ y superficie en el área urbana de Lérida (fuente: elaboración propia)

En los diagramas de la Figura 6.44, que corresponden al área urbana de Lérida, se observa que los datos obtenidos no tienen ninguna similitud con los correspondientes a la totalidad de la Provincia.

Los valores del factor de corrección $\mathbf{u}_{1}$ se encuentran en la categoría 5 (valores de 1,14 a 1,37). El área urbana de Lérida está formada por 8 municipios que representa el $0,84 \%$ de los municipios que forman la Comunidad catalana. 


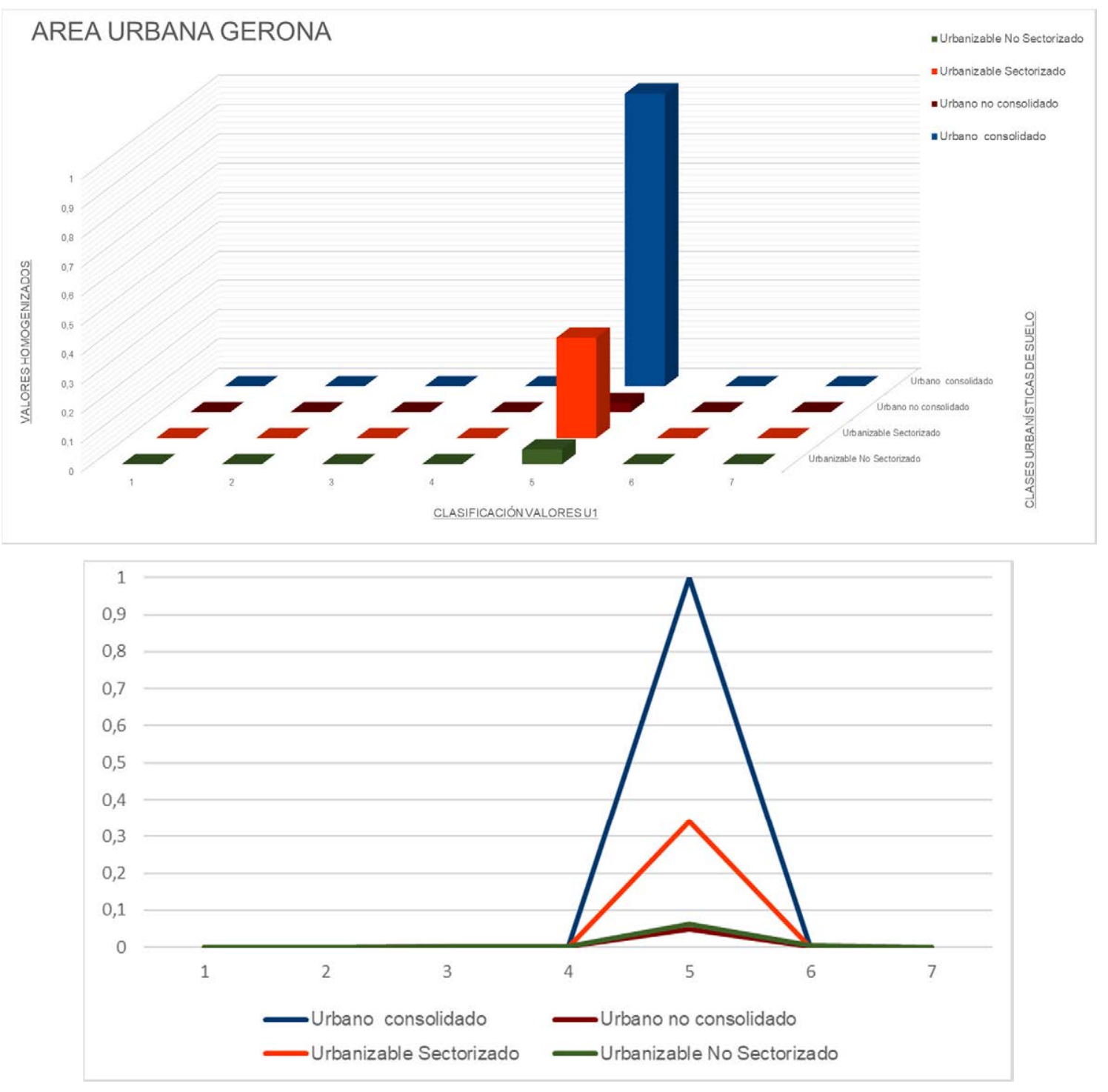

Figura 6.45. Diagrama de columnas y líneas, clasificación de suelo, clasificación de un y superficie en el área urbana de Gerona (fuente: elaboración propia)

En cuanto a la representación gráfica de los resultados correspondientes al área urbana de Gerona (Figura 6.45), puede señalarse que reflejan que los datos obtenidos tienen tan solo una ligera similitud con los resultantes de la totalidad de la Provincia.

Los valores del factor de corrección $\mathbf{u}_{1}$ se encuentran en la categoría 5 (valores de 1,14 a 1,37). El área urbana de Lérida está formada por 9 municipios que representa el 0,95\% de los municipios que forman la Comunidad Autónoma.

Al igual que se hizo en el apartado 6.3.3 Factor $u_{1}$ y expectativas en Cataluña, se ha analizado la relación entre el valor del factor $\mathbf{u}_{1}$ y la cantidad de suelo de cada una de las clasificaciones urbanísticas de suelo para conocer la relación de cada una de las áreas urbanas de las provincias con la totalidad de la Comunidad, obteniéndose en la Tabla 6.12 los siguientes resultados: 


\begin{tabular}{|c|c|c|c|c|c|c|c|c|c|}
\hline $\begin{array}{c}\text { Áreas } \\
\text { urbanas }\end{array}$ & $\begin{array}{c}\text { Municip. } \\
n^{\circ}\end{array}$ & $\%$ & $\begin{array}{c}\text { SUPERF. } \\
\left(\mathrm{Km}^{2}\right)\end{array}$ & $\%$ & $\begin{array}{c}\text { Poblaciones } \\
\text { habitantes }\end{array}$ & $\begin{array}{l}\text { SUC } \\
\mathrm{Km}^{2}\end{array}$ & $\begin{array}{c}\text { SUNC } \\
\mathrm{Km}^{2}\end{array}$ & $\begin{array}{l}\text { SUS } \\
\mathrm{Km}^{2}\end{array}$ & $\begin{array}{c}\text { SUNS } \\
\mathrm{Km}^{2}\end{array}$ \\
\hline AU Barcelona & 165 & 17,42 & $3.271,51$ & 10,19 & 5.042 .757 & 615,50 & 30,29 & 143,30 & 48,35 \\
\hline AU Tarragona & 16 & 1,69 & 355,87 & 1,11 & 384.041 & 78,22 & 3,12 & 34,06 & 3,28 \\
\hline AU Lérida & 8 & 0,84 & 426,30 & 1,33 & 169.419 & 22,53 & 1,44 & 14,56 & 1,61 \\
\hline AU Gerona & 9 & 0,95 & 180,24 & 0,56 & 154.079 & 23,95 & 0,75 & 8,24 & 12,30 \\
\hline Total, áreas & 198 & 20,91 & $4.233,92$ & 13,19 & 5.750 .296 & 740,20 & 35,60 & 200,16 & 65,54 \\
\hline $\begin{array}{l}\text { TOTAL, } \\
\text { Cataluña }\end{array}$ & 947 & 100 & $32.090,80$ & 100 & 7.553 .650 & 1303,67 & 69,53 & 431,80 & 102,01 \\
\hline
\end{tabular}

Tabla 6.12. Valores de áreas urbanas de Barcelona, Tarragona, Lérida y Gerona (fuente: elaboración propia)

Del análisis de los diagramas de columnas y líneas realizados para cada área urbana y provincia respectiva puede concluirse que, salvo en el área urbana de Barcelona en el resto de las áreas urbanas no se encuentra una similitud importante entre sus resultados y los de las provincias correspondientes.

En cuanto a los valores del factor de corrección $\mathbf{u}_{1}$, salvo el área urbana de Barcelona que se encuentra en la categoría de mayor valor, 7 (valores de 2,02 a 3,82), el resto de las áreas urbanas estudiadas, tienen un valor del factor de corrección $\mathbf{u}_{1}$ situado dentro de la categoría 5 (valores de 1,14 a 1,37). La totalidad de los municipios que forman las 4 áreas urbanas estudiadas incluyen un total de 198 municipios que representan el $20,91 \%$ de la totalidad de los municipios que forman la Comunidad.

La cantidad de habitantes del área urbana de Barcelona es la mayor de las 4 áreas urbanas, representando el $17,42 \%$ del total de la Comunidad.

En lo que se refiere a la cantidad de suelo lucrativo en cada área urbana, Barcelona tiene un 25,60 \%, Tarragona el 33,35 \%, Lérida el 9,41 \% y Gerona el 25,09\%, por lo que todas las áreas urbanas de Cataluña tienen un total del $24,60 \%$ del suelo lucrativo de la Comunidad Autónoma. Hay que tener en cuenta que, de la totalidad de superficie de la Comunidad catalana solamente el 5,94\% se trata de suelo lucrativo. Por lo tanto, las áreas urbanas de Barcelona, Tarragona y Gerona tienen un porcentaje de suelo lucrativo muy elevado en comparación con la totalidad de la Comunidad.

Del mismo modo que ocurría en el estudio de todas las áreas urbanas todas las categorías del factor de corrección $\mathbf{u}_{1}$ se encuentran en todas las clases urbanísticas de suelo, desde el suelo urbano consolidado (SUC), hasta el suelo no urbanizable 
(SNU) pasando por todas las clases y categorías intermedias (SUNC, SUS, SUNS).

\subsubsection{Factor $u_{1}$ y las áreas urbanas}

Dentro de las 86 grandes áreas urbanas de España (áreas con población superior a 50.000 habitantes) Barcelona y, en segundo lugar, Madrid, son las dos primeras en número de habitantes. El área urbana de Madrid está formada por un total de 52 municipios, mientras que la de Barcelona la forman 165 municipios, y el área urbana de Murcia tan solo está formada por 10 municipios. A este respecto el porcentaje, sobre el total de municipios que forman cada una de las Comunidades a las que pertenecen, es muy similar. El área urbana de Murcia es la número 10 del total de las 86 áreas urbanas, teniendo en cuenta el número de habitantes.

Analizados los datos obtenidos sobre las áreas urbanas estudiadas se han tomado los más relevantes que se recogen en la tabla siguiente:

\begin{tabular}{lcccccc} 
& $\begin{array}{c}\text { Municipio } \\
\mathbf{n}^{\mathbf{0}}\end{array}$ & $\mathbf{\%}$ & $\begin{array}{c}\text { SUPERFICIE } \\
\left(\mathbf{K m}^{\mathbf{2}}\right)\end{array}$ & $\mathbf{\%}$ & $\begin{array}{c}\text { Población } \\
\text { habitantes }\end{array}$ & $\%$ \\
\hline AU Madrid & 52 & 29,05 & $2.890,10$ & 36,01 & 6.047 .108 & 93,10 \\
\hline TOTAL, CM & 179 & 100 & $8.025,58$ & 100 & 6.495 .551 & 100 \\
\hline AU Murcia & 10 & 22,22 & $1.230,90$ & 10,88 & 641.743 & 43,60 \\
\hline TOTAL, RM & 45 & 100 & $11.313,10$ & 100 & 1.472 .049 & 100 \\
\hline AU Barcelona & 165 & 17,11 & $3.271,50$ & 10,19 & 5.042 .757 & 66,76 \\
\hline AU Tarragona & 16 & 1,69 & 355,87 & 1,11 & 384.041 & 5,08 \\
\hline AU Lérida & 8 & 0,84 & 426,30 & 1,33 & 169.419 & 2,24 \\
\hline AU Gerona & 9 & 0,95 & 180,24 & 0,56 & 154.079 & 2,04 \\
\hline TOTAL CAT. & 947 & 100 & $32.090,80$ & 100 & 7.553 .650 & 100 \\
\hline
\end{tabular}

Tabla 6.13. Valores totales comparados en las áreas urbanas estudiadas (fuente: elaboración propia)

Las áreas urbanas estudiadas, como el resto de las grandes áreas urbanas de España, presentan valores situados en las categorías más altas del factor $\mathbf{u}_{1}$. Este dato tiene su lógica de acuerdo con la información facilitada por el Ministerio de Fomento ya que, en las grandes urbanas habita el $68 \%$ de la población española y se concentra el $75 \%$ del empleo.

En las grandes áreas urbanas estudiadas el valor del factor $\mathbf{u}_{1}$ se distribuye en función, como es lógico, del número de habitantes siendo en las áreas de Madrid y Barcelona en las que se encuentra el mayor valor, correspondiente a la categoría 7 , de forma que, a medida que se reduce el número de habitantes también disminuye el valor del factor $\mathbf{u}_{1}$. 


\subsubsection{El Factor $u_{1}$ y las redes de comunicación}

En el estudio realizado se ha constatado que existen seis corredores formados por las principales carreteras autovías y autopistas. Estos corredores conexionan los puntos con los valores más elevados del factor de corrección por accesibilidad a núcleos de población $\mathbf{u}_{1}$. Tal y como se puede observar en la Figura 6.46 los corredores son los siguientes:

- Corredor 1 desde Cádiz hasta la frontera catalana con Francia.

- Corredor 2 Madrid-Sevilla-Cádiz.

- Corredor 3 Bilbao-Tarragona.

- Corredor 4 Madrid-La Coruña

- Corredor 5 San Sebastián-Salamanca hasta la frontera con Portugal

- Corredor 6 Asturias-Sevilla. La ruta de la Plata

La longitud de cada uno de ellos se recoge en la Tabla 6.14.

\begin{tabular}{cc} 
Corredor & Longitud $(\mathbf{K m})$. \\
\hline 1 & $1.419,98$ \\
\hline 2 & 647,33 \\
\hline 3 & 532,72 \\
\hline 4 & 617,70 \\
\hline 5 & 512,27 \\
\hline 6 & 779,81 \\
\hline TOTAL & $\mathbf{4 . 5 0 9 , 8 1}$
\end{tabular}

Tabla 6.14. Longitud de los corredores (fuente: elaboración propia)

Dichos corredores se estructuran a lo largo de los grandes ejes de actividad económica que vertebran el territorio, generalmente coincidentes con las infraestructuras ferroviarias, en muchos casos de alta velocidad. 


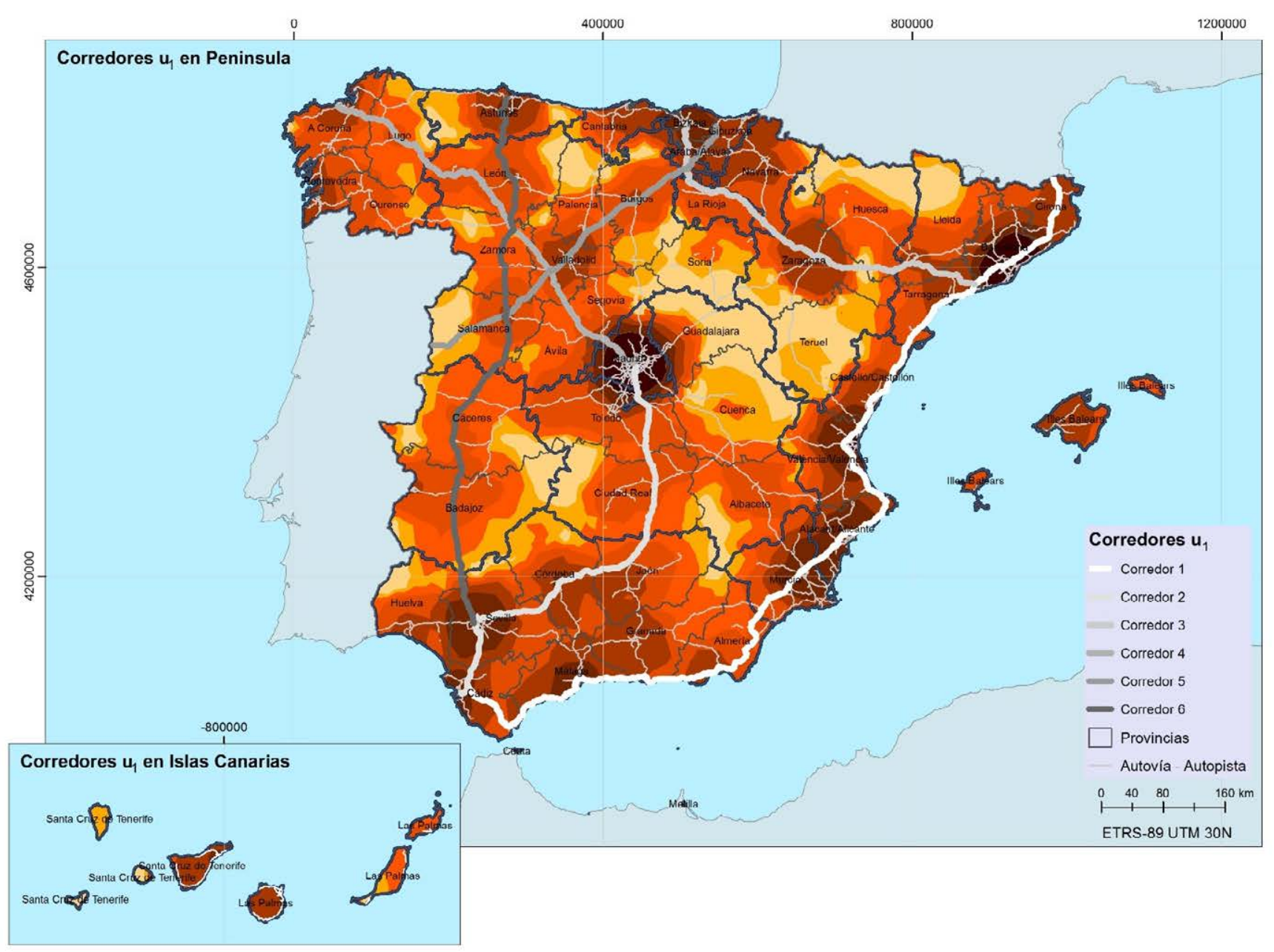

Figura 6.46. Corredores (fuente: elaboración propia)

En la superposición de los datos obtenidos de $\mathbf{u}_{1}$ en la interpolación, con los corredores y el resto de las autovías y autopistas (Figura 6.46) se ha estudiado la densidad de dichas infraestructuras en cada una de las categorías clasificadas del $\mathbf{u}_{1}$.

\begin{tabular}{cccc} 
Categoría & Área $\left(\mathbf{K m}^{2}\right)$ & Carreteras $\mathbf{( K m})$. & $\begin{array}{c}\text { Carreteras densidad } \\
\left(\mathbf{K m} . \text { carretera } / \mathbf{K m}^{2} \text { área }\right)\end{array}$ \\
\hline 1 & $55.010,99$ & 413 & 0,01 \\
\hline 2 & $67.000,21$ & 788 & 0,01 \\
\hline 3 & $111.069,13$ & 1.925 & 0,02 \\
\hline 4 & $130.497,02$ & 4.069 & 0,03 \\
\hline 5 & $88.875,26$ & 5.259 & 0,06 \\
\hline 7 & $30.816,52$ & 3.191 & 0,10 \\
\hline TOTAL & $8.905,87$ & 1.752 & 0,20 \\
\hline
\end{tabular}

Tabla 6.15. Carreteras en las distintas zonas de valor de $u_{1}$ (fuente: elaboración propia)

En la Tabla 6.15 puede observarse que la mayor densidad de carreteras se presenta en la categoría 7 del valor de $\mathbf{u}_{1}$ (correspondiente al mayor valor del factor de corrección $\mathbf{u}_{1}$ ), mientras que, en el resto de las categorías, la densidad disminuye del 
mismo modo que el valor del citado factor.

\subsubsection{Conclusión sobre el factor $u_{1}$ y el sistema urbano-territorial español}

En el análisis realizado en el presente trabajo de investigación queda constatado que los valores obtenidos del factor $\mathbf{u}_{1}$ siguiendo la formulación recogida en el RVLS 2011 tienen una relación inequívoca con la localización del sistema urbano - territorial definido en el apartado 3.4 de este trabajo.

Las grandes áreas urbanas delimitadas por el Ministerio de Fomento forman una red urbana en la que se refleja la jerarquía, tanto de cada una de ellas, como de la relación e influencia con las demás áreas y resto de territorio nacional. Todas ellas unidas y perfectamente relacionadas mediante la red de carreteras española, forman ese sistema urbano-territorial.

Los mayores valores del factor $\mathbf{u}_{1}$ se encuentran en las áreas urbanas que se encuentran un rango jerárquico superior, sin ninguna excepción.

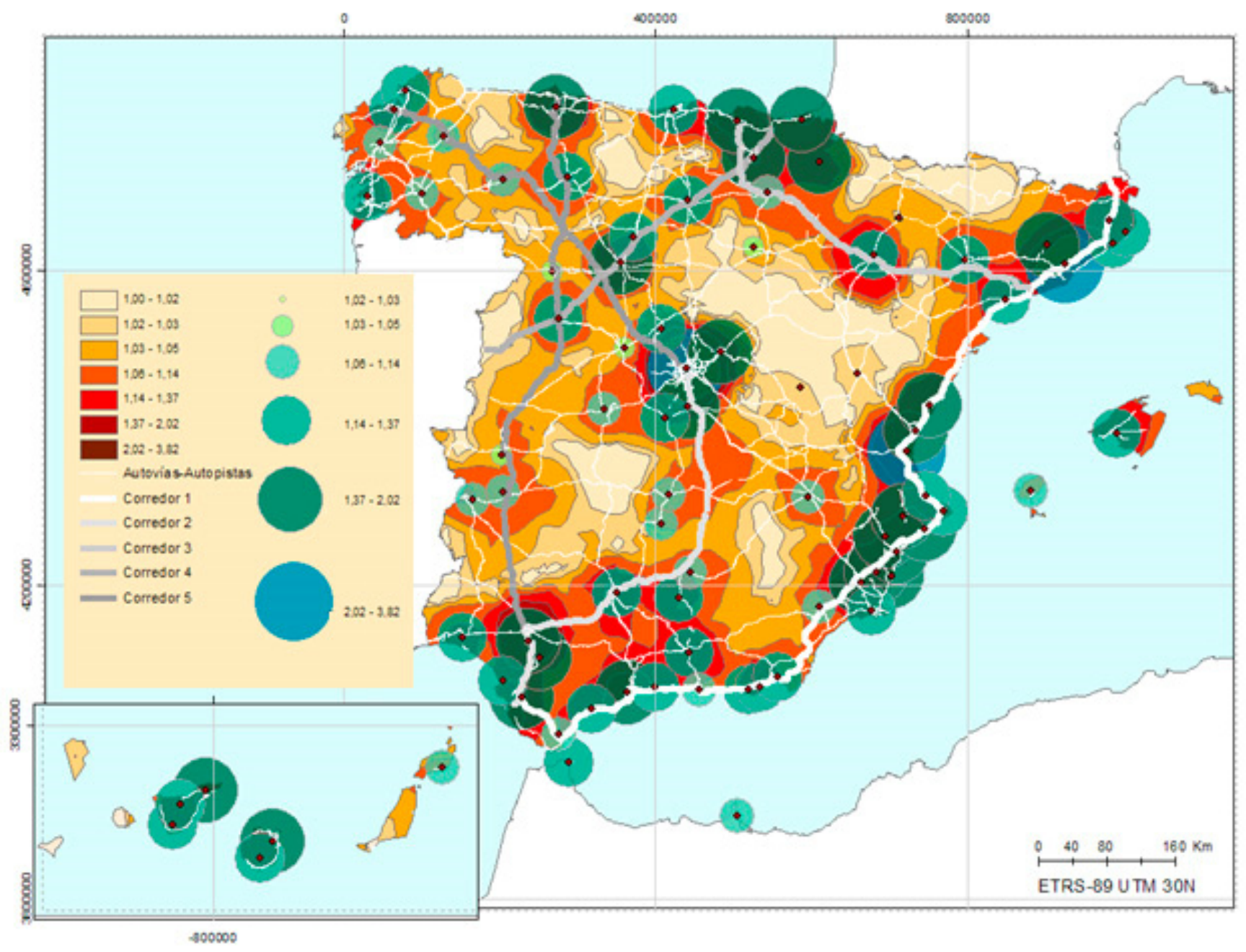

Figura 6.47. $\mathrm{KO}$ con valores $\mathrm{u}_{1}$, valores de $u_{1}$ y corredores. (fuente: elaboración propia) 


\subsection{CONCLUSIÓN}

Dada la complejidad del cálculo del valor del factor de corrección $\mathbf{u}_{1}$, se ha realizado un estudio del mismo en distintos puntos de la península y los territorios insulares, obteniendo como resultado final un mapa de la distribución espacial del valor de este factor en todo el territorio español.

Para ello se ha estudiado $\mathbf{u}_{1}$ en 1.836 puntos, obteniéndose valores con un rango que varía desde 1 hasta 3,82 . Se ha identificado que el mayor valor de $\mathbf{u}_{1}$ se da en la ciudad de Madrid, seguido de las ciudades de Barcelona, Valencia, Sevilla, Málaga y Bilbao.

Una vez analizados los datos obtenidos, con la interpolación realizada en este estudio se puede categorizar el territorio español y asignarle un incremento del valor del suelo a efectos expropiatorios. Con la categorización de la interpolación (Figura 5.7), se han diferenciado siete zonas:

\begin{tabular}{cccc} 
Categoría & Superficie $\mathbf{~ K m}^{\mathbf{2}}$ & $\mathbf{\%}$ & incremento valor suelo $\%$ \\
\hline $1-1,02$ & $56.584,03$ & 11,18 & $0-2$ \\
\hline $1,02-1,03$ & $68.916,08$ & 13,61 & $2-3$ \\
\hline $1,03-1,06$ & $114.245,14$ & 22,57 & $3-6$ \\
\hline $1,06-1,14$ & $134.228,57$ & 26,51 & $6-14$ \\
\hline $1,14-1,37$ & $91.416,64$ & 18,06 & $14-37$ \\
\hline $1,37-2,02$ & $31.697,72$ & 6,26 & $37-102$ \\
\hline $2,02-3,82$ & $9.155,64$ & 1,81 & $102-281$ \\
\hline TOTAL & $\mathbf{5 0 6 . 2 4 3 , 8 1}$ & $\mathbf{1 0 0 , 0 0}$ &
\end{tabular}

Tabla 6.16. Categorías de las distintas zonas de valor de $u_{1}$ (fuente: elaboración propia)

Se ha podido comprobar así que existen corredores del valor $\mathbf{u}_{1}$ que se estructuran a lo largo de las autovías y autopistas. En la Figura 6.46 se han introducido las principales carreteras, autovías y autopistas, e identificado la existencia de seis corredores en los que se recogen los valores más elevados del factor de corrección por accesibilidad. Estos corredores coinciden en su mayor parte con los ejes de alta velocidad ferroviaria: el corredor mediterráneo desde Murcia a la frontera catalana con Francia, el corredor Madrid-Sevilla-Cádiz coincidente con la línea de alta velocidad correspondiente, el eje Bilbao-Tarragona que se superpone al futuro corredor ferroviario Cantábrico-Mediterráneo; y, por último, los ejes León-Asturias, Vigo-La Coruña y, por último, Madrid-Bilbao, que vertebra las más importantes áreas urbanas de Castilla-León y el País Vasco. 

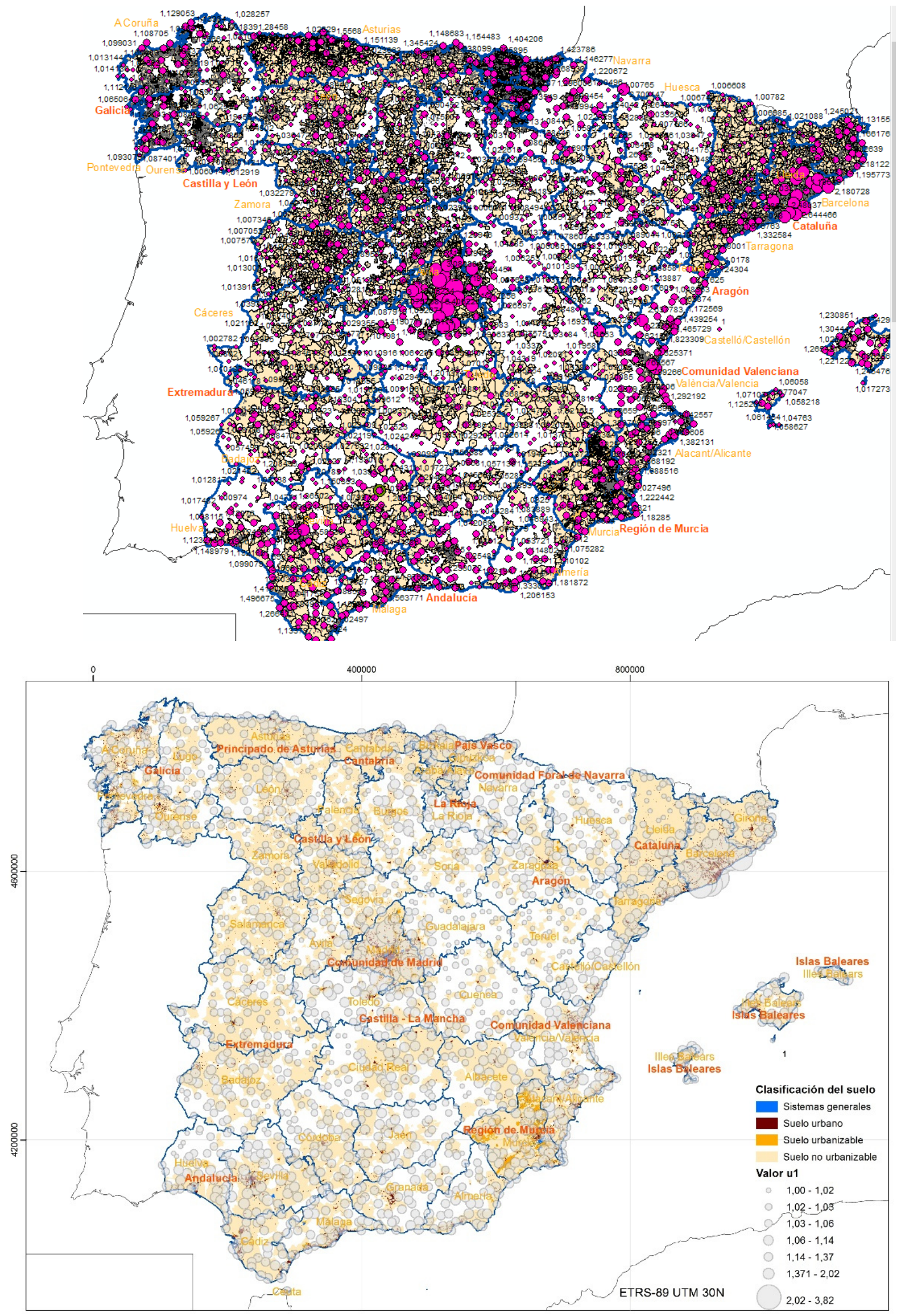

Figura 6.48. Clasificación de suelo y valor de u1 (fuente: elaboración propia) 



\section{CONCLUSIONES}

Con la aprobación de la actual legislación estatal de suelo, las condiciones básicas del ejercicio del derecho de propiedad de los titulares de suelo han sufrido un cambio importante, a efectos expropiatorios; sin embargo, sigue siendo competencia de dicha Ley, atribuida por la Constitución, garantizar la igualdad, en todo el territorio estatal, del ejercicio del derecho de propiedad y en el cumplimiento de los deberes de los propietarios de suelo.

En el presente capítulo del trabajo de investigación realizado se recogerán las conclusiones a las que se ha llegado tras el estudio y análisis de los resultados obtenidos.

Los objetivos formulados para la realización de la tesis doctoral ${ }^{21}$ se han llevado a cabo en el desarrollo del presente trabajo y se han recogido en los diferentes capítulos de este documento final presentado.

En los apartados 7.1 y 7.2 se hace una reflexión sobre los criterios legales recogidos tanto en el TRLSRU 2015 como en el su reglamento de desarrollo el RVLS 2011, donde se introducen las conclusiones a las que se ha llegado, realizando una crítica tanto a la intención de la legislación como a su desarrollo metodológico.

En cuanto a las Hipótesis de partida de la tesis doctoral, tal y como se recogía en el apartado 1.3, es en el presente capítulo donde se van a validar o no dependiendo de cada una de ellas. La validación será en aparatado 7.3.

\subsection{SOBRE LOS CRITERIOS LEGALES}

El desarrollo de la presente investigación ha servido para analizar en profundidad cómo se regula el cálculo del factor de corrección por accesibilidad a núcleos de población $\mathbf{u}_{1}$ en el RVLS 2011 como desarrollo reglamentario del TRLS 2008 (en la actualidad TRLSRU 2015).

La Exposición de Motivos del TRLS 2008 señalaba en relación con las valoraciones:

“... Para facilitar su aplicación y garantizar la necesaria seguridad del tráfico, la recomposición de este panorama debe buscar la sencillez y la claridad, además por

${ }^{21}$ Apartado "1.4 Formulación de objetivos" del presente trabajo. 
supuesto la justicia..." Mediante el desarrollo del presente trabajo se ha podido comprobar que la sencillez y claridad que busca el Legislador no ha sido un objetivo conseguido ni en el Texto Refundido ni en el desarrollo reglamentario (RVLS 2011), ya que para el cálculo de dichas valoraciones se ha propuesto, por una parte, una metodología demasiado específica y compleja y, por otra, la introducción de un nuevo factor de corrección a dicho valor, con una formulación reglamentaria también extremadamente complicada.

En lo que se refiere a la metodología específica, en el caso de las valoraciones de suelo en situación rural, para la aplicación del método de capitalización de las rentas, para cuyo desarrollo se requiere una formación específica y un conocimiento profundo de las distintas formas de producción agrícola, ganadera, forestal, etcétera. En concreto, y a modo de ejemplo, es preciso conocer cómo se calculan las rentas de una explotación agraria, para lo que se requieren conocimientos específicos (valor de transformación de $\mathrm{Kg}$. de un producto, coste de la producción, características de los ciclos propios de cada sistema productivo, etc.), que requieren una alta especialización que contrasta con la sencillez buscada.

En cuanto a la introducción de un nuevo factor de corrección al valor obtenido mediante la capitalización de las rentas, se hace referencia aquí al factor de corrección por localización (FL). El TRLSRU 2015 define este factor, señalándose únicamente que "podrá" ser utilizado para la corrección de la valoración calculada mediante la capitalización de las rentas, pero sin definir claramente la fórmula concreta de aplicación, mientras que en el desarrollo reglamentario (RVLS 2011) se definen una serie de fórmulas complejas. Los resultados numéricos de la aplicación de esta formulación matemática propuesta por el RVLS 2011 merece un análisis empírico para cada una de las localizaciones posibles, lo que ha constituido el objeto fundamental de esta investigación.

Por otra parte, la elevada subjetividad que se propone en la obtención de los coeficientes, y la libertad estimativa que ello supone, se contradice, en primer lugar, con la modificación del artículo 43 LEF introducida por la Disposición adicional quinta del TRLS 2008 (en la actualidad el TRLSRU 2015), que suprime el régimen estimativo en la expropiación de bienes inmuebles. $\mathrm{Y}$, en segundo término, la definición reglamentaria del coeficiente corrector correspondiente introduce un elevado grado de indeterminación jurídica, que parece contrario a los objetivos de sencillez y claridad propuestos en la Exposición de motivos del propio TRLS 2008. 


\subsection{SOBRE LA FÓRMULA DEL RVLS 2011 Y LOS VALORES DE SUS COMPONENTES}

\section{COMPARACION VALORES}

1,20

1,00

0,80

0,60

0,40

0,20

0,00

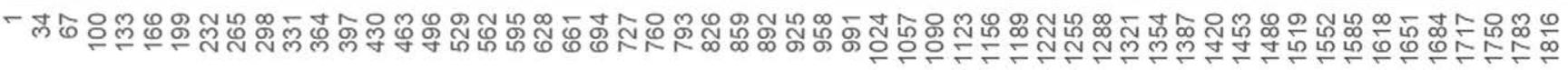

$$
\boxplus \mathrm{P} 2 / 3 \quad \mathrm{U} 1 \quad \square \mathrm{P} 1
$$

Figura 7.1 Comparación valores $P_{1}, P_{2} / 3$ y $u_{1}$ (fuente: elaboración propia)

En el desarrollo de este trabajo, se ha podido constatar que existe una descompensación en la fórmula de cálculo del factor $\mathbf{u}_{1}$, en concreto con el valor alcanzado por el sumando $\mathrm{P}_{2} / 3$ (habitantes a $40 \mathrm{Km}$.) frente al $\mathrm{P}_{1}$ (habitantes a $4 \mathrm{Km}$.). En el gráfico 7.1 se puede comprobar que la curva de los datos obtenidos del factor $\mathbf{u}_{1}$ del cálculo de la fórmula:

$$
u_{1}=1+\left[P_{1}+\frac{P_{2}}{3}\right] \times \frac{1}{1.000 .000}
$$

coincide con la curva de los datos de $\mathrm{P}_{2} / 3$. Sin embargo, la representación de los datos $\mathrm{P}_{1}$ no sigue una ley en la representación, alcanzando valores muy dispersos, que no se identifican con una variación significativa en el valor del factor a calcular.

Del análisis realizado se puede concluir que en el cálculo del factor $\mathbf{u}_{1}$ la cantidad de habitantes a mayor distancia tiene un peso muy superior a la cantidad de habitantes en las inmediaciones del inmueble. De este modo queda confirmado, como veremos en apartados siguientes, la importancia de las áreas de influencia que se forman en el sistema urbano-territorial. 


\subsection{VALIDACIÓN DE LAS HIPÓTESIS DE PARTIDA}

\subsubsection{Hipótesis 1. Es viable un cálculo sistemático del factor de corrección por accesibilidad a núcleos de población, que permita la aproximación a un valor objetivo}

Es necesario puntualizar que la validación de esta hipótesis es parcial.

Por un lado, es viable el cálculo sistemático del factor de corrección $\mathbf{u}_{1}$ y así se ha realizado con la metodología utilizada en el presente trabajo.

La utilización de un SIG donde se introduzcan los valores libres facilitados por organismos oficiales, facilita que el cálculo del valor se realice de forma sistemática, permitiendo actualizar dicho cálculo en la medida en que también lo hagan los datos públicos.

En cuanto a la aproximación de un valor objetivo del factor de corrección $\mathbf{u}_{1}$, no es viable por todo lo indicado en el apartado 7.1 Sobre los criterios legales. La subjetividad y la libertad estimativa necesaria en el cálculo del factor de corrección $\mathbf{u}_{1}$ no permiten que el valor obtenido pueda considerarse objetivo.

\subsubsection{Hipótesis 2. La aplicación del factor de corrección por accesibilidad a núcleos de población contradice la prohibición de la consideración de las expectativas urbanística}

En cuanto a la relación entre el factor corrector $\mathbf{u}_{1}$ y las expectativas urbanísticas, tradicionalmente se ha considerado por la doctrina jurisprudencial un incremento del valor de los suelos expropiados clasificados como no urbanizables, teniendo en cuenta las futuras expectativas urbanísticas que podrían obtener en función de su situación cercana a los núcleos de población o a grandes vías de comunicación. Es inevitable la similitud entre el factor corrector estudiado, desarrollado por el RVLS $2011 \mathrm{y}$ el incremento que la jurisprudencia tradicionalmente ha considerado.

A este respecto es necesario hacer referencia a Baño León (2008), que afirma que:

"...este punto ha sacrificado la congruencia a favor de cierta consideración de factores extra-rurales ... Parece indudable, sin embargo, que el plusvalor que puede obtenerse por elementos tales como la accesibilidad a núcleos de población o a centro de actividad económica está directamente ligado a una perspectiva urbanística". 
En el análisis realizado en el presente trabajo sobre la relación del factor $\mathbf{u}_{1}$ con las futuras expectativas urbanísticas se ha podido comprobar que a las distintas clasificaciones de suelo de cada uno de los municipios les corresponde el mismo factor de corrección $\mathbf{u}_{1}$. Este resultado es independiente de si se trata de un suelo con mayores expectativas (suelo urbano no consolidado, SUNC) o, por el contrario, un terreno al que debería aplicársele un valor menor del factor por requerir mayor desarrollo en todo el proceso de transformación urbanística del suelo (suelo urbanizable no sectorizado SUNS).

Es una realidad que la clasificación urbanística del suelo es potestad del planeamiento urbanístico de cada municipio y, por temas competenciales, de la Comunidad Autónoma a la que pertenece. Pero también es cierto que existe una falta de homogeneidad en la clasificación urbanística del suelo, tanto en el contenido como en la fecha de aprobación del planeamiento general que clasifica los suelos en España. Es por ello que no resulta posible considerar una regla homogénea a cerca de la clasificación urbanística de suelo en el territorio nacional ya que del total de los municipios españoles, el 28,31\% tienen un Plan General de Ordenación Urbana, el $38,56 \%$ tienen Normas Subsidiarias de planeamiento, el $14,98 \%$ tienen solamente Delimitación de Suelo Urbano (no se trata de un instrumentos de planeamiento sino de un instrumento complementario donde no se clasifica suelo sino que solamente se delimita suelo urbano y suelo no urbanizable), mientras que el $18,14 \%$ no tiene planeamiento general ${ }^{22}$, sin entrar a valorar la fecha de aprobación de dichos planeamientos generales.

Con lo expuesto anteriormente, se puede concluir que la clasificación urbanística de los suelos, no afecta en absoluto a los valores obtenidos del factor de corrección $\mathbf{u}_{1}$. De este modo el efecto del factor de localización sobre el valor de suelo calculado por la capitalización de las rentas, nada tiene que ver con el incremento del valor por la consideración de las expectativas urbanísticas que los tribunales han aceptado tradicionalmente. Si bien la terminología utilizada por la actual legislación cuando se refiere a los factores de corrección, es similar a la utilizada por los tribunales, el sentido es diferente. El factor de localización no se plantea como un incremento del valor de capitalización por la posibilidad de un futuro desarrollo, sino que responde a al plusvalor que en la capacidad de producción de las explotaciones se produce como consecuencia de la ubicación en las proximidades de los diferentes elementos del sistema urbano-territorial.

22 Datos obtenidos del SIU. Ministerio de Fomento. 
Cuando el Tribunal Supremo define como elemento que incrementa el valor la "proximidad a núcleos de población" realmente se refiere a la futura expansión urbanística del núcleo de población cercano a los suelos a valorar. Sin embargo, cuando la vigente Ley (y su desarrollo reglamentario mediante el RVLS 2011) define el Factor de Corrección por Localización y en concreto el factor de corrección $\mathbf{u}_{1}$, parece que se refiere a fines productivos en vez de a expectativas urbanísticas, de acuerdo con las tradicionales teorías económicas de la valoración de suelo, tal y como se ha expuesto en el desarrollo del marco teórico del valor de localización.

La Sentencia del Tribunal Supremo de 16 de abril de 2013 (recurso de casación $5016 / 2010$ ) parece apoyar lo recogido en el párrafo anterior en su fundamento jurídico 2 cuando indica que "...es constante la insistencia en que dichas expectativas han de resultar debidamente probadas, en relación con las características físicas del terreno, su proximidad inmediata al suelo urbano, la existencia de algunos servicios urbanísticos y demás circunstancias de toda índole concurrentes en el mismo, siendo también pacífico que tal carga probatoria corresponde, de acuerdo con las reglas que reparten entre las partes la carga de la prueba, a la parte que invoca la existencia de las expectativas y su incidencia en la valoración del suelo no urbanizable".

En dicho pronunciamiento se pone de manifiesto que la reiterada consideración de "expectativas urbanísticas" por los tribunales se refiere realmente a la expansión futura de la clasificación urbanística del suelo, lo que aparentemente nada tiene que ver con lo dispuesto por el TRLSRU 2015, en el que, como se recoge en la Exposición de motivos del TRLS 2008, la valoración se regula "sin considerar las expectativas urbanísticas la localización influye en el valor de este suelo, siendo la renta de posición un factor relevante en la formación tradicional del precio de la tierra".

Por otro lado, la fórmula de cálculo del factor $\mathbf{u}_{1}$ solamente tiene en cuenta la cantidad de población a 4 y $40 \mathrm{Km}$., lo que implica que la clasificación urbanística del suelo, de acuerdo con el RVLS 2011, no afecta ni incide en el valor del factor, en el que solamente influye el número de habitantes situados en la proximidad del punto en el que se valora. De ello resulta que en municipios cercanos a grandes núcleos de población del sistema urbano-territorial español, se obtienen valores elevados del factor $\mathbf{u}_{1}$ independientemente de la clasificación urbanística de suelo, simplemente por existir un gran número de habitantes a una distancia inferior a $40 \mathrm{Km}$., ya que en este trabajo ha podido comprobarse que el sumando que más incide en la fórmula de cálculo es el $\mathrm{P}_{2} / 3$ (un tercio del número de habitantes a $40 \mathrm{~km}$.) 


\subsubsection{Hipótesis 3. El plusvalor de posición de la legislación refleja la estructura, el desarrollo y dinamismo del sistema urbano-territorial español}

De lo expuesto en el apartado anterior se puede concluir que los valores obtenidos del factor de corrección $\mathbf{u}_{1}$ confirman la jerarquía existente en el sistema urbano-territorial de España, por lo que la hipótesis de partida queda validada.

- El plusvalor de posición de la legislación española refleja la definición del sistema urbano-territorial español con las relaciones existentes en dicho sistema, así como el desarrollo y el dinamismo socio-económico existente.

- Las ciudades de las grandes áreas urbanas provocan una atracción en las ciudades de su área de influencia, cosiendo esa estructura compleja mediante los corredores de comunicación.

Este es el efecto real de la aplicación del factor de corrección $\mathbf{u}_{1}$. 



\section{NUEVAS LÍNEAS DE INVESTIGACIÓN}

En el desarrollo del presente trabajo han surgido diferentes cuestiones, que por falta de tiempo material no ha sido posible desarrollar, pero que podrían considerarse interesantes en un desarrollo posterior. Estas nuevas líneas de investigación podrían ser:

- Aplicar la metodología al resto de los factores de corrección $u_{2}$ y $u_{3}$, para poder analizar los resultados globales del Factor de Localización. Para ello, en el caso del cálculo del factor de corrección $\mathbf{u}_{2}$, se dispondrían en el SIG os aeropuertos, estaciones, puertos, etc., que intervienen en el cálculo, para posteriormente medir la distancia a los mismos. Del mismo modo, para el cálculo del factor de corrección $\mathbf{u}_{3}$, se localizarían en el SIG los entornos de singular valor ambiental y paisajístico que intervienen en el cálculo, marcando diferentes valores de los coeficientes "p" y "t", en función de criterios objetivos.

- Creación de una fuente de datos institucional en la que se facilite el valor de cada uno de los factores de corrección al valor de suelo calculado mediante la capitalización de las rentas, tal y como establece el TRLSRU 2015, de forma que los datos facilitados permitan evitar la carga subjetiva del tasador. Además, esto permitiría obtener los valores de datos oficiales actualizados a tiempo real, tanto de número de población como de planeamiento actualizado.

- Actualizar a tiempo real el planeamiento urbanístico de cada uno de los municipios españoles.

- Cálculo de la distancia aplicable al valor $\mathrm{P}_{2} / 3$ para conseguir el equilibrio en la fórmula de cálculo. 



\section{BIBLIOGRAFÍA Y DOCTRINA JURISPRUDENCIAL}

\section{BIBLIOGRAFÍA:}

Alonso, R. y Iruretagoyena, M.T. (1995). Valoración agraria. Concepto, métodos y aplicaciones. Madrid: Mundi-Prensa.

Alonso, W. (1964). Location and land use. Toward a general theory of land rent. Cambridge, MA: Harvard University Press.

Alonso Timón, A. J. (2012). La insoportable gravedad de las valoraciones urbanísticas. Boletín Urbanimo (1 de septiembre de 2.012). Recuperado de http://www.elderecho.com/tribuna/administrativo/insoportable-gravedadvaloraciones-urbanisticas 11 455680003.html.

Ballesteros, E. (1991). Economía de la empresa agraria y agroalimentaria. Madrid: Mundi-Prensa.

Baño León, José María. (2008). Las valoraciones en la Ley de Suelo. Revista Vasca de Administración Pública, 79 (2), 43-63.

Burrough, P.A. y McDonnell, R.A. (1998). Principles of Geographical Information Systems. Oxford: University Press, New York.

Caballer Mellado, V. (2008). Valoración agraria. Teoría y práctica (5a ed.). Madrid: Mundi-Prensa.

Caballer Mellado, V. y Roger Fernández, G. (2012). Manual de valoraciones urbanísticas. Valencia:Tirant lo Blanch.

Caballer Mellado, V. (2008). La valoración rural en la Ley de Suelo (RDLS 2/2008). Hacia un cambio de paradigma en la valoración agraria. Recuperado de http://www.valtecsa.com/4.pdf

Calatrava Leyra. J. y Cañero León, R. (2000) Valoración de fincas olivareras de secano mediante métodos econométricos. Invest. Agr.: Prod. Prot. Veg, 15 (1-2). Recuperado de http://www.inia.es/gcontrec/pub/calat 1161155414953.pdf

Camagni, R. (2004). Economía urbana. Antoni Bosch Editor. S.A. (p. 80-81)

Cantillón, R. (1755) An essay on economic theory. An English translation of Richard Cantillon's Essai sur la Nature du Commerce en Général. (C. Saucier, trad.; M. Thornton, ed.). Auburn, AL: Ludwig von Mises Institute.

Codes Calatrava, G. (2009). Las valoraciones del suelo en el Texto Refundido de la Ley de Suelo. Análisis crítico. Revista reestudios Locales (Cunal),121, 16-20.

Cressie, N. (1990) The origins of kriging. Mathematical Geology, 22(3), 239-252. doi: 10.1007/BF00889887

Cuadrado-Roura, Juan R. (2014). ¿Es tan "nueva" la "Nueva Geografía Económica"?: Sus aportaciones, sus límites y su relación con las políticas. EURE (Santiago), 40(120), 5-20. https://dx.doi.org/10.4067/S0250-71612014000200001

Cuadrado Zuloaga, D. (2009). Valoración del suelo rural a efectos expropiatorios. 
Boletín de sumarios 363, pp 2469. Gobierno de España. Recuperado de http://www.mitramiss.gob.es/es/sec bep/bibliotecas/central/Novedades/BoletinSu marios/Sumarios2009/Noviembre2009segunda/Boletin Completo.pdf

Chinchilla Peinado, J. A. (2004). La problemática incorporación de expectativas urbanísticas en la determinación del valor de terrenos clasificados como suelo no urbanizable o urbanizable no sectorizado: la (hasta el momento irreductible) tensión entre el legislador y los Tribunales. Análisis de las decisiones de los Tribunales Superiores de Justicia entre 2000 y 2003. Revista de Derecho Urbanístico y Medio Ambiente, 208, 39-116.

Chinchilla Peinado, J.A. y Sánchez Goyanes, E. (2009) Ley del Suelo. Comentarios sistemáticos del Texto Refundido de 2008. Artículos 21 a 28. Madrid: La Ley.

Chinchilla Peinado, J.A. (2008). Los criterios de valoración en la Ley 8/2007 y su proyección en la Comunidad Autónoma del País Vasco. Derecho urbanístico del País Vasco, dirigido por Enrique Sánchez Goyanes, La Ley.

Christaller, W. (1966). Central places in Southern Germany. Englewood Cliffs, NJ: Prentice Hall.

De la Encarnación Valcárcel, A.M. (2015) La expectativa en la Valoración Suelo en estudiantes de la Comunidad Valenciana (Tesis doctoral). Recuperado de http://roderic.uv.es/handle/10550/44896

De la Encarnación Valcárcel, A.M. (2016) Las expectativas urbanísticas. Cizur Menor (Navarra): Aranzadi

De la Encarnación Valcárcel, A.M (2013). New Land valuation criteria after the spanish 2011 valuation of land regulation: the objectivation of building expectations in rural land. Revista Territorio Italia, 2013, 71-83.

Derycke, P. (1971). La economía urbana. Madrid: Instituto de Estudios de Administración Local.

Derycke, P. (1983). Economía y planificación urbanas. Madrid: Instituto de Estudios de Administración Local.

Díaz Viera, M. A. (2002), Geoestadística aplicada. México, D.F.: Instituto de Geofísica, Universidad Nacional Autónoma de México (UNAM) / La Habana: Instituto de Geofísica y Astronomía; Ministerio de Ciencia, Tecnología y Medio Ambiente, Cuba.

Duch Brown, N. (2005). La teoría de la localización. Barcelona: Universitat de Barcelona.

Emery, X. (2000). Geoestadística lineal. Departamento Ingeniería de Minas.

Enériz Olaechea, F. J. (1995). Una reforma necesaria: el procedimiento de expropiación forzosa. especial referencia a la expropiación urbanística. Revista Vasca de Administraciones Pública, 41, 565-586.

Falcón Pérez, E. (2007). La valoración del suelo rural en el nuevo proyecto de Ley de Suelo: Una visión económica. Práctica Urbanística, 58, Sección Estudios,19. La Ley

Fernández, T.R, Parejo Alfonso, L., Baño de León, J.M., Menéndez Rexach, A. y 
Vaquer Caballería, M (2008). El Nuevo Régimen Jurídico del Suelo. Madrid: lustel.

Fernández, T.R. (2007). La Nueva Ley 8/2007, de 28 de mayo, de Suelo: Valoración General. Revista de Administración Pública, 174, 61-74.

Fernández Güell, J.M. (2006). Planificación estratégica de ciudades, Barcelona: Reverté, S.A.

Fernández Torres, J.R., Táboas, M., Humero, A.E., Llorens, M., Mayoral del Barrio, B. y Trayter, J.M. (2010). La aplicación del sistema de valoraciones en la Ley del Suelo. Atelier.

Ferrando Corell, J. V. y Romero Aloy, M.J. (2011). El Anteproyecto de Reglamento de la Ley de Suelo. Práctica Urbanística, 103, 18 - 23.

Fundación BBVA (2008). La distribución espacial de la actividad económica. Cuadernos Fundación BBVA. Serie Capital y Crecimiento, 9. Recuperado de: http://www.fbbva.es/TLFU/dat/cd_09_08_distribucion.pdf

Fujita, M., Krugman, P. y Venables A.J. (1999). The Spatial Economy. Cities, Regions and International Trade. Cambridge, Massachusets: The MIT Press (pp. 97-115)

Fujita, M., Krugman y Venables, A.J. (1999). The Spacial Economy. Cties, Regions and International Trade. Massachusetts Institute of Technology.

Fujita, Masahisa, Krugman P. y Venables A. (2000). Economía espacial: las ciudades, las regiones y el comercio internacional. Barcelona: Editorial Ariel S.A.

Fujita, M. y Krugman, P. (2004). La nueva geografía económica: pasado, presente y futuro. Investigaciones Regionales. Journal of Regional Research, 4, 177-206.

Garcia Almirall, P., Valls Dalmau, F., y Moix Bergadá, M. (2011). SIG en la Gestión de la Información Urbanística en el ámbito local. Centro de Política de Suelo y Valoraciones (CPSV) Universidad Politécnica de Cataluña. Fundació Politécnica de Calalunya

García Erviti, F. (2006). Compendio de arquitectura legal: derecho profesional y valoraciones. Barcelona: Editorial Reverté S.A.

García Erviti, F (2007). La práctica de las valoraciones en la Ley 8/2007 de Suelo. Revista de Derecho Urbanístico y Medio Ambiente, 237, 119-133.

García González, J.A. y Cebrián Abellán, F.. La interpolación como método de representación cartográfica para distribución de población: aplicación provincia de Albacete. El acceso a la información espacial y las nuevas tecnologías geográficas, 165-178

Ghiasi, Y. y Nafisi, V. (2016). Strain estimation using ordinary Kriging interpolation. Survey Review, 48(350), 361-366.

Gómez Orea, D. (2008). Ordenación Territorial. Ediciones Mundi-Prensa.

González Ruiz, R.M. (2012). Los efectos de la localización en la valoración rural: análisis de los factores de corrección. Revista de Derecho Urbanístico y Medio Ambiente, 46(273), 13-74. 
González Ruiz, R.M., Martínez Cuevas, S., García Erviti, F. y Morillo Balseras, C. (2019). Análisis geoestadístico del coeficiente de corrección por accesibilidad a núcleos de población en las valoraciones urbanísticas en España. EURE 45 (134), 125-146

Goodchild, M.F. y Haining, R. P. (2004). GIS and spatial data analysis: Converging perspectives. Papers in Regional Science 83(1), 363-385. https://doi.org/10.1007/s10110-003-0190-y

Haining, R. (2003). Spatial Data Analysis. Theory and practice. Cambridge, UK. Cambridge University Press.

Harvey, D. (1977). Urbanismo y desigualdad social. Siglo XXI de España Editores, S.A.

Harvey, D. (2013). Ciudades Rebeldes. Del derecho de la ciudad a la revolución urbana. Ediciones Akal, S.A.

Hernández Jiménez, H. M. (2017). Las actuaciones sobre suelo urbano en Actualidad Administrativa, $N^{\circ}$ 9. Sección Urbanismo. Editorial Wolters Kluwer

Jlménez Bueso, A. (2013). La ponderación de expectativas urbanísticas en la valoración del suelo en situación rural. Madrid. Revista Práctica Urbanística, 124, 28-43.

Johnston, K., Ver Hoef, J.M., Krivoruchko, K. y Lucas, N. (2001). Using ArcGIS Geostatistical Analyst. ArcGIS 9. Redlands, CA:ESRI.

En http://dusk2.geo.orst.edu/gis/geostat_analyst.pdf

Kravchenko A. N. (2003). Influence of spatial structure on accuracy of interpolation methods. Soil Science Society of American Journal 67(5), 1564-1571. https://doi.org/10.2136/sssaj2003.1564

Krige, D. G. (1951). A statistical approach to some basic mine valuation problems on the Witwatersrand. Journal of the Chemical, Metallurgical and Mining Society of South Africa, 52(6), 119-139.

Lefebvre, H. (2017). El derecho a la ciudad. Capitan Swing.

Lipietz, A. (1979). El capital y su espacio. México, D.F.: Siglo Veintiuno.

Lora-Tamayo Vallvé, M. (2007) Historia de la Legislación Urbanística. Iustel

Lösch, A. (1954). The economics of location. New Haven, CT: Yale University Press.

Martínez Garrido, E. y Mata Olmo, R. (1987) Estructura y Estrategias Productivas del regadío metropolitano de Madrid. Agricultura y Sociedad, 42, 181-202.

Méndez, R. y Molinero, F. (2008). Espacios y sociedades. Introducción a la geografía regional del mundo. Ariel.

Menendez Rexach, A. (2017). Situaciones básicas y clases de suelo: la consideración activa del suelo rural y el protagonismo de la renovación del suelo urbano en Práctica Urbanística, № 146, Sección Estudios, Editorial Wolters Kluwer

Merchand Rojas, M. A. (2010) Reflexiones en torno a la nueva Geografía Económica en la perspectiva de Paul Krugman y la localización de la actividad económica. Breves Contribuciones del I.E.G. - No 21 (pp. 206-223) 
Mitášová, H., y Hofierka, J. (1993), Interpolation by regularized spline with tension: II. Application to terrain modeling and surface geometry analysis. Mathematical Geology 25(6), 657-669. https://doi.org/10.1007/BF00893172

Ministerio de Fomento (2.017). Las áreas urbanas. Recuperado de https://www.fomento.gob.es/NR/rdonlyres/30FB929E-009E-41E4-B020F2EDD37A9AB0/146839/Metodologia 2017.pdf

Ministerio de Fomento (2.019). La Agenda Urbana Española.

Montero, J.M. y Larraz, B. (2008). Introducción a la geoestadística lineal. Perillo, La Coruña: Netbiblo, S.L.

Moral-García, F.J. (2003). La representación gráfica de las variables regionalizadas. Geoestadística lineal. Cáceres: Universidad de Extremadura.

Moreno Jiménez, A. (2007). Sistemas y Análisis de la Información Geográfica. Madrid: Ra-Ma.

Ortiz Ballester, J. (2010). Algunas reflexiones sobre la incidencia de la LS 07 en el Derecho Urbanístico Valenciano: La Valoración del Suelo en el Proyecto de Reparcelación. Revista de Derecho Urbanístico y Medio Ambiente, 2S9, 173192.

Ortuño Pérez, S. F., Madrigal Collazo, A. y González Doncel, I. (2007). Apuntes de valoración Agraria y Forestal. Escuela Universitaria Forestal Madrid.

Pebesma, E.J. (2006). The role of external variables and GIS databases in geostatistical analysis. Transactions in GIS10(4), 615-632. https://doi.org/10.1111/j.1467-9671.2006.01015.x

Perez-Sala, J.L., Marques, I., Segura B., Mora G., Femenia C. y Velilla J. M. (2016).Cálculo del Factor de Localización en las Valoraciones de Suelo Rural sometidas a procedimientos expropiatorios conforme a la ley de suelo. Agrónomos. Revista profesional de Ingenieros Agrónomos 45, 92-102

Porto Rey, E. (2008). Las valoraciones en la Ley 8/2007 de Suelo. Madrid: Editorial Montecorvo, S.A.

Quintana López, T. (2003). Manual de Urbanismo en Madrid. Colección: Manuales. Serie: Administración General. Ministerio de Administraciones Públicas. Instituto Nacional de Administración Pública, pp. 597-624

Ramos Ramos, E., Fortaleza del Rey Morales, M. y Virgos Soriano, L. I. (2009). Observatorio del mercado de bienes inmuebles rústicos con redes neuronales. Catastro 65, 7-40.

Ricardo, D. (1817). The principles of political economy and taxation(3a ed.). Londres: John Murray

Roca Cladera, J. (1998) La valoración del suelo en la Ley 6/1998 (LA LEY 1489/1998), Documentación Administrativa, 252-253, 307, en nota, y 313.

Roca Cladera, J. y Marmolejo, C. (2006). Hacia un modelo de aglomeración y desaglomeración del espacio regional urbano. Arquitectura, Ciudad y Entorno 1, 60-79. 
Roca Cladera, J. (2017). El régimen de valoraciones de la Ley de Suelo de 2007. Luces y sombras. Práctica Urbanística, 146.

Rodríguez Jaume, M. J. (2010). Modelos Socio-Demográficos en Universidad de Alicante (Tesis doctoral). Recuperado de https://rua.ua.es/dspace/bitstream/10045/3925/1/Rodriguez-Jaume-M-Jose-t1.pdf

Ruiz García, F. (1986). Manual de valoración agraria y urbana. Madrid: Intervalora.

Salazar, Z. (1950). Valoración agrícola y catastro. Madrid: Espasa-Calpe.

Santi Juárez, T. (1952). Valoración de fincas y precios. Madrid: Dossat.

Serrano, A., Suarez de Cepeda, M. y Sanchez-Giron, V. (2008). Rentabilidad económica de explotaciones agrarias de secano según tamaño y tipo de laboreo. Economía Agraria y Recursos Naturales 8(2), 73- 91.

Serrano Alberca, J. M. (2007). Las valoraciones en la Ley del Suelo 8/2007, de 28 de mayo. Una inducción a la arbitrariedad. Revista Aranzadi de Urbanismo y Edificación, 16, 95-111.

Schweikert, D.G. (1966). An interpolation curve using splines in tensión. Studies in Applied Mathematics, 45(1-4), 312-317. https://doi.org/10.1002/sapm1966451312

Smith, A. (1778). An Inquiry into the Nature and Causes of the Wealth of Nations: By Adam Smith, LL. D. and FRS Formerly Professor of Moral Philosoophy in the University of Glasgow; in Two Volumes (Vol. 1, The Second Edition). London: Printed from W. Strahan, and T. Cadell, in the Strand.

Sobral García, S. (2004). Metodología de análisis de un espacio periférico a través de un SIG. Catastro, 51, 23-40.

Tobler, W. R. (1970). A computer movie simulating urban growth in the Detroit region. Economic Geography, 46(sup1), 234-240. https://doi.org/10.2307/143141

Trivez Bielsa, F.J. (2004). Economía Espacial: una disciplina en auge. Estudios de economía aplicada, 22(3), 409-429.

Tsutsumi M. \& Seya, H. (2008). Measuring the impact of large-scale transportation projects on land price using spatial statistical models. Papers in Regional Science,87(3), 385-401. https://doi.org/10.1111/j.1435-5957.2008.00192.x

Wackernagel, H. (2013). Multivariate geostatistics: an introduction with applications. Springer Science \& Business Media.

Weber, A. (1929). Theory of the location of industries. Chicago, IL: University of Chicago Press.

Weih, R.C. \& Dick, A.J. (2008).Modeling the pre-Euroamerican landscape with government land office surveys and geostatistics. Transactions in GIS 12(4), 443457. https://doi.org/10.1111/j.1467-9671.2008.01115.x 


\section{DOCTRINA JURISPRUDENCIAL}

Las sentencias del TS se han sacado del fondo documental del Consejo General del Poder Judicial http://www.poderjudicial.es/search/index.jsp (para las del TS) y http://www.poderjudicial.es/search/indexAN.jsp. (para las del TSJ)

\begin{tabular}{|c|c|}
\hline Sentencia & Reseña \\
\hline STS de 12 de noviembre de 1960 & STS $1369 / 1960$ \\
\hline STS de 13 de mayo de 1967 & STS $238 / 1967$ \\
\hline STS de 13 de junio de 1973 & STS $1762 / 1973$ \\
\hline STS de 26 de junio de 1978 & STS $404 / 1978$ \\
\hline STS de 28 de febrero de 1.979 & STS $2510 / 1979$ \\
\hline STS de 30 de abril de 1980 & STS $3438 / 1980$ \\
\hline STS de 16 de diciembre de 1980 & STS $3626 / 1980$ \\
\hline STS de 30 de septiembre de 1986 & STS $5083 / 1986$ \\
\hline STS de 30 de septiembre de 1991 & STS $897 / 1991$ \\
\hline STS de 17 de octubre de 1.995 & STS $5113 / 1995$ \\
\hline STS de 4 de junio de 1996 & STS $3400 / 1996$ \\
\hline STS de 23 de noviembre de 1996 & STS $6611 / 1996$ \\
\hline STS de 10 de marzo de 1.998 & STS $1621 / 1998$ \\
\hline STS de 18 de octubre de 1999 & STS $6440 / 1999$ \\
\hline STS de 27 de febrero de 2001 & STS $1461 / 2001$ \\
\hline STS de 26 de octubre de 2.006 & STS $6246 / 2006$ \\
\hline STS de 17 de noviembre de 2008 & STS $6058 / 2008$ \\
\hline STS de 24 de abril de 2009 & STS $2723 / 2009$ \\
\hline STS de 1 de julio de 2013 & STS $3721 / 2013$ \\
\hline STS de 8 de julio de 2014 & STS 3069/2014 \\
\hline STS de 13 de junio de 2016 & STS $2792 / 2016$ \\
\hline STS de 1 de marzo de 2018 & STS $685 / 2018$ \\
\hline
\end{tabular}


TRIBUNALES SUPERIORES DE JUSTICIA

\begin{tabular}{ll} 
Sentencia & Reseña \\
\hline STSJ MU de 15 de noviembre de 2000 & 3323/200 Murcia \\
\hline STSJ CL 20 de noviembre de 2.000 & 5883/2000 Burgos \\
\hline STSJMU de 21 de marzo de 2.001 & STSJMU 173/2001 Rec. 287/1998 \\
\hline STSJ AR de 30 de noviembre de 2006 & 1706/2006 Zaragoza \\
\hline STSJ MAD de 22 de diciembre de 2.006 & 19840/2006 Madrid \\
\hline STSJ CM de 17 de diciembre de 2012 & 3502/2012 Albacete \\
\hline STSJ M de 22 de enero de 2.013 & 757/2013 Madrid. \\
\hline
\end{tabular}




\section{ENLACES DE INTERNET UTILIZADOS}

Teoría de Walter Christaller.http://geoeconomicaglobal.blogspot.com.es/2007/11/teora-de-walter-christaller.html

http://www.madrid.org/iestadis/fijas/clasificaciones/nucleos.htm NÚCLEOS POBLACIÓN COMUNIDAD DE MADRID

http://www.madrid.org/nomecalles/Inicio.icm?capaBusqueda=6 PLANO DE NÚCLEOS POBLACIÓN

http://www.madrid.org/nomecalles/lnicio.icm?capaBusqueda=6 PLANO NÚCLEOS ENTIDADES SECTORES

http://www.elmundo.es/callejero/ Callejero donde se ven núcleos con nombres (no se diferencian municipios)

http://www.ign.es/siane/Miniaturas.do?objs=12095,12093,12096,12097,12049,12172,1 $\underline{2221,12173,12177,12220,12222,12242,12243,12286,12280,11887,12252,12258,1227}$ $\underline{2,12273,12275,12274,12283,12285,12292,12295,12294,12364,12327,12326,12350,12}$ $\underline{366,12367,12372,12374,12373,12360,12170,12104,12296,12325,12282,12363 \& \text { TIPO }}$ CONSULTA=1\&CONSULTA=caja $\% 253$ D $\% 2540 \% 2526 \% 2540 \% 2540$ combo $\% 253$ D $\%$ 2540---Demograf\%25C3\%25ADa\%2By\%2Basentamientos\%2Bhumanos INSTITUTO GEOGRÁFICO NACIONAL POBLACIÓN (conecta con INE núcleos de población)

http://www.ign.es/signa/SISTEMA DE INFORMACIÓN GRAFICA NACIONAL

http://www.ign.es/ign/main/index.do INSTITUTO CARTOGRÁFICO NACIONAL TODO http://alarcos.inf-cr.uclm.es/per/fruiz/pobesp/index.htm POBLACIÓN DE ESPAÑA Y DATOS ESTADÍSTICOS

http://www.netmaps.es/mapas/ MUNICIPIOS

http://www.comarcas.es/MUNICIPIOS ARAGÓN DATOS ESTADÍSTICOS INE

http://www.ine.es/inebmenu/mnu cifraspob.htm Dirección general de cifras de población INE 
http://www.ine.es/nomen2/index.do INE NÚCLEOS DE POBLACIÓN

http://www.ine.es/jaxi/tabla.do?path=/t20/e260/a2010//0/\&file=mun28.px\&type=pcaxis\& $\underline{\mathrm{L}=0}$ Municipios completos de la CM

http://www.marm.es/es/estadistica/temas/anuario-de-estadistica/default.aspx CULTIVOS GENERAL

http://www.marm.es/es/estadistica/temas/encuesta-sobre-superficies-y-rendimientosde-cultivos-esyrce-/MADRID tcm7-133156.pdf CULTIVOS

http://www.marm.es/es/estadistica/temas/encuesta-sobre-superficies-y-rendimientosde-cultivos-esyrce-/DefinicionesESYRCE tcm7-14344.pdf DEFINICIONES ESYRCE

http://www.marm.es/es/estadistica/temas/encuesta-de-precios-de-latierra/Encuesta Precios Tierra 2009 tcm7-132034.pdf ENCUESTA PRECIO DE LA TIERRA

http://www.marm.es/es/estadistica/temas/encuesta-de-precios-de-latierra/Comparaci\%C3\%B3n Precios Tierra-C\%C3\%A1nones Arrendamiento 19982006 tcm7-14536.pdf COMPARACIÓN PRECIO TIERRA CÁNONES ARRENDAMIENTO RUSTICO

http://www.marm.es/es/estadistica/temas/canones-de-arrendamientosrusticos/C\%C3\%A1nones Arrendamiento 2009 Resumen tcm7-156372.pdf CANON RESUMEN 2009

http://www.marm.es/es/estadistica/temas/rentaagraria/CEA 20101 Estimacion diciembre 2010 tcm7-132462.pdf RENTA AGRARIA NACIONAL 2010

http://www.marm.es/es/estadistica/temas/default.aspx DATOS ESTADÍSTICOS DE MARM Y REFERENCIA AL INE (TEXTO)

\section{CULTIVOS RENTAS}

http://www.ine.es/ioe/ioeOper.jsp?cod=01\&tipo=area\&L= DIRECTORIO TEMAS INE 
http://www.madrid.org/desvan/AccionLlamadaArbolDesvan dwr.icm?tipoArbol=almude na BANCO DE DATOS MUNICIPAL ALMUDENA

http://www.madrid.org/desvan/AccionDatosTemaMunicipal.icm?codTema=1104007 SUPERFICIE EXPLOTACIONES

http://www.agriculturadeconservacion.org/

ASOCIACIÓN

ESPAÑOLA

DE AGRICULTURA 



\section{ACRÓNIMOS}

AR: Aragón.

Arts.: Artículos.

B.O.E.: Boletín Oficial del Estado.

CE: Constitución española, 1978.

CLM; Castilla La Mancha.

CM: Comunidad de Madrid.

FJ: Fundamento jurídico.

FL: Factor de corrección por localización del artículo 17 del RVLS 2011.

Ha: Hectárea.

Hab: Habitantes.

IG: Información geográfica.

INE: Instituto Nacional de Estadística.

Km.: Kilómetro.

$\mathrm{Km}^{2}$.: Kilómetro cuadrado

KO: Kriging ordinario.

LEF: Ley de 16 de diciembre de 1954, de Expropiación Forzosa.

Ley 6/1998: Ley 6/1998, de 13 de abril, sobre régimen de suelo y valoraciones.

Ley 8/2007: Ley 8/2007, de 28 de mayo, de suelo.

LS 56: Ley de Régimen del Suelo y Ordenación Urbana de 12 de mayo de 1.956

LGT: Ley 58/2003, de 17 de diciembre, General Tributaria.

M: Madrid.

MU: Murcia.

No: Número.

NGE: Nueva Geografía Económica.

$\mathbf{P}_{1}$ : Número de habitantes a menos de $4 \mathrm{Km}$.

$\mathbf{P}_{2}$ : Número de habitantes de $4 \mathrm{Km}$. a $40 \mathrm{Km}$.

PDF: Denominación de formato de almacenamiento para documentos digitales.

PDI: Plan Director de Infraestructuras 1.993-2.007 del Ministerio de Fomento.

RCE: Red de Carreteras del Estado.

Rec: Recurso.

REC: Recurso.

RD: Real Decreto.

RDL: Real Decreto Legislativo.

RD 1492/2011: Real Decreto 1492/2011, de 24 octubre por el que se aprueba el Reglamento de valoraciones de la Ley de suelo.

RDU: Real Decreto 2187/1978, de 23 de junio, por el que establece el Reglamento de 
disciplina urbanística.

RGU: Real Decreto 3288/1978, de 25 de agosto, por el que se aprueba el Reglamento de Gestión Urbanística para el desarrollo y aplicación de la Ley sobre régimen de Suelo y Ordenación Urbana.

RPU: Real Decreto 2159/1978, de 23 de junio, por el que se aprueba el Reglamento de Planeamiento Urbanístico.

RVLS 2011: Real Decreto 1492/2011, de 24 octubre por el que se aprueba el Reglamento de valoraciones de la Ley de suelo.

SIG: Sistema de Información Geográfica.

SIU: Sistema de Información Urbana del Ministerio de Fomento.

SG: Sistemas Generales.

SNU: Suelo no urbanizable.

SU: Suelo urbano.

SUC: Suelo urbano consolidado.

SUNC: Suelo urbano no consolidado.

SUNS: Suelo urbanizable no sectorizado.

SUS: Suelo urbanizable sectorizado.

SSTS: Sentencias del Tribunal Supremo.

STC: Sentencia del Tribunal Constitucional.

STC 61/1997: Sentencia del Tribunal Constitucional de 20 de marzo de 1997.

STS: Sentencia Tribunal Supremo.

STSJ: Sentencia Tribunal Superior de Justicia.

TC: Tribunal Constitucional.

TRLS 76: Real Decreto 1346/1976, de 9 de abril, por el que se aprueba el texto refundido de la Ley sobre Régimen de Suelo y Ordenación Urbana.

TRLS 92: Real Decreto Legislativo 1/1992, de 26 de junio, por el que se aprueba el Texto Refundido de la Ley sobre el Régimen de Suelo y Ordenación Urbana.

TRLS 2008: Real Decreto Ley $2 / 2008$, de 20 de junio, por el que se aprueba el texto refundido de la Ley de suelo.

TRLSRU 2015: Real Decreto Ley 7/2015, de 30 de octubre, por el que se aprueba el Texto Refundido de la Ley de Suelo y Rehabilitación Urbana.

TS: Tribunal Supremo.

TSJ: Tribunal Superior de Justicia.

$\mathbf{u}_{1}$ : Factor de corrección por accesibilidad a núcleos de población. Artículo 17.3 del RVLS 2011.

$\mathbf{u}_{2}$ : Factor de corrección por accesibilidad a centros de actividad económica. Artículo 17.4 del RVLS 2011.

$\mathbf{u}_{3}$ : Factor de corrección por ubicación en entornos de singular valor ambiental o 
paisajístico. Artículo 17.5 del RVLS 2011.

V: Valor de capitalización de la renta real o potencial de la explotación en suelo.

$\mathbf{V}_{\mathbf{f}}$ : Valor final del suelo. 
